KENDI SANBONSUGE

COMPORTAMENTO MECÂNICO E DESEMPENHO EM CAMPO DE BASE DE SOLO-CIMENTO

\author{
SÃO PAULO
}


KENDI SANBONSUGE

\section{COMPORTAMENTO MECÂNICO E DESEMPENHO EM CAMPO DE BASE DE SOLO-CIMENTO}

Dissertação apresentada a Escola Politécnica da Universidade de São Paulo, como parte dos requesitos para obtenção do título de Mestre em Engenharia de Transportes.

SÃO PAULO 
KENDI SANBONSUGE

\title{
COMPORTAMENTO MECÂNICO E DESEMPENHO EM CAMPO DE BASE DE SOLO-CIMENTO
}

Dissertação apresentada a Escola Politécnica da Universidade de São Paulo, como parte dos requesitos para obtenção do título de Mestre em Engenharia de Transportes.

Área de Concentração: Infraestrutura de Transportes

Orientador: Prof ${ }^{\mathrm{a}} \mathrm{Dr}^{\mathrm{a}}$ Kamilla Lima Vasconcelos

\author{
SÃO PAULO
}


Este exemplar foi revisado e alterado em relação à versão original, sob responsabilidade única do autor e com a anuência de seu orientador.

São Paulo, de fevereiro de 2013.

Assinatura do autor

Assinatura do orientador

FICHA CATALOGRÁFICA

Sanbonsuge, Kendi

Estudo laboratorial e de campo de base de solo-cimento I

K. Sanbonsuge. -- ed.rev. -- São Paulo, 2013. $135 \mathrm{p}$.

Dissertação (Mestrado) - Escola Politécnica da Universidade de São Paulo. Departamento de Engenharia de Transportes.

1. Solo-cimento 2. Estudo laboratorial 3. Estudo de campo I. Universidade de São Paulo. Escola Politécnica. Departamento de Engenharia de Transportes II. t. 


\section{DEDICATÓRIA}

aos meus pais, Tsuyoshi e Maria

à minha irmã e irmão, Elaine e Márcio

à família Barreto,

à prima Aline (In memorian)

Pelo apoio nos estudos e compreensão de minha ausência, mesmo quando

presente. 


\section{AGRADECIMENTOS}

Primeiramente a Deus, pela força que guia minha vida.

Ao Dr. Edson de Moura, pelo incentivo desde a graduação na FATEC-SP e seu bom humor contagiante em suas aulas e no ambiente de trabalho.

A Dra Liedi L. B. Bernucci, pela oportunidade, incentivo à pesquisa e sugestões no exame de qualificação.

A Dra. Kamilla L. Vasconcelos, pela orientação, constante incentivo e dedicação sempre presente.

Ao Dr. Suzuki, pelas sugestões no exame de qualificação e incentivo.

Aos amigos das incontáveis horas de estudo, Claudio, Daniele, Mariana e Poliana.

Ao amigo Igor "o galado", pela ajuda na coleta das amostras no trecho experimental, nossas constantes "reflexões técnicas" à meia noite e incentivo na pesquisa.

Ao amigo Caio, pela formatação dos dados pluviométricos e dedicação na base de dados do trecho experimental.

Ao amigo Rodrigo, pela revisão no método de controle estatístico.

Aos amigos de trabalho, Diomária, Erasmo, Robson e Vanderlei, pelo incentivo.

A Votorantim Cimentos S/A, por enviar cordialmente os relatórios de controle tecnológico das amostras de cimento.

Ao Laboratório de Tecnologia de Pavimentação, pela disponibilidade dos equipamentos e flexibilidade nos horário para o desenvolvimento desta pesquisa.

Ao Laboratório de Praticas de Construção Civil, pela disponibilidade de uso da câmara úmida.

Ao Laboratório de Caracterização Tecnológica, pelo ensaio de difratometria.

Ao INMET, pela disponibilidade de consulta ao banco de dados climáticos.

A Linda, pela compreensão, aconselhamento, carinho e amizade, sobretudo, nos momentos difíceis. 


\section{RESUMO}

O solo-cimento é um material de alta qualidade e durabilidade, empregado em camadas de base na pavimentação rodoviária. Atualmente no Brasil, sua dosagem é realizada a partir de ensaios mecânicos, de forma a definir um valor mínimo de cimento que apresente resistência compatível com o projeto do pavimento onde será empregado. $\mathrm{O}$ foco da pesquisa consiste no estudo da forma de adição do cimento: (i) mistura realizada com o solo seco, procedimento comumente adotado para dosagem, ou ainda (ii) mistura realizada com solo úmido, condição que representa o processo de produção em pista, ou usina. Ensaios mecânicos de resistência e rigidez foram realizados para as duas condições de umidade de mistura e para quatro tempos de cura $(3,7,14$ e 28 dias). As amostras moldadas a partir da umidade higroscópica apresentaram maiores valores de resistência à compressão simples e de módulo de resiliência, porém menores valores de resistência à tração por compressão diametral. O grau de saturação obtido na compactação Proctor das amostras de solo mostram que o solo compactado na umidade de campo atinge menores índices de vazios, resultando em peso específico aparente seco superior ao solo compactado a partir da umidade higroscópica. Foi verificada uma influência nos resultados de rigidez e resistência nas amostras de solo-cimento ocasionadas pelo fator água cimento $(\mathrm{a} / \mathrm{c})$. Ensaios para avaliação da retração e contração foram desenvolvidos pela metodologia MCT, mostrando uma maior sensibilidade do solocimento à contração, mas ainda classificados como valores baixos pela metodologia. Através do acompanhamento de um trecho experimental, foram realizadas medidas de bacias de deflexão com equipamento FWD. Os valores de módulo de resiliência retroanalisados através do BACKFAA (considerando todas as camadas elásticas lineares) apresentaram-se inferiores aos resultados de rigidez determinados em laboratório.

Palavras-chave: Solo-cimento. Estudo laboratorial. Estudo de campo. 


\begin{abstract}
The soil-cement base-layer is a high quality and durable material employed in road construction. In Brazil, the soil-cement mix design is based on mechanical tests, in order to define a minimum cement content to assure satisfactory strength. The aim of this research is to study possible differences in the way cement is added to the mixture: (i) soil in the dry condition (hygroscopic moisture), common procedure adopted in laboratory for the mixture design, or (ii) soil in the wet condition, common procedure used in the road construction, or in the mix plant. Mechanical tests for strength and stiffness measurement were performed using both initial moisture conditions, for four curing times $(3,7,14$, and 28 days). The sample compacted in the hygroscopic moisture condition showed higher ultimate compressive strength (UCS) and resilient modulus (RM). The degree of saturation calculated for the soil samples from the compaction test (Proctor) showed that the soil at wet moisture condition decreased the air voids. It resulted in higher dry density when compared with the soil at the dry moisture condition. The influence of water/cement ratio was verified in the strength and stiffness results. Tests to evaluate the retraction and contraction were developed through the MCT methodology. The soil-cement mixtures presented higher sensibility to contraction, although the results were considered low. One experimental test site, with soil-cement in the base layer was constructed and monitored. Its structural evaluation with the Falling Weight Deflectometer (FWD) was used for backcalculation of the resilient modulus of each pavement layer. The backcalculated resilient modulus were smaller than the values obtained for the laboratory sample tested.
\end{abstract}

Keywords: Soil-cement. Laboratory study. Field study. 


\section{SUMÁRIO}

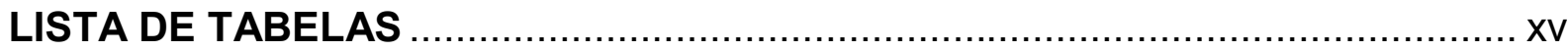

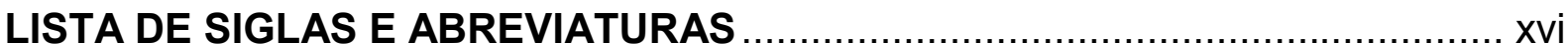

LISTA DE SÍMBOLOS .........................................................................

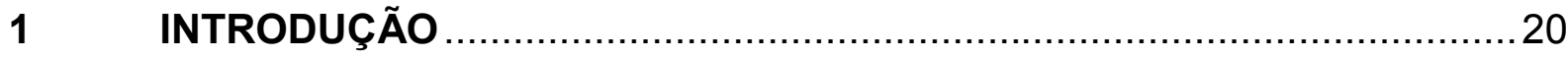

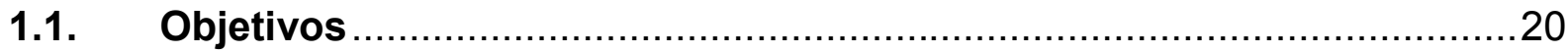

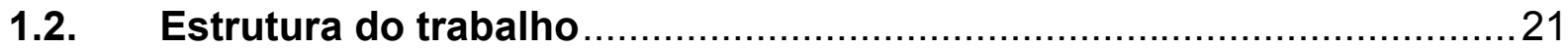

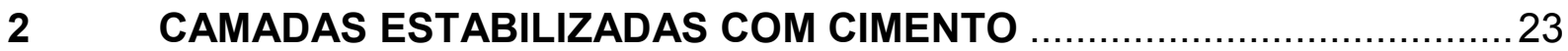

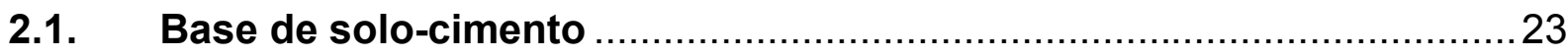

2.2. Comportamento mecânico do solo-cimento .................................. 25

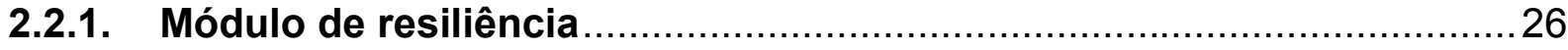

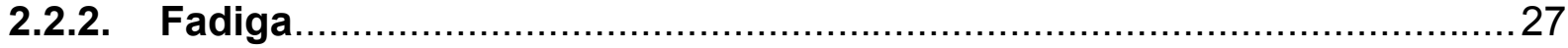

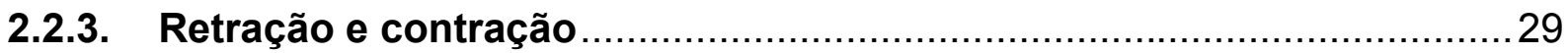

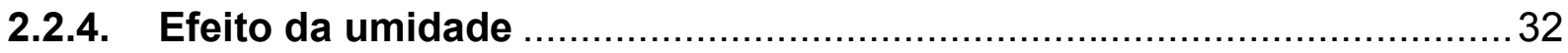

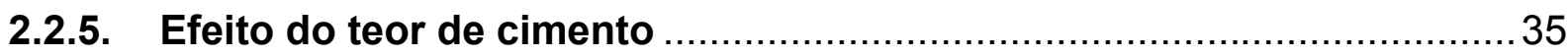

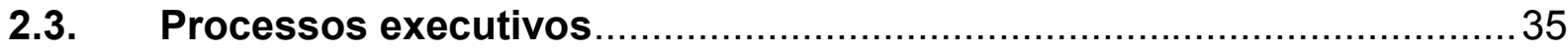

3 METODOLOGIA E MATERIAIS UTILIZADOS ................................. 37

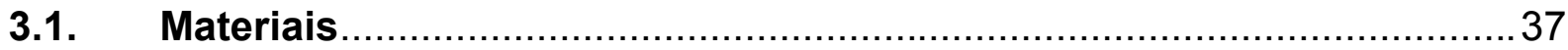

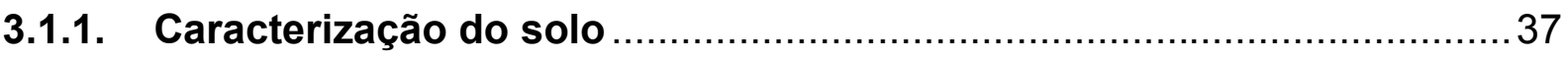

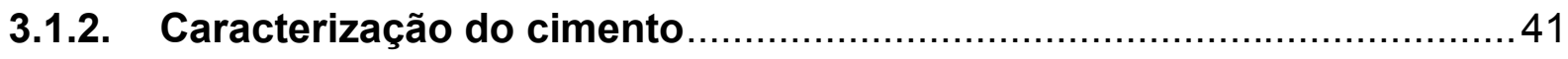

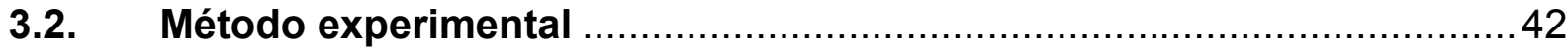

3.2.1. Coleta e preparo do solo para ensaios físicos ............................... 42

3.2.2. Compactação do solo (Proctor) .................................................. 44

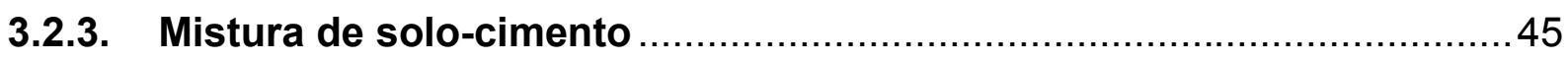




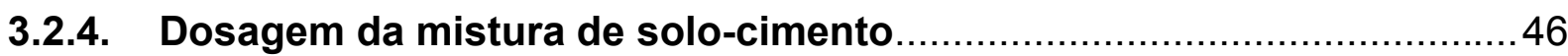

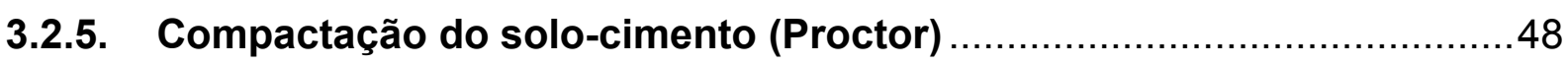

3.2.6. Compactação do solo-cimento para ensaios mecânicos .....................48

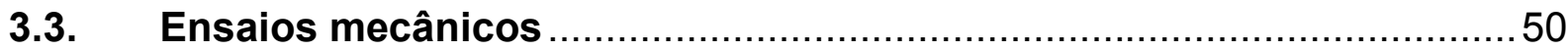

3.3.1. Resistência à tração por compressão diametral (RTCD) ....................50

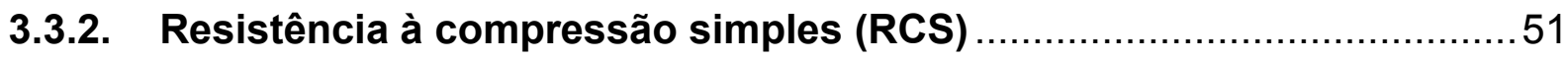

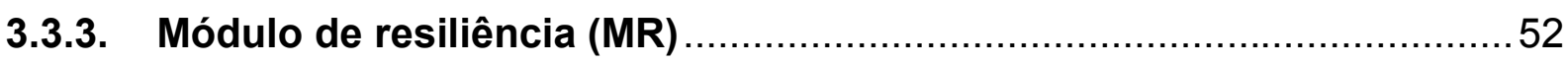

3.3.4. Contração do solo e retração das misturas de solo-cimento ...............53

3.4. Retroanálise das bacias de deflexão ...............................................56

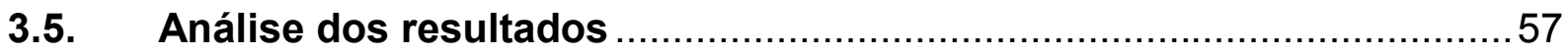

4 APRESENTAÇÃO E ANÁLISE DE RESULTADOS ...........................60

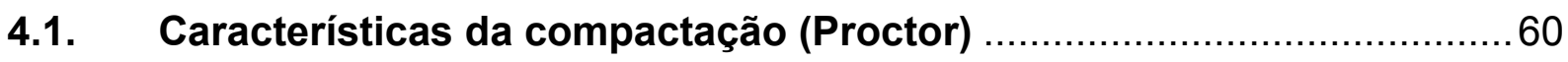

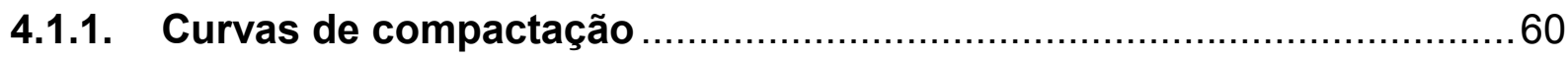

4.1.2. Grau de saturação do solo e resistência à compressão simples (RCS)61

4.1.3. Resistência à compressão simples (RCS) para o solo-cimento ...........63

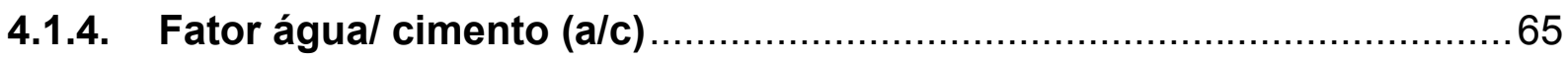

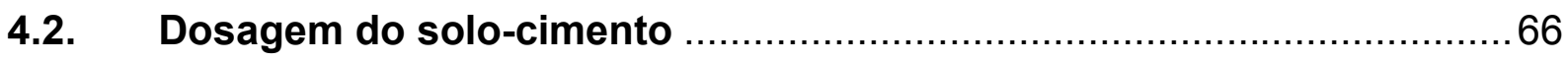

4.3. Ensaios mecânicos nas misturas de solo-cimento..........................68

4.3.1. Resistência à tração por compressão diametral (RTCD) ......................69

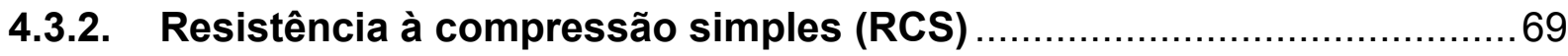

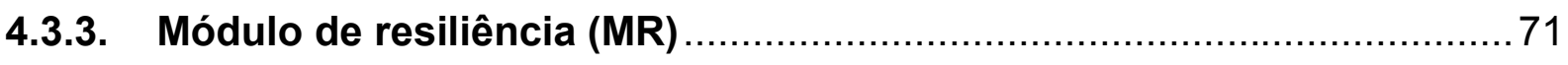

4.4. Efeito da umidade (UH e UC) no comportamento mecânico das

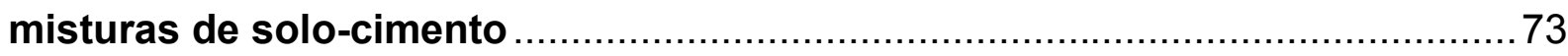

4.5. Contração e retração pela metodologia MCT ............................... 74

4.5.1. Retração e contração da dosagem de SC-UH ................................. 75 
4.5.2. Efeito da umidade de mistura (UH e UC) na contração do Solo e do SC77

5 TRECHO EXPERIMENTAL. 79

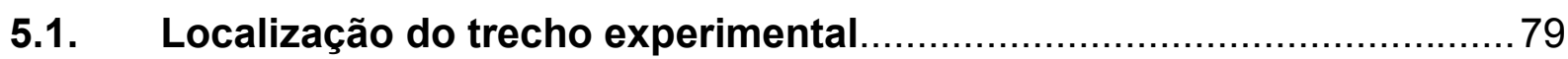

5.2. Projeto original e proposta para o trecho experimental .................... 81

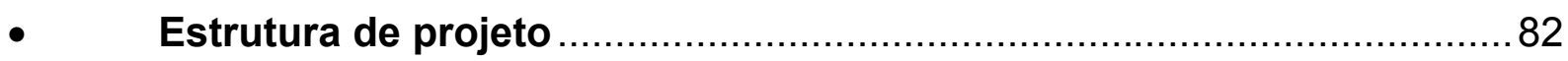

5.3. Estrutura proposta para o trecho experimental ............................. 84

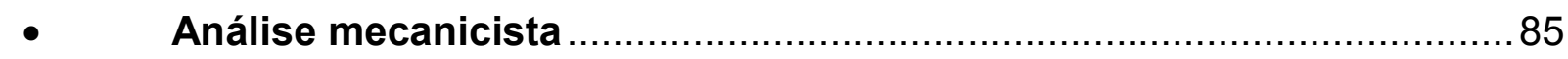

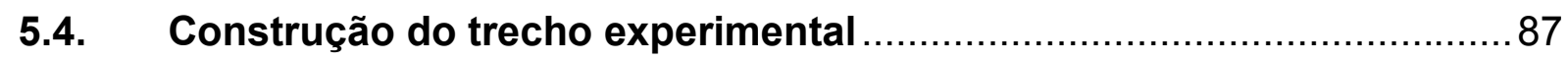

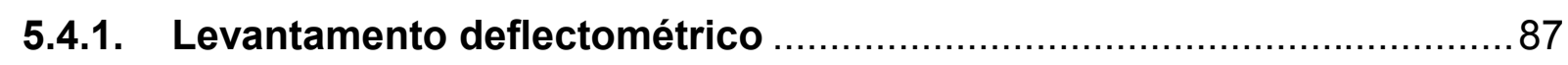

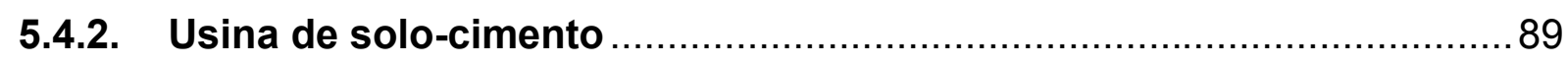

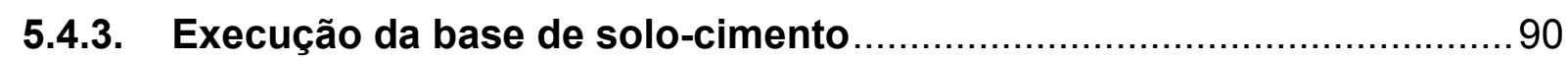

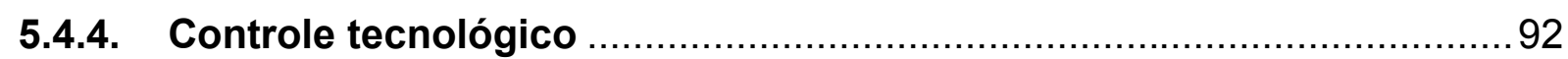

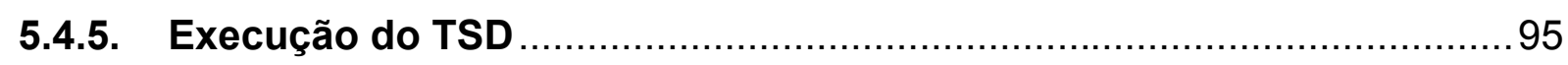

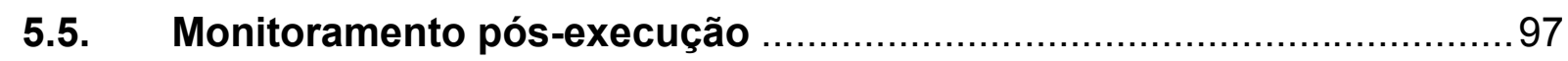

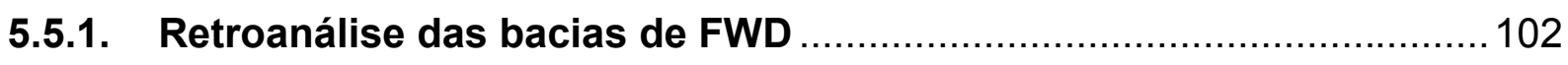

5.5.2. Determinação do erro máximo admissível ................................ 104

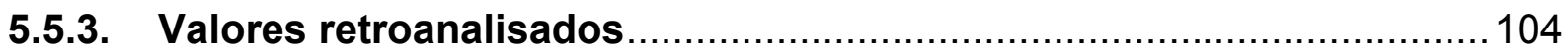

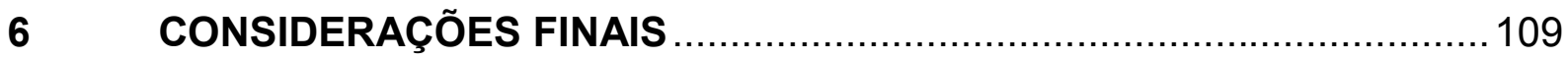

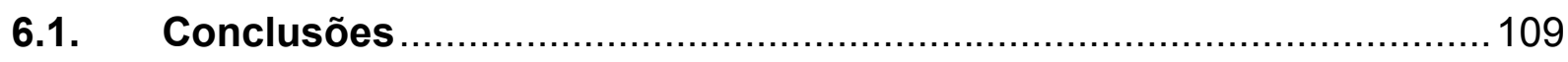

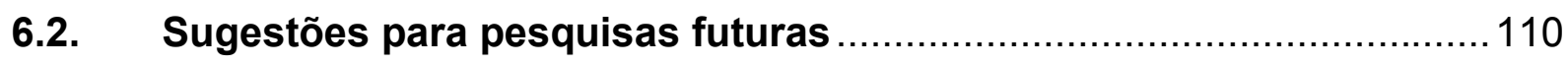

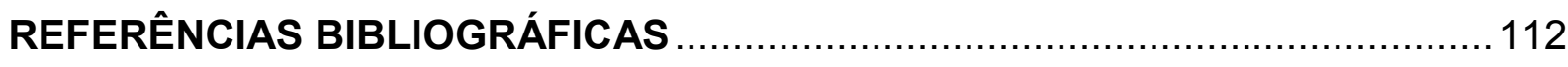

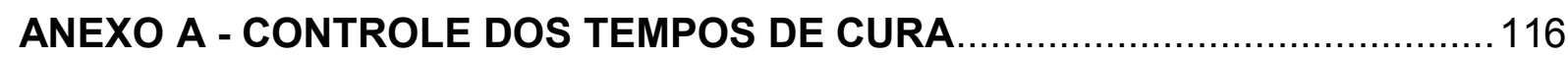

ANEXO B - DIMENSIONAMENTO DA ESTRUTURA DO PAVIMENTO PELO

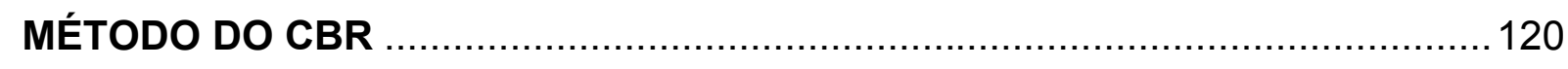

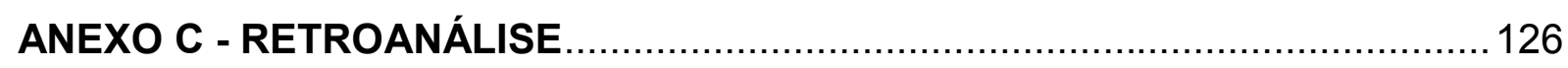




\section{LISTA DE FIGURAS}

Figura 2.1 - Formas de água presentes naturalmente nos solos finos (Adaptado de SAARENKETO, 1998) 33

Figura 3.1 - Distribuição granulométrica do solo 38

Figura 3.2 - (a) Resultado da difratometria e (b) identificação dos minerais 40

Figura 3.3 - Coleta do solo na jazida: (a) escavação e (b) coleta e armazenamento43 Figura 3.4 - Preparação do solo: (a) espalhamento, (b) quarteamento e (c) estocagem das amostras na umidade de campo 44

Figura 3.5 - Retirada de umidade do solo com soprador térmico 45

Figura 3.6 - Mistura de solo-cimento para cada condição inicial de mistura (a) UH e (b) UC 46

Figura 3.7 - Processo da dosagem do SC (a) envelopamento para retenção de umidade, b) cura em câmara com temperatura e umidade controlada, (c) imersão prévia em água e (d) ruptura da amostra

Figura 3.8 - Compactação do SC para ensaios mecânicos: a) cilindro tripartido, (b) controle da altura das camadas, (c) extração da amostra e (d) determinação da massa úmida da amostra.

Figura 3.9 - Tempo de tolerância permitido para amostras de concreto (Fonte: ASTM C39/2012) 50

Figura 3.10 - Ensaio de RTCD: (a) suporte e detalhe dos frisos e (b) aspecto da amostra após ensaio 51

Figura 3.11 - Ensaio de MR: a) entalhamento na amostra para verificação da tensão confinante durante o ensaio, (b) espessura do capeamento, (c) instrumentação e (d) ensaio em andamento 
Figura 3.12 - Ensaio de contração/ retração pela metodologia MCT: (a) aquecimento da parafina com soprador térmico, (b) fixação do cubo acrílico com parafina, (c) montagem da amostra no suporte e (d) leitura da contração/ retração 55

Figura 3.13 - Umidade relativa do ar (UR) verificada no ano de 2009 na estação de Franca - SP (Fonte: BDMET - INMET 2010) 55

Figura 3.14 - Levantamento deflectométrico com uso de FWD - modelo KUAB: (a) ensaio em andamento e (b) detalhe dos geofones e prato de carregamento 57 Figura 4.1 - Curvas de compactação do solo para as duas condições de mistura UH e UC. 60

Figura 4.2 - Curvas de compactação do solo-cimento para as duas condições de mistura - UH e UC

Figura 4.3 - Curvas de RCS e S\% para as amostras de solo na condição: (a) UH e (b) UC 63

Figura 4.4 - Curvas de RCS após 7 dias de cura e peso específico seco para as amostras de solo-cimento na condição: (a) UH e (b) UC 64 Figura 4.5 - Comparação da RCS obtida após 7 dias de cura nas amostras de solo e solo-cimento para as duas condições de mistura - UH e UC 65

Figura 4.6 - Relação a/c para as amostras de solo-cimento para as duas condições de mistura - UH e UC 66

Figura 4.7 - Curva de RCS versus percentual de cimento 67

Figura 4.8 - Dosagem do SC em duas condições de mistura - UC e UH 68 Figura 4.9 - Valores de RTCD para 3, 7, 14 e 28 dias de cura nas duas condições de mistura - UH e UC 69

Figura 4.10 - Valores de RCS para 3, 7, 14 e 28 dias de cura nas duas condições de mistura - UH e UC 70 
Figura 4.11 - Regressão da RCS da argamassa de cimento e do SC nas duas condições de mistura - UH e UC .71

Figura 4.12 - Módulo de resiliência para 3, 7, 14 e 28 dias de cura nas duas condições de mistura - UH e UC 72

Figura 4.13 - Acréscimo do valor de MR com o tempo de cura para um o3 de 1,05 $\mathrm{MPa}$, nas duas condições de mistura - UH e UC 73

Figura 4.14 - Solicitações em um terreno por efeito de carregamento na superfície (Adaptado de PINTO, 2006) 74

Figura 4.15 - Valores médios da retração com o tempo para a dosagem de SC-UH75 Figura 4.16 - Valores médios da contração com o tempo para a dosagem de SC-UH76 Figura 4.17 - Junção dos valores médios de retração e contração na dosagem SC$\mathrm{UH}$ 76

Figura 4.18 - Valores médios da retração/ contração com o tempo para o SC e solo - UH e UC 77

Figura 5.1 - Mapa de localização do trecho experimental (Fonte: DER-SP) ...........80

Figura 5.2 - Croquis esquemático de localização do trecho experimental..... 81

Figura 5.3 - Curvas de fadiga para misturas de solo-cimento (CERATTI, 1991) ..... 86

Figura 5.4 - Levantamentos iniciais: a) ensaio de viga Benkelman em andamento e (b) vista geral do trecho experimental 88

Figura 5.5 - Precipitação mensal acumulada para o ano de 2009. Fonte: BDMET INMET 2010 89

Figura 5.6 - Usina de solos: (a) silos de materiais granulares, (b) silo para incorporação de aditivos pulverizados, (c) detalhe do silo com cimento e (d) produção de solo-cimento 
Figura 5.7 - Execução da base de solo-cimento (a) carregamento, (b) lançamento, (c) espalhamento, (d) compactação com rolo pé de carneiro, (e) acabamento com rolo de pneu liso e (f) imprimação 91

Figura 5.8 - Cura da base de solo-cimento: (a) sinalização de desvio de tráfego e (b) acostamento para desvio de tráfego 92

Figura 5.9 - Controle tecnológico pelo método do frasco de areia 93

Figura 5.10 - Resumo da RCS aos 7 e 28 dias para amostras de solo-cimento de laboratório e obra 93

Figura 5.11 - Comparativo do incremento da RCS para o cimento empregado na pesquisa e do cimento empregado no trecho experimental 95

Figura 5.12 - Execução de TSD com AMP: (a) limpeza da base de SC, (b) aplicação da $1^{\text {a }}$ camada, (c) compactação, (d) aplicação da $2^{a}$ camada, (e) compactação e (f) aplicação de banho diluído "Fog" 96

Figura 5.13 - Distribuições granulométricas do TSD com AMP: (a) $1^{\mathrm{a}}$ camada e (b) $2^{\mathrm{a}}$ camada 97

Figura 5.14 - Levantamento estrutural no TSD com viga Benkelman 98

Figura $5.15-D_{0}-$ Média e desvio padrão na base do trecho experimental para três levantamentos: a) sentido Batatais e (b) sentido Patrocínio Paulista. 99

Figura 5.16 - Precipitação mensal acumulada para os anos: (a) 2009, (b) 2010, (c) 2011 e (d) 2012. Fonte: BDMET - INMET 2012 101

Figura 5.17 - Bacia média de deflexões do trecho experimental: (a) T=21M e (b) $\mathrm{T}=33 \mathrm{M}$ 103

Figura 5.18 - Bacias previstas e retroanalisadas no sentido Batatais $-\mathrm{T}=21 \mathrm{M} \ldots . .105$ Figura 5.19 - Bacias previstas e retroanalisadas no sentido Patrocínio Paulista $\mathrm{T}=21 \mathrm{M}$ 106 
Figura 5.20 - Bacias previstas e retroanalisadas no sentido Batatais $-\mathrm{T}=33 \mathrm{M}$....106 Figura 5.21 - Bacias previstas e retroanalisadas no sentido Patrocínio Paulista $\mathrm{T}=33 \mathrm{M}$ 107

Figura 5.22 - Estudo paramétrico: variação do MR da base de solo-cimento do trecho experimental com a espessura da camada 108 


\section{LISTA DE TABELAS}

Tabela 3.1 - Resumo das características físicas e morfológicas do solo 38

Tabela 3.2 - Resumo dos compostos identificados 40

Tabela 3.3 - Resumo das características do cimento 42

Tabela 3.4 - Dados da estação meteorológica 55

Tabela 3.5 - Valores críticos (T) para desvio padrão calculado na mesma amostra (Fonte: GRUBBS (1950)) 59

Tabela 5.1 - Espessuras das camadas calculadas. 82

Tabela 5.2 - Valores de MR, Poisson e espessuras adotadas 83

Tabela 5.3 - Solicitações atuantes e admissíveis para N 2,5×10 84

Tabela 5.4 - Estruturas propostas para o trecho experimental 84

Tabela 5.5 - Coeficientes da curva de fadiga em amostras de solo-cimento (CERATTI, 1991) 85

Tabela 5.6 - Valores de MR, Poisson e espessura para a estrutura do trecho experimental. 86

Tabela 5.7 - Solicitações teóricas atuantes e admissíveis nas bases da estrutura proposta do trecho experimental para N $2,5 \times 10^{6}$ 87

Tabela 5.8 - Resumo dos dados de compactação obtidos para amostras de obra e de laboratório 94

Tabela 5.9 - Caracterização física, química e mecânica do cimento empregado na pesquisa e do cimento empregado no trecho experimental 94

Tabela 5.10 - Resumo das deflexões obtidas nos dois sentidos e em dois tempos103 Tabela 5.11 - Resumo da retroanálise do trecho experimental 105 


\section{LISTA DE SIGLAS E ABREVIATURAS}

\begin{tabular}{|c|c|}
\hline AASHO & American Association of State Highway Officials \\
\hline AASHTO & $\begin{array}{l}\text { American Association of State Highway and Transportation } \\
\text { Officials }\end{array}$ \\
\hline ADP & Asfalto Diluído de Petróleo \\
\hline ASTM & American Society for Testing Materials \\
\hline BAKFAA & Backcalculation of Federal Aviation Administration \\
\hline BGTC & Brita graduada tratada com cimento \\
\hline CAP & Cimento Asfáltico de Petróleo \\
\hline CBR & Califórnia Bearing Ratio \\
\hline CBUQ & Concreto Betuminoso Usinado à Quente \\
\hline CCR & Concreto Compactado com Rolo \\
\hline DER/SP & Departamento de Estradas de Rodagem do estado de São Paulo \\
\hline DNER & Departamento Nacional de Estradas de Rodagem \\
\hline DNIT & Departamento Nacional de Infraestrutura de Transporte \\
\hline El e EN & Energia do Proctor, Intermediária e Normal \\
\hline ELSYM 5 & Elastic Layer System Model 5 \\
\hline EPUSP & Escola Politécnica da Universidade de São Paulo \\
\hline FWD & Falling Weight Deflectometer \\
\hline HRB & Highway Research Board \\
\hline IBGE & Instituto Brasileiro de Geografia e Estatística \\
\hline IP & Índice de Plasticidade \\
\hline LC & Limite de Contração \\
\hline $\mathrm{LL}$ & Limite de Liquidez \\
\hline
\end{tabular}


Limite de Plasticidade

LTP

Laboratório de Tecnologia de Pavimentação

MCT

Moisture Condition Test

MR

Módulo de Resiliência

MTS

Material Testing System; prensa servo-hidráulica

NBR

Norma Brasileira Regulamentadora

RCS

Resistência à Compressão Simples

RI

Resíduos Insolúveis

RTCD

Resistência à Tração por Compressão Diametral

SC

Solo-Cimento

SMC

Solo Melhorado com Cimento

TSCE

Teoria de Sistema de Camadas Elásticas

TSD

Tratamento Superficial Duplo

UC

Solo mantido na umidade de campo

$\mathrm{UH}$

Solo na umidade higroscópica

UR

Umidade Relativa

USACE

United State Army Corps Engineers 


\section{LISTA DE SÍMBOLOS}

\begin{tabular}{|c|c|}
\hline $\mathrm{Al}(\mathrm{OH})$ & Gibbsita \\
\hline $\mathrm{Al}_{2} \mathrm{Si}_{2} \mathrm{O}_{5}(\mathrm{OH})_{4}$ & Caulinita \\
\hline $\mathrm{C}_{1 \text { e }} \mathrm{C}_{2}$ & $\begin{array}{l}\text { Coeficientes determinados experimentalmente no ensaio de } \\
\text { módulo de resiliência. }\end{array}$ \\
\hline $\mathrm{CO}_{2}$ & Dióxido de carbono \\
\hline $\mathrm{D}_{0}$ & Deflexão máxima \\
\hline e & Índice de vazios \\
\hline $\mathrm{Fe}_{2} \mathrm{O}_{3}$ & Hematita \\
\hline $\mathrm{K}_{1}, \mathrm{~K}_{2}, \mathrm{~K}_{3}$ e $\mathrm{K}_{4}$ & $\begin{array}{l}\text { Coeficientes determinados experimentalmente no ensaio de } \\
\text { módulo de resiliência. }\end{array}$ \\
\hline LA $^{\prime}$ & Grupo de solos da classificação MCT \\
\hline LG' & Grupo de solos da classificação MCT \\
\hline $\mathrm{MgO}$ & Óxido de mercúrio \\
\hline $\mathrm{MPa}$ & Mega Pascal \\
\hline NA & Grupo de solos da classificação MCT \\
\hline NA' & Grupo de solos da classificação MCT \\
\hline $\mathrm{S} \%$ & Porcentagem do grau de saturação \\
\hline $\mathrm{SiO}_{2}$ & Quartzo \\
\hline $\mathrm{SO}_{3}$ & Trióxido de enxofre \\
\hline $\mathrm{TiO}_{2}$ & Anatásio \\
\hline $\mathrm{Ys}_{\mathrm{s}}$ & Peso específico aparente seco \\
\hline$\varepsilon_{\mathrm{t}}$ & Deformação horizontal de tração \\
\hline$\varepsilon_{\mathrm{v}}$ & Deformação vertical \\
\hline
\end{tabular}


Coeficiente de Poisson

$\sigma$

Desvio padrão

$\sigma 3$

Tensão de confinamento, tensão principal menor

$\sigma d$

Tensão desviadora; diferença entre tensão principal maior e tensão principal menor 


\section{INTRODUÇÃO}

A utilização de materiais granulares em camadas de base e sub-base é de uso corriqueiro na pavimentação. Sua restrição geralmente está associada à escassez do material pétreo na região da obra, ocasionando altos custos de transporte e inviabilizando sua utilização. A partir desta situação, surge a necessidade do aproveitamento de materiais disponíveis na própria região. O solo local pode ser uma alternativa, desde que atenda a critérios de resistência, durabilidade e estabilidade após sua compactação.

O solo é um material complexo, variável e com extensa aplicação na engenharia rodoviária devido a sua ocorrência em abundância. Porém, dependendo de sua origem pedológica e condições de tráfego, pode não ser apropriado para camadas de base e sub-base de pavimentos. Dentro destas limitações, devem ser estudadas alternativas que melhorem as características do solo. A estabilização com aglomerantes hidráulicos pode ser uma solução interessante, tanto do ponto de vista técnico, como econômico.

\subsection{Objetivos}

O objetivo geral desta dissertação é estudar os fatores envolvidos na rigidez e na resistência de uma mistura de solo-cimento. $O$ foco da pesquisa consiste no estudo de prováveis diferenças causadas pela forma da adição do cimento, seja: (i) mistura realizada com o solo seco, procedimento comumente adotado para dosagem, ou ainda (ii) mistura realizada com solo úmido, condição que representa o processo de produção em pista, ou usina.

Dentre os objetivos específicos, podem ser citados: 
- Verificar o efeito da umidade inicial de mistura (umidade higroscópica versus umidade de campo) no comportamento mecânico de misturas de solocimento;

- Quantificar o efeito do teor de cimento na resistência a compressão simples do solo-cimento;

- Verificar a influência do tempo de cura nos resultados de resistência e rigidez;

- Determinar a retração e contração em misturas de solo-cimento em condições de umidade relativa do ar e temperatura controladas;

- Monitorar um trecho experimental, com base de solo-cimento, através de levantamento deflectométricos (FWD) para verificação da rigidez in situ, através de retroanálise.

\subsection{Estrutura do trabalho}

Esta dissertação está dividida em 6 capítulos.

O capítulo 1 traz uma introdução sobre o tema proposto nesta pesquisa, objetivos, bem como a estrutura do trabalho aqui apresentado.

O capítulo 2 aborda uma revisão bibliográfica sobre o emprego de solo-cimento, além de suas propriedades e características como material de pavimentação. São comentados alguns aspectos construtivos que podem interferir na qualidade final da mistura.

O capítulo 3 apresenta uma descrição dos materiais utilizados e a metodologia empregada para a realização dos ensaios em laboratório.

O capítulo 4 apresenta os resultados obtidos no trabalho e são tecidos alguns comentários sobre os mesmos.

O capítulo 5 aborda a construção do trecho experimental com a utilização da mistura de solo-cimento como camada de base, sua concepção e considerações mecanicistas sobre a estrutura implementada. 
O capítulo 6 traz as conclusões obtidas através do desenvolvimento desta pequisa, além de sugestões para pesquisa futuras. 


\section{CAMADAS ESTABILIZADAS COM CIMENTO}

O emprego de aglomerantes hidráulicos com 0 intuito de melhoria das características de materiais naturais empregados para pavimentação não é de uso recente. A utilização de pozolanas e cal como materiais estabilizantes já são conhecidos desde a época áurea de Roma, de acordo com Bolis e Renzo, 1949

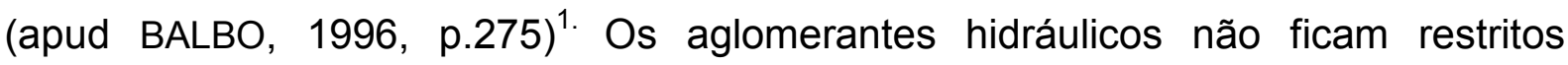
somente ao cimento Portland, podendo ser aplicados outros materiais com o mesmo princípio cimentante, como por exemplo, a cal, cinzas volantes e escórias granuladas.

O cimento pode agir de formas distintas, dependendo da granulometria do material estabilizado e também da quantidade de vazios. Quando empregado em uma matriz predominantemente fina como a de solos, por exemplo, atua como uma pasta, recobrindo suas partículas, criando uma matriz que fixa os grãos soltos de solo. Já no caso de materiais granulares, o efeito ocorre de forma pontual, não recobrindo os agregados devido ao tamanho dos mesmos serem superiores a argamassa e também pela quantidade de vazios existente entre os grãos. A resistência passa a ser dependente também destes contatos pontuais gerados pela pasta de cimento, causando uma coesão aparente (LILLEY, 1973 apud BALBO, 1996, p.278)2.

\subsection{Base de solo-cimento}

Existem diversos materiais empregados na pavimentação que levam o cimento como estabilizante e melhorador de resistência. Pode-se citar a mistura de solo melhorado com cimento (SMC), solo-cimento $(\mathrm{SC})$, solo-brita-cimento $(\mathrm{SBC})$, brita graduada tratada com cimento (BGTC), o concreto compactado a rolo (CCR), além

\footnotetext{
${ }^{1}$ BOLIS, B.; RENZO, A. di. Pavimentazioni stradali. Hoepli, Milano, 1949.

${ }^{2}$ LILLEY, A. A. Cement-stabilized materials for road and airfield pavement. London, 1971.
} 
dos materiais reciclados. Nos parágrafos a seguir são descritos alguns materiais com maior detalhe.

A mistura de solo com cimento pode se apresentar de duas formas, de acordo com o comportamento desejado: (i) material resistente à presença de água, caso do solo melhorado com cimento, ou (ii) conjugado a este comportamento, uma alta rigidez, como verificado no solo-cimento. Para Balbo (2007), a diferença entre a mistura de SMC e a mistura de SC reside na quantidade de cimento empregado e também na resposta do material, seja de comportamento resistente apenas à presença de água, ou trabalhando à flexão com resistências elevadas.

O solo melhorado com cimento tem como função aumentar a estabilidade do solo, diminuir sua expansão e seu índice de plasticidade, resultando em um material estável, mas de baixa rigidez quando comparado com o solo-cimento. Geralmente são empregados teores de 2 a $4 \%$ de cimento em massa na sua dosagem (DNIT, 2010; AUST STAB, 2012).

O solo-cimento é o material resultante da mistura de solo, cimento e água em proporções determinadas previamente por processo de dosagem em laboratório, de forma a apresentar determinadas características de resistência e durabilidade (DNIT, 2010). Sua rigidez e tensão de deformação possuem valores suficientes para serem considerados como rígidos, inclusive devem ser consideradas desta forma no dimensionamento de pavimentos (AUST STAB, 2012).

De acordo com Bernucci et al. (2006), para que o solo seja estabilizado com cimento de forma econômica o mesmo deve conter porção de areia, pois caso tenha um teor muito elevado de argila pode exigir um aumento considerável de cimento, apresentar elevada retração e, ainda, tornar o processo mais caro. As misturas de solo-cimento podem acontecer de duas formas distintas: (i) no caso de se objetivar um enrijecimento significativo do solo, empregam-se percentuais em massa em geral acima de $5 \%$ e (ii) no caso da melhoria parcial das propriedades, principalmente trabalhabilidade conjugada com certo aumento da capacidade de suporte, empregam-se percentuais mais baixos, da ordem de $3 \%$, caso do solo melhorado com cimento. 
A base de solo-cimento tem se mostrado bastante resistente e durável desde que: (i) a mistura seja bem dosada, (ii) sejam respeitados os prazos máximos de mistura, espalhamento e compactação, (iii) seja minimizada a ocorrência excessiva de trincas por retração, e (iv) o subleito tenha boa capacidade de suporte para que o solocimento seja compactado de forma eficiente (BERNUCCl et al., 2006).

É comum a presença de fissuras e/ou trincas que se formam inicialmente em bases do tipo solo-cimento, devido à retração térmica ocasionada pela hidratação do cimento (cura), bem como pela consequente contração causada através da perda de umidade. O espaçamento e a abertura dessas trincas dependem da quantidade de cimento e, principalmente, das características do solo. Quando são utilizados solos mais coesivos e argilosos, a base de solo-cimento sofre trincamento mais severo que acabam refletindo na camada de rolamento. No entanto, esta estrutura "trincada" não necessariamente compromete o bom comportamento do pavimento, conforme atestam mais de $10.000 \mathrm{~km}$ dessas bases, executadas no estado de São Paulo (VILLIBOR et al., 2005). Os mesmos autores afirmam que este bom comportamento está associado à forma de dissipação das tensões. A base de solocimento trabalha em blocos irregulares, de baixa permeabilidade e elevada rigidez. Parte das tensões, ocasionadas pela ação das cargas dos veículos, são absorvidas por esses blocos e a outra parcela é transferida para os outros blocos adjacentes, através do atrito entre as placas, sendo essa segunda parcela dissipada em uma maior área para alívio das tensões impostas pelo tráfego.

\subsection{Comportamento mecânico do solo-cimento}

$\mathrm{O}$ adequado dimensionamento da estrutura com base de solo-cimento requer $\mathrm{O}$ conhecimento de algumas informações sobre seu comportamento mecânico. Sua rigidez e resistência às solicitações das cargas impostas pelo tráfego são fundamentais para a concepção de uma estrutura semi-rígida. Outros fatores como a contração do solo, umidade e tempo de cura podem alterar seu comportamento mecânico, conforme abordado adiante. 


\subsubsection{Módulo de resiliência}

O valor de rigidez determinado em laboratório (módulo de resiliência) pode divergir do valor determinado para o material empregado em campo. Isto se deve principalmente pelas microfissuras geradas na camada, onde a mesma passa a não trabalhar com o mesmo valor de módulo resiliente determinado em laboratório, mas com um módulo resiliente "efetivo" de valor inferior. A dispersão entre os valores de laboratório e campo será proporcional à severidade das dimensões das fissuras desenvolvidas.

Parente; Parreira e Soares (2002) alertam que em um dimensionamento racional, os valores modulares do solo-cimento precisam ser escolhidos com rigor devido às trincas presentes no material criarem uma estrutura em blocos, ocasionando comportamento diferente dos corpos de prova intactos ensaiados em laboratório.

Trindade et al. (2003) em um estudo com um solo arenoso de classificação HRB A2-4 e MCT NA, misturado com 5\% de cimento e um outro argiloso, de classificação HRB A-7-5 e MCT LG', misturado com 11\% de cimento, verificaram a influência do teor de umidade de moldagem nos valores de módulo de resiliência. As misturas foram compactadas na energia Intermediária, com três variações de umidade: (i) umidade ótima, (ii) umidade ótima $-2 \%$ e (iii) umidade ótima $+2 \%$. Os autores verificaram que quanto maior o teor de umidade da mistura, menor seu valor de módulo resiliente, sendo este comportamento verificado para as duas misturas de solo-cimento. As misturas de solo-cimento mantiveram a mesma sensibilidade dos solos quanto às tensões atuantes, sendo o solo-cimento com solo coesivo sensível a tensão desviadora ( $\sigma$ d) e o solo-cimento com material granular sensível a tensão confiante (б3). Esta verificação foi possível pelo fato das amostras terem sido ensaiadas nas duas combinações de carregamentos previstas na antiga versão da norma de Módulo de Resiliência (DNER-ME 131-94). Nesta antiga versão são apresentados dois modelos de regressão, de acordo com o tipo de material a ser ensaiado. Para solos granulares adotavam-se dois modelos lineares: $M R=K_{1} \sigma 3^{K 2} e$ $\mathrm{MR}=\mathrm{C}_{1} \sigma \mathrm{d}^{\mathrm{C} 2}$. Para solos coesivos adotava-se um modelo bi-linear: $\left(\mathrm{MR}=\mathrm{K}_{2}+\mathrm{K}_{3}\left(\mathrm{~K}_{1}\right.\right.$ $\sigma d)$ ) quando $k_{1}>\sigma d$ e $\left(M R=K_{2}+K_{4}\left(\sigma d-K_{1}\right)\right)$ quando $k_{1}<\sigma d$. O modelo bi-linear foi 
retirado da atual norma, DNIT-ME 134-10, restando as equações comportamento linear.

O tipo de solo empregado na confecção de misturas de solo-cimento (SC) e o aglomerante hidráulico interferem no valor de rigidez da mistura. Bechara et al. (2010) em um estudo laboratorial entre duas misturas de solo-cimento, sendo um solo laterítico (LA') e o segundo solo não laterítico (NA'), verificaram que os ganhos de propriedades mecânicas foram mais acentuados para o solo não laterítico, principalmente nos ensaios de módulo de resiliência. Ainda no mesmo estudo, foi verificado que os maiores incrementos de resistência das misturas, cerca de $50 \%$ do valor final, ocorrem nos primeiros 3 dias de cura.

Pinilla et al. (2011) realizaram um estudo com cinco solos de locais distintos. Dois tratados com cinza de alto forno, designados de "EN" e "ES", sendo "EN" de classificação HRB A-6, tratado com 14\% e "ES", de classificação HRB A-2-4, tratado com $12 \%$. Os três restantes tratados com cinza volante, designados de "AD", "PR" e "PN", sendo "AD" de classificação HRB A-4 tratado com 15\%, "PR" de classificação HRB "A-6", tratado com 15\% e "PN", de classificação A-4-2 e tratado com 16\%. Os ensaios de módulo de resiliência mostraram um maior aumento de rigidez para a amostra arenosa "ES", seguida da amostra "EN", sendo os valore obtidos de 4.208 $\mathrm{MPa}$ e $2.380 \mathrm{MPa}$, respectivamente. As amostras tratadas com cinza volante obtiveram os seguintes valores: "AD" $580 \mathrm{MPa}$, "PR" $1.052 \mathrm{MPa}$ e "AD" $442 \mathrm{MPa}$. Os autores concluem que cinza de alto forno é um aditivo mais eficiente na estabilização de solos com baixa plasticidade quando comparada a cinza volante e a cal. Os valores foram determinados para amostras confeccionadas em molde cilíndrico com $10 \mathrm{~cm}$ diâmetro e $20 \mathrm{~cm}$ de altura e compactadas na energia Normal, após 28 dias de cura em câmara úmida.

\subsubsection{Fadiga}

A fadiga é um processo contínuo de degradação da camada cimentada, ocorrendo em locais com concentrações de tensões ou deformações de tração. De acordo com 
Ceratti e Medina (1983), a máxima tensão ou deformação de tração em estruturas com solo-cimento ocorre quase sempre na própria camada cimentada. Este fato pode ser verificado por um simples programa de análise estrutural, onde a camada de maior rigidez apresenta a maior concentração de tensões.

Os ensaios de fadiga podem ser realizados por tensão ou deformação controlada. Segundo Monishimit e Deacon, 1969 (apud CERATTI; MEDINA, 1983) ${ }^{3}$, os ensaios a deformação controlada aplicam-se melhor a camadas de baixa rigidez e pequena espessura, sendo seu comportamento quanto à deformação controlado pelas camadas inferiores do pavimento, enquanto os ensaios a tensão controlada aplicamse melhor às camadas de maior rigidez e espessura. Neste mesmo estudo, foi verificado o desempenho de três misturas de solo-cimento quanto à fadiga por compressão diametral, a partir de três solos ("A", "B" e "C"), sendo o solo "A", de classificação HRB A-1-b misturado com 6\% cimento, o solo "B", de classificação HRB A-2-4 misturado com 7\% de cimento e o solo "C", de classificação HRB A-7-5 misturado com $13 \%$ de cimento. A porcentagem de cimento adicionada foi calculada em relação à massa de solo seco. Também foram moldados para os três solos, misturas de solo melhorado com cimento com $2 \%$ em massa. As três amostras de solo-cimento apresentaram desempenho superior a $10^{6}$ repetições de carga para níveis de carregamento abaixo de $65 \%$ da resistência de ruptura das amostras, sendo este valor recomendado como limite para os materiais estudados. As curvas de fadiga não apresentaram diferenças significativas entre os três materiais estudados. Os solos arenosos (A e B) melhorados com cimento apresentaram diminuição da deformação resiliente nas primeiras 24 horas enquanto que na amostra argilosa (solo $\mathrm{C}$ ), o mesmo efeito foi verificado após 72 horas.

Ceratti (1991) em um estudo laboratorial para misturas de solo-cimento verificou que misturas preparadas com solos finos apresentam maiores valores de vida de fadiga à flexão quando comparadas a misturas preparadas com solos granulares. No mesmo estudo, utilizando dois solos do mesmo perfil, mas de duas camadas distintas separadas por seixos, foi verificado que a origem pedológica dos solos

\footnotetext{
${ }^{3}$ MONISHIMIT, C. L.; DEACON, J.A. Fatique of asphalt pavement mixtures. Proceding, ASTM. 1969.
} 
influencia nos resultados de vida de fadiga desse tipo de mistura cimentada. Os ensaios realizados com solo presente na parte superior do perfil, classificado como LA', apresentaram maiores valores de vida à fadiga na flexão quando comparados com os valores obtidos para o segundo solo, da parte inferior do perfil, classificado como NA'.

\subsubsection{Retração e contração}

Estes dois fenômenos atuam conjuntamente em misturas de solo-cimento, sendo a retração ligada diretamente à hidratação do cimento e a contração relacionada às propriedades do solo utilizado (VILLIBOR et al., 2005). Os dois fenômenos atuando em conjunto, ou isoladamente, podem ocasionar trincas nesse tipo de mistura.

Sebesta (2005) classifica o trincamento de misturas de solo-cimento em duas categorias: (i) autógeno, ocasionado por características do próprio material e associado à hidratação do cimento, (ii) secagem, associado a perda de água para o ambiente.

A contração está associada à perda de água do solo e pode causar trincamento. Este fenômeno é verificado em solos argilosos lateríticos, que, após compactados, perdem água superficialmente e trincam em forma de couro de jacaré (VILLIBOR et al., 2005). Para Bernucci (1987), a fissuração e o trincamento estão relacionados com a coesão do material frente à perda de umidade, também ressalta que a contração em solos não coesivos, quando existente, é inexpressiva, além do fato destes solos não serem propícios ao desenvolvimento de fissuras.

Para Costa (2005), a contração está associada à coesão do solo, sua suç̧ão e capilaridade. A fração mais fina em um solo possui coesão, ou seja, a capacidade de resistir a tensões cisalhantes (TERZAGHI, 1948). Para Vargas (1978), a coesão é a resistência ao cisalhamento de um solo, quando sobre o mesmo não atua nenhuma pressão interna. Sua origem pode ser associada a três fatores: natureza cimentante da fração argilosa, atração intermolecular ou coloidal entre as partículas de solo, 
denominada de "coesão verdadeira" ou ainda, ser resultante das forças dos capilares internos do solo, denominada de "coesão aparente" (VARGAS, 1978).

Nos solos tropicais, há um intenso processo de lixiviação durante sua formação que remove grande parte da fração argilosa, o restante desta fração é composto por argilas de baixa atividade, sendo a capilaridade um fator essencial para a existência de coesão neste tipo de solo (COSTA, 2005).

A sucção representa a capacidade que um solo possui de absorver água e sua explicação teórica é baseada em complexas interações físico-químicas da água com as partículas de solo. A presença de água, em condições de não saturação, cria uma situação onde os meniscos de ar-água provocam uma pressão neutra negativa na água, a pressão de sucção (PINTO, 2006).

A capilaridade é responsável por atrair os grãos do solo através da tensão desenvolvida pelos meniscos de água interna na estrutura. De acordo com Pinto (2006), quando existe um menisco capilar, a água se encontra abaixo da pressão atmosférica. O menisco possui um limite de pressão negativa, a partir da qual a tensão superficial é vencida e a água evapora. Quanto menor o tamanho das partículas, menores são os capilares formados e maiores são as forças desenvolvidas. Desta observação, conclui-se que solos plásticos possuem um grande potencial de sofrerem contração, comportamento contrário ao de solos com predominância arenosa, onde o tamanho dos meniscos são maiores, resultando em menores forças de atração.

A contração pode ser determinada experimentalmente pelo Limite de Contração (LC), que integra os índices de consistência determinados pelos Limites de Atterberg. O LC é definido no instante onde ocorre a perda de água no solo sem a ocorrência de variação volumétrica.

A retração, associada ao processo de hidratação do cimento, é refletida na forma de fissuras ou, nos casos mais severos, sob a forma de trincas. Balbo (2007) relata que o alto consumo empregado em misturas de solo-cimento propicia o aparecimento de fissuras por retração, que ocorrem durante o processo de cura e pode ser ainda mais relevante quando são empregados solos argilosos. Teixeira e Pitta (1982) realizaram uma extensa pesquisa com o intuito de entender e quantificar os 
princípios da retração em solos com adição de cimento. A medida da retração foi realizada por um instrumento desenvolvido durante a pesquisa em corpos de prova prismáticos, curados tanto em câmara úmida, quanto submersos em água, com períodos de cura variando de alguns dias a até 50 semanas. Para o estudo, foram empregados cinco solos, sendo: duas argilas de alta plasticidade e diferentes índices de atividade, altamente sujeitas a variações volumétricas, uma areia argilosa com pequena plasticidade, um pedregulho areno-siltoso e um silte de baixa plasticidade e alto limite de liquidez. A argila com adição de bentonita se alterou para um silte não plástico. Os corpos de prova foram moldados na energia Normal de compactação, sendo adotadas cinco condições de misturas para cada solo: (i) Série A, mistura de solo-cimento de referência; (ii) Série $B$, menor teor de cimento, mantida a mesma umidade da série A; (iii) Série $C$, maior teor de cimento, mantida a mesma umidade da série $A$; (iv) Série $D$, menor teor de umidade, mantida a mesma quantidade de cimento da séria $A$; e (v) Série $E$, maior teor de umidade, mantido os teores de cimento da série $A$. Uma Série $F$ foi criada apenas com o solo, para manter uma referência sem adição de cimento. A partir deste estudo foi possível concluir que a retração nos solos argilosos tratados com cimento é muito mais lenta quando comparadas aos solos granulares, que estabilizaram a variação volumétrica em alguns dias, exigindo maiores cuidados durante as primeiras 48 a 72 horas de mistura, mostrando que os solos argilosos requerem maiores períodos de cura. No mesmo estudo, foi verificado que quanto maior a concentração da fração argilosa (< $0,002 \mathrm{~mm}$ ), maior será sua tendência de retração. A mistura de aditivos expansores como a bentonita mostrou-se favorável na redução deste fenômeno. A quantidade de água no momento da compactação se mostrou como um dos principais fatores na retração do solo-cimento, sendo indicada uma compactação com teor de umidade ligeiramente inferior a umidade ótima para minimizar este fenômeno. Por fim, foi verificado que períodos extensos de cura não aumentam de forma significativa a retração total. 


\subsubsection{Efeito da umidade}

Para Terzaghi (1948), a superfície de cada partícula de solo é carregada negativamente e a intensidade desta carga depende da largura, extensão e das características mineralógicas das partículas. As manifestações físicas e químicas constituem a superfície ativa do mineral. Na natureza, as partículas de solos são envoltas por água, as moléculas de água são polares e sofrem atração pela carga negativa das partículas de solo.

Entre a superfície do sólido e a água, ocorre a formação de estrutura composta por moléculas de água atraídas pelo sólido. A água presente entre esta estrutura e a borda sofre a influência das mudanças de cargas e é denominada de camada adsorvida. A água adsorvida possui propriedades muito distintas da água normal, ou livre, na mesma temperatura. Próximo da partícula de solo, a água se comporta como um sólido; no meio, como um liquido viscoso; e na superfície, a água possui propriedades de água normal (TERZAGHI, 1948).

De acordo com Saarenketo (1998), a água no solo pode ser classificada de três formas: (i) água adsorvida, também denominada água higroscópica, (ii) água viscosa, ou água capilar e (iii) água capilar, ou água livre, conforme mostrado na Figura 2.1. A água higroscópica é resultante da força de absorção das partículas de solo da água molecular presente no ar. Consiste em uma camada molecular bem estruturada em torno da superfície mineral carregada negativamente e outra ligada por adsorção (MITCHELL, 1992). A água viscosa, ou água capilar, é aquela em torno da partícula do solo, entre a camada estruturada e que não responde às forças da gravidade. A quantidade de água capilar presente no solo é controlada pela textura, estrutura e matéria orgânica presente no solo (LYON; BUCKMAN, 1937). Essa água capilar desenvolve tensões na superfície, formando meniscos capilares entre as partículas e o ar em uma massa de solo não saturado (MITCHEL, 1992). As contrações existem na superfície de água livre, mas também formam a interface de ar-água em solos não saturados (SAARENKETO, 1998). A água livre, ou água gravitacional, é atraída fracamente pelas partículas de solo e podem responder aos esforços da gravidade e movimentação do solo. (LYON; BUCKMAN, 1937). 

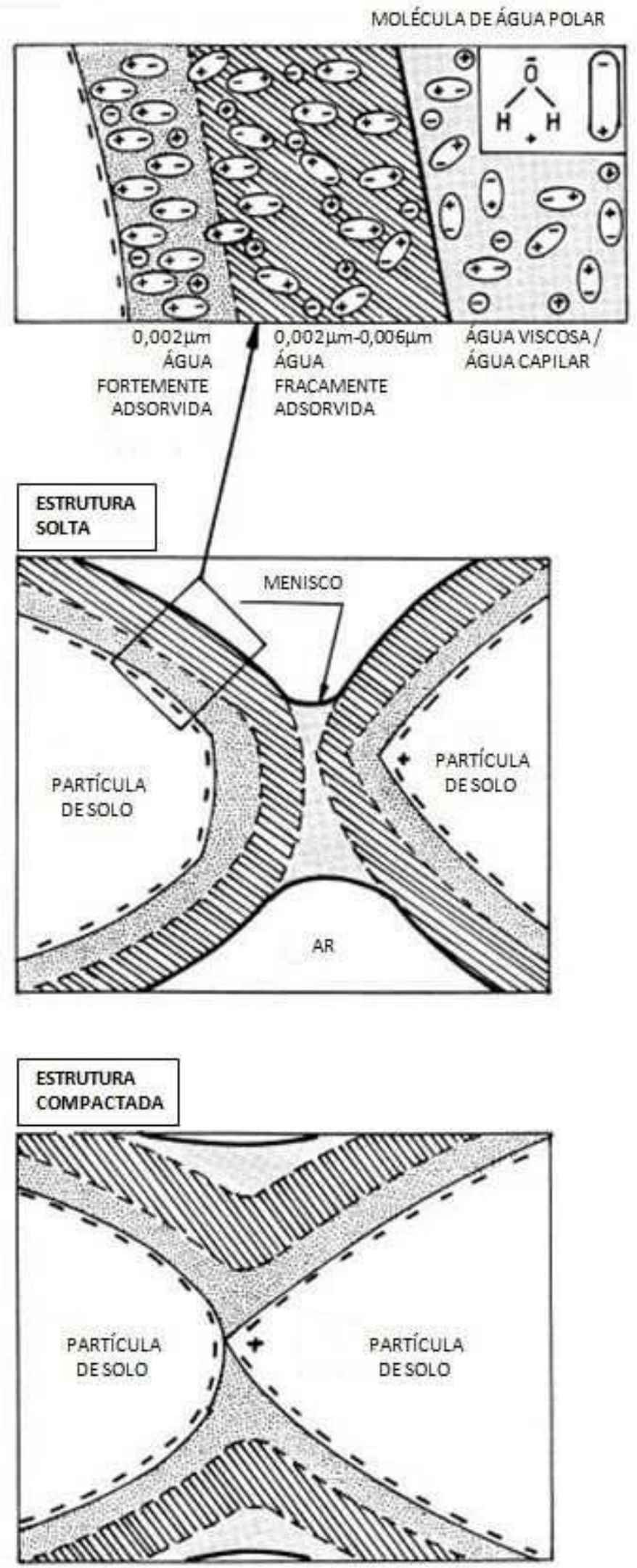

Figura 2.1 - Formas de água presentes naturalmente nos solos finos (Adaptado de SAARENKETO, 1998) 
Nos solos, a variação da umidade afeta substancialmente sua resistência, principalmente no ramo úmido da curva de compactação. A quantidade de água presente no solo no momento de sua compactação afeta seu peso específico aparente seco $\left(\gamma_{s}\right)$, índice de vazios (e) e grau de saturação (S\%). Depois de compactado, a variação da umidade também afeta o comportamento mecânico do solo. Sabe-se que os solos com menor influência deste comportamento são os lateríticos, que depois de compactados permitem a perda água, mas não a reabsorvem totalmente devido à estrutura dos minerais presentes no solo agirem como hidrofugantes (NOGAMI; VILLIBOR, 1995; LUZ; PARREIRA, 2003). Este comportamento é designado de irreversibilidade, ou seja, o solo não retorna a mesma consistência após a reabsorção da umidade.

A secagem prévia do solo interfere nos valores de massa específica seca máxima e teor de umidade ótima. Para Nogami e Villibor (1995), a secagem prévia em alguns solos lateríticos pode modificar irreversivelmente as propriedades da fração argilosa e destacam que essa peculiaridade se manifesta de forma acentuada em lateritas hidromorfas (plíntitas), que podem endurecer de forma irreversível. Massad (2003) comenta um caso do solo da barragem de Ponte Nova, onde foi verificada uma diferença de $4 \%$ a menos entre a umidade ótima do ensaio de Proctor e a compactação realizada com o solo na umidade de campo. Para Pinto (2006), a présecagem para alguns solos pode ser considerável, aumentando seu peso específico aparente seco e o teor de umidade ótima no caso de solos argilosos de decomposição de gnaisse e em solos areno-argilosos lateríticos, umidades ótimas menores com pouca influência no peso específico. A norma de compactação de solos (NBR 7182/86) prevê a realização do ensaio com o material preparado $5 \%$ baixo da umidade ótima presumível, evitando assim a secagem total (umidade higroscópica). O solo, por ser o componente em maior proporção em misturas de solo-cimento, atribui suas características a mistura. Com a adição do cimento, o fator água/cimento também causará grande influência na resistência desse tipo de mistura. Estes fenômenos foram estudados por Yoon e Farsakh (2008) para um solo de classificação HRB A-2, misturados com teores de 8\%, 10\% e 12\% de cimento. Foi verificado que a adição de água reduz de forma acentuada sua resistência à compressão simples. 
A influência da quantidade de água durante o processo de compactação da mistura de solo-cimento será muito próxima à verificada no solo, uma vez que pouco tempo após a mistura, o cimento é uma fração granular ainda sem função aglomerante. Depois de compactado, o ganho de resistência causado pela hidratação do cimento afetará o comportamento do material, que com o aumento da rigidez, diminuirá sua influência à ação direta da água.

\subsubsection{Efeito do teor de cimento}

A quantidade de cimento afeta de forma significativa a resistência da mistura de solo-cimento. Isto se deve em parte pelo aumento da peso específico aparente máximo da mistura. O cimento age como um fíler, preenchendo os vazios entre as partículas do solo até um determinado teor, após este ponto, o peso específico aparente seco do solo-cimento pode diminuir (LADE; LYGIO; YAMAMURO, 1998).

Yoon e Farsakh (2008) indicam um aumento da resistência à compressão simples com o aumento da quantidade de cimento para uma amostra de solo de classificação HRB A-2. Os autores avaliaram a variação na quantidade de cimento de $8 \%, 10 \%$ e $12 \%$ de cimento, em massa.

Parente; Parreira e Soares (2002) verificaram maiores valores de rigidez e resistência com o aumento do teor de cimento para dois solos, misturados com $4 \%$, $7 \%$ e $10 \%$ em massa, sendo um de classificação MCT NA' e outro LA'. Os maiores valores foram obtidos para os solos de origem laterítica.

\subsection{Processos executivos}

O processo de adição do cimento ao solo pode ser feito de duas formas: misturado em pista ou produzido em usina. A produção em usina conduz a misturas de maior homogeneidade e qualidade, resultante da eficiência do controle na adição do 
cimento e processo de misturação. A produção em pista pode ser realizada de duas formas:

- Disposição de sacos de cimento em pista, com quantidade calculada volumetricamente. A homogeneização do material é realizada com grades de discos ou motoniveladora.

- $\quad$ Mistura de solo cimento processada por pulvimisturadora, equipamento móvel destinado a misturação e a homogeneização. Esta técnica apresenta melhor qualidade quando comparada com a anterior.

A compactação geralmente é realizada com rolo pé de carneiro vibratório. O número de passadas deve ser definido em um trecho experimental juntamente com o controle do peso específico aparente seco. O acabamento pode ser realizado com rolo liso, ou de pneus, e as regularizações sempre efetuadas em operações de corte, uma vez que a mistura solo-cimento não adere adequadamente após sua compactação, tornando o ponto de aterro vulnerável a descolamento (DER-SP ET DE P00/004, 2006).

Os órgãos rodoviários recomendam em geral 7 dias de cura sem tráfego de veículos pesados, (DNIT ES-143/2010). Neste período, o solo-cimento começa a ganhar resistência para suportar o tráfego futuro, de forma que a falta de controle nesta etapa pode ocasionar danos irreversíveis à estrutura.

A selagem da base de solo-cimento pode ser executada através da aplicação de emulsão asfáltica, comumente denominada de imprimação, que deve ser realizada após o término dos serviços de compactação e regularização da camada. O uso da emulsão asfáltica e não do asfalto diluído de petróleo (ADP) deve-se a dois fatos: (i) a imprimação com ADP torna o cimento inerte, não permitindo a ocorrência do processo de hidratação do cimento e (ii) por ser composto a base de solventes nocivos ao meio ambiente, os ADP's estão cada vez mais em desuso na pavimentação rodoviária (BERNUCCl et al., 2006). 


\section{METODOLOGIA E MATERIAIS UTILIZADOS}

Este capítulo aborda as características dos materiais empregados no estudo experimental, o procedimento para coleta e armazenamento do solo e a metodologia empregada na realização dos ensaios.

\subsection{Materiais}

A seguir, são apresentadas as características do solo e do cimento empregado nesta pesquisa.

\subsubsection{Caracterização do solo}

Foram realizados ensaios dos índices de consistência (limites de Atterberg) para a parcela de solo passante na peneira \#40. O Limite de Liquidez (LL) foi determinado de acordo com a NBR 6459/84 e o Limite de Plasticidade (LP) de acordo com a NBR $7180 / 84$.

A análise granulométrica foi realizada de acordo com a NBR 7181/84, utilizando defloculante hexa-metafosfato. O emprego do defloculante não é recomendado para solos laterizados, uma vez que o solo apresenta-se estável na presença de água, mas desagrega com o defloculante, gerando uma distribuição com maior concentração de finos (REZENDE, 1991). A distribuição granulométrica obtida é apresentada na Figura 3.1. Os dados dos índices de consistência e granulometria foram utilizados para classificar o solo no sistema Highway Research Board (HRB), conforme apresentado na Tabela 3.1. 
Ensaios de compactação em equipamento miniatura foram realizados de acordo com a DNER ME 258/94 e a perda por imersão determinada de acordo com a DNER ME 256/94 para posterior classificação do solo dentro do sistema MCT aplicado a solos tropicais. Os cálculos dos coeficientes da metodologia MCT e a classificação do solo foram realizados de acordo com a DNER CLA-259/96. A classificação do solo, bem como outros índices são apresentadas na Tabela 3.1.

Tabela 3.1 - Resumo das características físicas e morfológicas do solo

\begin{tabular}{|c|c|}
\hline LL (\%) & 17,3 \\
\hline LP (\%) & 16,0 \\
\hline IP & 1,3 \\
\hline Peso específico dos grãos ( $\left.\mathrm{g} / \mathrm{cm}^{3}\right)$ & 2,703 \\
\hline Esfericidade Média & 0,90 \\
\hline Passante \# 2,00mm (\%) & 100,00 \\
\hline Passante \# 0,42mm (\%) & 99,5 \\
\hline Passante $75 \mu \mathrm{m}(\%)$ & 29,5 \\
\hline "'n' & 0,75 \\
\hline ' d' & 30,15 \\
\hline$e^{\prime}$ & 0,61 \\
\hline PI (\%) & 117 \\
\hline Classificação HRB & A-2-4 \\
\hline Classificação MCT & $\mathbf{L A}^{\prime}$ \\
\hline
\end{tabular}

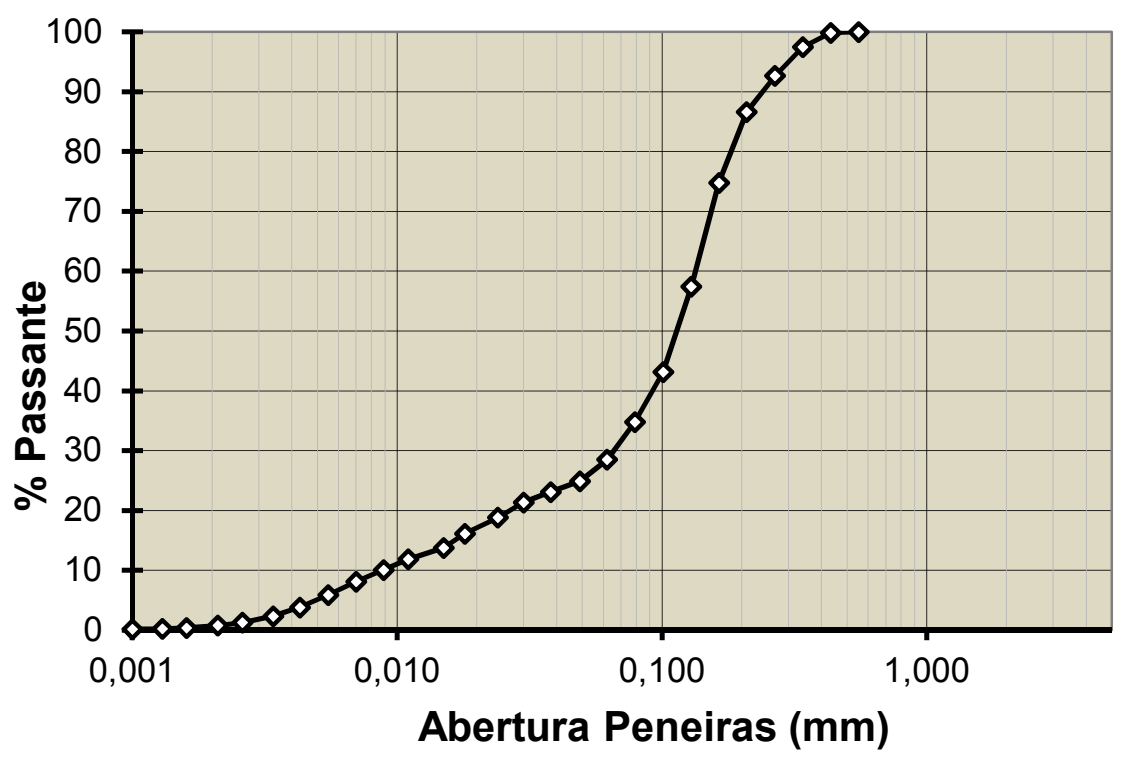

Figura 3.1 - Distribuição granulométrica do solo 
A análise mineralógica do solo foi realizada com $O$ difratômetro de raio $X$ PANalytical, modelo X'pert PRO com detector X'Celerator, pelo Laboratório de Caracterização Tecnológica (LCT) do Departamento de Engenharia de Minas e de Petróleo da EPUSP.

O estudo foi realizado através do método do pó, também conhecido como mineralogia total. A identificação das fases cristalinas foi feita por comparação do difratograma da amostra ensaiada com o banco de dados PDF2 do ICDD International Centre for Diffraction Data (2003) e da PAN-ICSD - PANalytical Inorganic Crystal Structure Database (2007). O difratograma gerado e as fases identificadas são apresentados na Figura 3.2.

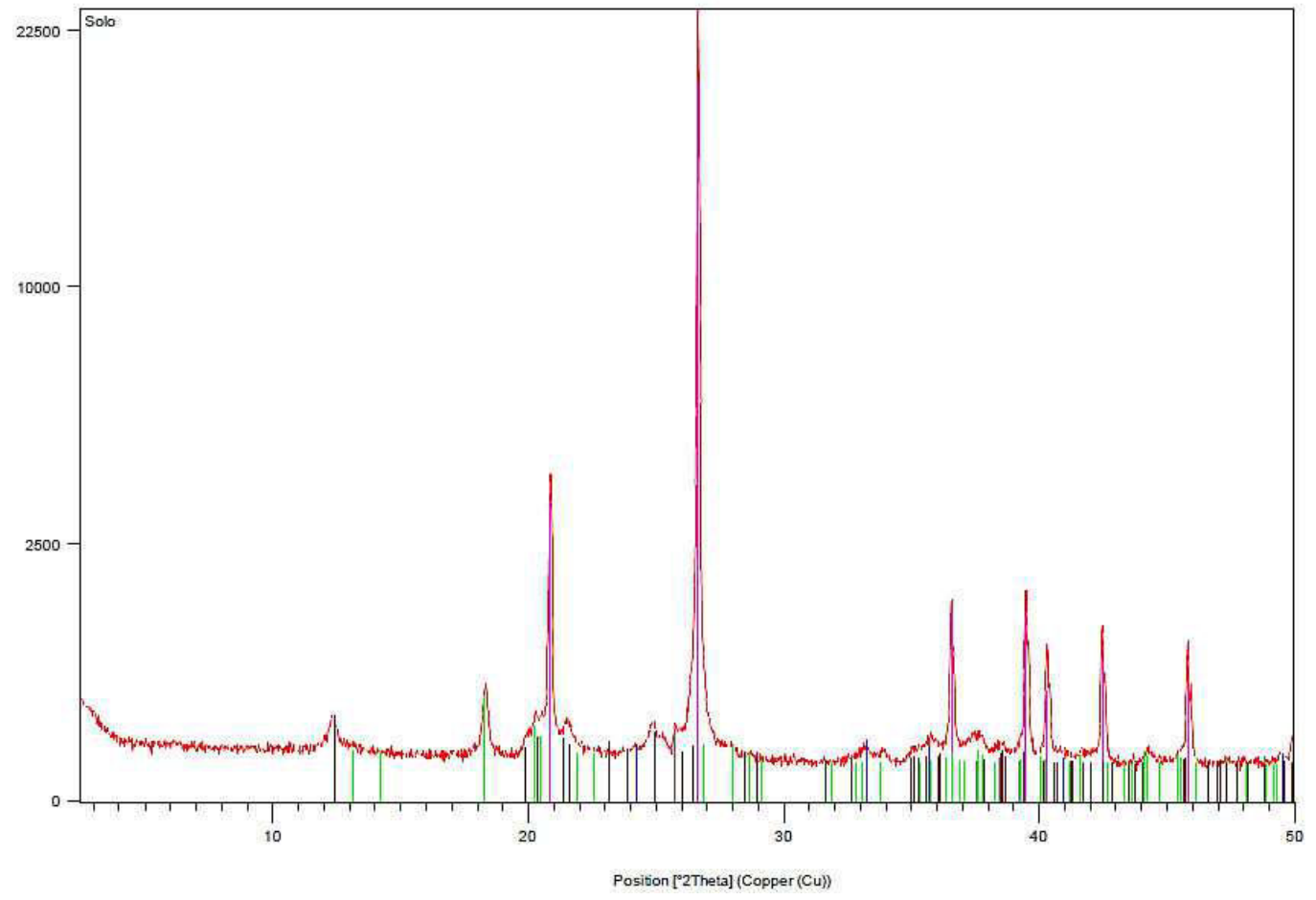

(a) 


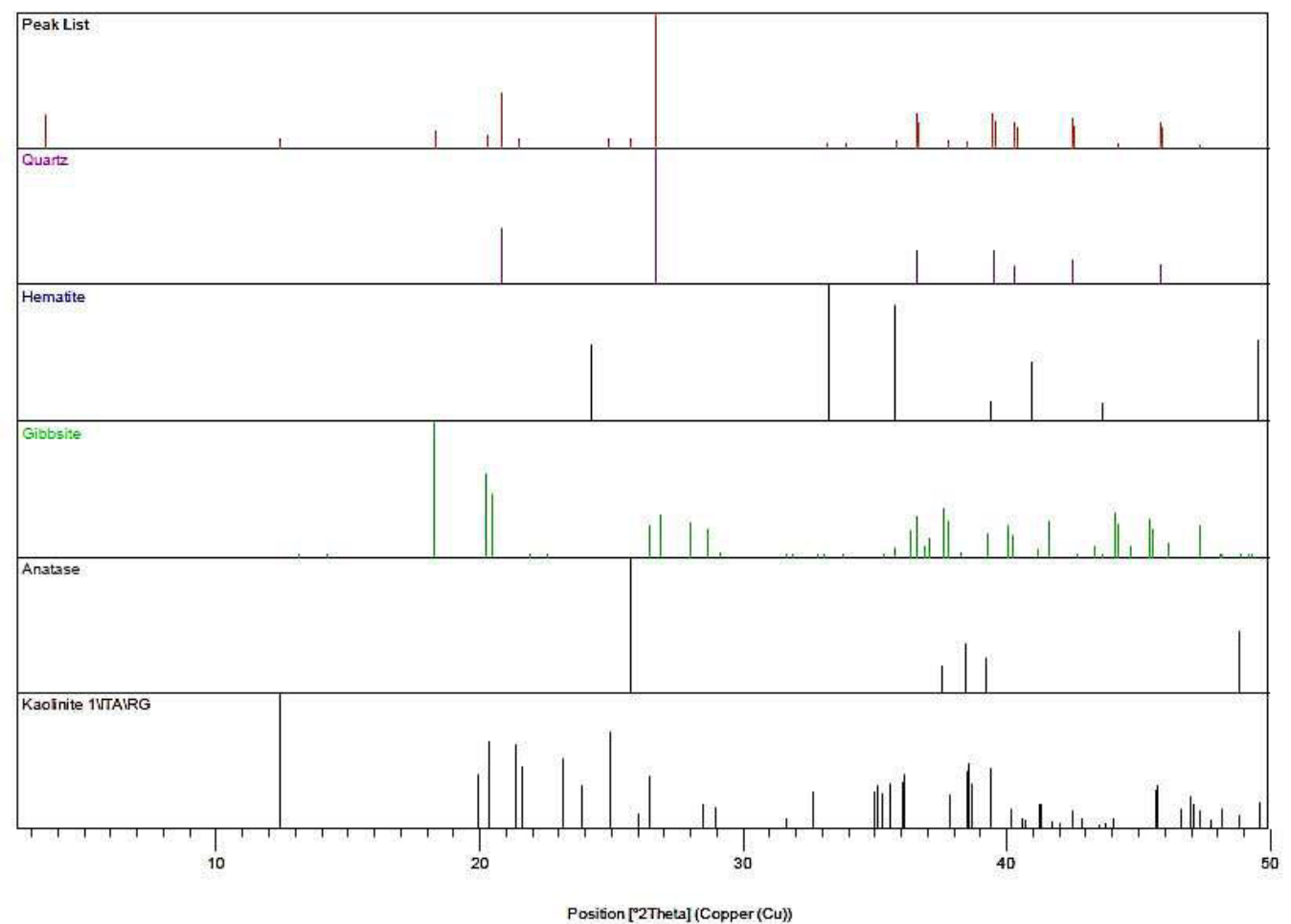

(b)

Figura 3.2 - (a) Resultado da difratometria e (b) identificação dos minerais

Os compostos identificados e sua forma cristalina são apresentados na Tabela 3.2.

Tabela 3.2 - Resumo dos compostos identificados

\begin{tabular}{c|c|c|c}
\hline Código ICDD & Nome do Composto & Fórmula Química & Mineral \\
\hline $01-085-0794$ & Quartzo & $\mathrm{SiO}_{2}$ & Quartzo \\
$01-074-1775$ & Gibbsita & $\mathrm{Al}(\mathrm{OH})_{3}$ & Gibbsita \\
$01-074-1778$ & Caulinita & $\mathrm{Al}_{2} \mathrm{Si}_{2} \mathrm{O}_{5}(\mathrm{OH})_{4}$ & Caulinita \\
$01-075-1537$ & Anatásio & $\mathrm{TiO}_{2}$ & Anatásio \\
\hline $01-079-0007$ & Hematita & $\mathrm{Fe}_{2} \mathrm{O}_{3}$ & Hematita \\
\hline
\end{tabular}

A presença do quartzo (fração $>0,02 \mathrm{~mm}$ ) indica a predominância da fração arenosa do solo e os compostos ferrosos e aluminosos indicam que o solo passou por um processo de laterização (NOGAMI; VILLIBOR, 1995), comprovada pelo resultado LA' (arenoso laterítico) obtido pela metodologia MCT. A avaliação realizada é qualitativa, podendo ser quantitativa com o emprego de cálculos estequiométricos. 
Para Nogami e Villibor (1995), os principais constituintes da fração argilosa do solo $(<0,002 \mathrm{~mm}$ ) são formados por argilo-minerais e óxidos e hidróxidos de ferro e/ou alumínio. A caulinita é um argilomineral de estrutura cristalina tabular, constituído de uma repetição sucessiva de pacotes de camadas de tetraedros de sílica e uma camada de octaedros de alumina, estes pacotes são fortemente ligados por força atômica de hidrogênio. É o membro da família dos argilominerais com menor atividade coloidal quando comparado com a montmorillonita (smectita) e a ilita, segundo sua superfície ativa (TERZAGHI, 1948), e segundo sua atividade coloidal pela conceituação de Skempton ${ }^{4}$ (NOGAMI; VILLIBOR, 1995). Os argilominerais possuem algumas características, destacando-se (i) grande superfície específica, (ii) tornam-se plásticos quando devidamente umedecidos e nesta situação, quando perdem água, aumentam sua resistência, (iii) altamente reativos, sofrem grandes variações volumétricas por perda de água ou expandem por aplicação de pressão quando saturados e (iv) possuem predominância de cargas elétricas negativas. A gibbsita e a hematita constituem o grupo de óxidos e hidróxidos de ferro e de alumínio mais frequentes na fração argilosa de solos tropicais. O comportamento destes materiais é diferente do encontrado nos argilominerais, além disso, possuem propriedades cimentantes que podem propiciar a formação de agregados $\mathrm{e}$ concreções lateríticas (NOGAMI; VILLIBOR, 1995).

\subsubsection{Caracterização do cimento}

O cimento aplicado para preparação das misturas de solo-cimento foi o CPII-E32. Os resultados das caracterizações físicas, químicas e mecânicas do cimento foram cordialmente fornecidos pelo fabricante. Um resumo dos valores é apresentado na Tabela 3.3.

\footnotetext{
${ }^{4}$ SKEMPTON, A.W. The coloidal activity of clays. $3^{\text {rd }}$ International Soil Mechanical Conference. $p$. 57-61, Zurich, 1953.
} 
Tabela 3.3 - Resumo das características do cimento

\begin{tabular}{|c|c|c|c|}
\hline Características & Caracterização & $\begin{array}{c}\text { Referência } \\
\text { Normativa NBR }\end{array}$ & Resultados \\
\hline \multirow{5}{*}{ Químicas } & Perda ao Fogo (\%) & $<6,5$ & 5,08 \\
\hline & $\mathrm{MgO}$ & $<6,5$ & 5,23 \\
\hline & $\mathrm{SO}_{3}$ & $<4,0$ & 1,91 \\
\hline & $\mathrm{CO}_{2}$ & $<5,0$ & 4,16 \\
\hline & $\mathrm{RI}$ & $<2,5$ & 1,74 \\
\hline \multirow{4}{*}{ Físicas } & Finura \# 0,075mm (\%) & $<12,0$ & 1,3 \\
\hline & Blaine $\left(\mathrm{cm}^{2} / \mathrm{g}\right)$ & $>2.600$ & 4.092 \\
\hline & Tempo de pega- inicio (h) & $>1$ & $3: 26$ \\
\hline & Tempo de pega - fim (h) & $<10$ & $4: 46$ \\
\hline \multirow{3}{*}{ Mecânicas } & RCS 3 dias cura (MPa) & $>10$ & 20,0 \\
\hline & RCS 7 dias cura (MPa) & $>20$ & 26,9 \\
\hline & RCS 28 dias cura (MPa) & $>32$ & 36,0 \\
\hline
\end{tabular}

\subsection{Método experimental}

A seguir encontram-se descritos os métodos e procedimentos de ensaio empregados no desenvolvimento desta pesquisa.

\subsubsection{Coleta e preparo do solo para ensaios físicos}

A coleta da amostra deformada de solo foi realizada nas proximidades do acostamento da vicinal PTP-10 - Estrada do Leite, no km 6,3, no mesmo local que serviu como jazida para a construção das camadas de reforço do subleito e base do trecho experimental, detalhado no capítulo 5. Após a remoção da cobertura vegetal e posterior escavação, as amostras de solo foram armazenadas em sacos plásticos protegidos por sacos de ráfia, conforme ilustrado na Figura 3.3. Este procedimento 
teve como objetivo manter a umidade natural do solo, objeto sob investigação deste estudo, e também facilitar o manuseio para transporte.

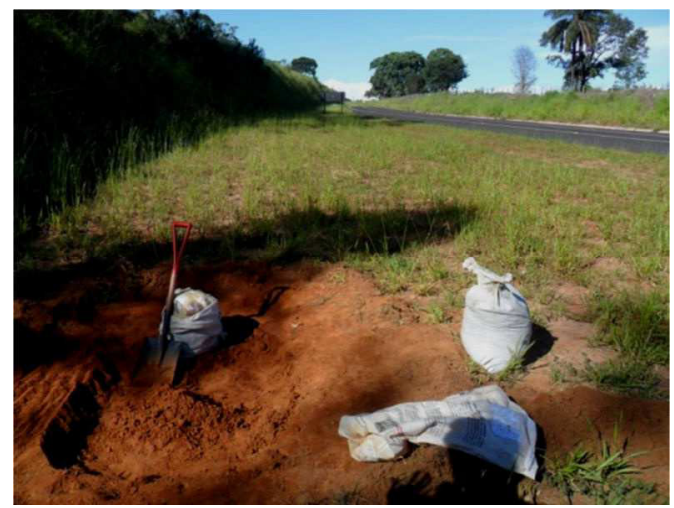

(a)

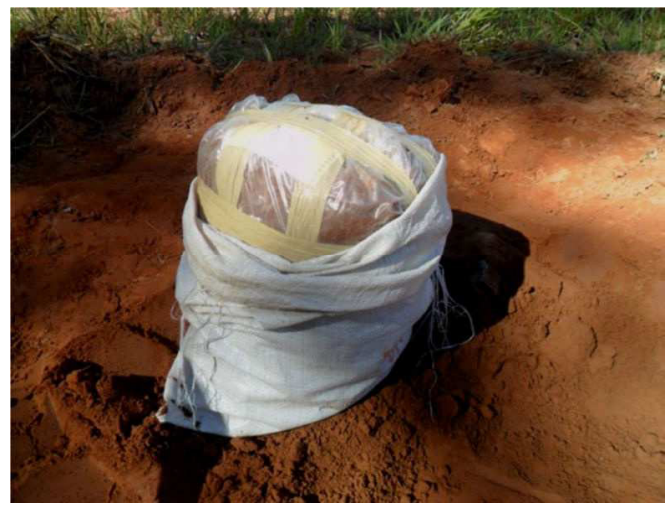

(b)

Figura 3.3 - Coleta do solo na jazida: (a) escavação e (b) coleta e armazenamento

No laboratório, o solo foi espalhado em lonas, misturado com auxílio de pá e posteriormente quarteado (Figura 3.4). Uma parte das amostras foi seca ao ar até atingir a umidade higroscópica (UH) e outra mantida na condição natural de umidade de campo (UC) através de nova estocagem em sacos plásticos, conforme mostrado na Figura 3.4. Os valores do teor de umidade verificados no laboratório foram de 0,5\% para a condição UH e 9,0\% para a condição UC. Após atingir a umidade higroscópica, o solo foi destorroado e preparado de acordo com a especificação NBR 6457/86 para os ensaios de granulometria, Limites de Atterberg, compactação e classificação pela metodologia MCT. A umidade higroscópica é obtida após uma simples secagem por exposição ao ar. A umidade natural presente no solo é retirada até entrar em equilíbrio com o ambiente. O valor da umidade higroscópica varia de acordo com a umidade relativa do ar, temperatura ambiente e com o tipo de solo. 


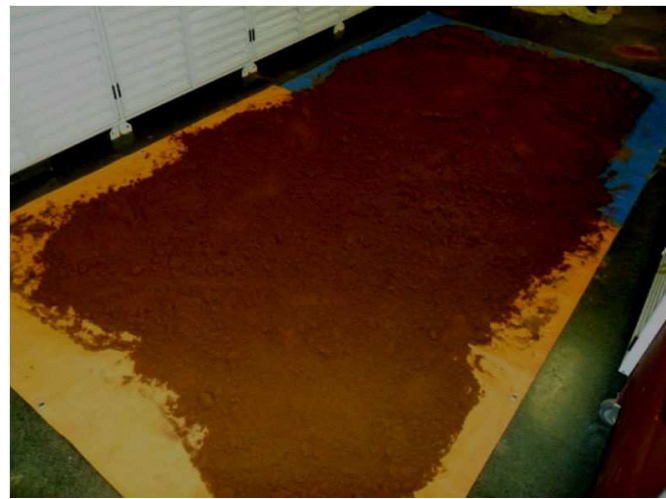

(a)

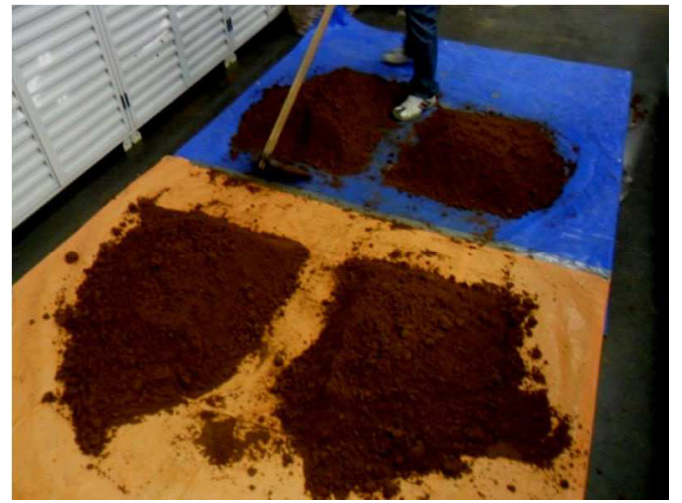

(b)

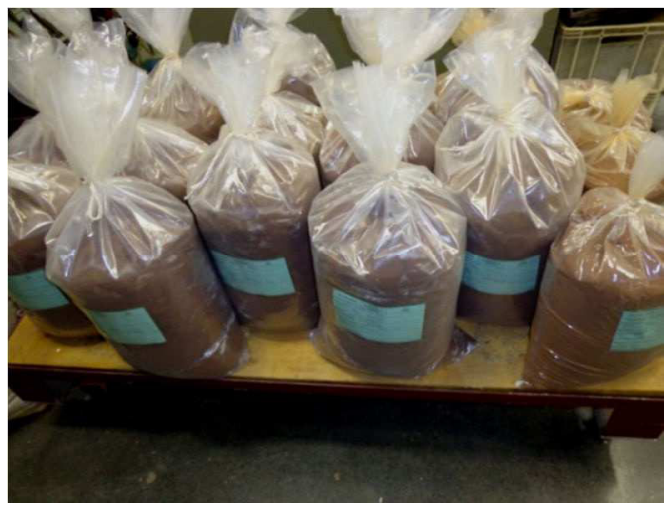

(c)

Figura 3.4 - Preparação do solo: (a) espalhamento, (b) quarteamento e (c) estocagem das amostras na umidade de campo

\subsubsection{Compactação do solo (Proctor)}

As amostras de solo foram compactadas na energia Normal, em três camadas de igual espessura, 26 golpes/camada, com o soquete de $2,5 \mathrm{~kg}$ e altura de queda de $30,5 \mathrm{~cm}$ em um cilindro de $1.000 \mathrm{~cm}^{3}$, conforme recomenda a NBR 7182/86. A compactação foi realizada para a amostra seca até a umidade higroscópica (UH) e também para a amostra seca apenas o suficiente para compactação do primeiro ponto do ramo seco, sem levar a mesma até umidade higroscópica (UC). Este procedimento integra o objeto desta pesquisa, que consiste em quantificar através 
de ensaios mecânicos, uma possível diferença na forma de adição do cimento realizada em laboratório (a partir de amostra de solo na umidade higroscópica e com o solo na umidade natural de jazida). Para retirada da umidade nos primeiros pontos de compactação, foi utilizado um soprador térmico (Figura 3.5). A perda de água foi controlada por massa até que fosse atingida a umidade desejada.

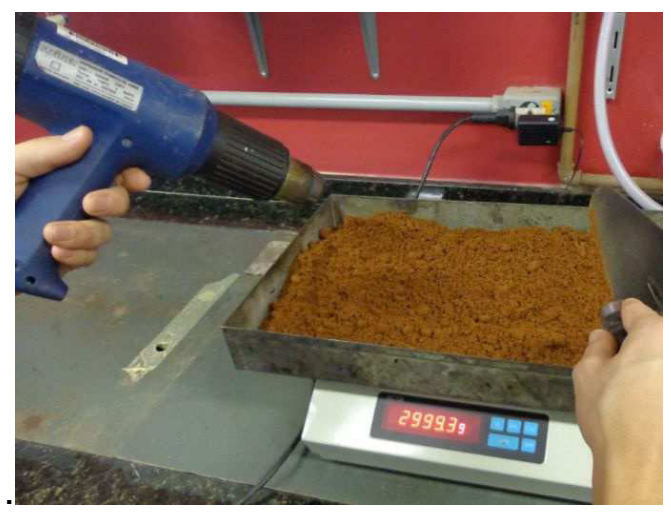

Figura 3.5 - Retirada de umidade do solo com soprador térmico

\subsubsection{Mistura de solo-cimento}

Os materiais empregados para a mistura do solo-cimento (solo, cimento e água) foram pesados com precisão de $\pm 0,1 \mathrm{~g}$. A quantidade de cimento a ser incorporada foi calculada em porcentagem sobre a massa de solo seca. As misturas de solocimento seguiram duas formas de preparação, levando em consideração a umidade inicial do solo:

- Umidade higroscópica (UH): o cimento foi adicionado na amostra de solo na umidade higroscópica (NBR 12023/12). Após a mistura e homogeneização, foi adicionada água até a umidade de mistura desejada. Esta situação representa a condição de mistura em laboratório.

- Umidade de campo (UC): o cimento foi adicionado à amostra de solo na condição de extração da jazida, conservando sua umidade natural. Após a 
adição de cimento, foi realizada a adição, ou remoção, de água, conforme descrito no ítem 3.2.2, quando necessário. Esta situação teve como objetivo uma melhor aproximação do procedimento de execução da mistura de solocimento realizado em obra. Os dois processos de misturas são mostrados na Figura 3.6

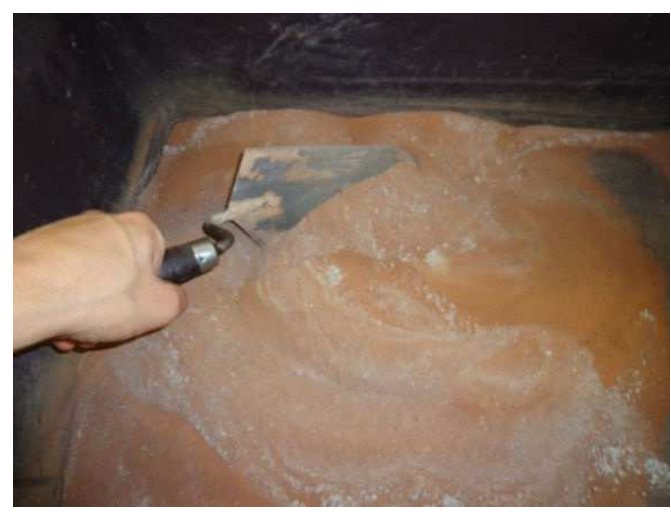

(a)

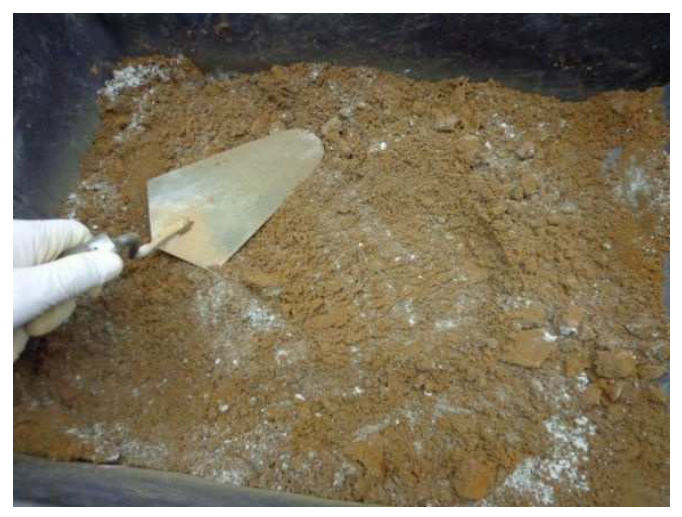

(b)

Figura 3.6 - Mistura de solo-cimento para cada condição inicial de mistura (a) UH e (b) UC

\subsubsection{Dosagem da mistura de solo-cimento}

A dosagem da mistura de solo-cimento foi realizada de acordo com NBR 12253/2012. O método consiste na moldagem de corpos de prova com diferentes quantidades de cimento e sua posterior ruptura após 4 horas de imersão em água. $O$ valor da porcentagem de cimento é definido como aquele que atinja uma resistência à compressão simples (RCS) mínima de 2,1 MPa aos 7 dias de cura.

Para iniciar o processo de dosagem do solo-cimento, é necessário obter um valor de peso específico seco máximo e umidade ótima para uma determinada quantidade de cimento. A NBR 12253/2012 recomenda alguns teores que levam em conta a classificação do solo pelo sistema HRB.

Com os valores de peso específico seco máximo e umidade ótima, foram realizadas variações na quantidade de cimento a ser incorporado. Foram moldados três corpos 
de prova para cada teor de cimento empregado, permanecendo em cura em câmara úmida por 7 dias. Como medida complementar para evitar a perda de água, as amostras foram colocadas em sacos plásticos e lacradas. Ao final do período de cura, os corpos de prova foram imersos em água potável e mantidos por 4 horas, seguidos de sua ruptura. Os valores aceitos para cada teor de cimento são aqueles que não diferem em mais de $10 \%$ da resistência média. A dosagem foi realizada para as duas condições de umidade (UH) e (UC). Os detalhes do processo de cura e ruptura das amostras são apresentados na Figura 3.7.

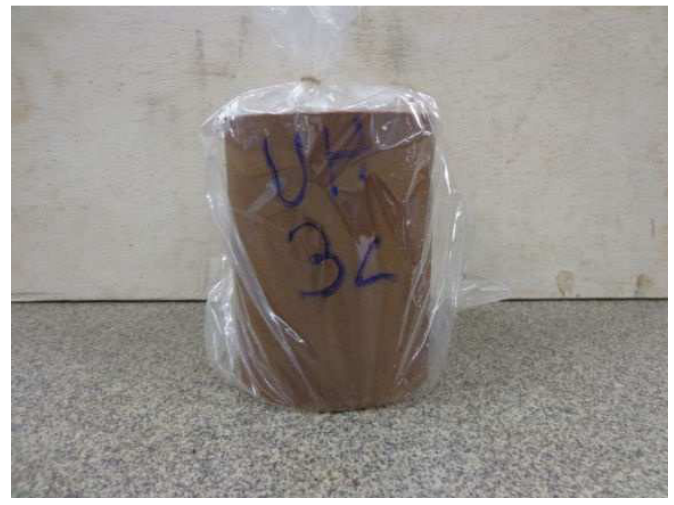

(a)

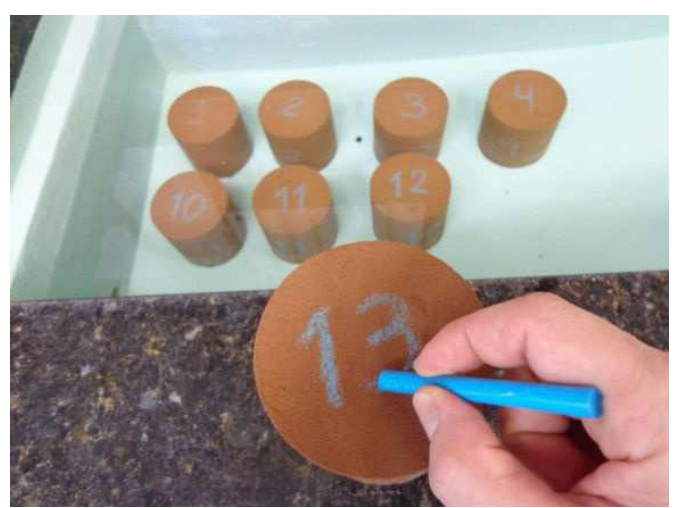

(c)

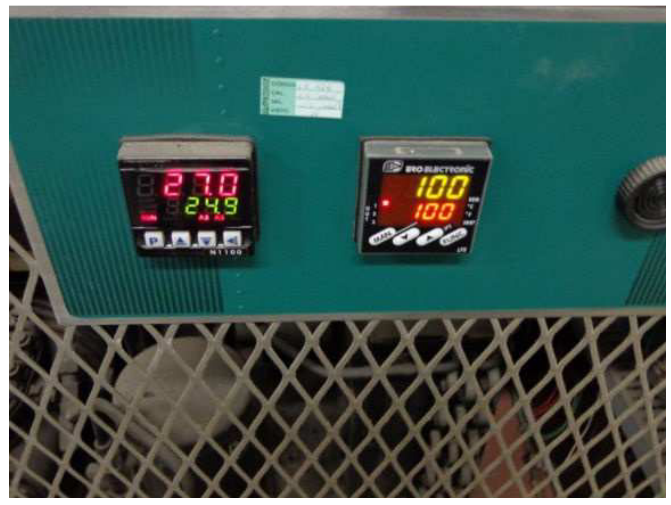

(b)

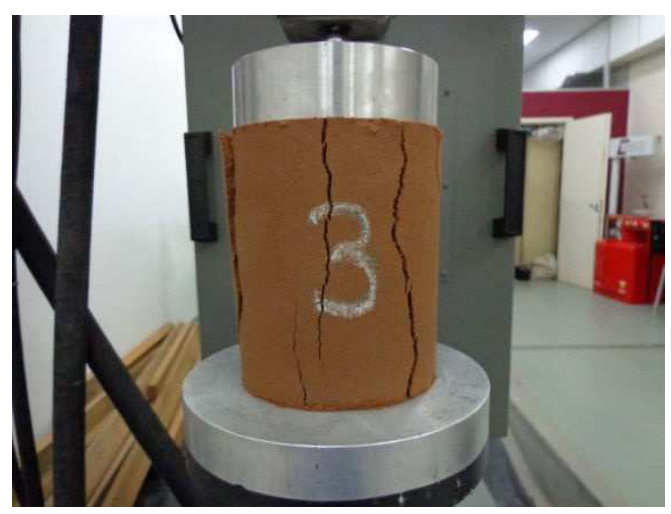

(d)

Figura 3.7 - Processo da dosagem do SC (a) envelopamento para retenção de umidade, b) cura em câmara com temperatura e umidade controlada, (c) imersão prévia em água e (d) ruptura da amostra 


\subsubsection{Compactação do solo-cimento (Proctor)}

As amostras de solo-cimento foram compactadas na energia Normal em três camadas de igual espessura, 26 golpes/camada, com o soquete de 2,5 kg e altura de queda de $30,5 \mathrm{~cm}$ em um cilindro de $1000 \mathrm{~cm}^{3}$, conforme preconiza a NBR 12023/2012. A compactação foi realizada para a amostra seca até a umidade higroscópica e também para a amostra seca apenas o suficiente para compactação do primeiro ponto do ramo seco, sem levar a mesma até umidade higroscópica. $\mathrm{O}$ procedimento utilizado para remoção da umidade é descrito em detalhes no item 3.2.2.

\subsubsection{Compactação do solo-cimento para ensaios mecânicos}

A partir dos valores obtidos peso específico seco máximo $\left(\gamma_{s} \max \right)$ e teor de umidade ótimo $\left(\mathrm{h}_{\mathrm{ot}}\right)$ da curva de compactação para a amostra de solo-cimento moldada na energia Normal, foram compactados corpos de prova para os ensaios de Resistência a Compressão Simples (RCS), Resistência à Tração por Compressão Diametral (RTCD) e Módulo de Resiliência (MR). A compactação foi realizada em cinco camadas de igual espessura, medidas durante o ensaio com auxílio de uma régua metálica. Cada camada recebeu a aplicação de 24 golpes com o soquete de $2,5 \mathrm{~kg}$ e uma altura de queda de $30,5 \mathrm{~cm}$. Foi utilizado molde cilíndrico tripartido, com diâmetro interno de $10 \mathrm{~cm}$ e altura de $20 \mathrm{~cm}$. Durante a compactação, foram retiradas três amostras da mistura úmida de solo-cimento para determinação da umidade de moldagem. Após a compactação, as amostras foram extraídas e pesadas para determinação do peso úmido e obtenção do grau de compactação (GC). Os detalhes da compactação são mostrados na Figura 3.8. As amostras apresentaram um GC médio de 100,4\% com um coeficiente de variação de 0,5\%. Os ensaios foram realizados para as idades de 3, 7, 14 e 28 dias de cura, com a mistura de solo-cimento utilizando solo na umidade higroscópica (UH) e solo na umidade de campo (UC). 


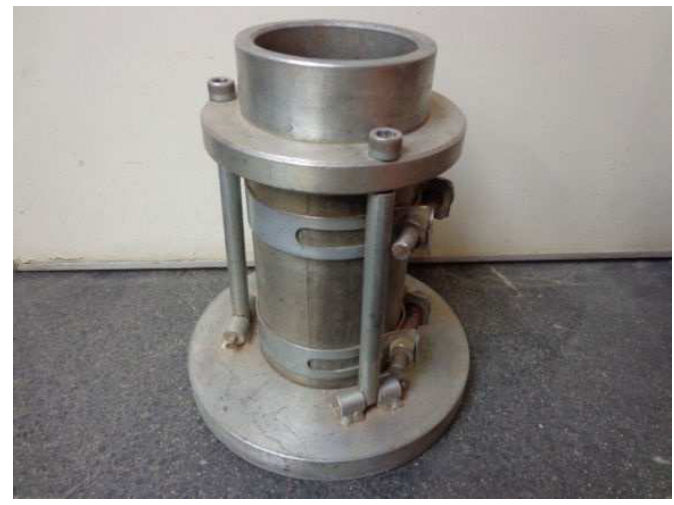

(a)

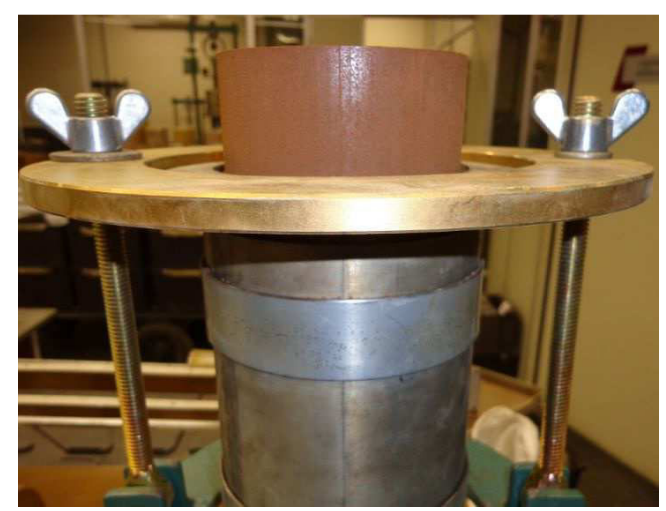

(c)

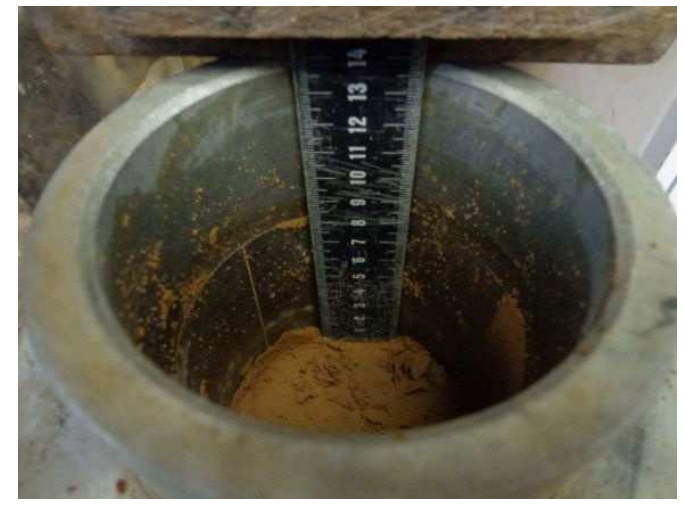

(b)

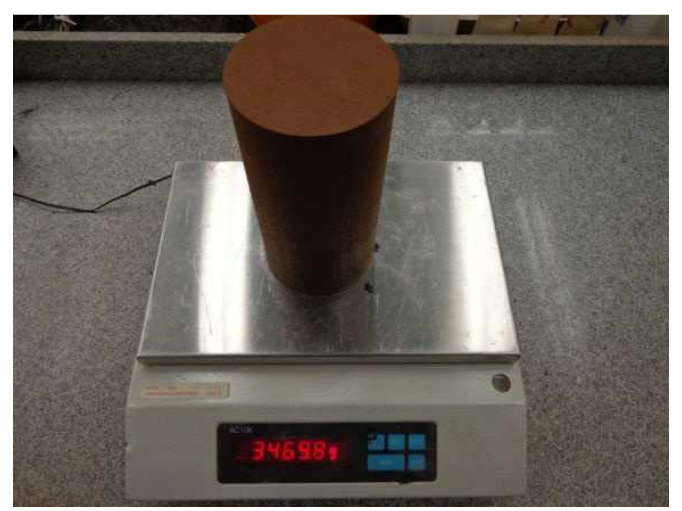

(d)

Figura 3.8 - Compactação do SC para ensaios mecânicos: a) cilindro tripartido, (b) controle da altura das camadas, (c) extração da amostra e (d) determinação da massa úmida da amostra.

A cura foi realizada em câmara úmida (UR>95\%) e temperatura controlada em $25^{\circ} \mathrm{C}$. Foram compactadas 6 amostras para cada idade de cura e teor de umidade inicial de mistura do solo-cimento ( $U H$ e UC), resultando em um total de 48 corpos de prova. As amostras submetidas ao ensaio de MR foram posteriormente rompidas no ensaio de RCS. Buscando uma melhor qualidade nos ensaios e acurácia nos resultados mecânicos, foi utilizado o tempo de tolerância (horas) para as idades de ensaio seguindo as recomendações da ASTM-C-39/2012. Para a idade de 14 dias de cura, o tempo de tolerância foi obtido a partir de uma equação linear, conforme apresentado na Figura 3.9. 


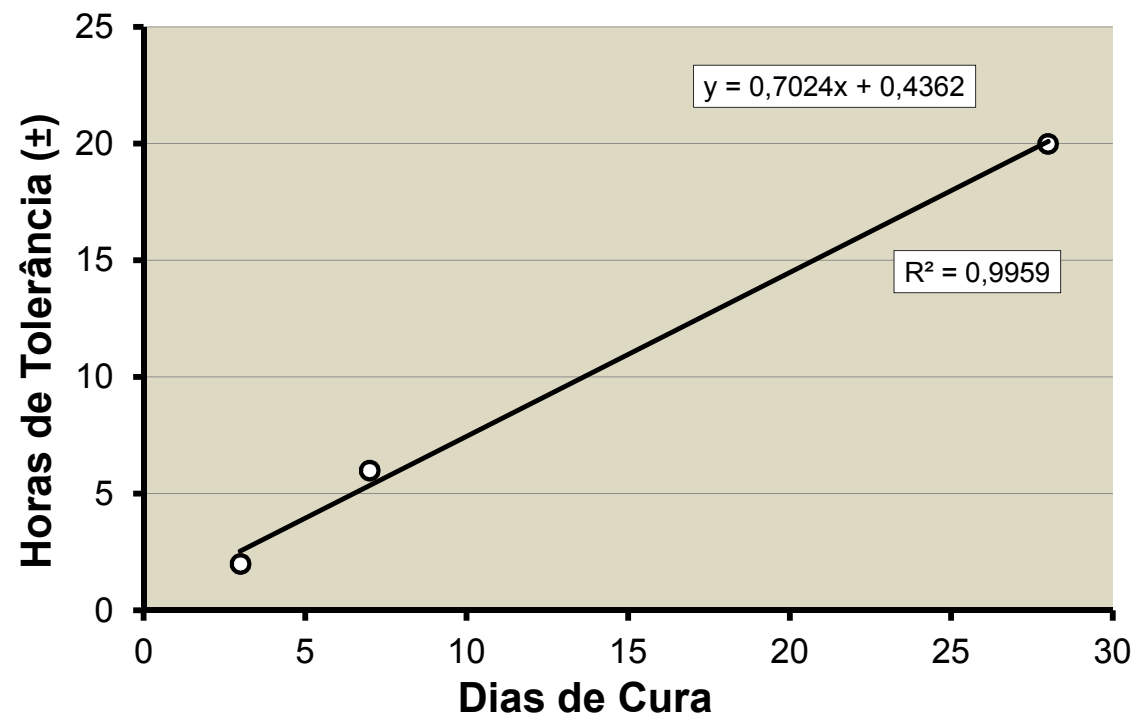

Figura 3.9 - Tempo de tolerância permitido para amostras de concreto (Fonte: ASTM C39/2012)

\subsection{Ensaios mecânicos}

A seguir são descritos os ensaios utilizados para caracterização mecânica do material empregado nesta pesquisa.

\subsubsection{Resistência à tração por compressão diametral (RTCD)}

Os ensaios de RTCD foram realizados com deslocamento controlado, a uma taxa de $1 \mathrm{~mm} / \mathrm{min}$, até a amostra atingir $5 \%$ da força máxima registrada no instante da ruptura, utilizando uma prensa hidráulica (MTS 810 "Material Test System"). Um detalhe do suporte e dos frisos utilizados é mostrado na Figura 3.10. Foram registrados os valores de carga máxima e calculado o valor de RTCD através da eq.(3.1).

$$
\mathrm{RTCD}=\frac{20 \cdot \mathrm{F}_{\max }}{\pi \cdot \mathrm{D} \cdot \mathrm{h}}
$$


Onde: $\quad$ RTCD = Resistência à Tração por Compressão Diametral (MPa)

$$
\begin{aligned}
& F_{\max }=\text { força máxima aplicada }(\mathrm{N}) \\
& \mathrm{D}=\text { diâmetro da amostra }(\mathrm{mm}) \\
& \mathrm{h}=\text { espessura da amostra }(\mathrm{mm})
\end{aligned}
$$

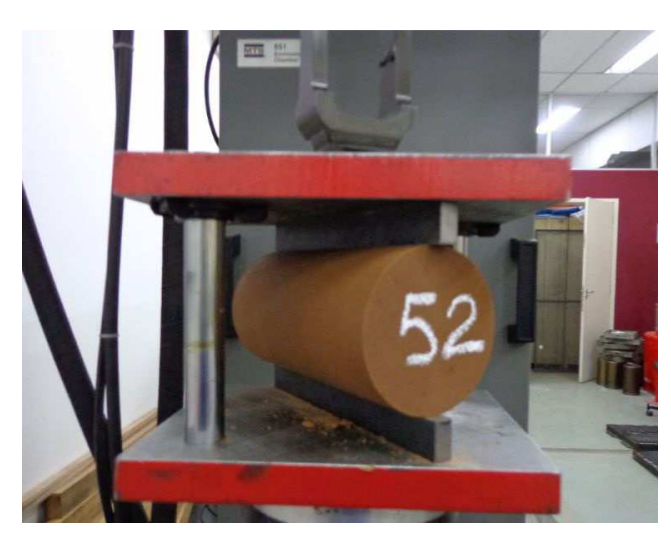

(a)

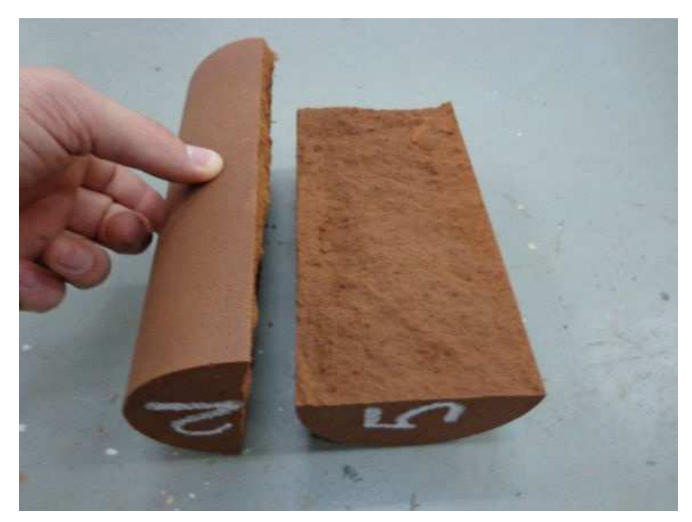

(b)

Figura 3.10 - Ensaio de RTCD: (a) suporte e detalhe dos frisos e (b) aspecto da amostra após ensaio

\subsubsection{Resistência à compressão simples (RCS)}

Os ensaios de resistência à compressão simples foram realizados conforme NBR 12025/12 e ASTM D 1633/07. As amostras foram carregadas axialmente a uma taxa de deformação de $1 \mathrm{~mm} / \mathrm{min}$, até $5 \%$ da força máxima registrada no instante da ruptura, utilizando uma prensa hidráulica (MTS 810 "Material Test System"). Foram registrados os valores de carga máxima e calculado o valor de RCS através da eq.(3.2).

$$
\mathrm{RCS}=\frac{\mathrm{F}_{\max }}{\mathrm{A}}
$$


Onde: $\quad$ RCS $=$ Resistência à Compressão Simples (MPa)

$\mathrm{F}_{\max }=$ força máxima aplicada $(\mathrm{N})$

$\mathrm{A}=$ área do corpo de prova $\left(\mathrm{mm}^{2}\right)$

\subsubsection{Módulo de resiliência (MR)}

As amostras foram ensaiadas de acordo com a especificação do DNIT (ME148/2010). Para uma melhor distribuição das tensões desviadoras aplicadas (od), os corpos de prova foram capeados com gesso ortodôntico com RCS de $45 \mathrm{MPa}$ após secagem e retração inferior a $0,5 \%$, sua espessura deve ser mínima, servindo apenas para regularizar a superfície faceada com régua biselada após a compactação. Foram entalhadas ranhuras nas amostras para uma melhor visualização da aplicação da tensão confinante pela membrana e também identificar vazamentos de ar no sistema. Os detalhes do capeamento, instrumentação e ensaio são apresentados na Figura 3.11. Os valores de deformação foram coletados para cada tensão desviadora aplicada, em cada combinação de tensão confinante $\left(\sigma_{3}\right)$. A partir dos dados coletados, foram calculados os valores de módulo de resiliência em cada uma das 18 combinações estabelecidas em norma, utilizando a eq.(3.3).

$$
\operatorname{MR}=\frac{\sigma \mathrm{d}}{\varepsilon}
$$

Onde: $\quad$ MR $=$ Módulo de Resiliência $(\mathrm{MPa})$

$$
\begin{aligned}
& \sigma_{d}=\text { tensão aplicada (MPa) } \\
& \varepsilon=\text { deformação específica }
\end{aligned}
$$

A deformação específica $(\varepsilon)$ é calculada através da razão entre a deformação registrada no momento de aplicação da tensão desviadora $\left(\sigma_{d}\right)$ pela altura do corpo de prova. 


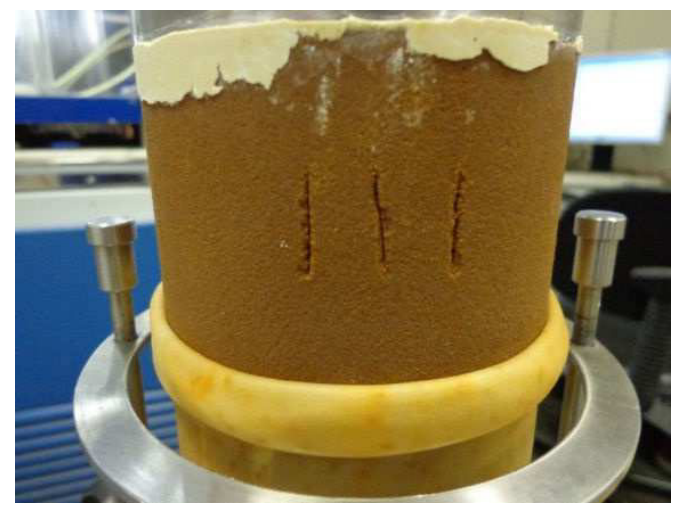

(a)

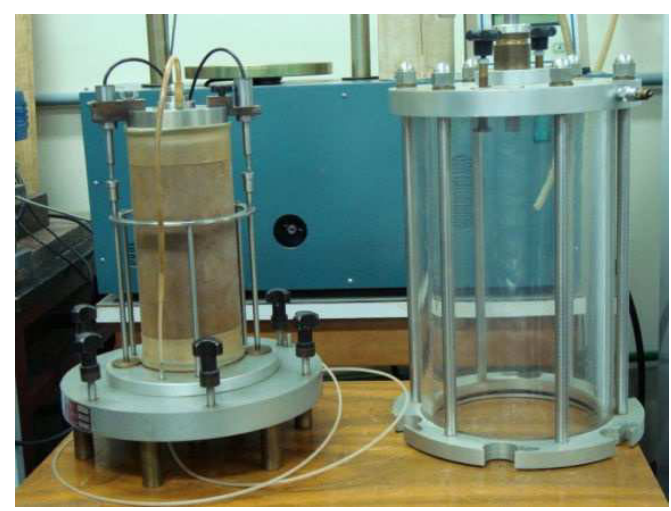

(c)

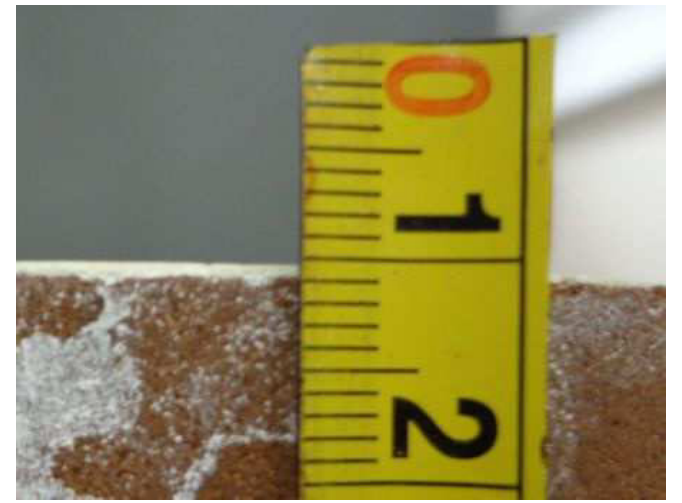

(b)

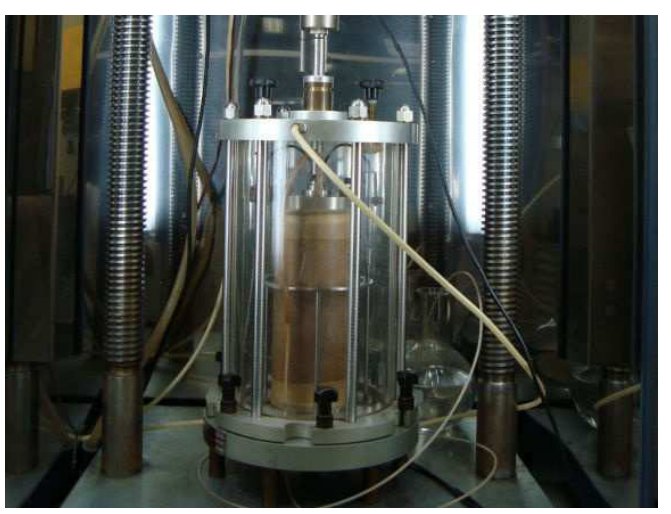

(d)

Figura 3.11 - Ensaio de MR: a) entalhamento na amostra para verificação da tensão confinante durante o ensaio, (b) espessura do capeamento, (c) instrumentação e (d) ensaio em andamento

\subsubsection{Contração do solo e retração das misturas de solo-cimento}

Conforme abordado no ítem 2.2.3, a contração é um parâmetro importante em se tratando de materiais cimentados. Nesse estudo, para determinar a contração das amostras de solo e de solo-cimento foi utilizada a metodologia MCT, proposta por Nogami e Villibor (1995). Existem outras formas de determinar a contração em solos como o apresentado pela DNER ME 087/94 que emprega o mercúrio na determinação, sendo um ensaio de difícil realização, além dos riscos ambientais e a saúde. O ensaio de contração pela metodologia MCT permite um monitoramento do progresso da contração, bem como ter sido elaborado para aplicação em solos tropicais. O método consiste na moldagem de corpos de prova em equipamento 
Miniatura (MCT) na umidade e densidade esperada de aplicação do material. Após a moldagem, as amostras são medidas com paquímetro, montadas em suporte apropriado, instrumentadas com um extensômetro e deixadas em local para perda de água. As medidas de contração foram efetuadas em intervalos regulares de 12 horas até a estabilização da amostra, detectado por leituras sucessivas com valores repetidos. Para evitar a deformação superficial no ponto de contato do extensômetro na amostra, foram fixados cubos acrílicos impregnados com parafina, conforme mostrado na Figura 3.12. O valor de contração é a razão da subtração entre a leitura final e a leitura inicial de ensaio, divido pela altura do corpo de prova.

A retração das amostras de SC foi determinada em câmara com umidade relativa (UR) $>95 \%$ e, a contração das amostras de Solo (UH) e (UC) e do SC em câmaracom UR de 50\%. O valor de UR foi adotado em função do valor mínimo encontrado no local de execução do trecho experimental, conforme dados mostrados na Figura 3.13. Os dados da estação meteorológica são apresentados na Tabela 3.4. Costa e Lollo (2006) utilizaram a mesma metodologia para determinar a contração de um solo melhorado com cimento para base de lagoas de tratamento de esgoto. Os ensaios foram realizados com medidas axiais e diametrais. Os resultados entre as duas formas de medida da contração não apresentaram diferenças significativas e por essa razão, no presente estudo, adotou-se apenas as medidas axiais.

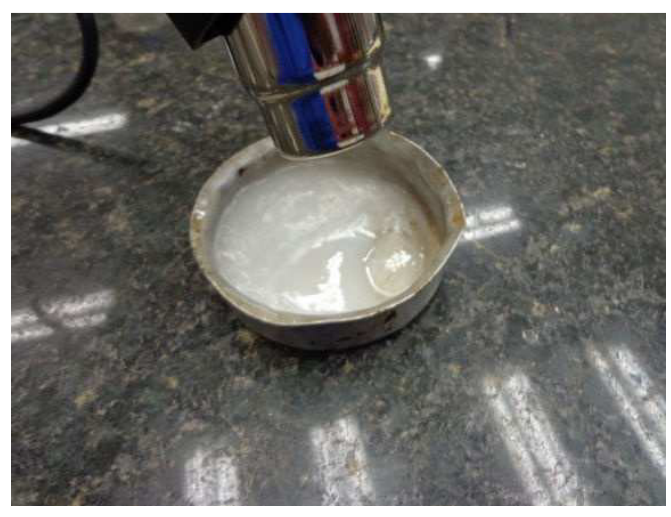

(a)

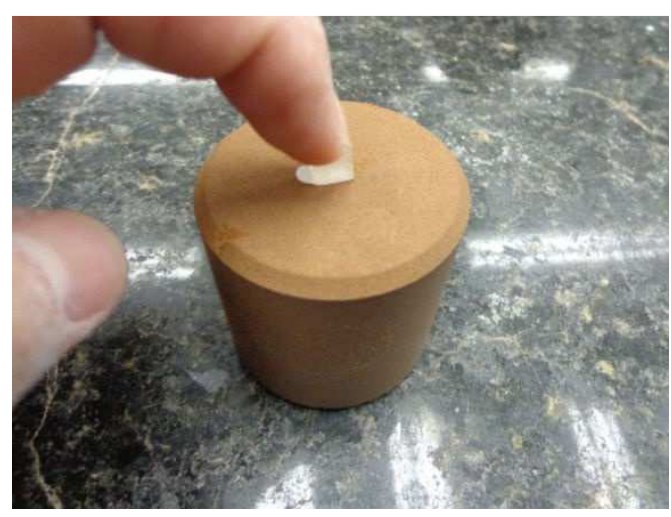

(b) 


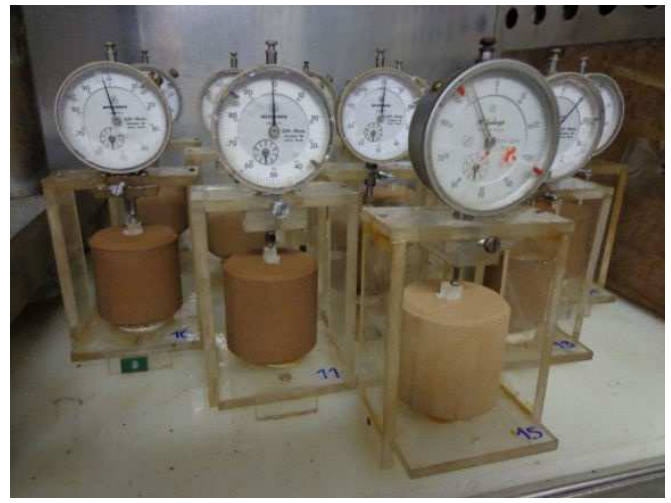

(c)

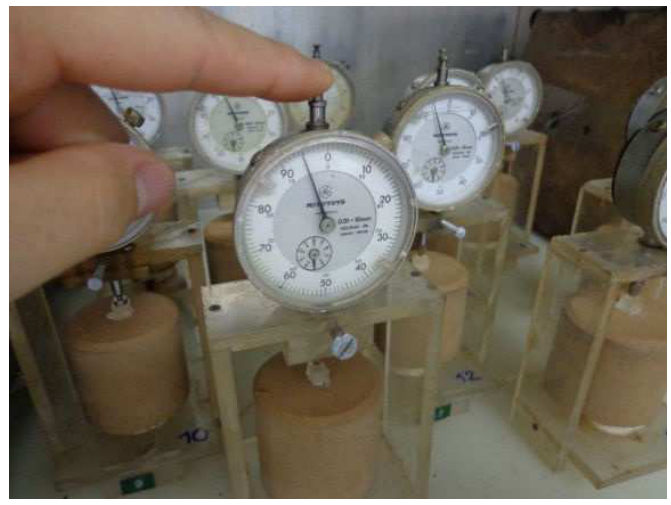

(d)

Figura 3.12 - Ensaio de contração/ retração pela metodologia MCT: (a) aquecimento da parafina com soprador térmico, (b) fixação do cubo acrílico com parafina, (c) montagem da amostra no suporte e (d) leitura da contração/ retração

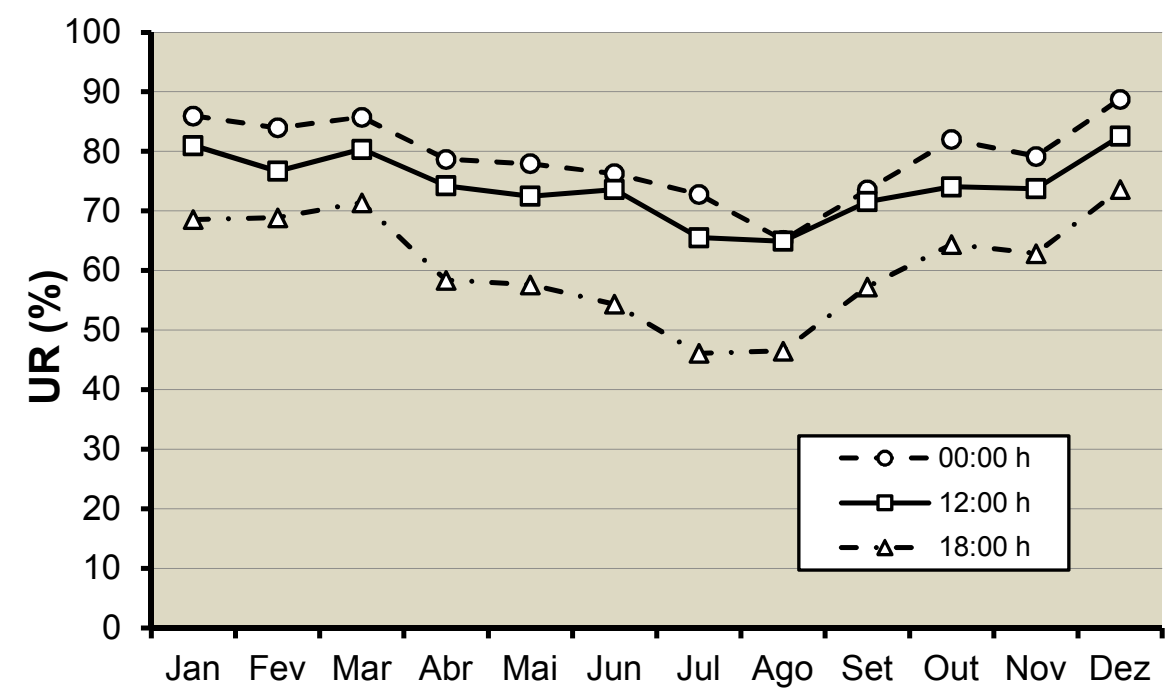

Figura 3.13 - Umidade relativa do ar (UR) verificada no ano de 2009 na estação de Franca - SP (Fonte: BDMET - INMET 2010)

Tabela 3.4 - Dados da estação meteorológica

\begin{tabular}{c|c|c|c}
\hline Estação & Latitude & Longitude & Altitude \\
\hline Franca - SP & $-20,58^{\circ}$ & $-47,36^{\circ}$ & $1.026,2 \mathrm{~m}$ \\
\hline
\end{tabular}




\subsection{Retroanálise das bacias de deflexão}

Foram realizadas retroanálise com os dados das bacias deflectométricas obtidas através de equipamento FWD - Falling Weight Deflectometer, modelo KUAB, de origem Sueca, conforme apresentado na Figura 3.14. Os dados de deflexão com FWD foram coletados em duas ocasiões: após 21 meses e 33 meses ( $T=21 \mathrm{M}$ e $\mathrm{T}=33 \mathrm{M})$ de construção do trecho experimental, pela equipe do CENPES da Petrobras S.A. Por motivos logísticos, foram realizadas medidas no eixo da faixa de rolamento no levantamento de T $21 \mathrm{M}$, já o segundo foi realizado nas trilhas internas e externas da faixa de rolamento, alternadamente ao longo do estaqueamento. Os valores de deflexão foram normalizados para um único valor de carregamento, tendo como referência um semi-eixo padrão de $4.100 \mathrm{kgf}$. Os dados de partida para os valores de módulos de resiliência dos materiais foram empregados tendo como referência ensaios desenvolvidos no LTP-EPUSP. Os coeficientes de Poisson empregados estão de acordo com as faixas recomendadas na IP-DE-P00/001 do DER/SP e também nos valores citados por Balbo (2007). Para tornar o processo de retroanálise ágil, foi empregado o programa BACKFAA, desenvolvido pela FAA Federal Aviation Administration dos EUA, com uma posterior verificação dos valores retroanalisados de MR utilizando um programa que trabalha com TSCE - Teoria de Sistema de Camadas Elásticas, ELSYM 5. A verificação consiste na comparação das bacias de deflexão geradas por cada um dos programas.

Os dados de carregamento e condições impostas são apresentados a seguir:

- $\quad$ Carga para normalização: $4.100 \mathrm{~kg}$

- Raio do prato: $15,0 \mathrm{~cm}$

- Distância dos pontos da bacia de deformada: 0, 20, 30, 45, 60, 90 e 120 cm. 


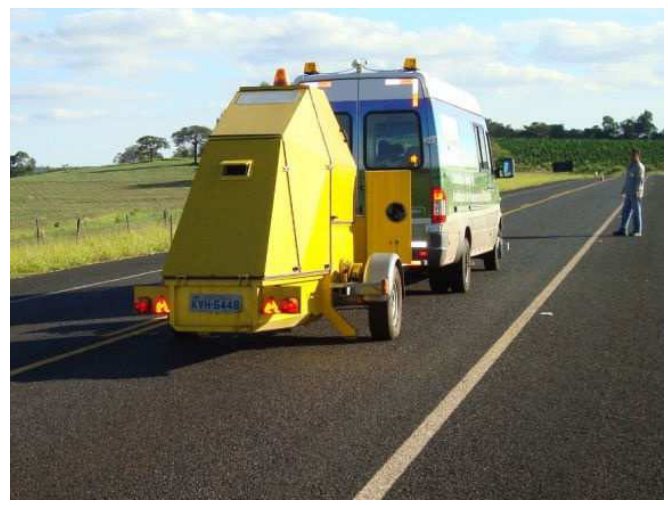

(a)

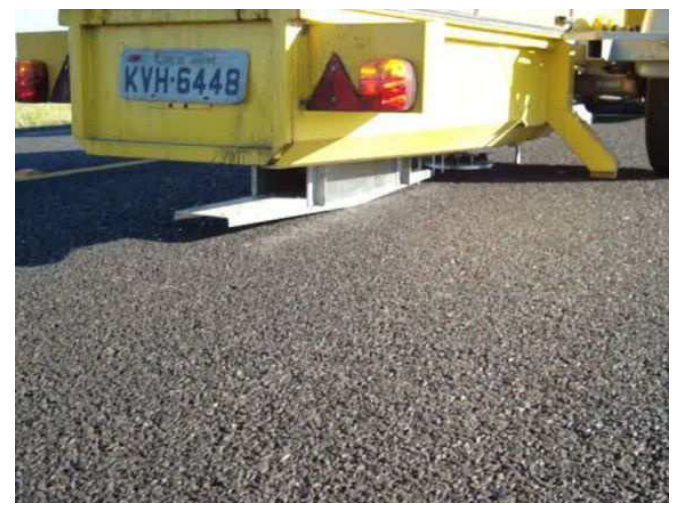

(b)

Figura 3.14 - Levantamento deflectométrico com uso de FWD - modelo KUAB: (a) ensaio em andamento e (b) detalhe dos geofones e prato de carregamento

\subsection{Análise dos resultados}

A análise dos resultados de MR, RCS, RTCD, Contração, Retração e Retroanálise das bacias de deflexão obtidas por equipamento FWD, foi realizada baseada no valor médio e desvio padrão. Para a identificação de valores discrepantes, denominados "outliers", foi empregado o teste de Grubbs (1969). O teste de Grubbs (1969) é uma ferramenta estatística para identificar valores discrepantes dentro de uma amostragem de dados e pode ser aplicado quando a distribuição dos dados se aproxima de uma distribuição normal. Uma vez detectado o outlier, duas hipóteses podem ser utilizadas:

- O valor identificado como outlier pode resultar de uma manifestação da variabilidade inerente dos dados. Neste caso, o valor identificado como outlier deve ser mantido e processado da mesma forma que os demais valores da amostragem.

- O valor identificado como outlier pode resultar de erro grosseiro no procedimento experimental, erro de cálculo ou ainda ser erro da coleta do valor numérico. Nestes casos, é recomendada uma investigação para identificar as razões para o aparecimento do valor outlier. Uma vez identificada a fonte do erro, o valor pode ser retirado da amostragem. 
A detecção do outlier é realizada comparando-se o valor apurado com um valor crítico $(\mathrm{T})$, este último baseado na teoria da amostragem aleatória. O valor crítico $(\mathrm{T})$ depende do número de valores apurados da amostragem e também varia de acordo com o nível de significância desejado. A significância estatística está relacionada ao grau de confiabilidade que um valor possui de ser "verdadeiro", ou seja, de representar um valor que ocorra dentro de uma amostragem. O nível de significância pode ser entendido como o risco de rejeitar um valor "verdadeiro" dentro de uma amostragem observada. Para testes estatísticos com observação de outliers, é recomendado um valor de significância entre 1 e $5 \%$, valores acima de $5 \%$ não são de prática comum (GRUBBS, 1969). Nesta pesquisa, foi empregado um nível de significância de $5 \%$, que remete a uma confiabilidade de $95 \%$.

Para a aplicação deste teste, é necessário conhecer o valor máximo (xn) e o valor mínimo $\left(x_{1}\right)$ que ocorrem dentro da amostragem. De posse destes valores, é determinado o potencial do valor analisado ser um outlier máximo $\left(T_{n}\right)$ eq.(3.4), acima da média, ou um outlier mínimo ( $\left.T_{1}\right)$ eq.(3.5), abaixo da média.

$$
\begin{aligned}
& T_{n}=\frac{x n-\bar{x}}{\sigma} \\
& T_{1}=\frac{\bar{x}-x_{1}}{\sigma}
\end{aligned}
$$

Onde: $\quad x_{n}=$ valor máximo da amostra

$\mathrm{x}_{1}=$ valor mínimo da amostra

$\overline{\mathrm{x}} \mathrm{n}=$ média dos valores

$\sigma=$ desvio padrão

Os valores $T_{n}$ e $T_{1}$ são comparados com o valor crítico $(T)$, fornecido de acordo com o número de amostras e o nível de significância empregado, conforme exposto na Tabela 3.5. 
Tabela 3.5 - Valores críticos ( $\mathrm{T}$ ) para desvio padrão calculado na mesma amostra (Fonte: GRUBBS (1950))

\begin{tabular}{|c|c|c|c|}
\hline \multirow{2}{*}{$\begin{array}{l}\text { Número de } \\
\text { amostras }\end{array}$} & \multicolumn{3}{|c|}{ Nível de Significância } \\
\hline & $5,0 \%$ & $2,5 \%$ & $1,0 \%$ \\
\hline 3 & 1.15 & 1.15 & 1.15 \\
\hline 4 & 1.46 & 1.48 & 1.49 \\
\hline 5 & 1.67 & 1.71 & 1.75 \\
\hline 6 & 1.82 & 1.89 & 1.94 \\
\hline 7 & 1.94 & 2.02 & 2.10 \\
\hline 8 & 2.03 & 2.13 & 2.22 \\
\hline 9 & 2.11 & 2.21 & 2.32 \\
\hline 10 & 2.18 & 2.29 & 2.41 \\
\hline 11 & 2.23 & 2.36 & 2.48 \\
\hline 12 & 2.29 & 2.41 & 2.55 \\
\hline 13 & 2.33 & 2.46 & 2.61 \\
\hline 14 & 2.37 & 2.51 & 2.66 \\
\hline 15 & 2.41 & 2.55 & 2.71 \\
\hline 16 & 2.44 & 2.59 & 2.75 \\
\hline 17 & 2.47 & 2.62 & 2.79 \\
\hline 18 & 2.50 & 2.65 & 2.82 \\
\hline 19 & 2.53 & 2.68 & 2.85 \\
\hline 20 & 2.56 & 2.71 & 2.88 \\
\hline 21 & 2.58 & 2.73 & 2.91 \\
\hline 22 & 2.60 & 2.76 & 2.94 \\
\hline 23 & 2.62 & 2.78 & 2.96 \\
\hline 24 & 2.64 & 2.80 & 2.99 \\
\hline 25 & 2.66 & 2.82 & 3.01 \\
\hline
\end{tabular}

Para esta pesquisa, os outliers identificados foram retirados e calculados novos valores de $T_{n}$ e $T_{1}$, até o valor calculado ficar abaixo dos mencionados na Tabela 3.5. Nos ensaios de RTCD, RCS e MR foram utilizados um mínimo de 3 amostras. Os ensaios de contração e retração foram realizados com 5 amostras. As bacias foram calculadas com base inicial de12 amostras, obtidas em estacas distintas. 


\section{APRESENTAÇÃO E ANÁLISE DE RESULTADOS}

\subsection{Características da compactação (Proctor)}

As amostras de solo e solo-cimento foram ensaiadas de acordo com as metodologias apresentadas no item 3.2.5. Foram comparadas as duas condições de umidade inicial (UH e UC) para as amostras de solo e de solo-cimento. Também são apresentadas nesse ítem as curvas de saturação, resistência e fator água/cimento.

\subsubsection{Curvas de compactação}

A Figura 4.1 apresenta a curva de compactação do solo obtida para as duas condições de umidade estudadas (UH e UC). Houve um aumento no peso específico aparente seco máximo para o solo na condição UC sem ocorrer variação na umidade ótima nas duas condições (UH e UC).

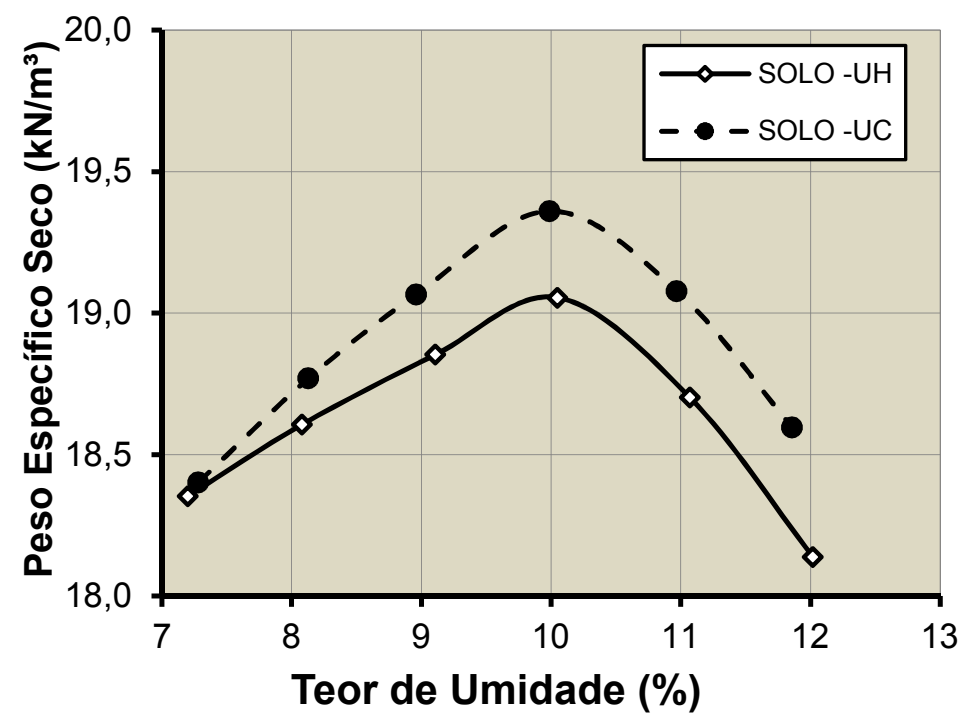

Figura 4.1 - Curvas de compactação do solo para as duas condições de mistura - UH e UC 
A Figura 4.2 apresenta as curvas de compactação obtidas para a mistura de solocimento nas duas condições de umidade estudadas (UH e UC). O comportamento relacionado ao peso específico aparente seco foi o mesmo observado nas amostras de solo. As variações verificadas quando comparadas com o solo consistem (i) no aumento do peso específico aparente seco com relação aos resultados de solo e (ii) em um pequeno aumento no teor de umidade ótima. Estes dois fatos estão relacionados ao peso específico do cimento, maior que o do solo, e a sua grande área específica, resultante da sua finura.

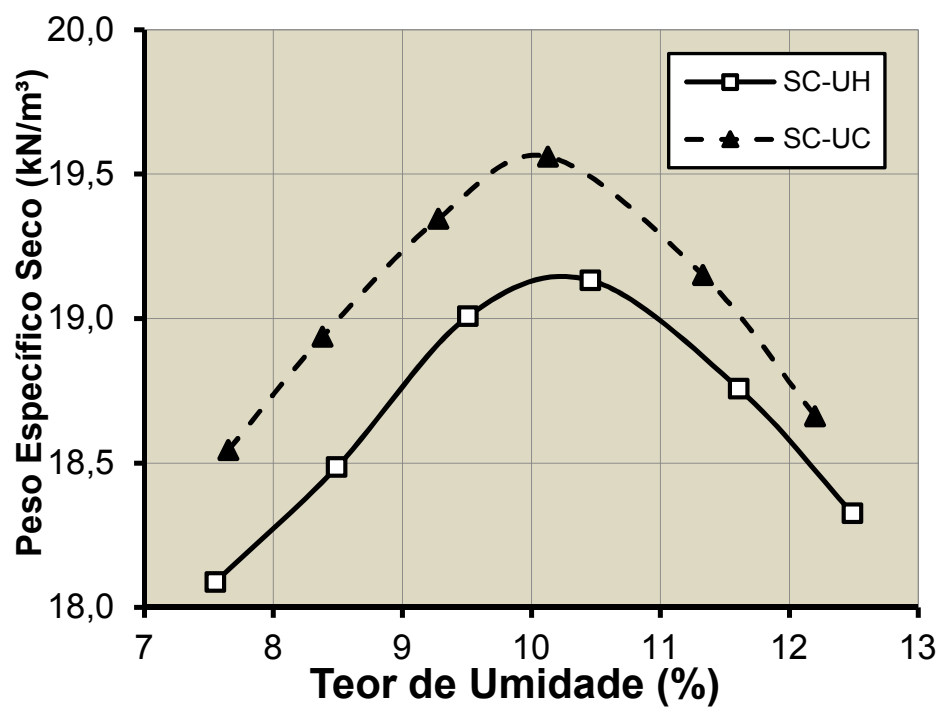

Figura 4.2 - Curvas de compactação do solo-cimento para as duas condições de mistura - UH e UC

\subsubsection{Grau de saturação do solo e resistência à compressão simples (RCS)}

Com os valores obtidos de peso específico real dos grãos, teor de umidade e peso específico aparente seco, é possível obter as curvas de saturação presentes na curva de compactação, conforme apresentado na Figura 4.3. Na mesma figura são apresentadas as curvas de RCS, obtidas para as amostras da curva de Proctor.

Com os dados do grau de saturação ( $\mathrm{S} \%$ ), é possível verificar que o solo compactado na condição UC apresenta um menor índice de vazios, com grau de 
saturação próximo de $75 \%$, enquanto que o solo compactado na condição UH atinge grau de saturação de $70 \%$, ambos verificados nas proximidades da umidade ótima. Pode-se concluir que o solo compactado a partir da condição UC obtém maior eficiência de compactação. Os maiores valores de resistência são verificados no ramo seco da curva, para as duas condições de umidade testadas.

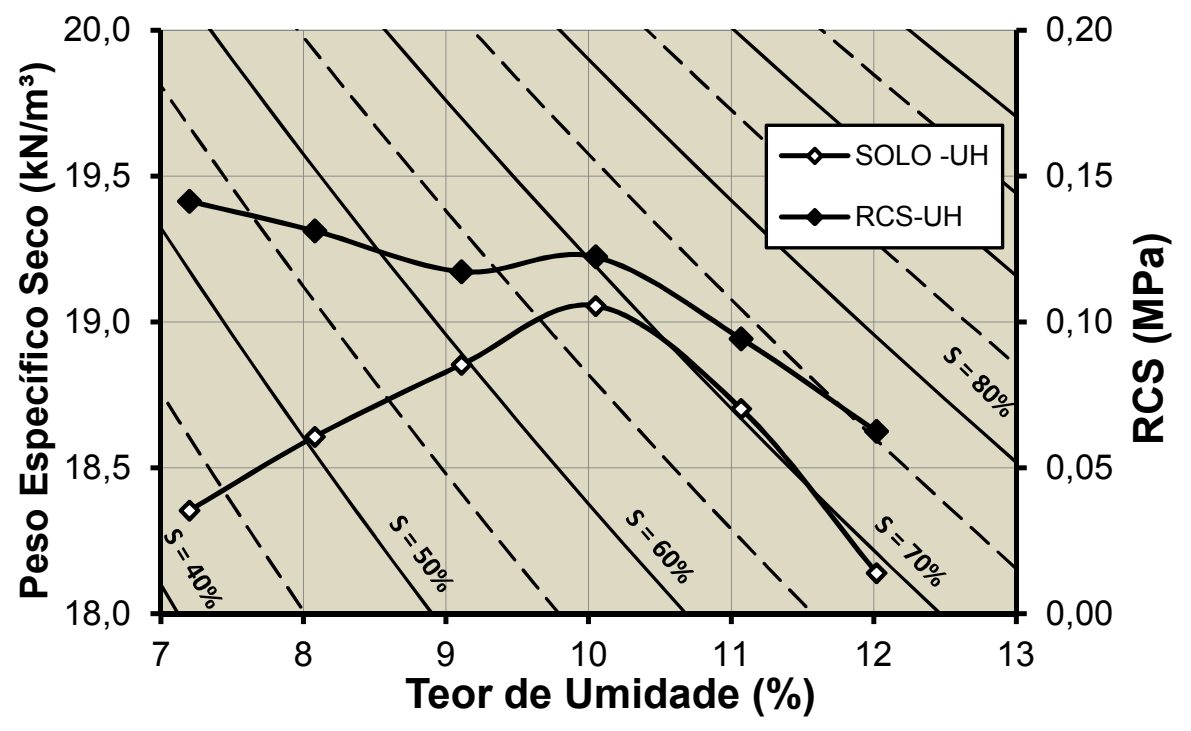

(a) 


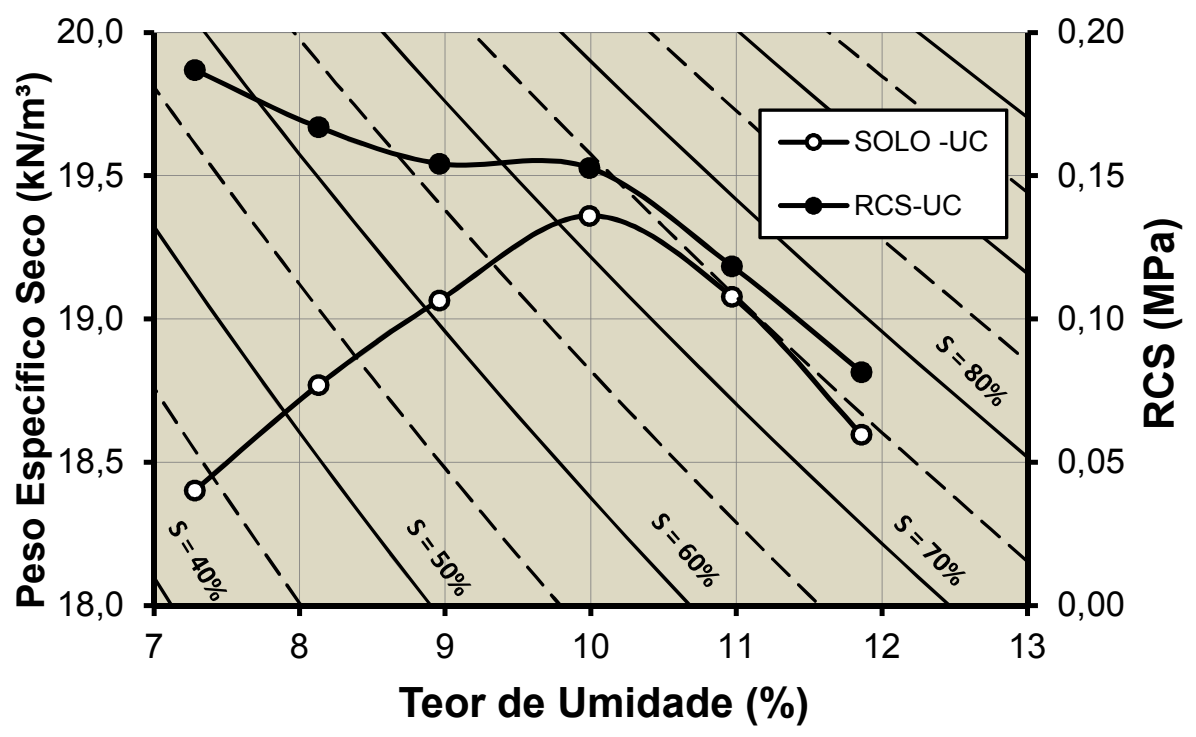

(b)

Figura 4.3 - Curvas de RCS e S\% para as amostras de solo na condição: (a) UH e (b) UC

\subsubsection{Resistência à compressão simples (RCS) para o solo-cimento}

A partir dos corpos de prova confeccionados para o ensaio de compactação, foram realizados ensaios de RCS após 7 dias de cura dos mesmos. Os resultados são apresentados na Figura 4.4. Os valores de RCS máximos encontram-se deslocados do ponto de umidade ótima no ramo seco da curva Proctor. Este fato foi verificado para as duas condições de umidade de mistura. Este comportamento foi também verificado em pesquisas anteriores para misturas de solo-cimento com $8 \%, 10 \%$ e $12 \%$ de cimento em massa para um solo de classificação HRB A-2 (YOON; FARSAKH, 2008). Os valores de RCS obtidos do lado úmido da curva de Proctor apresentaram resistências próximas para as duas condições de umidade estudadas. 


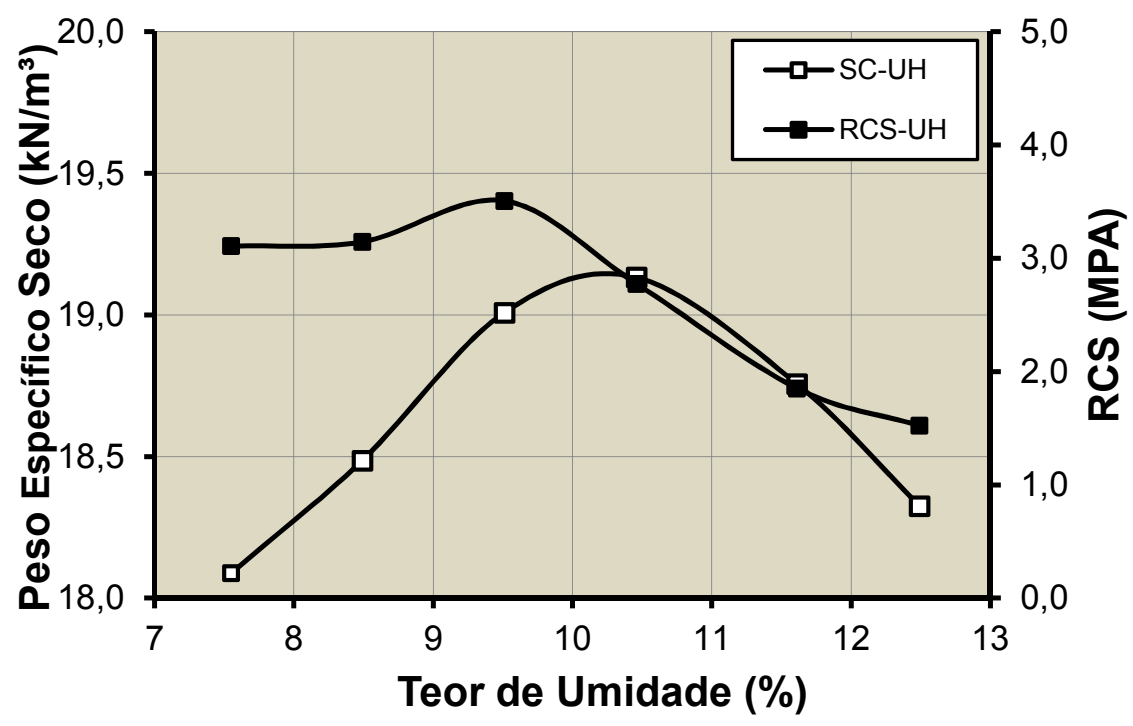

(a)

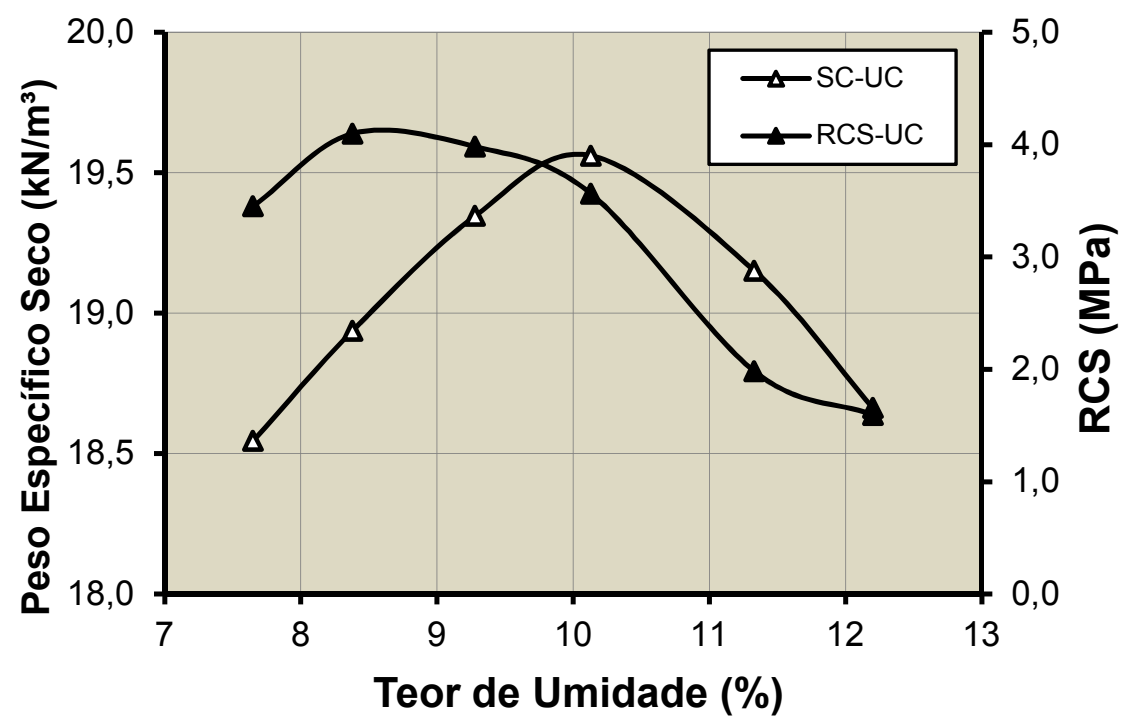

(b)

Figura 4.4 - Curvas de RCS após 7 dias de cura e peso específico seco para as amostras de solocimento na condição: (a) UH e (b) UC

Os valores obtidos de RCS para as amostras de SC foram aproximadamente 20 vezes superiores aos resultados de RCS nas amostras de solo, conforme mostrado na Figura 4.5. 


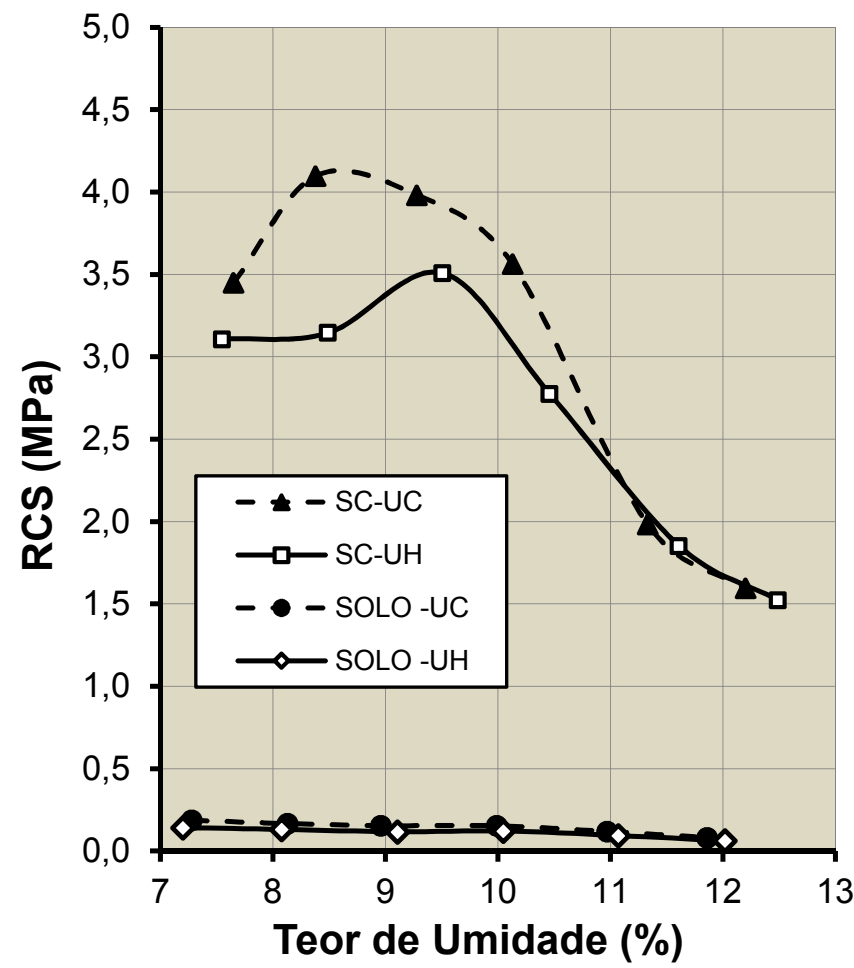

Figura 4.5 - Comparação da RCS obtida após 7 dias de cura nas amostras de solo e solo-cimento para as duas condições de mistura - UH e UC

\subsubsection{Fator água/ cimento $(a / c)$}

A Figura 4.6 mostra a relação a/c calculada para cada ponto da curva de Proctor. Os valores são calculados com base na umidade de compactação e da massa de cimento adicionada, esta última fixa devido ao emprego da mesma massa seca de solo em cada ponto, variando-se apenas a massa de água incorporada na mistura. A interpretação direta dos valores do fator a/c pode levar a conclusões precipitadas com relação à RCS. Quanto maior a relação a/c menor os valores RCS, mas, ao mesmo tempo, este fator coexiste com a variação do peso específico aparente seco. Então, a comparação dos valores de RCS com o fator a/c deve ser realizada para valores próximos de peso específico aparente seco. 


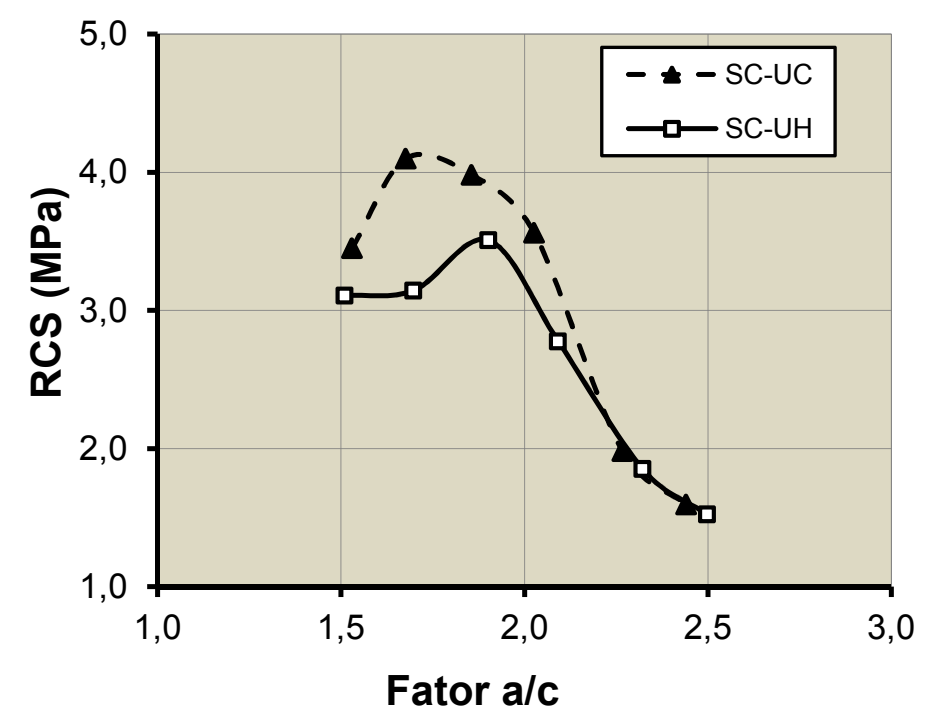

Figura 4.6 - Relação a/c para as amostras de solo-cimento para as duas condições de mistura - UH e UC

\subsection{Dosagem do solo-cimento}

A Figura 4.7 apresenta a curva de dosagem do solo-cimento com os valores de RCS médios por teor de cimento, além da resistência mínima de 2,1 MPa (aos 7 dias de cura) requerida pela especificação de dosagem. 


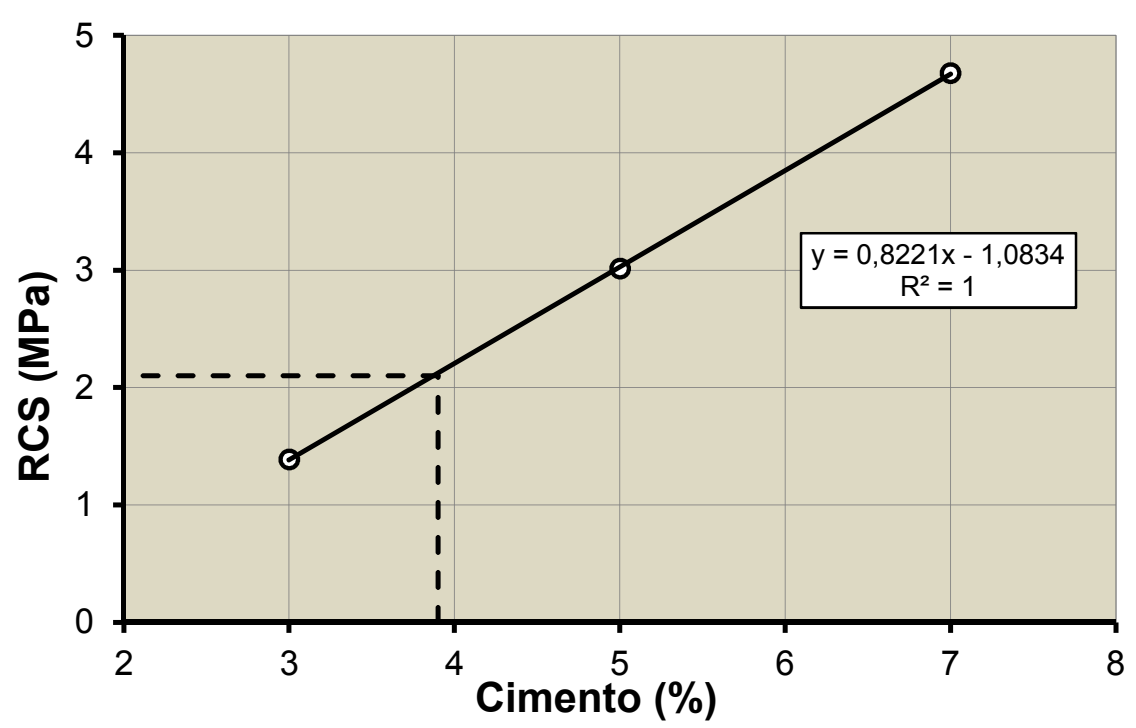

Figura 4.7 - Curva de RCS versus percentual de cimento

O emprego de aproximadamente $4 \%$ de cimento é suficiente para atingir a resistência mínima aos 7 dias de 2,1 MPa. Visando uma maior segurança para as amostras a serem ensaiadas nos demais procedimentos, adotou-se um teor de $5 \%$ de cimento. De acordo com a NBR 12253/2012, os resultados não devem ser extrapolados além dos teores verificados na dosagem. Para um estudo comparativo, também foi realizada a dosagem com o solo na umidade de campo (UC) e, visando um estudo da adição de cimento, mais um ponto com $9 \%$ foi estudado nas duas dosagens (UH e UC). Os resultados são apresentados na Figura 4.8. 


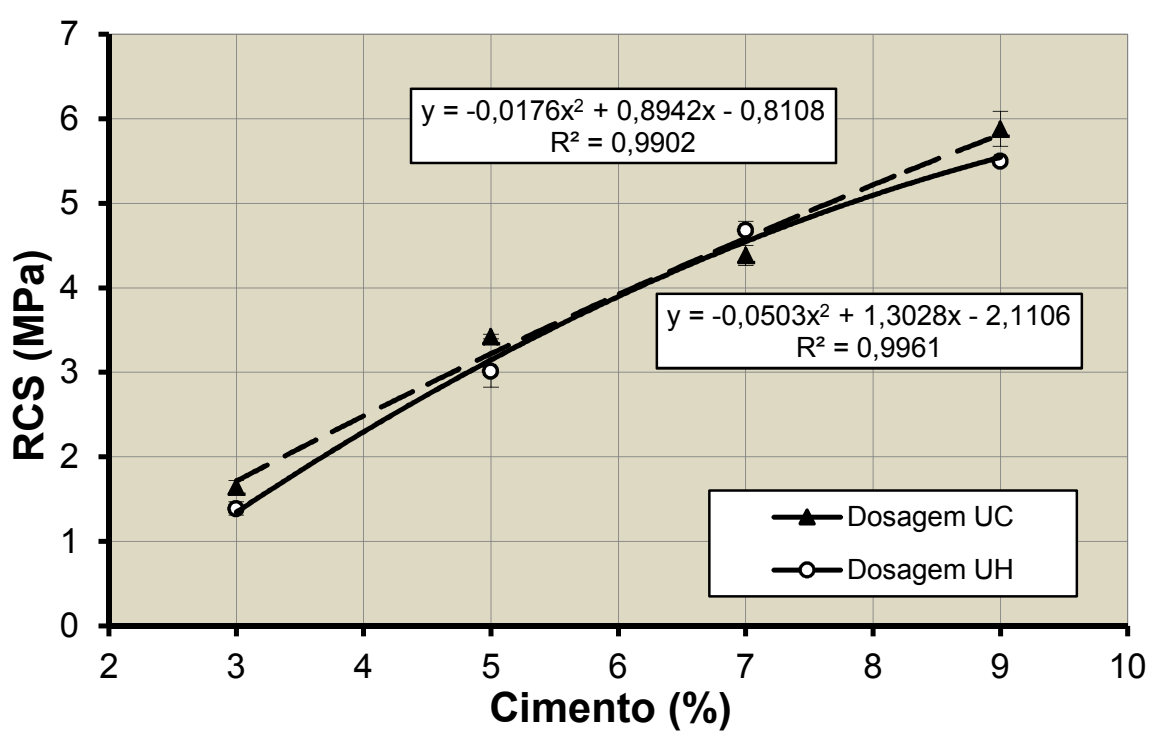

Figura 4.8 - Dosagem do SC em duas condições de mistura - UC e UH

Observa-se dos quatro teores de cimento investigados que o incremento da resistência não é linear, evidenciando uma pequena queda de resistência nos maiores valores (9\%). Resultado semelhante foi obtido por Lade et al. (1998), de acordo com os autores, o índice de vazios do solo satura nesta condição e o cimento em excesso promove o afastamento os grãos do solo, reduzindo o contato grão a grão. Não houve diferença significante entre as duas umidades de moldagem. Esta aproximação pode decorrer do procedimento de imersão em água por 4 horas realizado previamente à ruptura das amostras.

\subsection{Ensaios mecânicos nas misturas de solo-cimento}

A partir dos valores de peso específico seco máximo e umidade ótima, obtidos para as misturas de solo-cimento nas duas condições de umidade inicial (UH e UC), foram confeccionados corpos de prova cilíndricos de $10 \mathrm{~cm}$ de diâmetro por $20 \mathrm{~cm}$ de altura. Os resultados obtidos são apresentados nos subitens a seguir. O controle dos tempos de cura, dados da moldagem dos CP's e execução dos ensaios são apresentados no ANEXO A. 


\subsubsection{Resistência à tração por compressão diametral (RTCD)}

Os valores obtidos de RTCD para as idades de 3, 7, 14 e 28 dias de cura nas duas umidades (UH e UC) são apresentados na Figura 4.9. A amostra na umidade de campo (UC) apresentou maiores valores de resistência para as quatro idades ensaiadas. Observa-se do gráfico que a diferença nos valores RTCD para as duas umidades foi crescente com o aumento no tempo de cura dos corpos de prova, tendo a mistura moldada na condição UC apresentado um incremento superior.

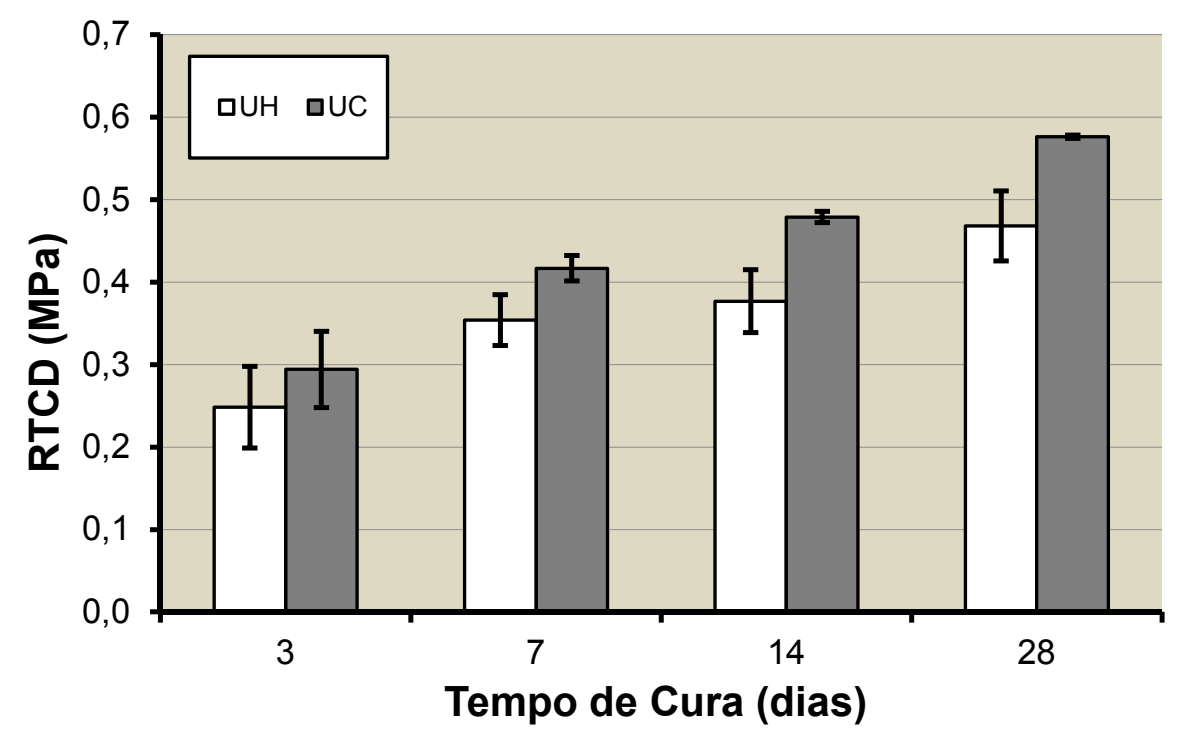

Figura 4.9 - Valores de RTCD para 3, 7, 14 e 28 dias de cura nas duas condições de mistura - UH e UC

\subsubsection{Resistência à compressão simples (RCS)}

Os valores de RCS obtidos para as idades de 3, 7, 14 e 28 dias de cura são apresentados na Figura 4.10. Não houve diferenças entre os ensaios na condição UH e UC para 3 dias de cura. Aos 7 dias, nota-se que a amostra na condição UH apresenta maiores valores de RCS. Este resultado decorreu de um desvio no fator água/cimento $(\mathrm{a} / \mathrm{c})$ para este lote de moldagem (SC-UH 7 dias de cura). $\mathrm{O}$ valor 
verificado ao final da moldagem foi de um fator a/c de 2,08, todas as outras amostras obtiveram em média um fator a/c de 2,17. Aos 14 e 28 dias, foi verificada a mesma tendência, maior para a condição UH.

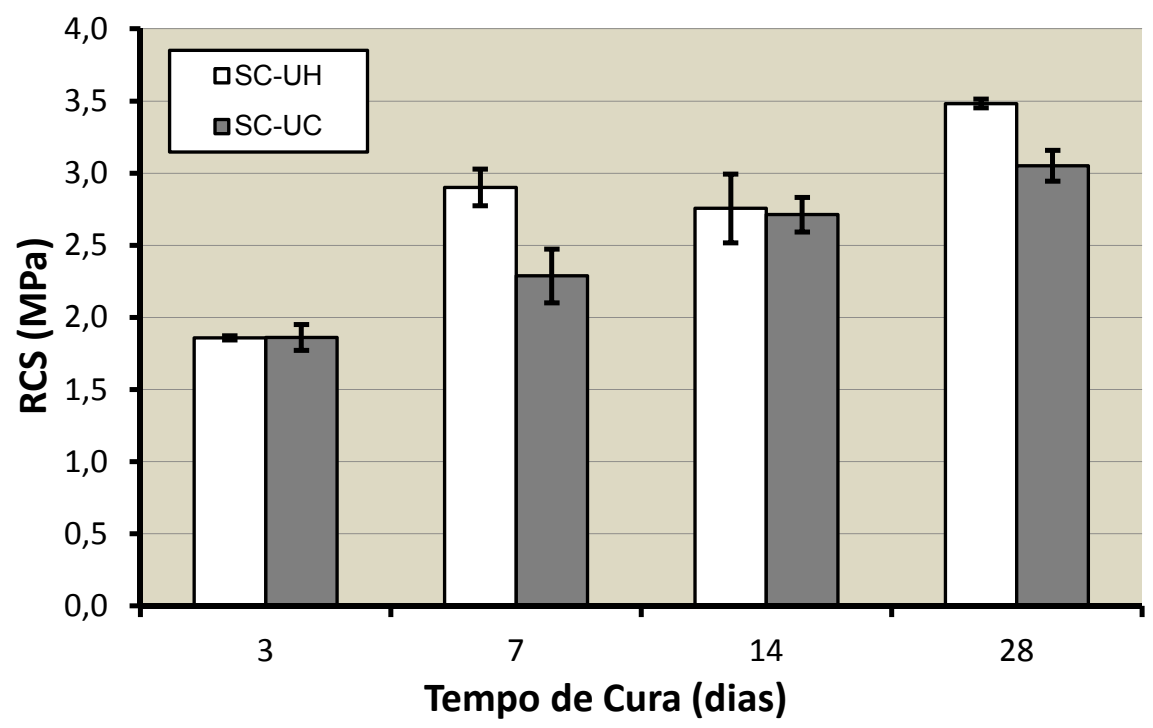

Figura 4.10 - Valores de RCS para 3, 7, 14 e 28 dias de cura nas duas condições de mistura - UH e UC

O ganho de resistência verificado nas idades ensaiadas é compatível com a curva de resistência do cimento empregado, conforme mostrado na Figura 4.11. Para evidenciar esta análise, tanto o eixo das abcissas quanto das ordenadas foram plotados em escala logarítmica e adotado um modelo de potência. Resguardadas as proporções do valor RCS da argamassa de cimento e do SC, o valor do exponente obtido destas equações é similar, evidenciando o comportamento da curva de RCS associado diretamente com o cimento empregado. Os valores da RCS do cimento foram gentilmente fornecidos pelo fabricante. 


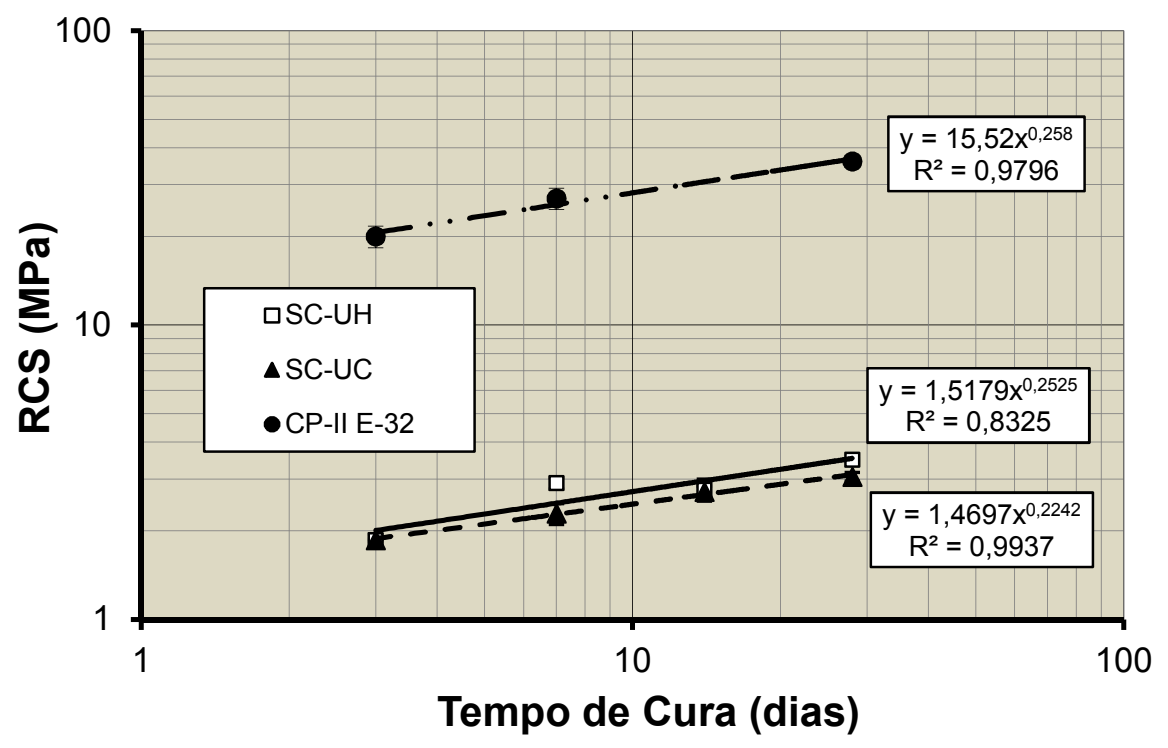

Figura 4.11 - Regressão da RCS da argamassa de cimento e do SC nas duas condições de mistura $-\mathrm{UH}$ e UC

\subsubsection{Módulo de resiliência (MR)}

Os valores obtidos para as idades de 3, 7, 14 e 28 dias de cura são apresentados na Figura 4.12. A Figura 4.13 apresenta os ganhos nos valores de MR com o tempo para uma tensão confinante de 1,05 MPa. 


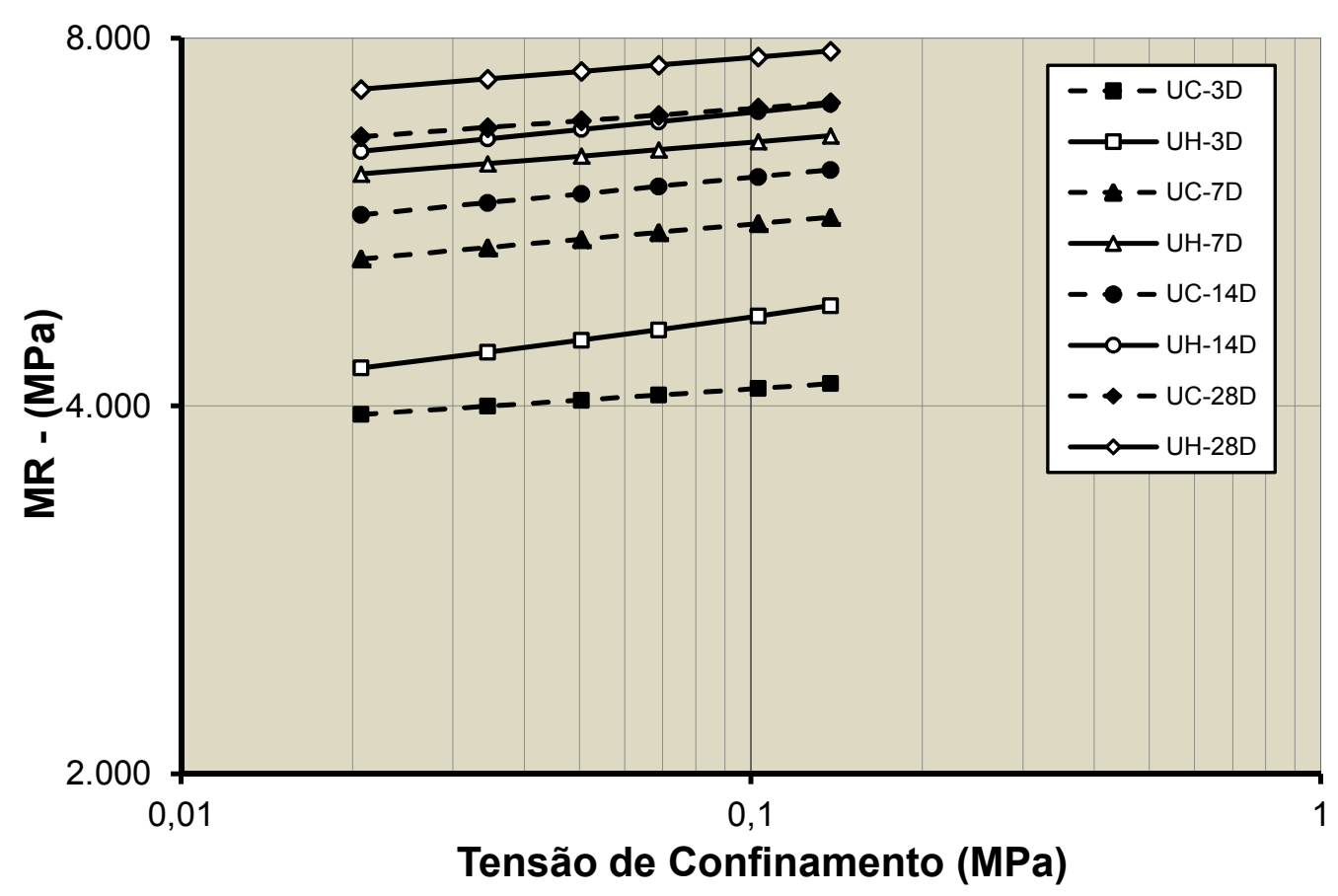

Figura 4.12 - Módulo de resiliência para 3, 7, 14 e 28 dias de cura nas duas condições de mistura $\mathrm{UH}$ e UC

Os valores de módulo de resiliência foram maiores para a amostra na condição UH para as quatro idades de cura ensaiadas. De forma geral, as amostras apresentam comportamento resiliente com baixa sensibilidade à tensão confinante $(\sigma 3)$ e a tensão desviadora $(\sigma d)$, comportamento esperado para materiais cimentados (MEDINA; MOTTA, 2005; BERNUCCl et al., 2006; BALBO; 2007). A tendência do ganho de rigidez é próxima à verificada nos ensaios de RCS (valores superiores para os corpos de prova preparados na $\mathrm{UH}$ ). Em parte, atribui-se essa similaridade à semelhança do plano de aplicação da carga (axialmente), em relação ao plano de moldagem. Esta ultima análise é feita com restrições por este ensaio tratar de rigidez (um ensaio não destrutivo) realizado com carregamento dinâmico, enquanto que o de RCS trata de resistência, determinado na ruptura com carregamento monotônico. 


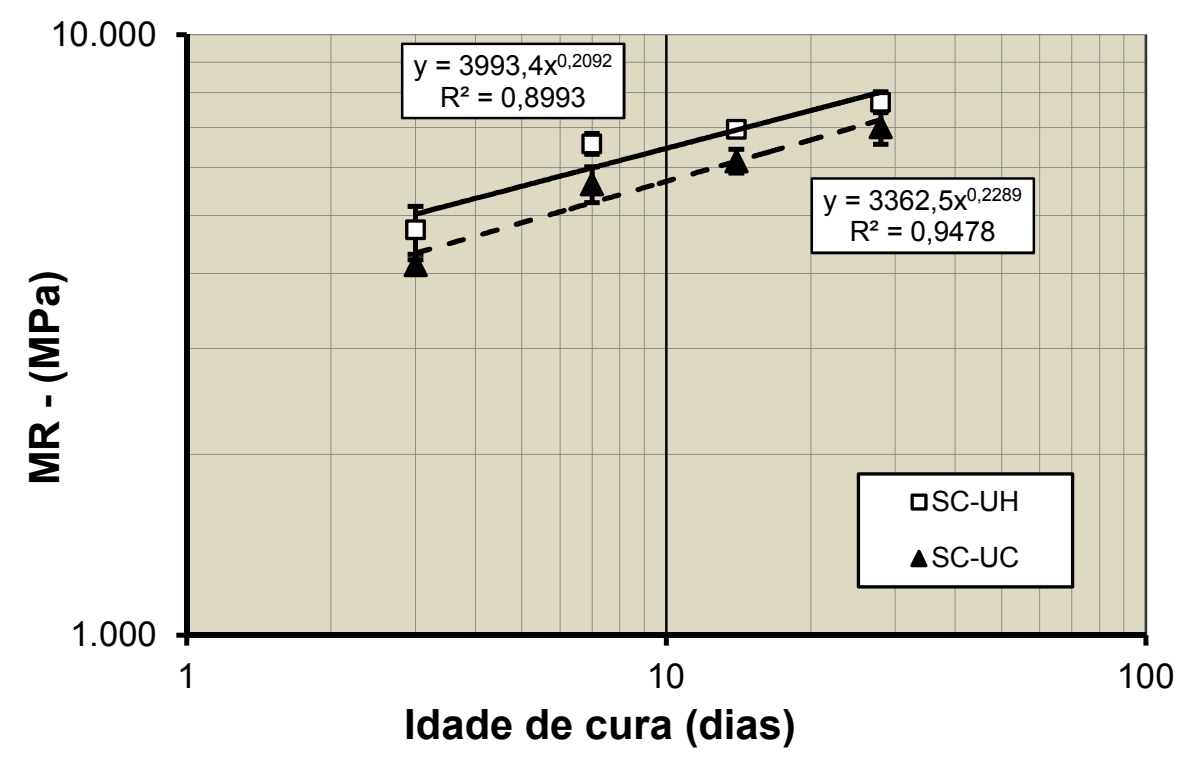

Figura 4.13 - Acréscimo do valor de MR com o tempo de cura para um $\sigma 3$ de 1,05 MPa, nas duas condições de mistura - UH e UC

\subsection{Efeito da umidade (UH e UC) no comportamento mecânico das misturas de solo-cimento}

A partir dos resultados encontrados nos ensaios de RTCD, RCS e MR (apresentados nos itens anteriores), obtidos para as duas umidades de moldagem (UH e UC), foi verificado que apenas no ensaio de RTCD os valores obtidos foram maiores para a umidade de campo. Observa-se que no ensaio de RTCD o plano de compactação (axial) com relação ao plano de aplicação do carregamento do ensaio (diametral) diverge do que ocorre nos ensaio de RCS e MR (compactação e solicitação de carregamentos realizados no mesmo plano, axial). Acredita-se que essa diferença possa estar associada à anisotropia do corpo de prova. A anisotropia pode ser definida como a variação das propriedades de um material dependente da direção em que o mesmo é solicitado. Esta variação dificulta a elaboração matemática da distribuição de tensões e deformações.

Na mecânica dos solos, a ruptura de solos argilosos é extremamente dependente da forma de solicitação. Pinto (2006) cita como exemplo, um corpo de aterro sobre solo argiloso, onde foram estudados os esforços ao longo do plano hipotético de ruptura em forma de cunha. Imediatamente abaixo do corpo do aterro, o solo trabalha em 
compressão, no meio da linha de ruptura existe cisalhamento e no final da linha de ruptura existe extensão, conforme apresentado na Figura 4.14. Em cada uma destas formas de solicitações o solo apresenta uma resistência (PINTO, 2006).

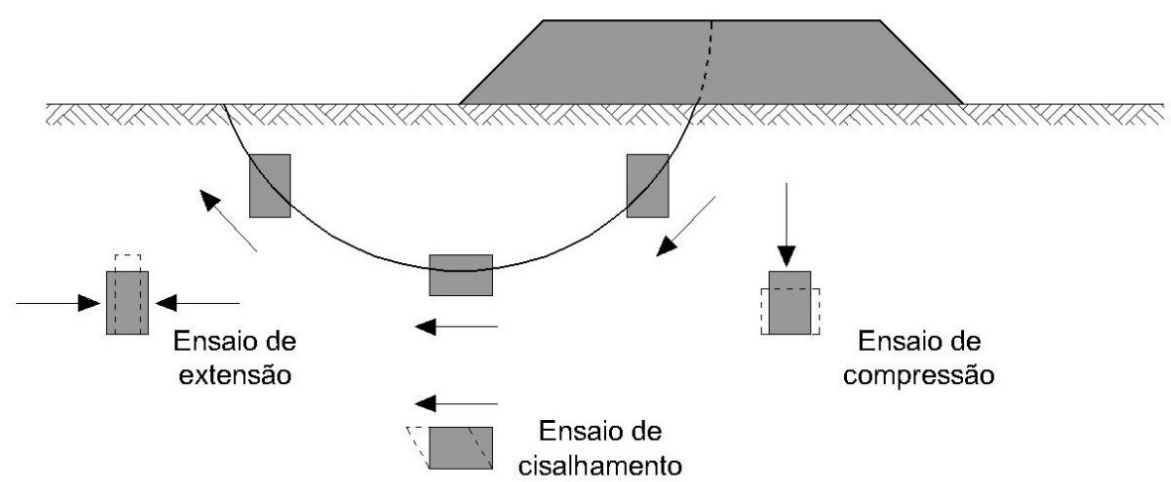

Figura 4.14 - Solicitações em um terreno por efeito de carregamento na superfície (Adaptado de PINTO, 2006)

\subsection{Contração e retração pela metodologia MCT}

Para avaliar um potencial de fissuração por contração ou retração, tanto no solo quanto na mistura de solo-cimento, foram realizados os ensaios de contração e retração, conforme metodologia apresentada no item 3.3.4. A seguir, são apresentados os resultados da retração e contração da dosagem do solo-cimento na umidade higroscópica e o efeito da umidade inicial de mistura nas amostras de solo e solo-cimento nas duas umidades de mistura (UH e UC). 


\subsubsection{Retração e contração da dosagem de SC-UH}

A retração do SC medida na umidade higroscópica foi determinada para as amostras mantidas em câmara úmida, com UR > 95\%. Os valores obtidos da evolução da retração com o tempo são mostrados na Figura 4.15.

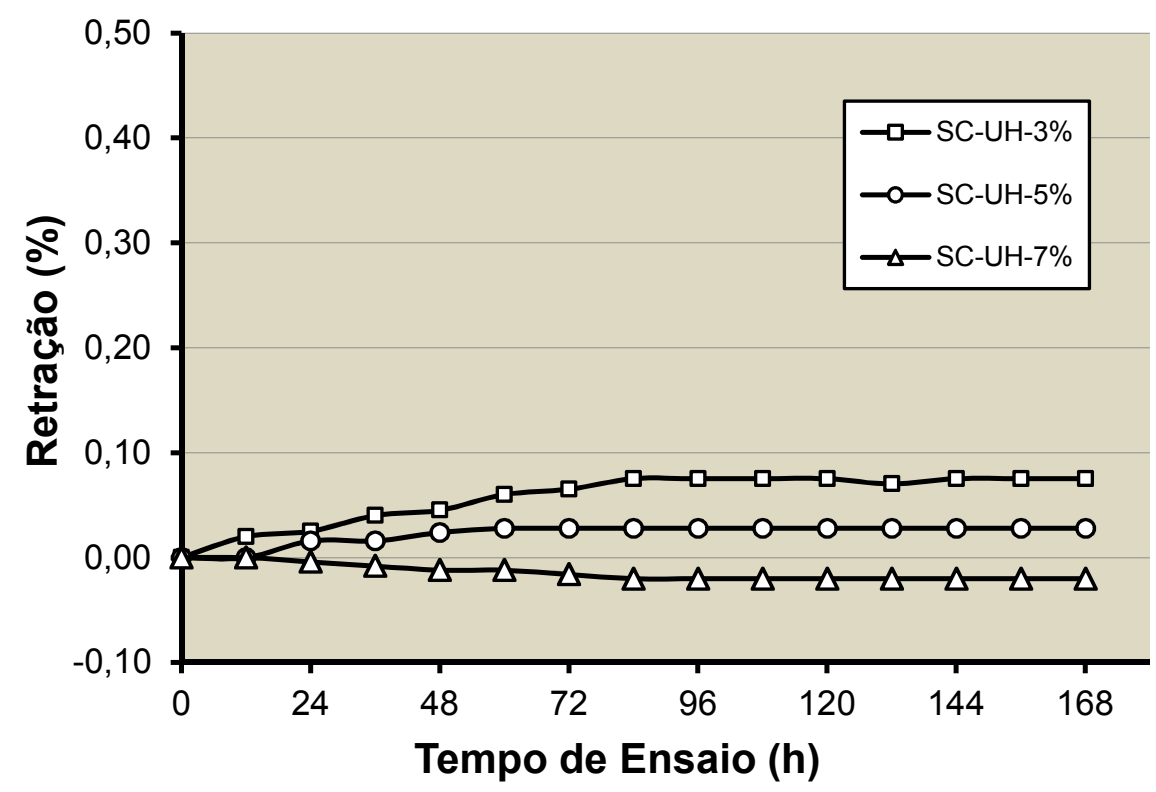

Figura 4.15 - Valores médios da retração com o tempo para a dosagem de SC-UH

A partir da análise dos dados de retração, observou-se que o aumento no teor de cimento inibiu a ocorrência de retração. A retração para este tipo de solo e cimento empregados desenvolveu-se de forma acentuada nas primeiras 72 horas. Este comportamento com relação ao tempo também foi verificado por Pitta (1982), para solos arenosos e granulares.

Após 7 dias de cura em câmara úmida (última leitura apresentada na Figura 4.15), as mesmas amostras foram submetidas ao ensaio de contração, em câmara com UR de $50 \%$ e temperatura de $25^{\circ} \mathrm{C}$. Os resultados obtidos são mostrados na Figura 4.16. 


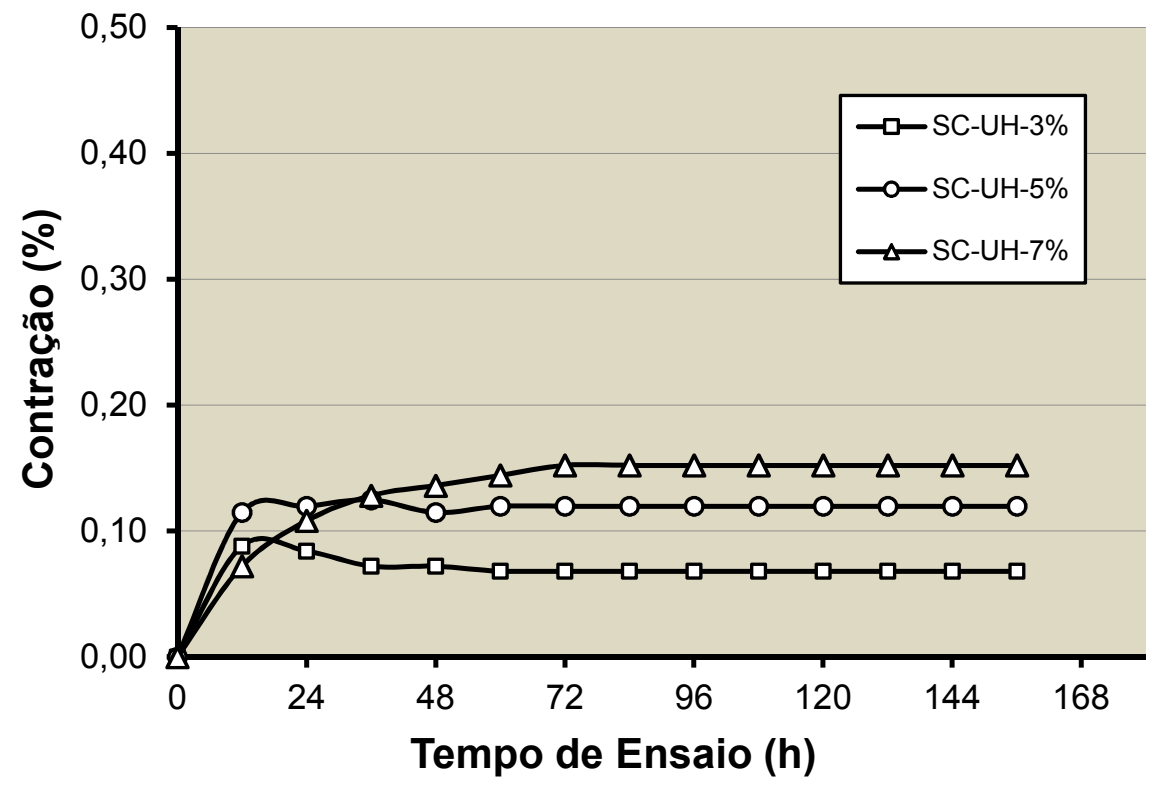

Figura 4.16 - Valores médios da contração com o tempo para a dosagem de SC-UH

Os valores obtidos de contração para a amostra ensaiada após 7 dias de cura em câmara com UR de $50 \%$ mostraram um acréscimo da contração proporcional a quantidade de cimento empregada nas amostras. Para uma melhor interpretação dos dados, os valores de retração e contração foram conectados, de forma a tornar o experimento contínuo. Os valores obtidos são mostrados na Figura 4.17.

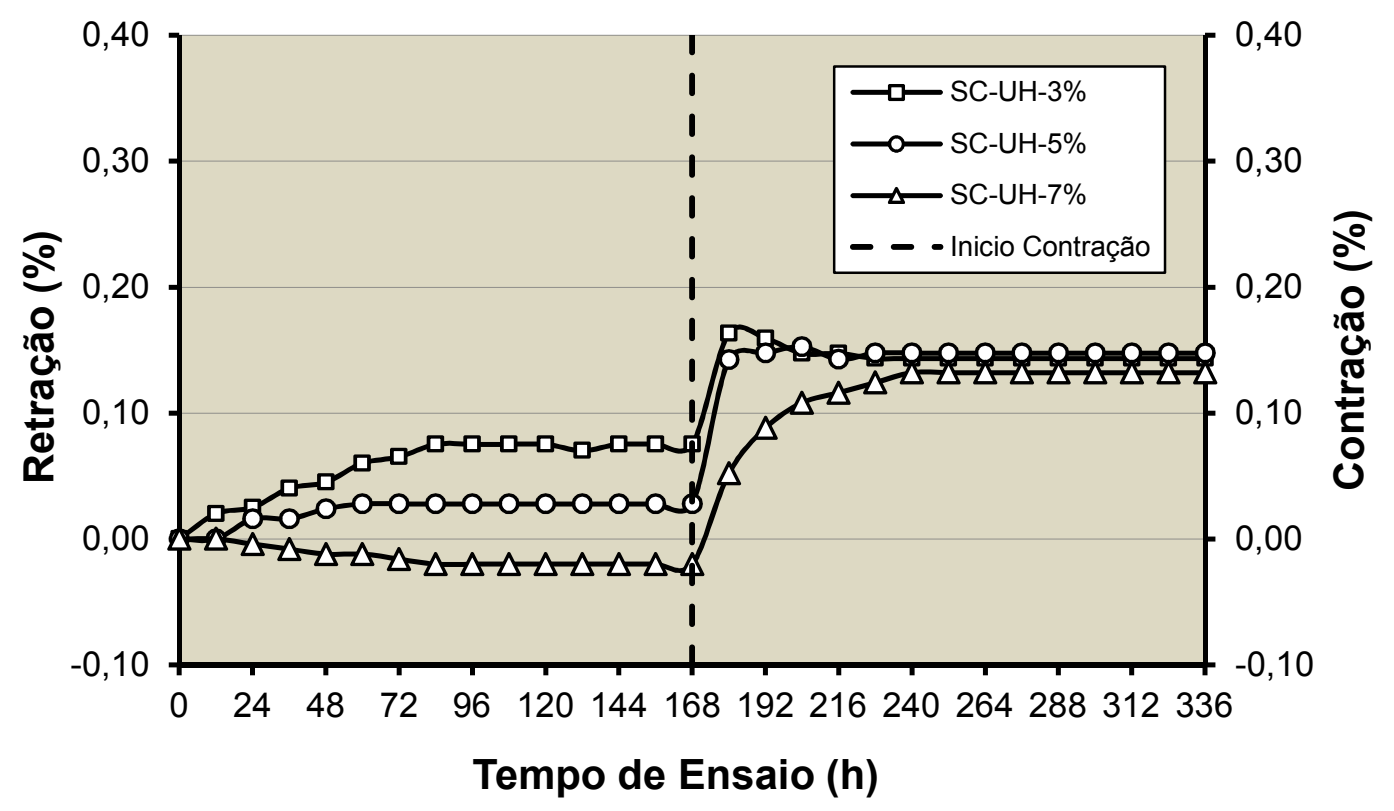

Figura 4.17 - Junção dos valores médios de retração e contração na dosagem SC-UH 
Com base nos dados expostos, verificou-se que a contração somada a retração atingiu valores finais aproximados para os três percentuais de cimento. As misturas de solo-cimento avaliadas mostraram uma maior sensibilidade a contração, causada pela perda de umidade.

\subsubsection{Efeito da umidade de mistura (UH e UC) na contração do Solo e do SC}

A contração depende principalmente da plasticidade do solo, e quando ocorre em excesso, pode gerar fissuras prematuras na camada do pavimento. A Figura 4.18 apresenta os valores de contração/retração obtidos em amostras de SC com $5 \%$ de cimento e os valores de contração obtidos em amostras de solo. Tanto o SC quanto o solo foram moldados nas duas condições de mistura (UH e UC) e ensaiados em câmara com UR de $50 \%$.

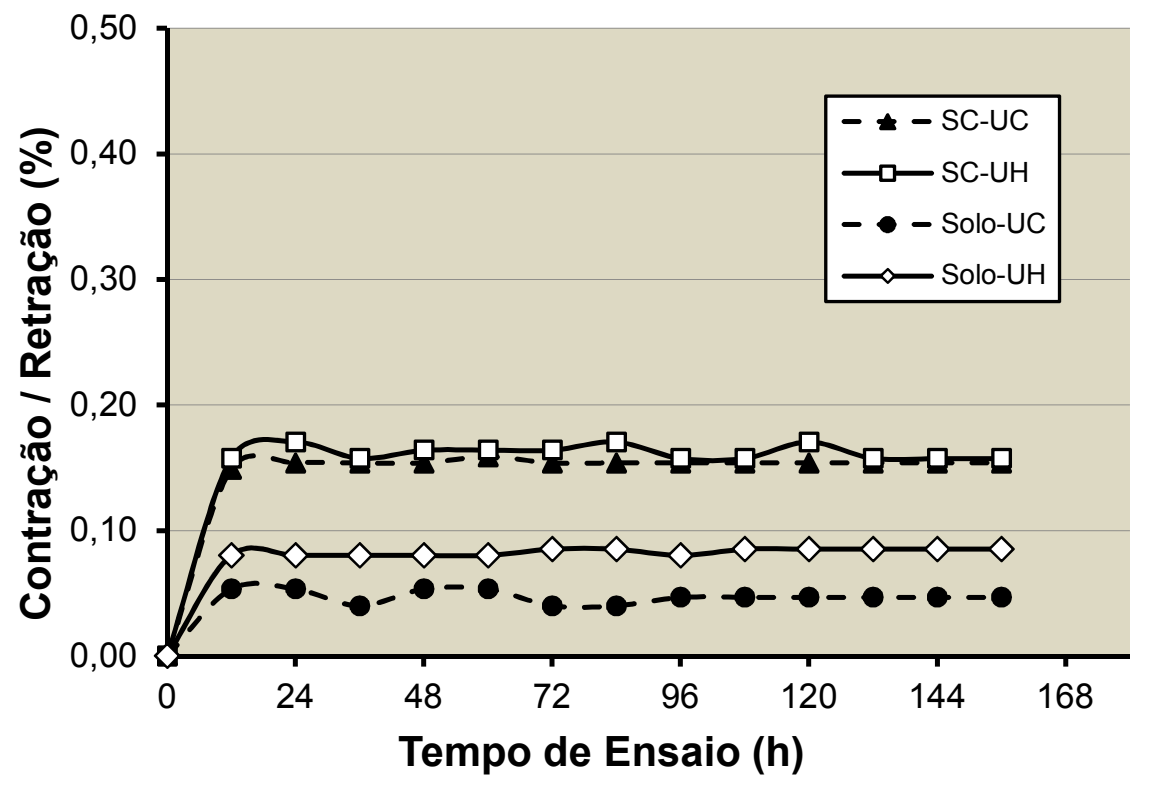

Figura 4.18 - Valores médios da retração/ contração com o tempo para o SC e solo - UH e UC

A contração na amostra de solo na condição UC foi inferior a do solo na condição $\mathrm{UH}$. As misturas de SC nas duas umidades de moldagem não apresentaram diferença significativa. Após 7 dias de cura em câmara úmida (cura realizado no 
ensaio de retração no teor de $5 \%$ da dosagem de SC-UH, com UR>95\%), o efeito da contração foi sutilmente inferior ao valor verificado para as amostras de SC-UH sem cura (moldagem seguida do ensaio de contração). Este menor valor de contração após a cura pode ser atribuído pelo aumento da coesão do solo frente à ação aglomerante do cimento. No comparativo das misturas de SC com as amostras de solo, observa-se que este último apresentou a metade do potencial de contração. Este resultado pode ser explicado pela alteração granulométrica e aumento da superfície específica da amostra com a adição do cimento. Como abordado no item 2.2.3, esse incremento propicia o desenvolvimento de um maior número de meniscos capilares no interior do solo com pequenos diâmetros. Cabe ressaltar ainda que mesmo para as misturas de SC, os valores obtidos de contração são baixos, evidenciando a baixa capacidade deste solo para desenvolvimento de fissuras por perda de água. 


\section{TRECHO EXPERIMENTAL}

A construção do trecho experimental é parte de um projeto financiado pela Petrobras - Petróleo Brasileiro S.A dentro da área de Asfalto, tendo como objeto desenvolver um método de dimensionamento de pavimentos. A execução dos trechos monitorados sob a coordenação do LTP-EPUSP tornou-se possível através de parceria com a Petrobras, DER-SP, pelo apoio e concordância no auxilio de execução dos trechos, LEÃO Engenharia, pela execução do trecho experimental e a projetista PENTÁGONO Engenharia.

O objetivo principal do projeto, e consequentemente dos Trechos Monitorados, é a ampliação da gama de soluções de pavimentação que poderão ser utilizadas em outras rodovias e obras futuras.

\subsection{Localização do trecho experimental}

Durante a idealização dos trechos monitorados, foi realizada uma visita técnica às obras da Estrada do Leite, que interliga os municípios de Altinópolis, Batatais, Itirapuã e Patrocínio Paulista, no trecho denominado "FURNAS", Km 15,300 da SP345 (Figura 5.1), sob administração da Regional 8 do DER-SP. Foram visitados os últimos $10 \mathrm{~km}$ da estrada, de um total de mais de $31 \mathrm{~km}$ de projeto de implantação, onde seriam executados os trechos monitorados, tendo início na cidade de Patrocínio Paulista. 


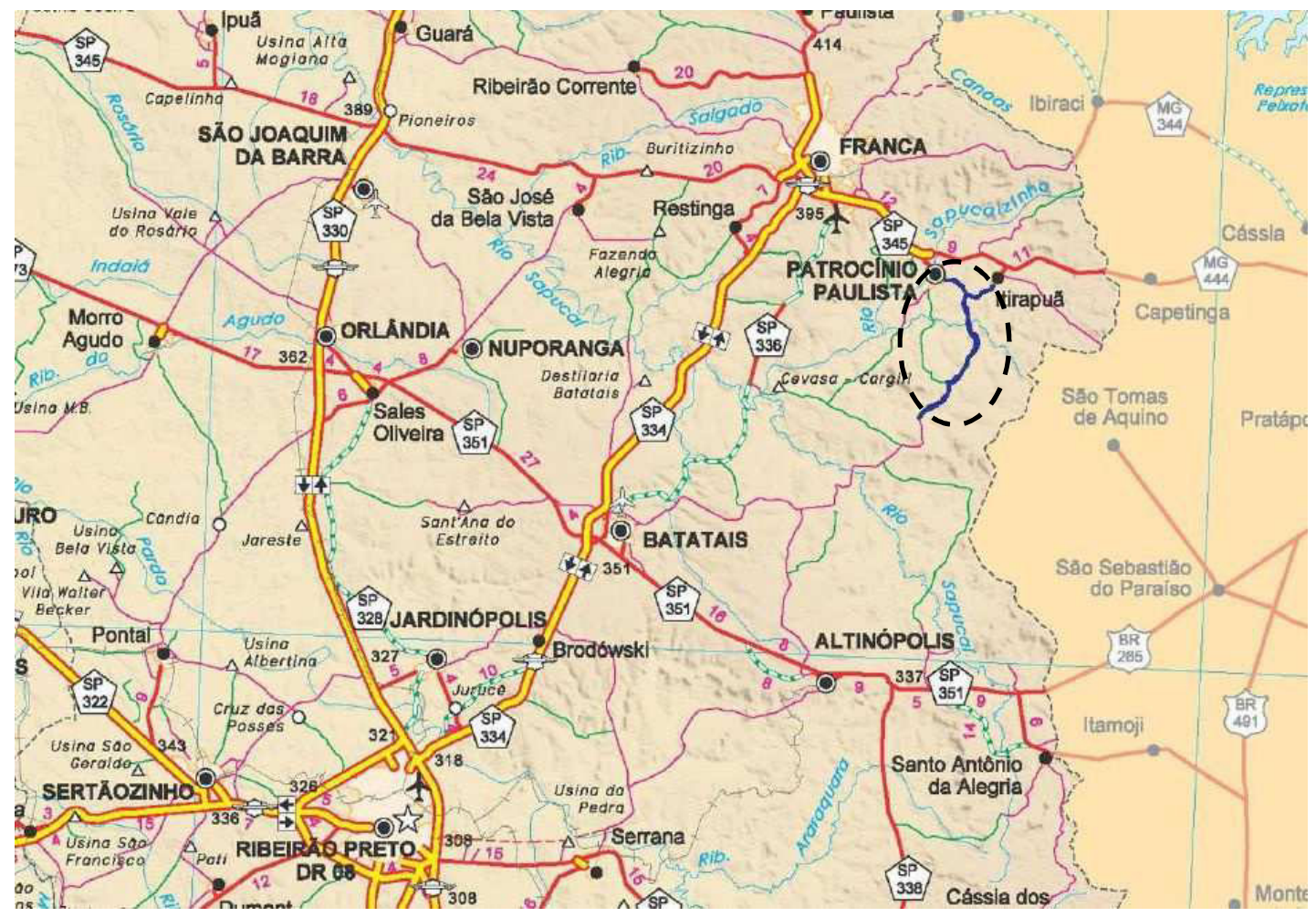

Figura 5.1 - Mapa de localização do trecho experimental (Fonte: DER-SP)

$\mathrm{Na}$ escolha da localização dos trechos, optou-se por um segmento em tangente, praticamente plano, em um local bem drenado da estrada (Km 15,770 ao Km 16,520, perfazendo 750 metros de extensão). A Figura 5.2 apresenta um croquis da Estrada do Leite, e localização do Trecho Experimental. 


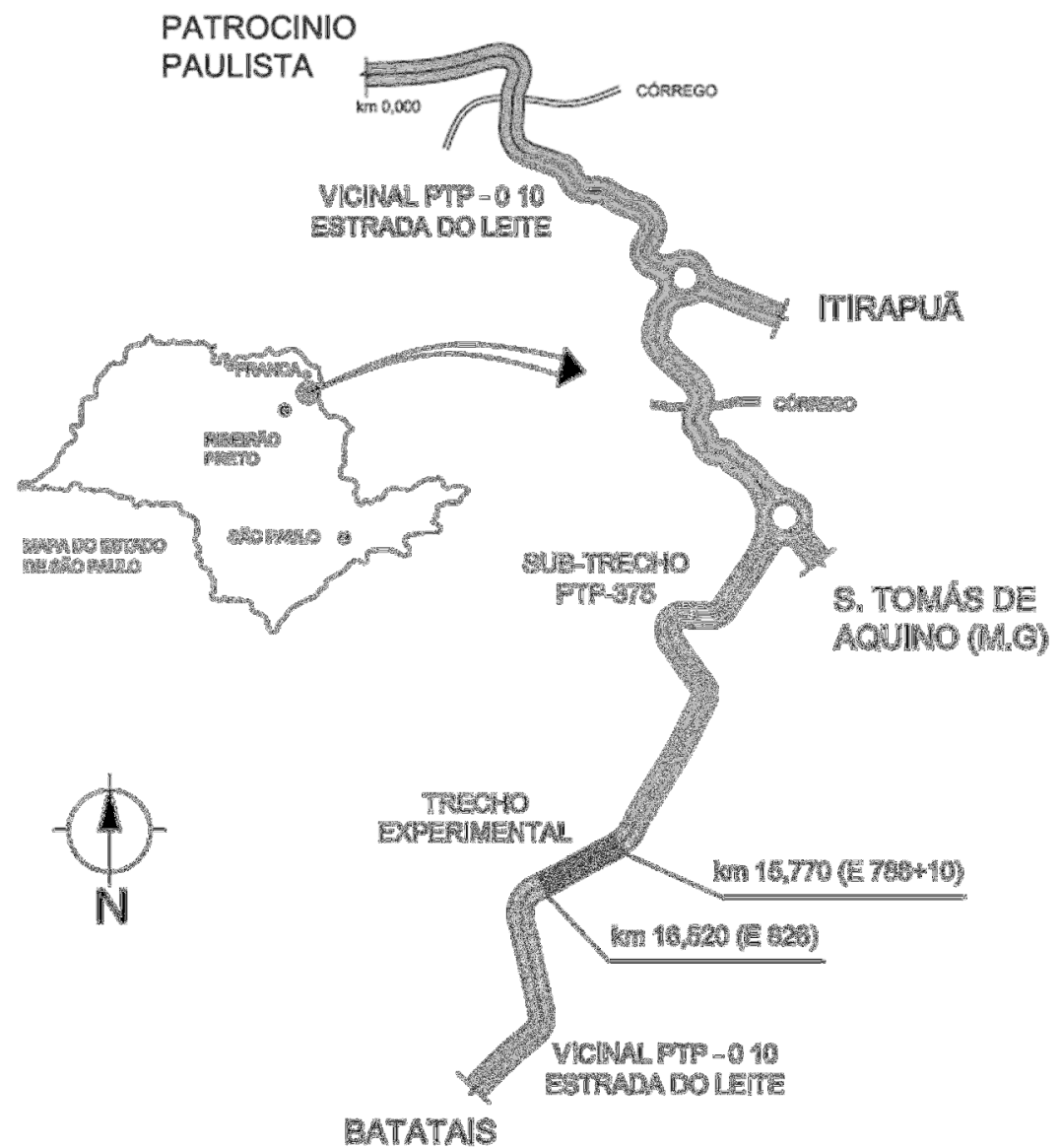

Figura 5.2 - Croquis esquemático de localização do trecho experimental

\subsection{Projeto original e proposta para o trecho experimental}

O projeto da estrutura do pavimento foi elaborado pela projetista Pentágono Serviços de Engenharia e Consultoria LTDA. O detalhamento do método de dimensionamento, coeficientes estruturais, espessuras das camadas e tráfego considerados encontram-se no ANEXO B. 


\section{- Estrutura de projeto}

$\mathrm{Na}$ Tabela 5.1 são apresentadas as espessuras calculadas para o projeto do pavimento. Para a camada de base, foi adotada espessura de $15 \mathrm{~cm}$ e para a camada de reforço do subleito foi adotada espessura de $30 \mathrm{~cm}$, subdivididos em duas camadas de $15 \mathrm{~cm}$ para execução.

Tabela 5.1 - Espessuras das camadas calculadas

\begin{tabular}{l|l|c|c}
\hline \multicolumn{1}{c|}{ Camada } & \multicolumn{1}{|c|}{ Material } & $\begin{array}{c}\text { Coeficiente } \\
\text { (K) }\end{array}$ & $\begin{array}{c}\text { Espessura } \\
\text { (cm) }\end{array}$ \\
\hline Revestimento & $\begin{array}{l}\text { CBUQ FX III DER-SP CAP } \\
30 / 45\end{array}$ & 2,0 & 4,0 \\
\hline Base & Solo Brita E.I (40x60) & 1,0 & 18,6 \\
\hline Reforço Subleito & Solo Jazida E.I & 0,69 & 5,21 \\
\hline Subleito & Solo E.N & - & - \\
\hline
\end{tabular}

Como houve a alteração das espessuras calculadas, foi realizada uma análise mecanicista com o intuito de verificar os pontos críticos da estrutura (deflexão máxima na superfície $D_{0}$, deformação específica horizontal de tração na fibra inferior do revestimento $\left(\varepsilon_{\mathrm{t}}\right)$ e deformação específica vertical no topo do subleito $\left.\left(\varepsilon_{\mathrm{v}}\right)\right)$. Para a análise, foi empregado o programa de elasticidade linear ELSYM 5. Os parâmetros de carregamento e geometria considerados na análise são:

- $\quad$ Carga de contato: $2.050 \mathrm{kgf}$ por roda

- $\quad$ Pressão de contato: 5,6 kgf./ $\mathrm{cm}^{2}$

- Área de contato circular: $\mathrm{R}=10,79 \mathrm{~cm}$

- Distância de eixo entre as rodas: $28,8 \mathrm{~cm}$

- Distância utilizada na análise dos pontos: $14,4 \mathrm{~cm}$

Os valores de módulos de resiliência, coeficientes de Poisson $(\mu)$ e espessuras adotadas são apresentados na Tabela 5.2. Os valores modulares e seus respectivos 
coeficientes de Poisson para os materiais adotados estão de acordo com os valores sugeridos na IP-DE-P00/001.

Tabela 5.2 - Valores de MR, Poisson e espessuras adotadas

\begin{tabular}{|c|c|c|c|c|}
\hline Camada & Material & $\begin{array}{c}\text { MR } \\
\left(\mathrm{kgf}^{2} \mathrm{~cm}^{2}\right)\end{array}$ & Poisson & $\begin{array}{c}\text { Espessura } \\
\text { (cm) }\end{array}$ \\
\hline Revestimento & CBUQ & 35.000 & 0,30 & 4,0 \\
\hline Base & Solo-brita & 3.000 & 0,35 & 15,0 \\
\hline Reforço & Solo E.I & 1.500 & 0,40 & 30,0 \\
\hline Subleito & Solo E.N & 1.350 & 0,45 & $\infty$ \\
\hline
\end{tabular}

Para o cálculo das solicitações admissíveis, foram empregadas as eq.(5.1), (5.2) e (5.3).

- Deslocamento vertical na superfície do pavimento - Do $\left(\times 10^{-2} \mathrm{~mm}\right)$ - TECNAPAV (PRO269) - (N USACE):

$$
\log D_{0 \mathrm{adm}}=3,148-0,188 \times \log \mathrm{N}
$$

- Deformação horizontal específica de tração na fibra inferior do revestimento - $\varepsilon_{\mathrm{t}}$ $\left(\times 10^{-4} \mathrm{~cm} / \mathrm{cm}\right)-\mathrm{FHWA}-(\mathrm{N}$ AASHTO$)$

$$
\mathrm{N}=1,09 \times 10^{-5} \times\left(\frac{1}{\varepsilon_{\mathrm{t} \mathrm{adm}}}\right)^{3,512}
$$

- Deformação vertical específica de compressão no topo do subleito - $\varepsilon_{v}\left(\times 10^{-4}\right)$ SHELL (DORMON \& METCALF)

$$
\mathrm{N}=6,069 \times 10^{-10} \times\left(\frac{1}{\varepsilon_{\mathrm{v} \text { adm }}}\right)^{4,762}
$$

As solicitações atuantes, determinados através dos ELSYM 5 para a estrutura proposta foram comparadas com as admissíveis, demonstrando que a estrutura proposta satisfaz as condições de tráfego e suporte do subleito. Os valores são apresentados na Tabela 5.3. 
Tabela 5.3 - Solicitações atuantes e admissíveis para N 2,5×10

\begin{tabular}{c|c|c}
\hline Tipo de Solicitação & Atuante & Admissível \\
\hline Deflexão máxima da estrutura $-\mathrm{D}_{0}\left(\times 10^{-2} \mathrm{~mm}\right)$ & 48,36 & 88,13 \\
\hline $\begin{array}{c}\text { Deformação especifica horizontal de tração na fibra } \\
\text { inferior do revestimento }-\varepsilon_{\mathrm{t}}\left(\times 10^{-4}\right)\end{array}$ & 2,28 & 3,02 \\
\hline $\begin{array}{c}\text { Deformação especifica vertical no topo do subleito - } \\
\varepsilon_{\mathrm{v}}\left(\times 10^{-4}\right)\end{array}$ & 3,45 & 5,26 \\
\hline
\end{tabular}

\subsection{Estrutura proposta para o trecho experimental}

Com o intuito de pesquisa, foram propostas estruturas alternativas ao projeto, apresentadas na Tabela 5.4 .

Tabela 5.4 - Estruturas propostas para o trecho experimental

\begin{tabular}{|c|c|c|c|c|c|c|}
\hline Camada & $\begin{array}{l}\text { Projeto } \\
\text { original }\end{array}$ & $\begin{array}{c}\text { Espessura } \\
\text { (cm) }\end{array}$ & \multicolumn{3}{|c|}{ Proposta Trecho Experimental } & $\begin{array}{c}\text { Espessura } \\
\text { (cm) }\end{array}$ \\
\hline Revestimento & CBUQ & 4,0 & \multicolumn{3}{|c|}{ TSD com AMP } & 2,5 \\
\hline Base & $\begin{array}{l}\text { Solo-brita } \\
(40 \times 60)\end{array}$ & 15,0 & $\begin{array}{l}\text { Solo-Brita } \\
(40 \times 60)\end{array}$ & $\begin{array}{l}\text { Solo-Brita- } \\
\text { Cimento } \\
(40 \times 60+4 \%)\end{array}$ & $\begin{array}{c}\text { Solo- } \\
\text { cimento } 5 \%\end{array}$ & 15,0 \\
\hline $\begin{array}{l}\text { Reforço do } \\
\text { Subleito }\end{array}$ & $\begin{array}{c}\text { Solo Jazida } \\
\text { E.I }\end{array}$ & $2 \times 15,0$ & $\begin{array}{c}\text { Solo Jazida } \\
\text { E.I }\end{array}$ & $\begin{array}{l}\text { Solo Jazida } \\
\text { E.I }\end{array}$ & $\begin{array}{c}\text { Solo Jazida } \\
\text { E.I }\end{array}$ & $2 \times 15,0$ \\
\hline Subleito & $\begin{array}{c}\text { Solo Local } \\
\text { E.N }\end{array}$ & - & $\begin{array}{c}\text { Solo Local } \\
\text { E.N }\end{array}$ & $\begin{array}{l}\text { Solo Local } \\
\text { E.N }\end{array}$ & $\begin{array}{c}\text { Solo Local } \\
\text { E.N }\end{array}$ & - \\
\hline
\end{tabular}

As estruturas propostas foram estudadas para aumentar a gama de soluções em materiais de base empregados para pavimentação e também verificar o desempenho destes materiais, sem ser uma forma de comparação direta com o projeto original. 


\section{- Análise mecanicista}

Para o cálculo da vida de fadiga na base de solo-cimento, foi adotada a eq.(5.4), proposta por Ceratti (1991). As variáveis a e b são obtidas de acordo com a classificação MCT do solo analisado, conforme mostrado na Tabela 5.5. Os ensaios foram desenvolvidos com carregamento em flexão alternada por controle de tensão. O valor de resistência à flexão adotado é de 1,05 $\mathrm{MPa}$, verificado pelo mesmo autor para a mistura 2. A Figura 5.3 mostra as curvas de fadiga em função da relação de tensões (RT).

$$
\mathrm{RT}=\mathrm{a}+\mathrm{b} \log N_{f}
$$

Onde: $\quad$ RT = relação entre a tensão atuante e a tensão de ruptura na flexão a e $b=$ coeficientes em função do tipo de solo, conforme Tabela 5.5 $\mathrm{N}_{\mathrm{F}}=$ número de vida de fadiga

Tabela 5.5 - Coeficientes da curva de fadiga em amostras de solo-cimento (CERATTI, 1991)

\begin{tabular}{c|c|c|c|c|c|c}
\hline \multirow{2}{*}{ Mistura } & \multirow{2}{*}{$\begin{array}{c}\text { Cimento } \\
(\%)\end{array}$} & \multicolumn{2}{|c|}{ Classificação } & \multicolumn{3}{|c}{ Coeficientes } \\
\cline { 3 - 7 } & MCT & HRB & $\mathbf{a}$ & $\mathbf{b}$ & $\mathbf{R}^{\mathbf{2}}$ \\
\hline 1 & 6 & NA & A-1-b & 1,2563 & $-0,14920$ & 0,87 \\
\hline $\mathbf{2}$ & $\mathbf{6}$ & LA & A-2-4 & $\mathbf{0 , 8 9 8 6}$ & $-\mathbf{0 , 0 3 9 3 0}$ & $\mathbf{0 , 7 6}$ \\
\hline 3 & 12 & LG' $^{\prime}$ & A-7-5 & 0,6401 & $-0,00822$ & 0,89 \\
\hline 4 & 10 & NA' & A-6 & 1,0346 & $-0,05056$ & 0,92 \\
\hline 5 & 8 & LA' $^{\prime}$ & A-2-6 & 0,9476 & $-0,02500$ & 0,74 \\
\hline 6 & 8 & NA' & A-2-6 & 0,6759 & $-0,01030$ & 0,17 \\
\hline
\end{tabular}




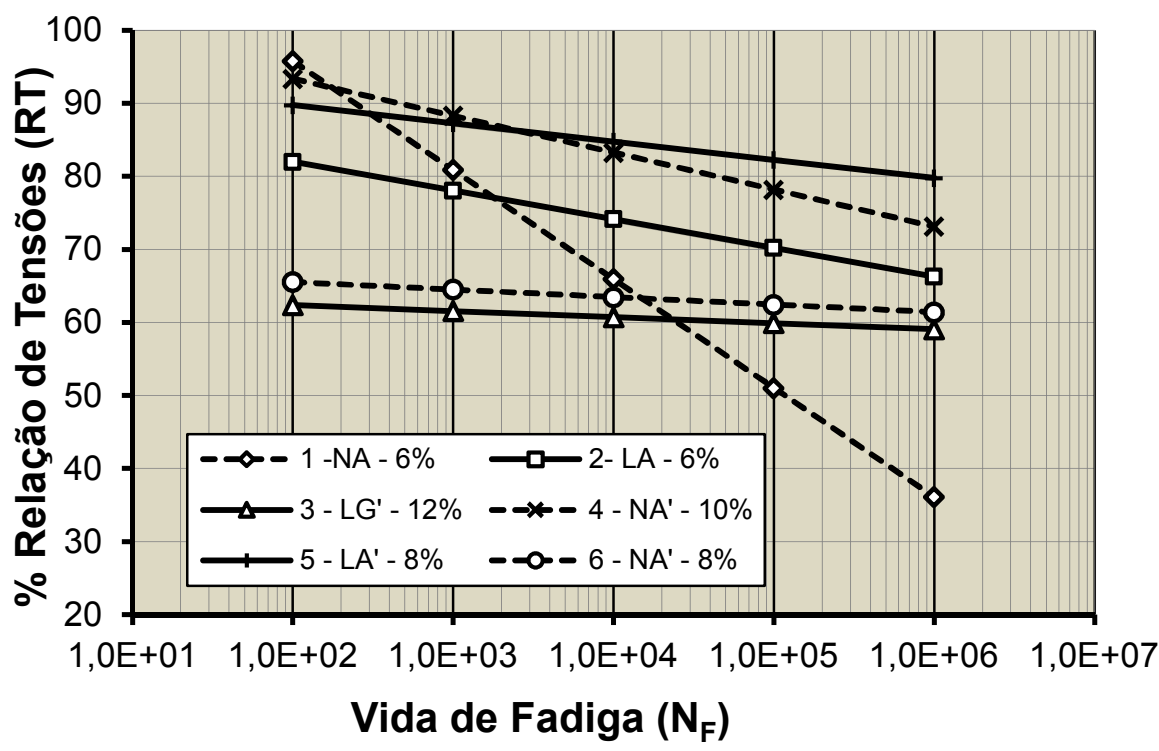

Figura 5.3 - Curvas de fadiga para misturas de solo-cimento (CERATTI, 1991)

Os valores de módulos de resiliência, coeficientes de Poisson $(\mu)$ e espessuras adotadas para a estrutura do trecho experimental são apresentados na Tabela 5.6. Os valores modulares e seus respectivos coeficientes de Poisson para os materiais adotados estão de acordo com os valores sugeridos na IP-DE-P00/001 e ASTM D5858/2008.

Tabela 5.6 - Valores de MR, Poisson e espessura para a estrutura do trecho experimental

\begin{tabular}{c|c|c|c|c}
\hline Camada & Material & $\begin{array}{c}\text { MR } \\
\left(\mathbf{k g f} / \mathbf{c m}^{\mathbf{2}}\right)\end{array}$ & Poisson & $\begin{array}{c}\text { Espessura } \\
\mathbf{( c m )}\end{array}$ \\
\hline Revestimento & TSD AMP & - & - & 2,0 \\
\hline Base & Solo-cimento & 50.000 & 0,25 & 15,0 \\
\hline Reforço & Solo E.I & 1.500 & 0,40 & 30,0 \\
\hline Subleito & Solo E.N & 1.350 & 0,45 & $\infty$ \\
\hline
\end{tabular}

As solicitações atuantes foram comparadas com as admissíveis, demonstrando que a estrutura proposta satisfaz as condições de suporte do subleito, mas não atende em termos de vida de fadiga para a base de solo-cimento. Na análise mecanicista, a camada de TSD com AMP não foi considerada como estrutural, sendo considerada apenas com aspecto funcional ligado a aderência e camada dissipadora de trincas proveniente da base cimentada. Os valores são apresentados na Tabela 5.7. 
Tabela 5.7 - Solicitações teóricas atuantes e admissíveis nas bases da estrutura proposta do trecho experimental para $\mathrm{N} 2,5 \times 10^{6}$

\begin{tabular}{l|c|c}
\hline \multicolumn{1}{c|}{ Tipo de Esforço } & Atuante & Admissível \\
\hline $\begin{array}{l}\text { Deflexão máxima no topo do revestimento }-\mathrm{D}_{0} \\
\left(\times 10^{-2} \mathrm{~mm}\right)\end{array}$ & 30,77 & $88,13^{*}$ \\
$\begin{array}{l}\text { Relação entre tensões (RT) } \\
\text { Deformação Específica vertical no topo do } \\
\text { subleito }-\varepsilon_{\mathrm{v}}\left(\times 10^{-4}\right)\end{array}$ & 0,95 & 0,65 \\
\hline
\end{tabular}

valores apresentados na Tabela 5.3

\subsection{Construção do trecho experimental}

A construção do trecho experimental ocorreu no mês de julho de 2009. Todas as etapas construtivas foram acompanhadas para fornecer informações sobre o comportamento futuro da estrutura. Após a realização da construção de cada camada, foram levantados os dados deflectométricos com viga Benkelman. Os detalhes construtivos, controle tecnológico e o aspecto final do trecho experimental são apresentados a seguir.

\subsubsection{Levantamento deflectométrico}

Com o intuito de avaliar a capacidade de suporte da estrada, uma vez que a mesma já tinha seu leito consolidado pelo tráfego, foram realizadas medidas de deflexão através de Viga Benkelman antes das operações de corte, aterro e escarificação do subleito, conforme apresentado na Figura 5.4. 


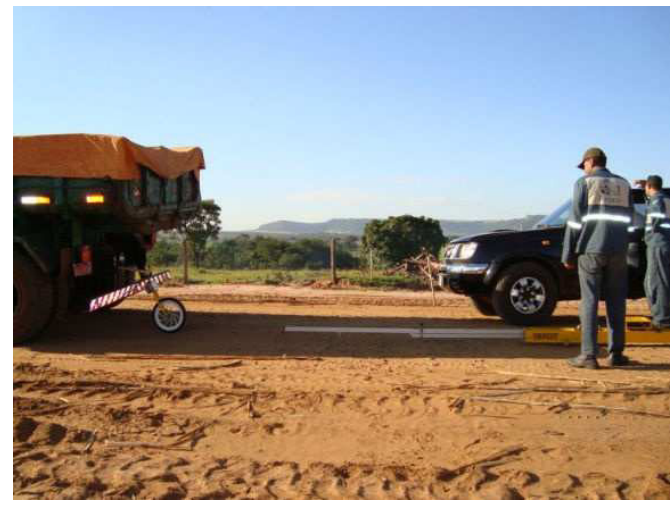

(a)

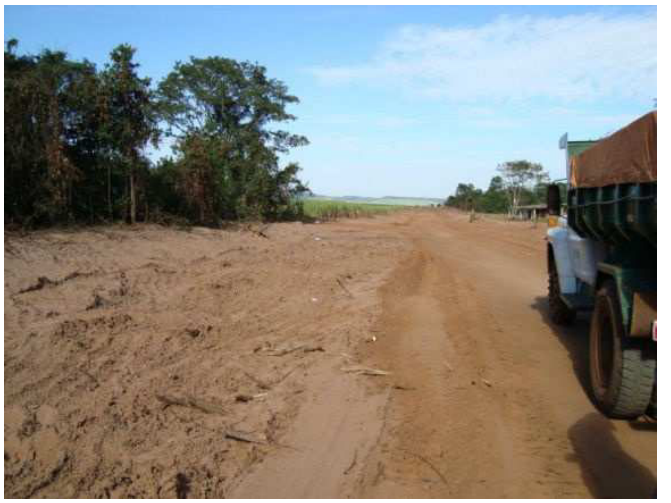

(b)

Figura 5.4 - Levantamentos iniciais: a) ensaio de viga Benkelman em andamento e (b) vista geral do trecho experimental

A deflexão média encontrada na ocasião foi de $27,9 \times 10^{-2} \mathrm{~mm}$ com um coeficiente de variação de $14,7 \%$. Os levantamentos foram executados na segunda quinzena de maio em 2009. A precipitação pluviométrica verificada para este mês em questão foi baixa, característica do período de estiagem, conforme mostrado na Figura 5.5. Como a estrada não possuía na ocasião dispositivos de drenagem profunda, tinha uma suscetibilidade a perda de suporte do subleito devido a saturação em períodos chuvosos. Os dados da estação meteorológica são os mesmos apresentados na Tabela 3.4. 


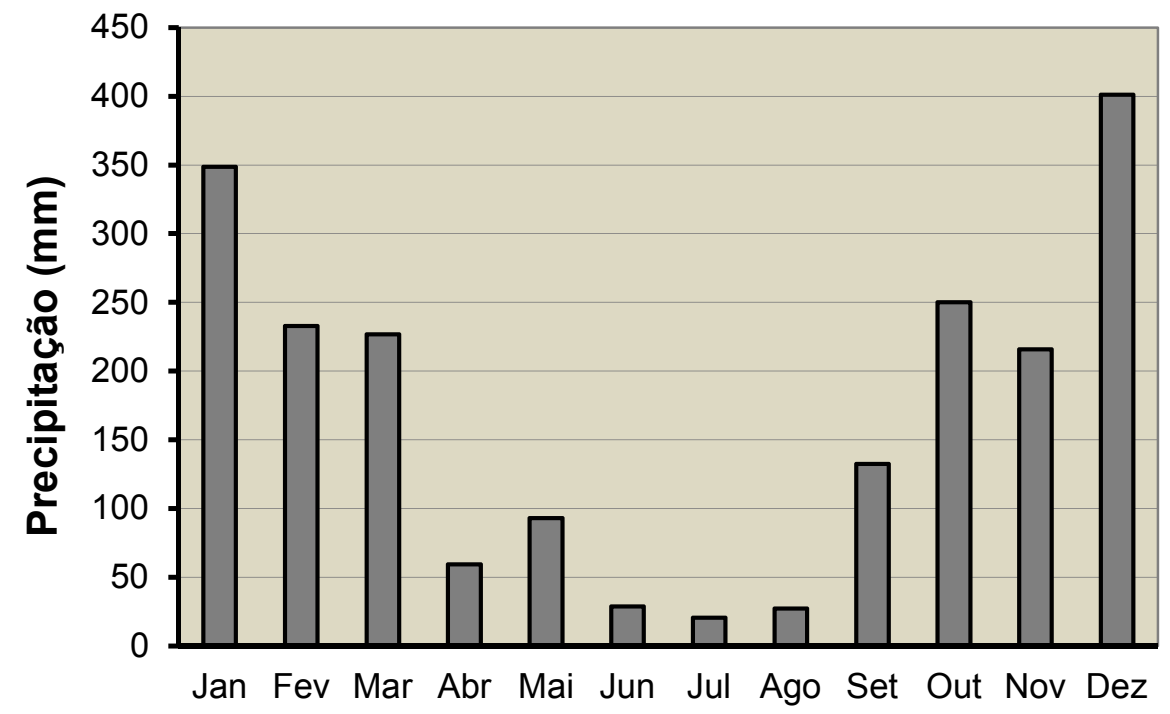

Figura 5.5 - Precipitação mensal acumulada para o ano de 2009. Fonte: BDMET - INMET 2010

\subsubsection{Usina de solo-cimento}

Por solicitação do LTP-EPUSP, foi realizada pela empreiteira e em comum acordo com o DER-SP, a instalação de um silo adicional na usina de solo para incorporação de cimento. A usina consiste basicamente de três silos para a alimentação materiais granulares, um silo menor para incorporação de aditivos pulverizados transportados por meio de rosca sem fim, um reservatório de água e para homogeneização do material, um misturador tipo "pugmill". O transporte dos materiais foi realizado por correia transportadora, conforme apresentado na Figura 5.6. A calibração da quantidade de cimento foi realizada por meio da pesagem dos materiais em segmentos da correia transportadora. As aberturas de saída dos silos foram ajustadas de acordo com a rotação do sistema de esteiras, até que a quantidade dos materiais estivesse de acordo com o proposto. 


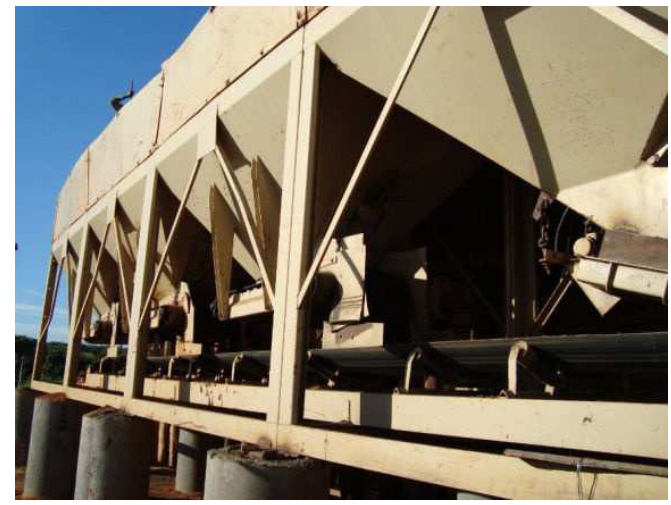

(a)

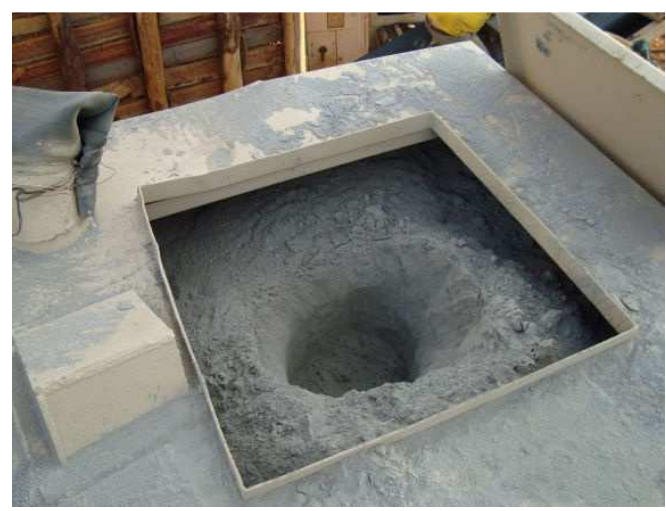

(c)

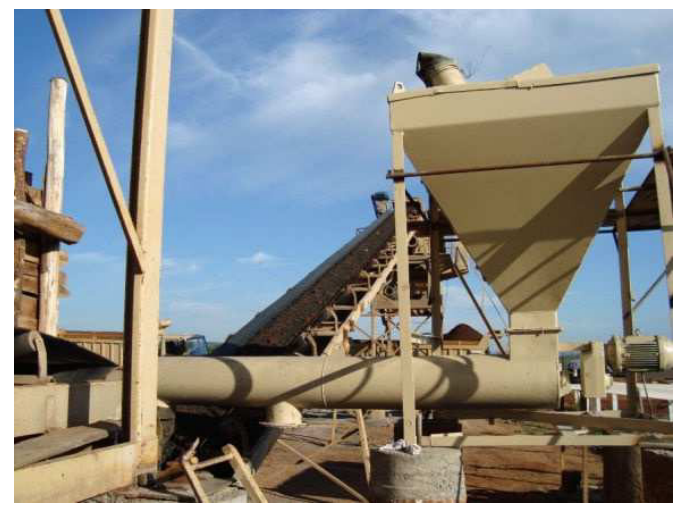

(b)

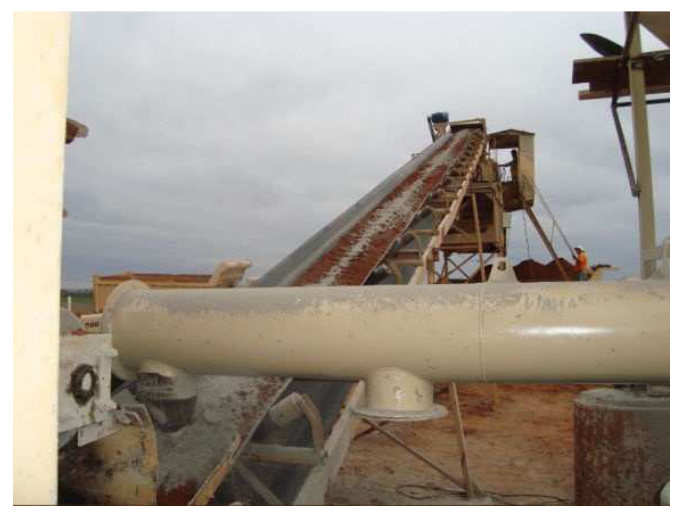

(d)

Figura 5.6 - Usina de solos: (a) silos de materiais granulares, (b) silo para incorporação de aditivos pulverizados, (c) detalhe do silo com cimento e (d) produção de solo-cimento

\subsubsection{Execução da base de solo-cimento}

Após a execução da segunda camada de reforço, foram iniciadas as operações para construção da base de solo-cimento, de acordo com a ET-DE-P00/004. As etapas construtivas são apresentadas na Figura 5.7. 


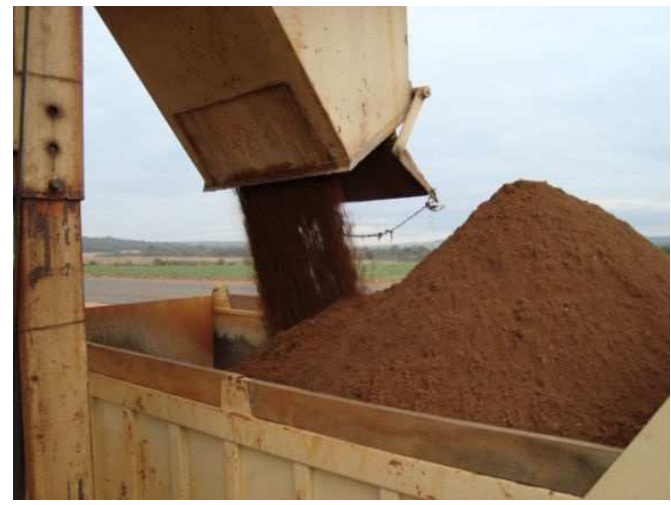

(a)

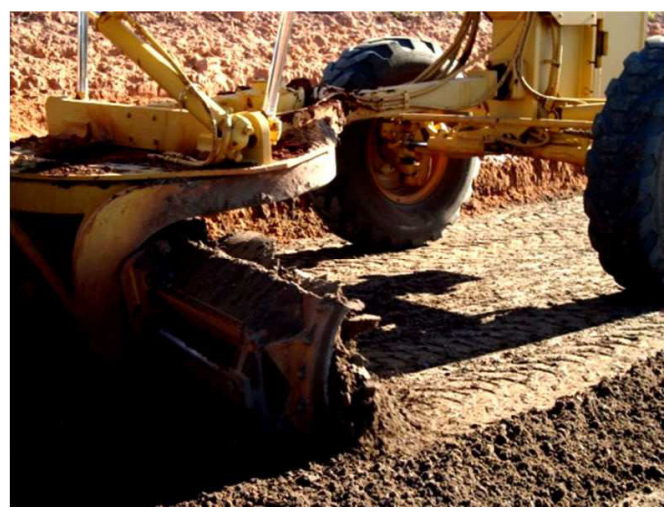

(c)

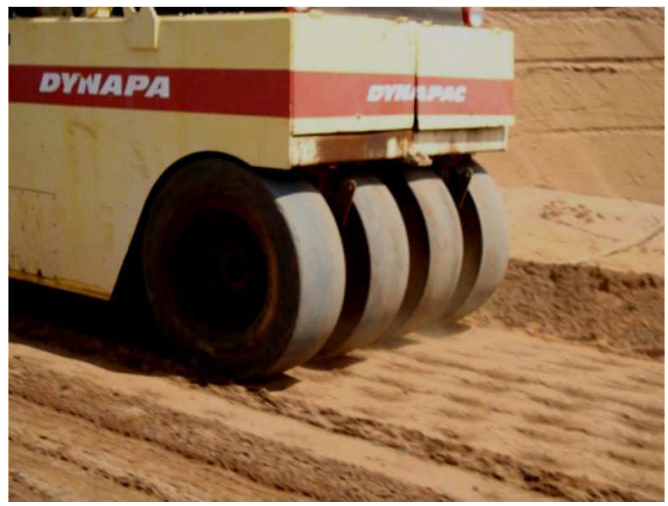

(e)

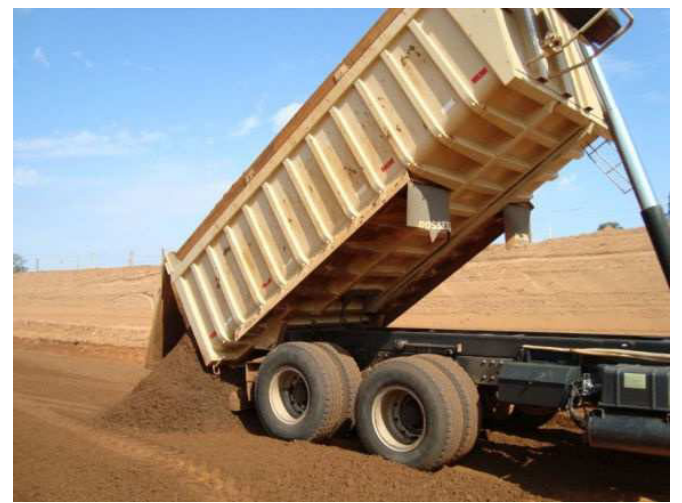

(b)

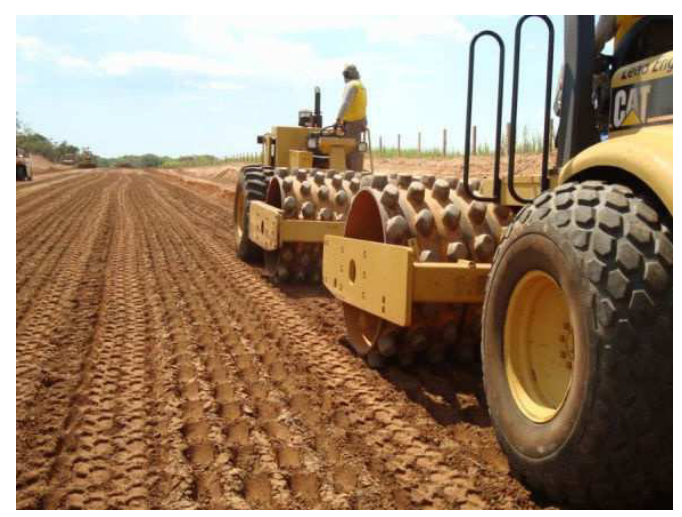

(d)

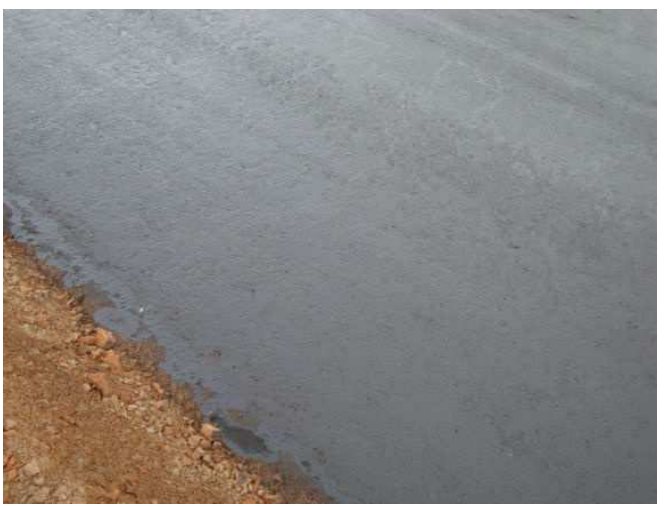

(f)

Figura 5.7 - Execução da base de solo-cimento (a) carregamento, (b) lançamento, (c) espalhamento, (d) compactação com rolo pé de carneiro, (e) acabamento com rolo de pneu liso e (f) imprimação 
Ao término da compactação, foi realizada uma imprimação impermeabilizante com emulsão asfáltica. A base foi mantida sem tráfego por 14 dias após a construção, o tráfego local foi desviado para o acostamento, conforme mostrado na Figura 5.8.

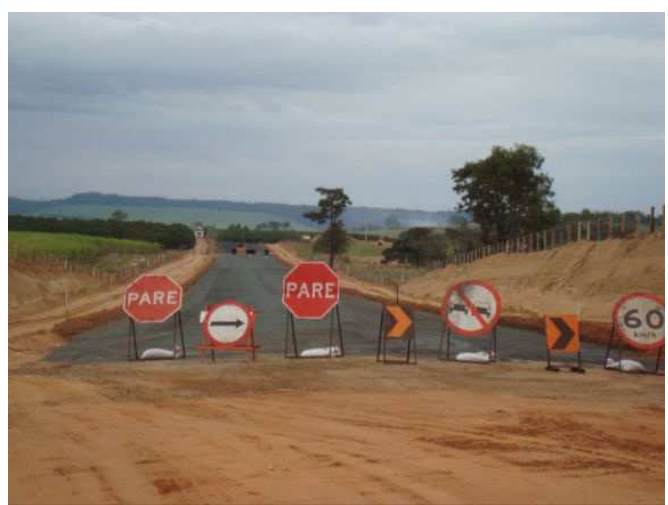

(a)

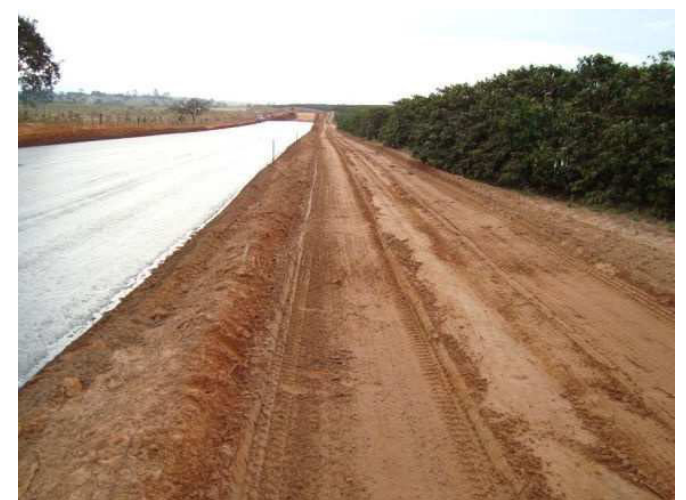

(b)

Figura 5.8 - Cura da base de solo-cimento: (a) sinalização de desvio de tráfego e (b) acostamento para desvio de tráfego

\subsubsection{Controle tecnológico}

De acordo com a finalização do número de passadas do rolo, foi efetuada a verificação do peso específico aparente seco e umidade de compactação. O peso específico in situ da amostra foi determinado pelo método do frasco de areia (DNER ME 092/94) e o teor de umidade determinado pelo método expedito do fogareiro (DER-SP M 28-61). A Figura 5.9 apresenta um detalhe do ensaio para determinação do peso específico aparente seco in situ. 


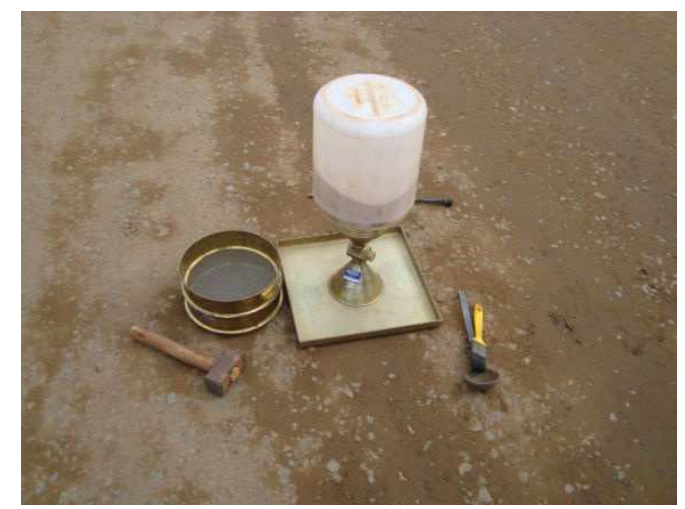

Figura 5.9 - Controle tecnológico pelo método do frasco de areia

Na Figura 5.10, é apresentado um comparativo dos dados de RCS obtidos para as amostras de laboratório e de obra. Os valores obtidos para as amostras de obra são uma média de três amostras. Na Tabela 5.8 é mostrado um comparativo com os dados de umidade de compactação, peso específico aparente seco máximo, grau de compactação e fator água/cimento para os ensaios realizados em laboratório com os ensaios de amostras de obra.

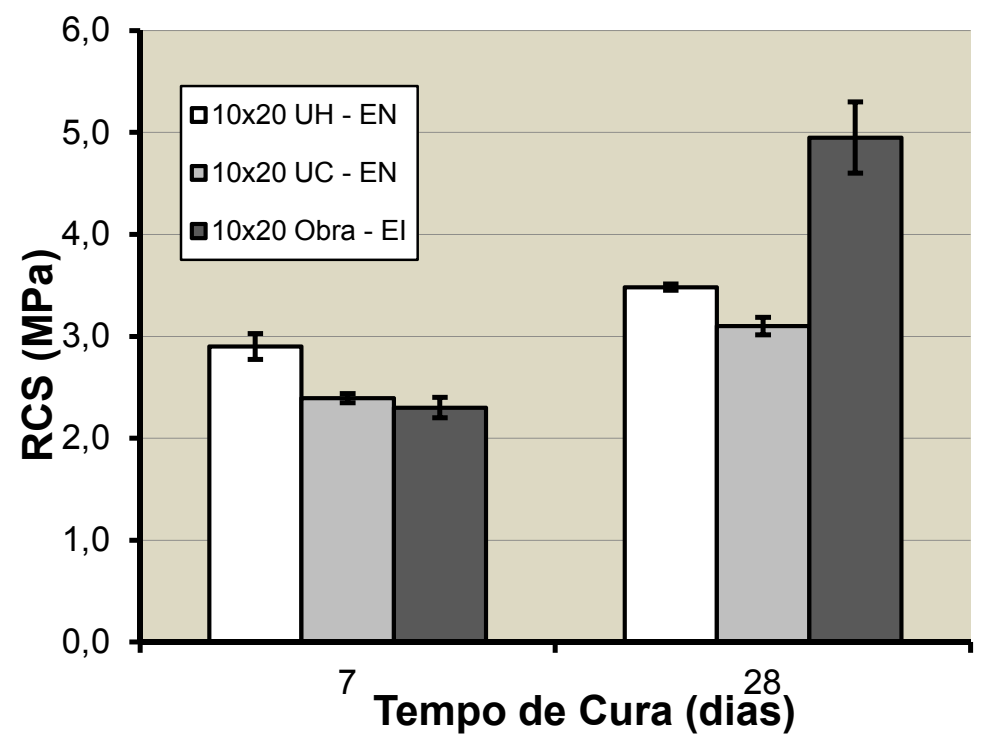

Figura 5.10 - Resumo da RCS aos 7 e 28 dias para amostras de solo-cimento de laboratório e obra 
Tabela 5.8 - Resumo dos dados de compactação obtidos para amostras de obra e de laboratório

\begin{tabular}{|c|c|c|c|c|c|c|c|c|c|}
\hline Condição & $\begin{array}{c}\text { Energia de } \\
\text { Compactação }\end{array}$ & $\begin{array}{l}\text { Idade } \\
\text { (dias) }\end{array}$ & $\begin{array}{l}\text { RCS } \\
\text { (Mpa) }\end{array}$ & $\begin{array}{l}\text { C.V } \\
\text { (\%) }\end{array}$ & YS max & ys & $\begin{array}{c}h \\
(\%)\end{array}$ & $\begin{array}{l}\text { GC } \\
(\%)\end{array}$ & $\begin{array}{l}\text { Fator } \\
\text { a/c }\end{array}$ \\
\hline \multirow{2}{*}{ Lab. - UH } & \multirow{2}{*}{ Normal } & 7 & 2,90 & 4,4 & \multirow{2}{*}{1,95} & 1,968 & 10,4 & 100,8 & 2,1 \\
\hline & & 28 & 3,48 & 0,8 & & 1,956 & 10,9 & 100,2 & 2,2 \\
\hline \multirow{2}{*}{ Lab. -UC } & \multirow{2}{*}{ Normal } & 7 & 2,29 & 8,2 & \multirow{2}{*}{1,99} & 2,005 & 10,8 & 100,8 & 2,2 \\
\hline & & 28 & 3,05 & 3,5 & & 1,991 & 10,9 & 100,1 & 2,2 \\
\hline \multirow{2}{*}{ Obra - UC } & \multirow{2}{*}{ Intermediária } & 7 & 2,30 & 4,3 & \multirow{2}{*}{2,02} & 2,020 & 9,7 & 100,0 & 1,9 \\
\hline & & 28 & 4,95 & 7,1 & & 2,030 & 9,3 & 100,5 & 1,9 \\
\hline
\end{tabular}

Na execução do trecho experimental, foi empregado cimento CPII-Z32, assim como uma variação na energia de compactação. Como uma referência comparativa, os valores da caracterização físico-quimica e mecânica são apresentados na Tabela 5.9. O incremento de resistência é apresentado na Figura 5.11. Os dados das duas amostras de cimento foram gentilmente fornecidos pelo fabricante.

Tabela 5.9 - Caracterização física, química e mecânica do cimento empregado na pesquisa e do cimento empregado no trecho experimental

\begin{tabular}{|c|c|c|c|c|}
\hline Características & Caracterização & $\begin{array}{c}\text { Referência } \\
\text { Normativa } \\
\text { NBR }\end{array}$ & $\begin{array}{c}\text { CPII-E32 } \\
\text { Laboratório }\end{array}$ & $\begin{array}{c}\text { CPII-Z32 } \\
\text { Obra }\end{array}$ \\
\hline \multirow{5}{*}{ Químicas } & Perda ao Fogo (\%) & $<6,5$ & 5,08 & 4,24 \\
\hline & $\mathrm{MgO}$ & $<6,5$ & 5,23 & 6,15 \\
\hline & $\mathrm{SO}_{3}$ & $<4,0$ & 1,91 & 2,91 \\
\hline & $\mathrm{CO}_{2}$ & $<5,0$ & 4,16 & 4,40 \\
\hline & $\mathrm{RI}$ & $<2,5$ & 1,74 & 7,97 \\
\hline \multirow{4}{*}{ Físicas } & Finura \# 0,075mm (\%) & $<12,0$ & 1,3 & 0,87 \\
\hline & Blaine $\left(\mathrm{cm}^{2} / \mathrm{g}\right)$ & $>2.600$ & 4.092 & 3.901 \\
\hline & Tempo de pega-inicio (h) & $>1$ & $3: 26$ & $3: 41$ \\
\hline & Tempo de pega - fim (h) & $<10$ & 4:46 & $4: 34$ \\
\hline \multirow{3}{*}{ Mecânicas } & RCS 3 dias cura (MPa) & $>10$ & 20,0 & 26,16 \\
\hline & RCS 7 dias cura (MPa) & $>20$ & 26,9 & 32,20 \\
\hline & RCS 28 dias cura (MPa) & $>32$ & 36,0 & 39,1 \\
\hline
\end{tabular}




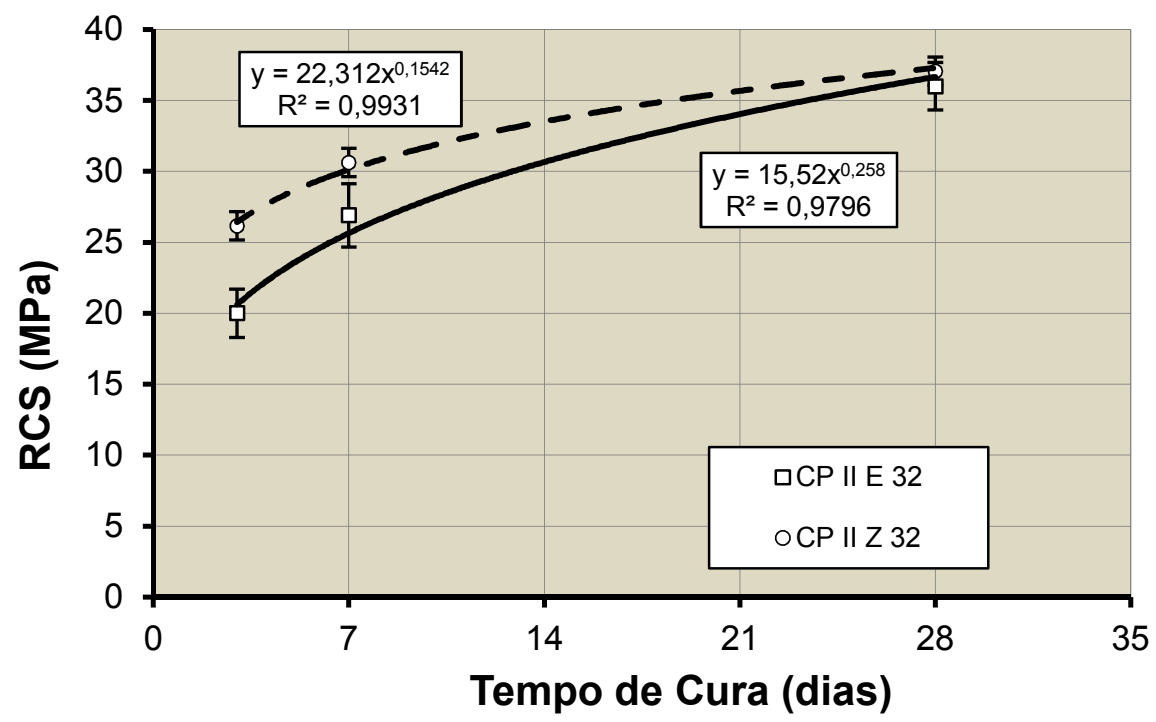

Figura 5.11 - Comparativo do incremento da RCS para o cimento empregado na pesquisa e do cimento empregado no trecho experimental

A caracterização física e química não apresentaram diferenças significantes. Os ensaios de RCS mostram um maior incremento nas primeiras idades para o CPIIZ32.

\subsubsection{Execução do TSD}

Após duas semanas da construção da base, foi realizada a construção do revestimento em TSD com emulsão modificada por polímero. As etapas construtivas são apresentadas na Figura 5.12. 


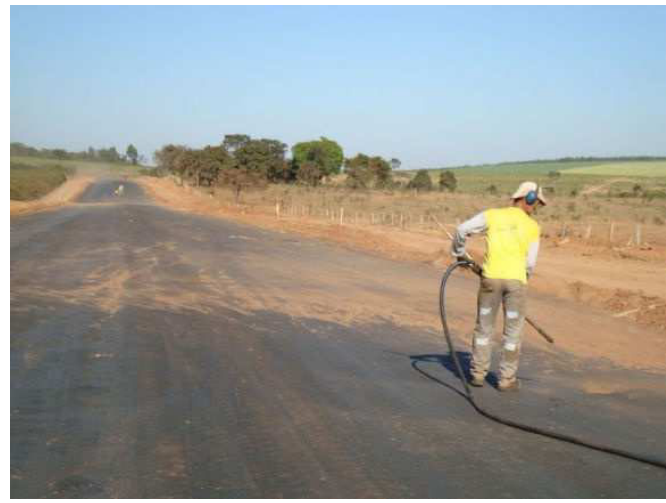

(a)

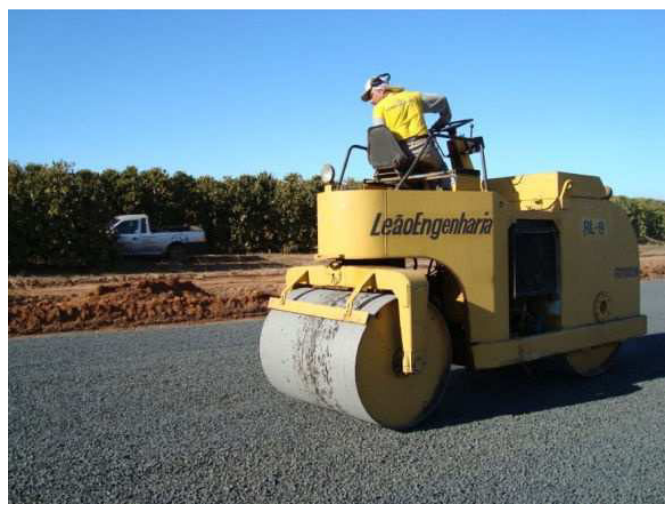

(c)

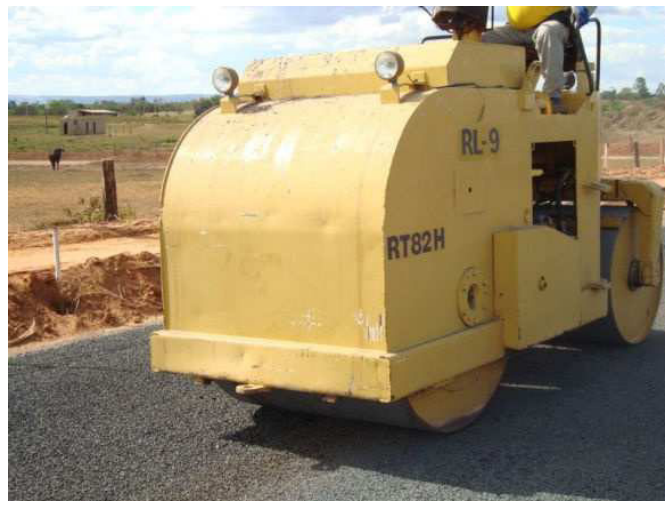

(e)

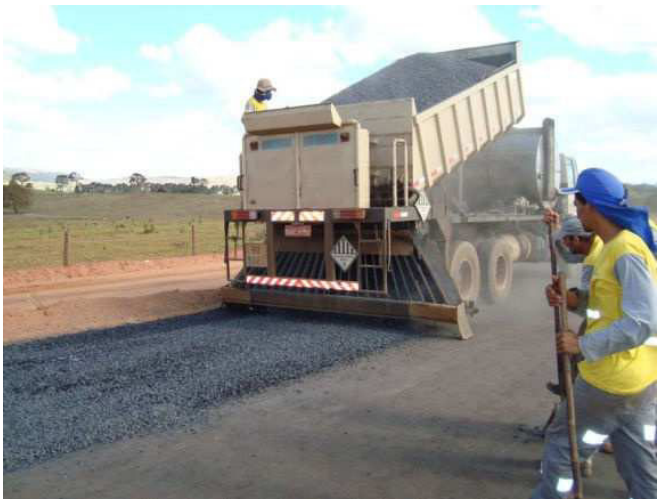

(b)

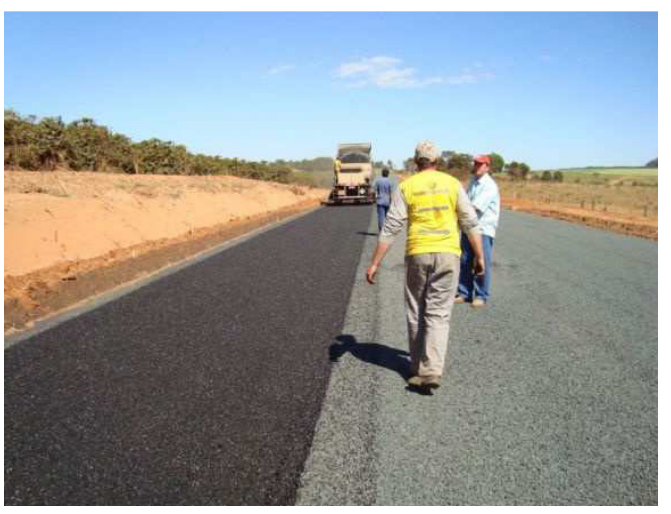

(d)

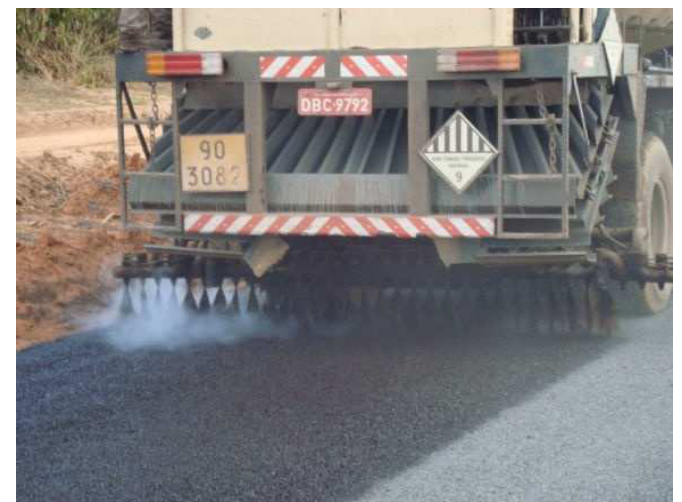

(f)

Figura 5.12 - Execução de TSD com AMP: (a) limpeza da base de SC, (b) aplicação da $1^{\text {a }}$ camada, (c) compactação, (d) aplicação da $2^{\mathrm{a}}$ camada, (e) compactação e (f) aplicação de banho diluído "Fog" 
O tratamento foi dosado com duas distribuições granulométricas, uma de maior diâmetro aplicado na $1^{\text {a }}$ camada e uma $2^{\mathrm{a}}$ camada com brita de pequeno diâmetro, conforme apresentado na Figura 5.13.

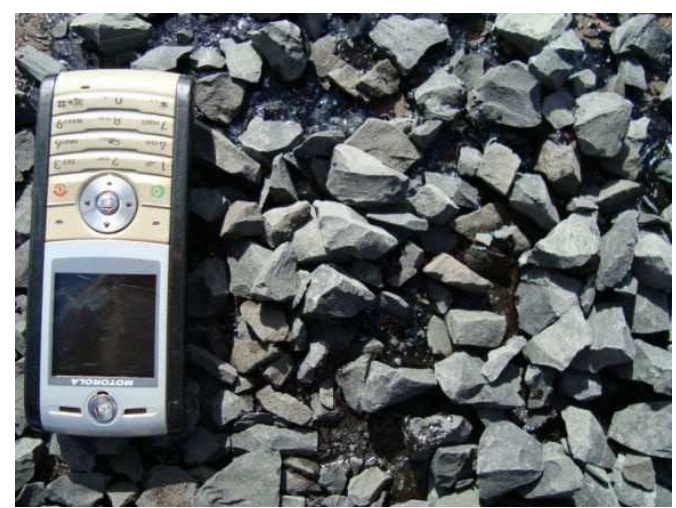

(a)

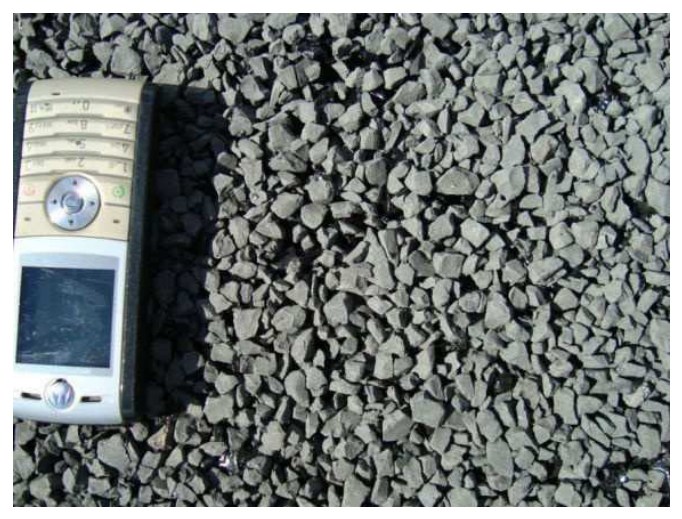

(b)

Figura 5.13 - Distribuições granulométricas do TSD com AMP: (a) $1^{\mathrm{a}}$ camada e (b) $2^{\mathrm{a}}$ camada

\subsection{Monitoramento pós-execução}

Como parte do monitoramento do trecho experimental, foram realizadas avaliações estruturais das bacias de deflexão com viga Benkelman e FWD, com alternância entre as trilhas externas e internas. Uma vista geral dos ensaio com viga Benkelman é apresentada na Figura 5.14. 


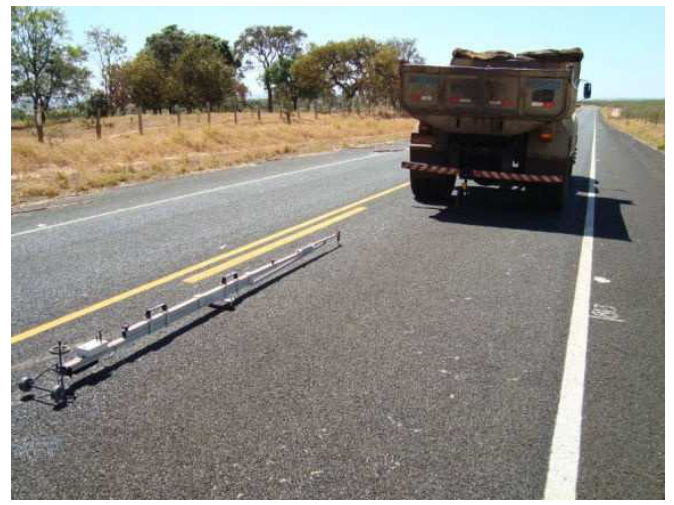

Figura 5.14 - Levantamento estrutural no TSD com viga Benkelman

Os levantamentos estruturais coletados com viga Benkelman, realizados em diferentes datas são apresentados na Figura 5.15.

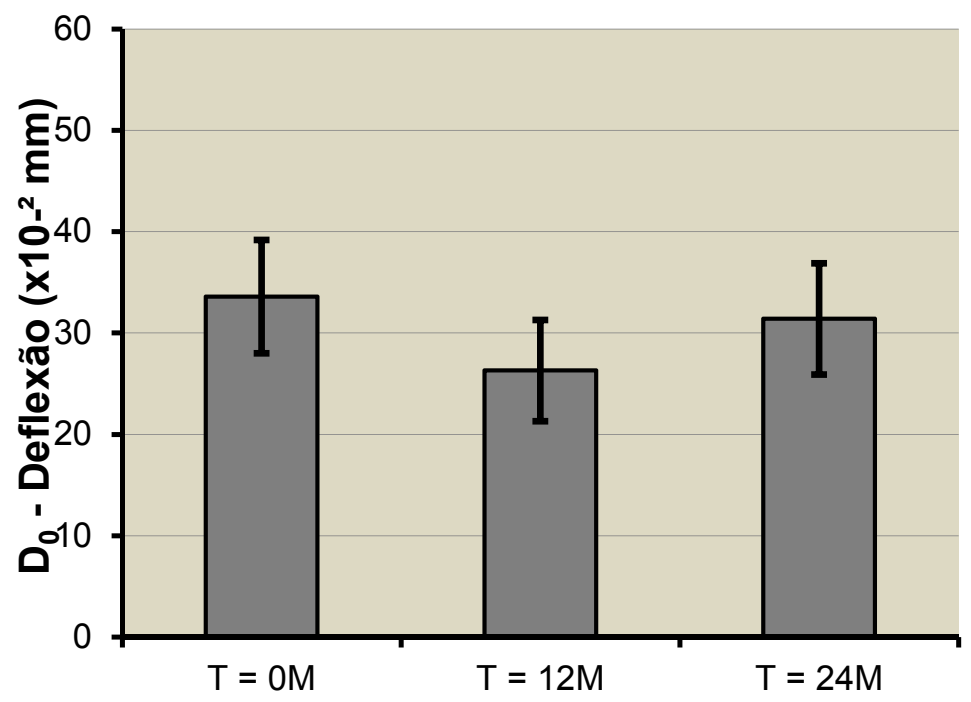

(a) 


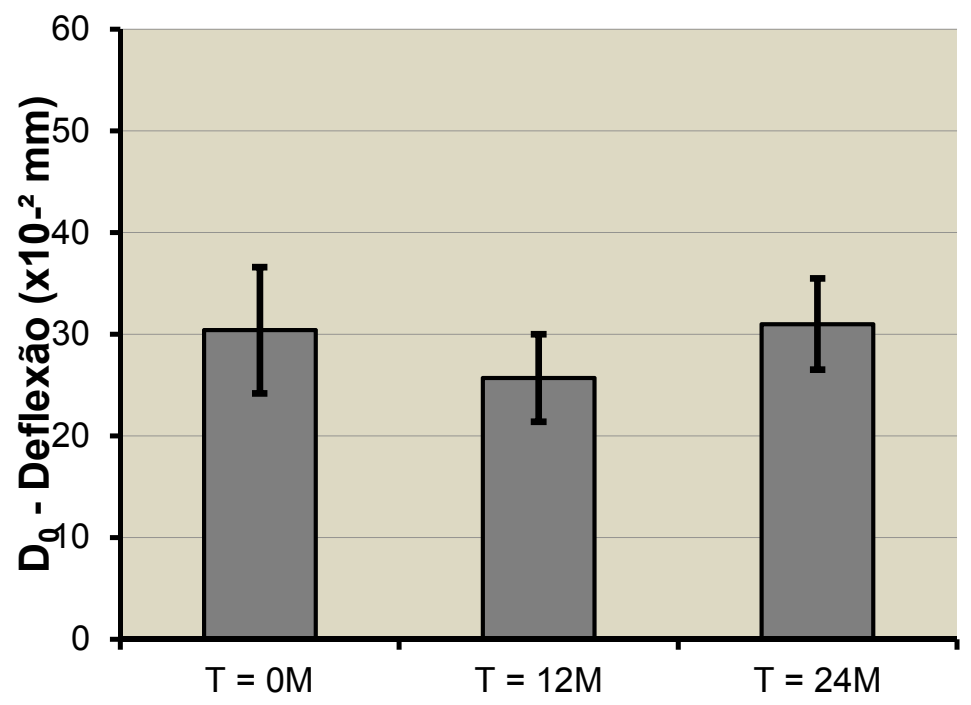

(b)

Figura $5.15-D_{0}$ - Média e desvio padrão na base do trecho experimental para três levantamentos: a) sentido Batatais e (b) sentido Patrocínio Paulista

Os levantamentos defectométricos foram realizados em diferentes datas, além de ter sido adotado dois equipamentos (Viga Benkelman e FWD). Para evidenciar um possível efeito climático sobre a determinação dos mesmos foram estudados os índices pluvimétricos, apresentados na figura 5.16. Ressalta-se que todos os levantamentos foram realizados em períodos de estiagem, caracterizando épocas de baixa saturação do subleito, o que pode ter colaborado para os baixos valores de deflexão. Por serem mais representativos para retroanálise, os dados de FWD são apresentatos em maior detalhe no ítem 5.5.1. 


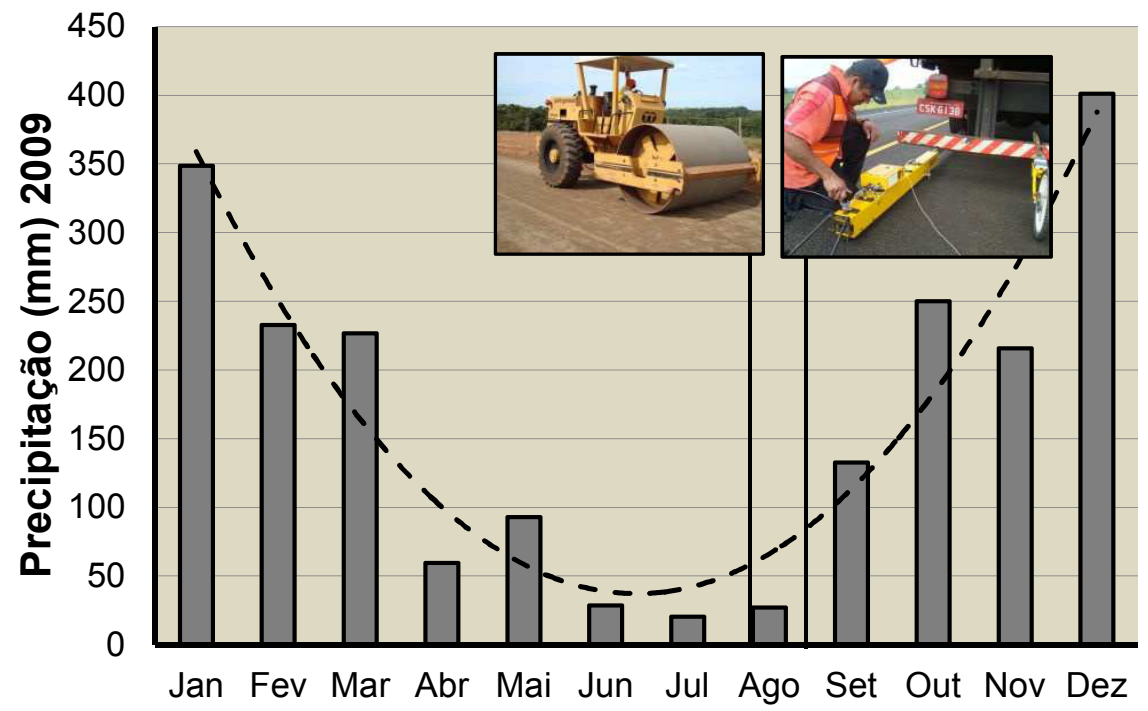

(a)

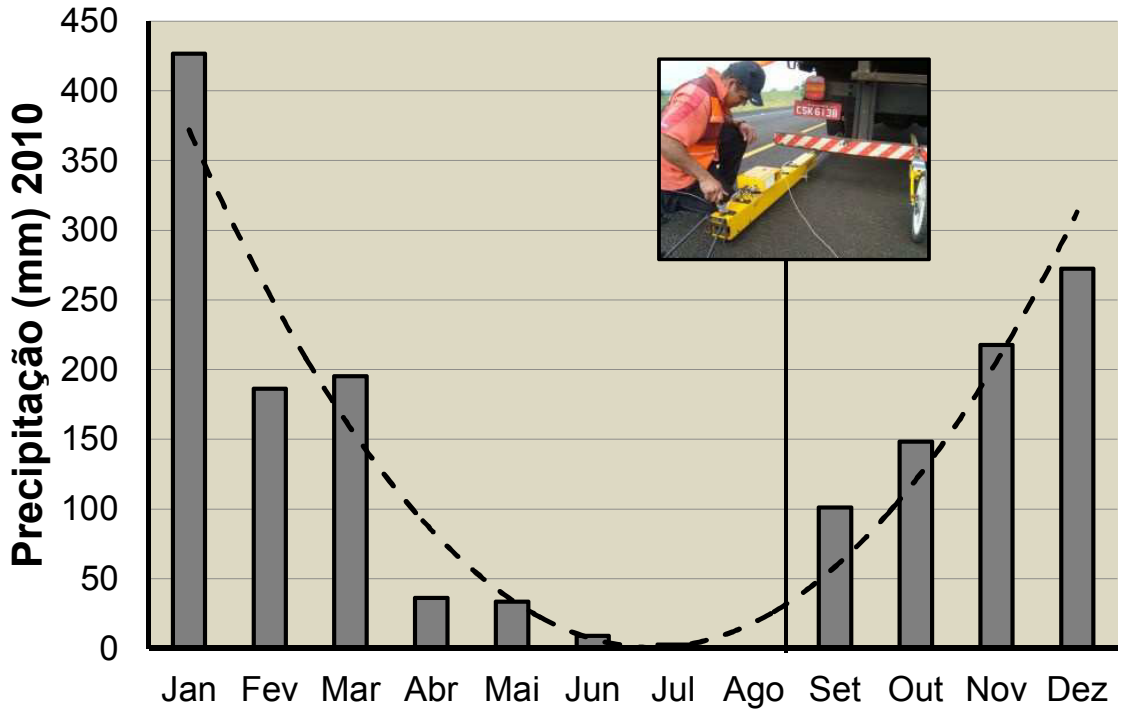

(b) 


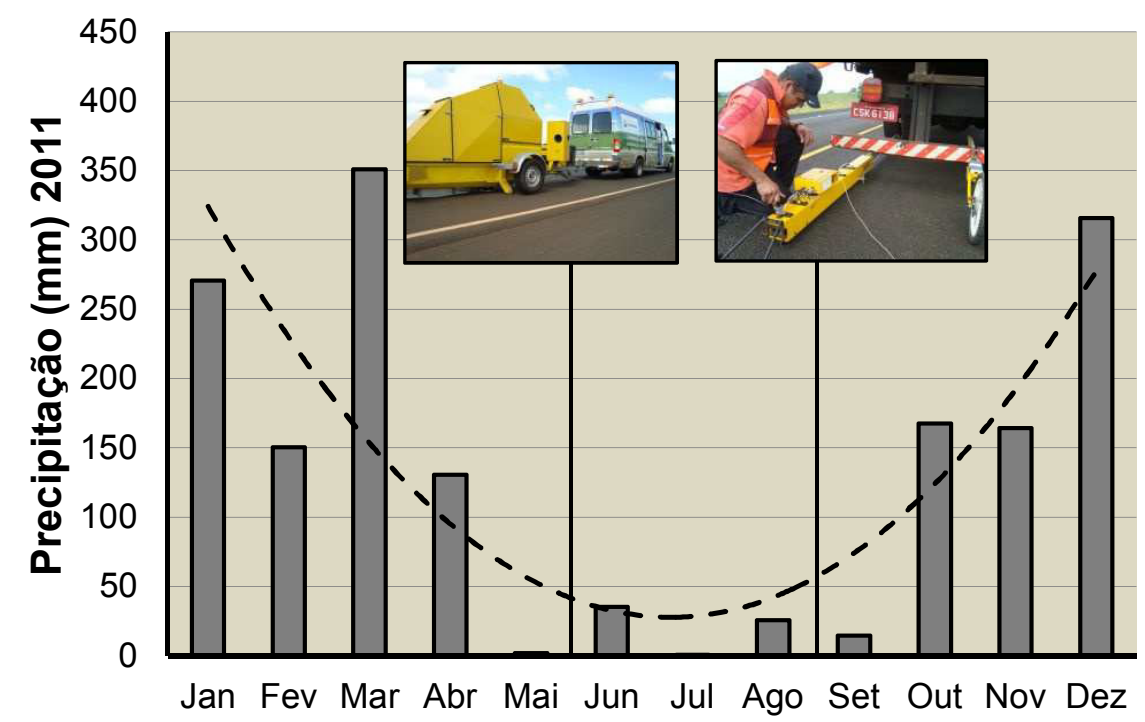

(c)

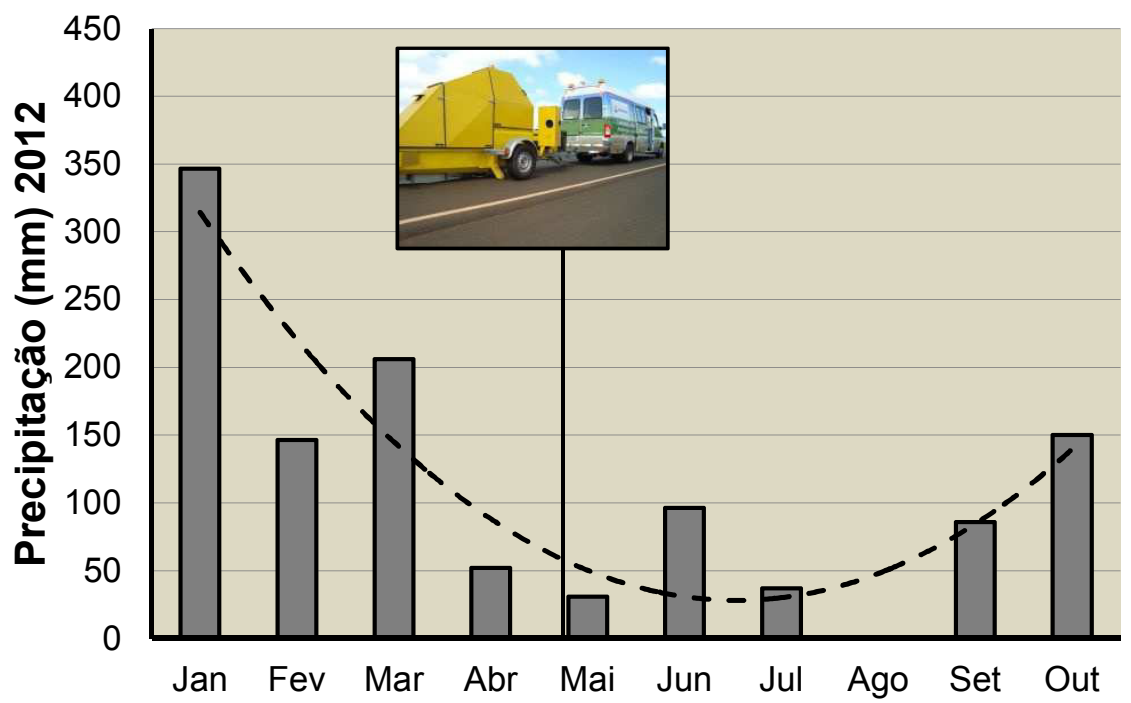

(d)

Figura 5.16 - Precipitação mensal acumulada para os anos: (a) 2009, (b) 2010, (c) 2011 e (d) 2012. Fonte: BDMET - INMET 2012 


\subsubsection{Retroanálise das bacias de FWD}

Previamente à realização da retroanálise, faz-se necessário a determinação de segmentos homogêneos. O mesmo foi determinado a partir da verificação de outliers pelo método de Grubbs (1969), citado no item 3.5. Para simplificar o processo de retroanálise, é determinada uma bacia característica para o segmento estudado com o objetivo de não tornar a retroanálise exaustiva, dado o grande número de bacias levantadas. Os valores das bacias determinadas em cada segmento homogêneo são mostrados na Figura 5.17 e na Tabela 5.10.

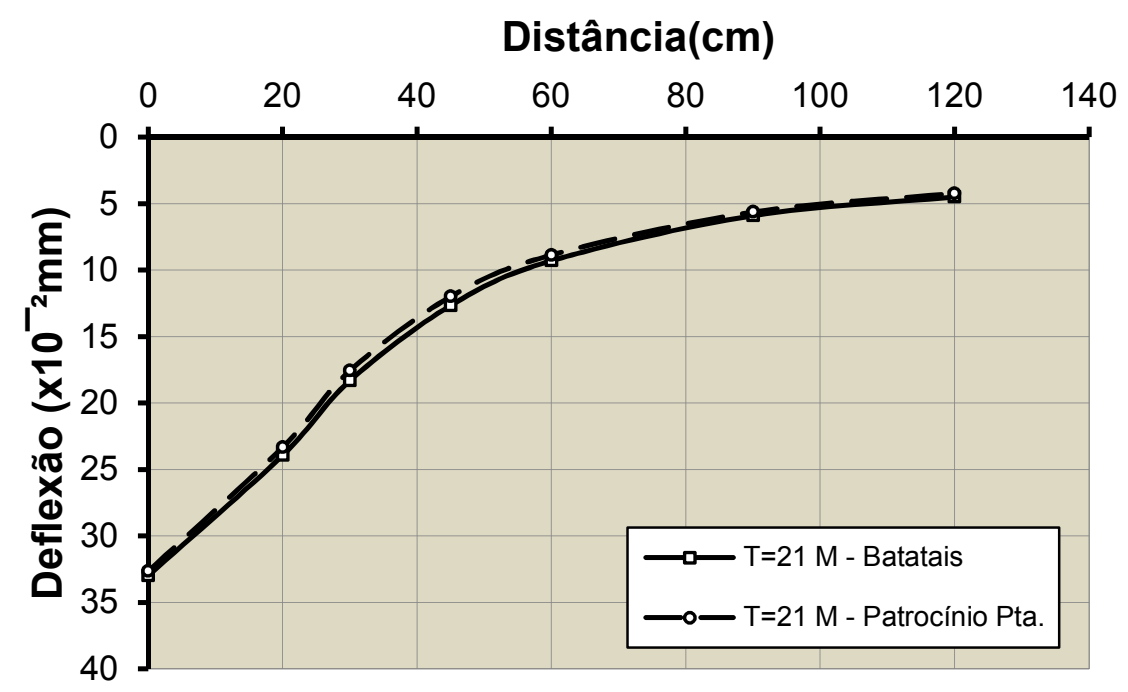

(a) 


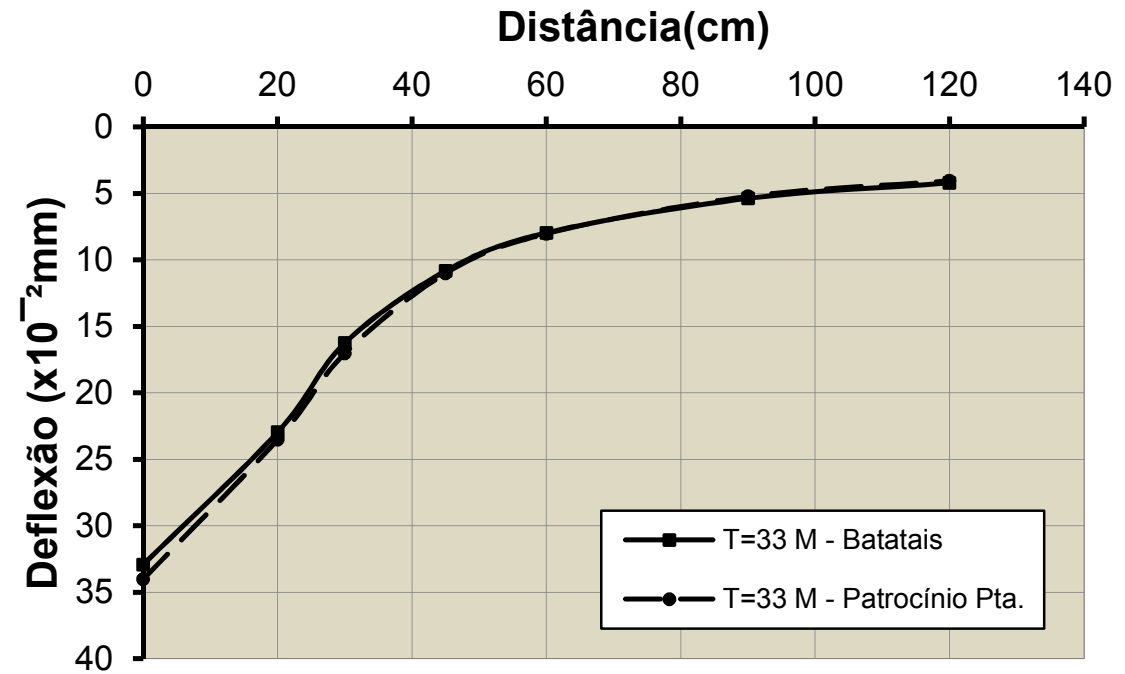

(b)

Figura 5.17 - Bacia média de deflexões do trecho experimental: (a) $\mathrm{T}=21 \mathrm{M}$ e (b) $\mathrm{T}=33 \mathrm{M}$

Tabela 5.10 - Resumo das deflexões obtidas nos dois sentidos e em dois tempos

\begin{tabular}{|c|c|c|c|c|c|c|c|c|c|}
\hline \multirow{2}{*}{$\begin{array}{l}\text { Tempo } \\
\text { (meses) }\end{array}$} & \multirow{2}{*}{ Sentido } & \multirow{2}{*}{ Parâmetro } & \multicolumn{7}{|c|}{ Deflexões (x10 $\left.{ }^{-2} \mathrm{~mm}\right)$} \\
\hline & & & $d_{0}$ & $d_{20}$ & $d_{30}$ & $d_{45}$ & $d_{60}$ & $d_{90}$ & $d_{120}$ \\
\hline \multirow{2}{*}{21} & \multirow{2}{*}{ Batatais } & Média & 33,0 & 23,9 & 18,3 & 12,7 & 9,3 & 5,9 & 4,5 \\
\hline & & Desvio & 3,9 & 2,2 & 1,2 & 0,5 & 0,4 & 0,2 & 0,2 \\
\hline \multirow{2}{*}{21} & \multirow{2}{*}{$\begin{array}{c}\text { Patrocínio } \\
\text { Pta. }\end{array}$} & Média & 32,7 & 23,3 & 17,6 & 12,0 & 8,9 & 5,6 & 4,2 \\
\hline & & Desvio & 3,9 & 1,6 & 0,9 & 0,7 & 0,5 & 0,3 & 0,2 \\
\hline \multirow{2}{*}{33} & \multirow{2}{*}{ Batatais } & Média & 32,9 & 23,0 & 16,3 & 10,8 & 8,0 & 5,4 & 4,2 \\
\hline & & Desvio & 3,4 & 1,6 & 1,0 & 0,5 & 0,4 & 0,3 & 0,2 \\
\hline \multirow{2}{*}{33} & \multirow{2}{*}{$\begin{array}{c}\text { Patrocínio } \\
\text { Pta. }\end{array}$} & Média & 34,0 & 23,5 & 17,0 & 11,0 & 8,0 & 5,2 & 4,0 \\
\hline & & Desvio & 3,6 & 1,8 & 1,1 & 0,8 & 0,5 & 0,3 & 0,3 \\
\hline
\end{tabular}




\subsubsection{Determinação do erro máximo admissível}

A precisão dos valores retroanalisados foi verificada através da aplicação da ferramenta RMSE - Root Mean Square Percent Error, sugerido na ASTM D5858/2008. São calculados os erros para cada distância entre a deflexão calculada e a medida, a seguir, é feita a extração da somatória dos erros, conforme apresentado na eq.(5.6). O valor de RMSE recomendado pela referida norma deve situar entre $1 \%$ e $2 \%$.

$$
\mathrm{RMSE}=100 \times \sqrt{1 / n \sum_{i=1}^{n}\left[\frac{\left(\text { (calc }_{i}-\text { Dmed }_{i}\right)}{\text { Dmed }_{i}}\right]^{2}}
$$

Onde: $\quad$ RMSE $=$ Root mean square percent error

$\mathrm{D}_{\text {calc }}=$ Deflexão calculada no ponto $i$

$\mathrm{D}_{\text {med }}=$ Deflexão medida no ponto $i$

\subsubsection{Valores retroanalisados}

Para verificar a amplitude das possíveis combinações modulares, foram retroanalisadas a bacia média, a bacia média $+1 \sigma$ e a bacia média $-1 \sigma$, conforme mostrado na Tabela 5.11. Os valores obtidos de RMSE para as análises com ELSYM 5 e BAKFAA das bacias médias encontram-se no ANEXO C. O levantamento $\mathrm{T}=21 \mathrm{M}$ obteve menores valores de RMSE quando comparados com o levantamento $\mathrm{T}=33 \mathrm{M}$. As Figuras 5.18 a 5.21 mostram as bacias médias, as demais

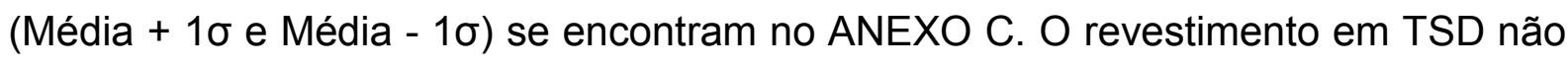
foi considerado como camada estrutural, portanto não há um valor de MR atribuído para o mesmo. 
Tabela 5.11 - Resumo da retroanálise do trecho experimental

\begin{tabular}{|c|c|c|c|c|c|c|c|c|}
\hline \multirow{2}{*}{ Tempo } & \multirow{2}{*}{ Sentido } & \multirow{2}{*}{ Camada } & \multirow{2}{*}{ Material } & \multicolumn{3}{|c|}{ MR (MPa) } & \multirow{2}{*}{ Poisson } & \multirow{2}{*}{$h(\mathrm{~cm})$} \\
\hline & & & & Média & Media + 1 $\sigma$ & Media - 1 $\sigma$ & & \\
\hline \multirow{5}{*}{$T=21 M$} & \multirow{5}{*}{ Batatais } & Revest. & TSD & - & - & - & - & 2,0 \\
\hline & & Base & SC & 1.978 & 1.601 & 2.804 & 0,30 & 15,0 \\
\hline & & Reforço & Solo E.I & 245 & 219 & 245 & 0,40 & 15,0 \\
\hline & & Reforço & Solo E.I & 235 & 209 & 240 & 0,40 & 15,0 \\
\hline & & Subleito & Solo E.N & 209 & 199 & 219 & 0,45 & $\infty$ \\
\hline \multirow{5}{*}{$T=21 M$} & \multirow{5}{*}{$\begin{array}{c}\text { Patrocínio } \\
\text { Pta. }\end{array}$} & Revest. & TSD & & & & - & 2,0 \\
\hline & & Base & SC & 1.876 & 1.489 & 2.549 & 0,30 & 15,0 \\
\hline & & Reforço & Solo E.I & 245 & 245 & 245 & 0,40 & 15,0 \\
\hline & & Reforço & Solo E.I & 240 & 219 & 240 & 0,40 & 15,0 \\
\hline & & Subleito & Solo E.N & 219 & 209 & 235 & 0,45 & $\infty$ \\
\hline \multirow{5}{*}{$\mathrm{T}=33 \mathrm{M}$} & \multirow{5}{*}{ Batatais } & Revest. & TSD & & & & - & 2,0 \\
\hline & & Base & $\mathrm{SC}$ & 1.479 & 1.224 & 1.835 & 0,30 & 15,0 \\
\hline & & Reforço & Solo E.I & 291 & 260 & 291 & 0,40 & 15,0 \\
\hline & & Reforço & Solo E.I & 235 & 250 & 255 & 0,40 & 15,0 \\
\hline & & Subleito & Solo E.N & 229 & 219 & 240 & 0,45 & $\infty$ \\
\hline \multirow{5}{*}{$\mathrm{T}=33 \mathrm{M}$} & \multirow{5}{*}{$\begin{array}{c}\text { Patrocínio } \\
\text { Pta. }\end{array}$} & Revest. & TSD & & & & - & 2,0 \\
\hline & & Base & SC & 1.530 & 1.275 & 1.703 & 0,30 & 15,0 \\
\hline & & Reforço & Solo E.I & 275 & 260 & 280 & 0,40 & 15,0 \\
\hline & & Reforço & Solo E.I & 255 & 229 & 260 & 0,40 & 15,0 \\
\hline & & Subleito & Solo E.N & 224 & 219 & 240 & 0,45 & $\infty$ \\
\hline
\end{tabular}

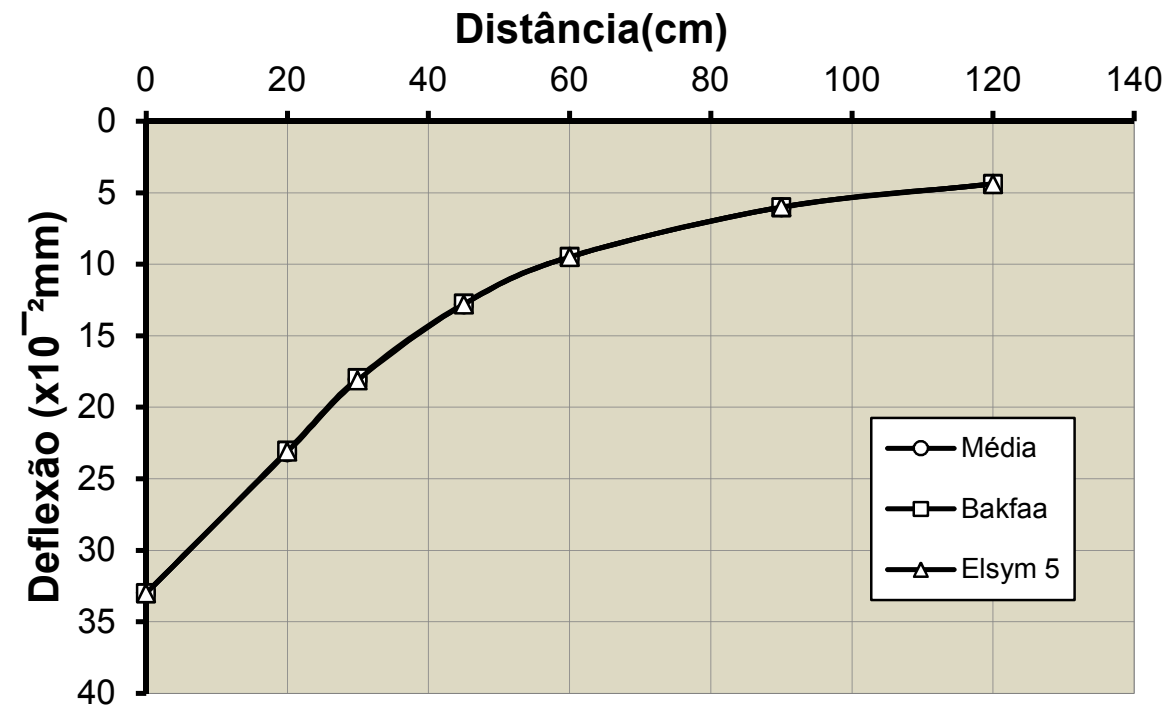

Figura 5.18 - Bacias previstas e retroanalisadas no sentido Batatais $-\mathrm{T}=21 \mathrm{M}$ 


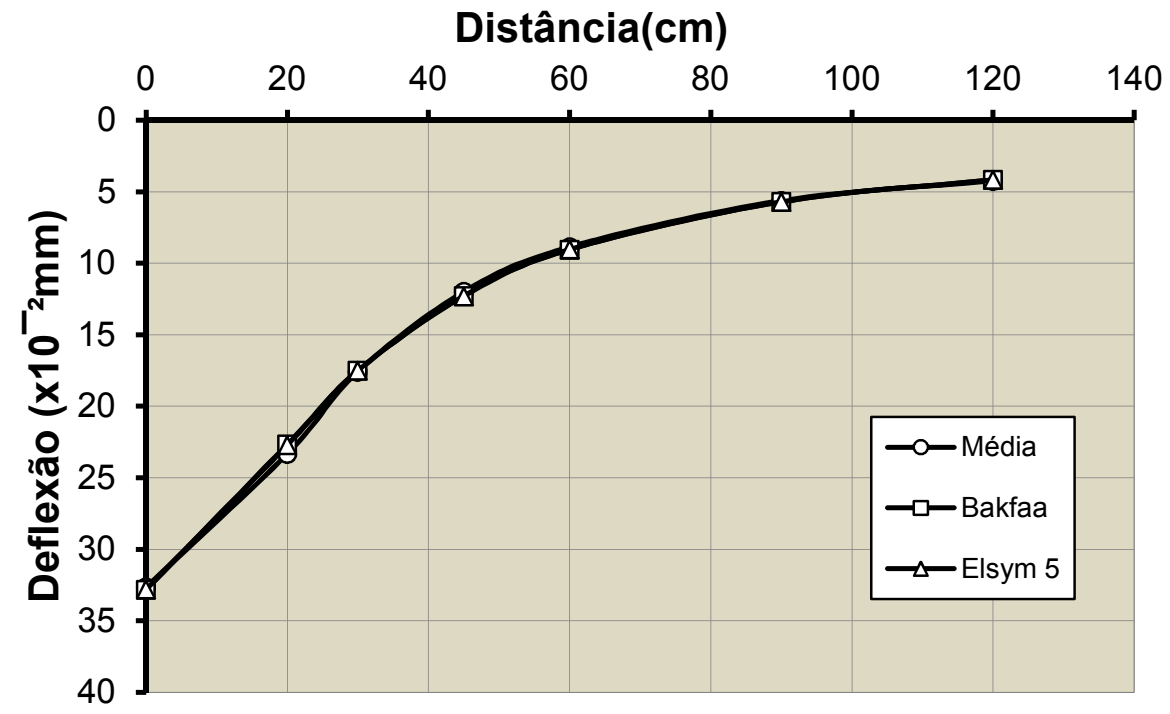

Figura 5.19 - Bacias previstas e retroanalisadas no sentido Patrocínio Paulista $-\mathrm{T}=21 \mathrm{M}$

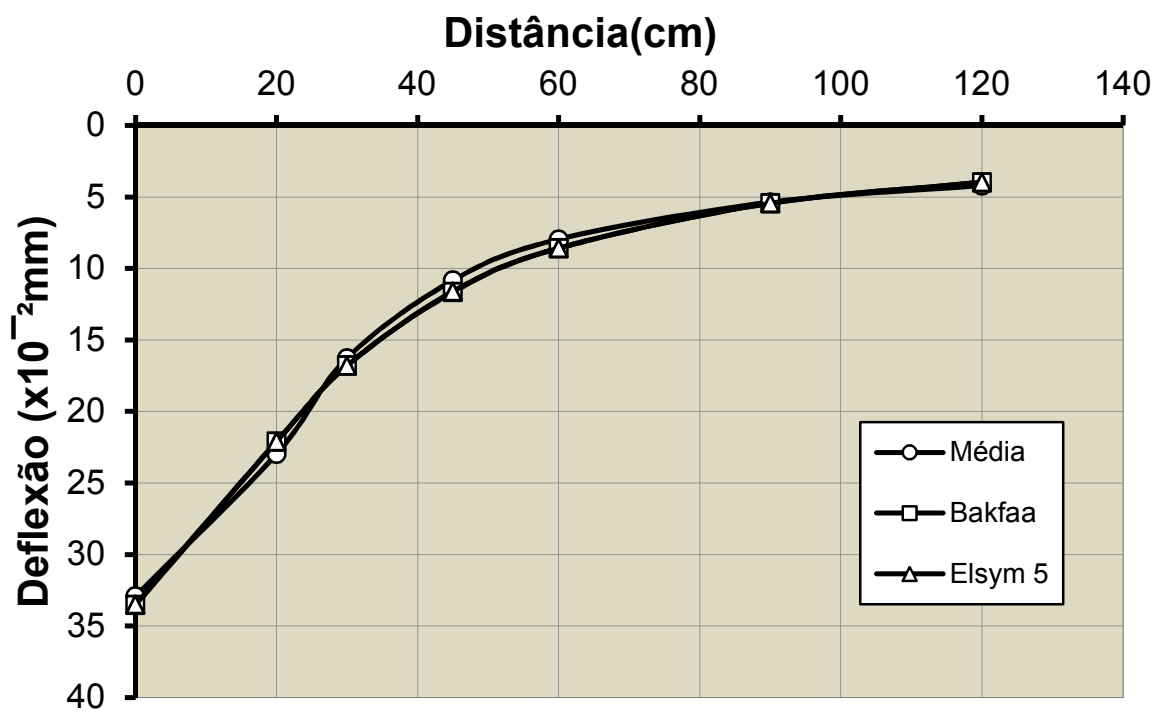

Figura 5.20 - Bacias previstas e retroanalisadas no sentido Batatais $-\mathrm{T}=33 \mathrm{M}$ 


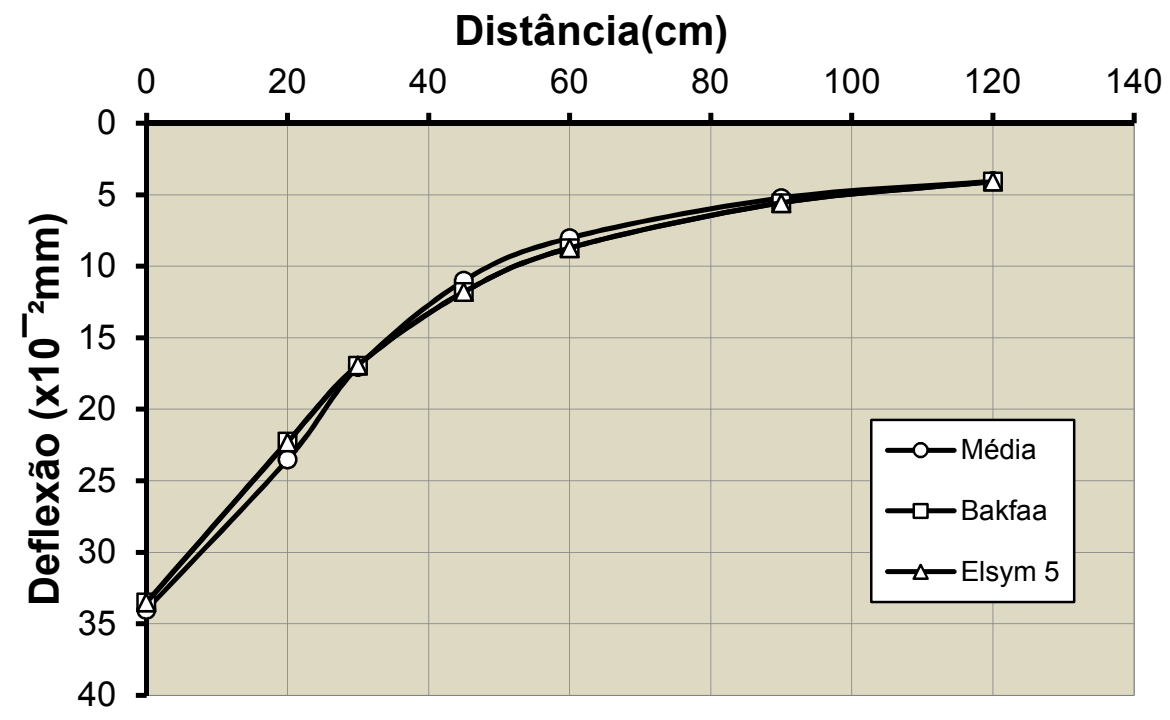

Figura 5.21 - Bacias previstas e retroanalisadas no sentido Patrocínio Paulista $-\mathrm{T}=33 \mathrm{M}$

Houve pouca variação entre os dois sentidos estudados (Batatais e Patrocínio Paulista) nos dois levantamentos ( $\mathrm{T}=21 \mathrm{M}$ e $\mathrm{T}=33 \mathrm{M})$. As deflexões nos primeiros 40 $\mathrm{cm}$ da bacia apresentam-se maiores no segundo levantamento ( $T=33 \mathrm{M})$, mas uma das prováveis causas está associada ao posicionamento do FWD, que no primeiro levantamento foi realizado no eixo da faixa e o segundo nas trilhas de roda, local solicitado pelo tráfego.

Para representar as possíveis variações na espessura da base, foi realizado um estudo paramétrico entre a espessura da camada de base de solo-cimento e o MR que atendesse a bacia de deformadas, conforme apresentado na Figura 5.22. Os valores foram apurados para as deflexões médias de cada segmento e os valores de módulos das camadas subjacentes foram fixados. 


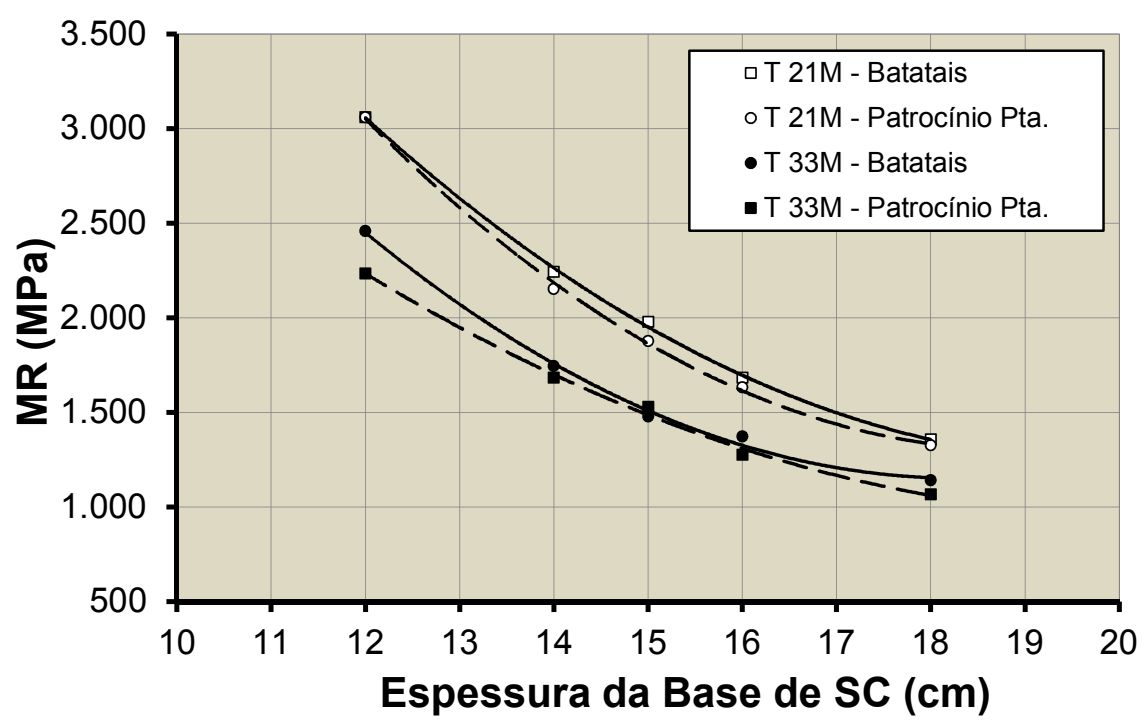

Figura 5.22 - Estudo paramétrico: variação do MR da base de solo-cimento do trecho experimental com a espessura da camada

As variações do MR encontrado no estudo paramétrico seguem o mesmo comportamento verificado na retroanálise. O maior valor de deflexão nos primeiros $40 \mathrm{~cm}$ da bacia deflectométrica no levantamento $\mathrm{T}=33 \mathrm{M}$ afetam diretamente na rigidez da base de solo-cimento. As menores espessuras de base produziram melhores correlações com o valor de RMSE, indicando que a camada de base em solo-cimento do trecho experimental possui menores espessuras. Este comportamento foi verificado para os dois levantamentos ( $T=21$ e $T=33 \mathrm{M})$. Os valores de RMSE são mostrados nas Tabelas do ANEXO C. 


\section{CONSIDERAÇÕES FINAIS}

\subsection{Conclusões}

O presente estudo constou da avaliação de misturas de solo-cimento em laboratório e em campo. Com base nos ensaios e análises realizados, pode-se concluir:

- A umidade inicial de mistura do solo afeta sua densificação, quando comparado o solo moldado na umidade higroscópica (UH) com o solo moldado na umidade de campo (UC). A amostra de solo na condição UC atinge maiores valores de peso específico aparente seco para um mesmo teor de umidade. Como apresentado na Figura 4.3, este fato fica evidenciado pelo grau de saturação atingido, maior nas amostras moldadas a partir da umidade de campo (UC).

- O fator água cimento $(\mathrm{a} / \mathrm{c})$ interfere na resistência final da mistura de solocimento (quanto maior seu valor, menor a resistência adquirida). Porém, sua interpretação deve ser realizada levando em consideração a variação do peso específico aparente seco, visto que este ocorre simultaneamente com a variação do fator a/c e produz alterações na estrutura compactada.

- O aumento no teor de cimento (até $9 \%$ ) levou a um incremento dos valores de resistência à compressão simples em amostras de Proctor. Observou-se um aumento não linear da RCS (após 7 dias de cura) com o aumento do teor de cimento para as duas umidades de misturas avaliadas.

- Os resultados para 3, 7, 14 e 28 dias de cura nos ensaios de MR e RCS apresentam maiores valores para a mistura de solo-cimento na condição UH, processo adotado em dosagens realizadas em laboratório. Os ensaios de RTCD nas misturas de solo-cimento apresentaram uma inversão de resultados para a umidade inicial de mistura, quando comparadas com os resultados de RCS e MR. O efeito do tempo de cura foi evidenciado nos três 
ensaios, aumentando as resistências e a rigidez com o aumento do tempo, independente da umidade inicial de mistura.

- Observou-se dos resultados de contração e retração, que o primeiro predomina na resposta das misturas de solo-cimento, porém não foi observada influência da umidade de mistura (UC versus UH) nos resultados desses ensaios, sendo os valores obtidos baixos para todos os percentuais de cimento avaliados.

- As amostras de solo-cimento apresentaram maiores valores de contração quando comparadas com as amostras de solo, nas duas condições de mistura. Isto decorre devido a uma alteração na plasticiadade do solo, imediatamente após a mistura com cimento.

- Os valores modulares obtidos em laboratório não correspondem aos valores obtidos em campo pela retroanálise. Atribui-se a diferença às seguintes hipóteses: (i) teor de cimento utilizado abaixo do especificado pela dosagem na construção do trecho experimental, (ii) variações na espessura da camada cimentada e (iii) microfissuração, uma vez que esta influencia na resposta do material frente às cargas impostas pelo tráfego.

As conclusões mencionadas limitam-se ao tipo de solo (MCT LA', HRB A-2-4), tipo e teores de cimento empregados nesta pesquisa.

\subsection{Sugestões para pesquisas futuras}

Como sugestões para pesquisas futuras, são destacadas:

- Avaliar o efeito da umidade de mistura para solos com diferentes características pedológicas. 
- Quantificar o efeito da anisotropia no comportamento mecânico de misturas de solo-cimento.

- Verificar o valor de umidade obtida para a máxima resistência a tração/ compressão de misturas de solo-cimento e sua diferença com relação à umidade obtida para o peso específico seco máximo.

- Quantificar o efeito da temperatura na contração e retração para diferentes tipos de solo.

- Verificar a compatibilização entre os resultados de módulo de resiliência retroanalizados com os obtidos através de ensaios de laboratório em corpos de prova extraidos de pista. 


\section{REFERÊNCIAS BIBLIOGRÁFICAS}

AUST STAB. Cement stabilization practice. Technical note, N ${ }^{\circ} 5$. Australian Stabilization of Industry Association. Australian, 2012.

BALBO, J. T. Alguns conceitos diferenciadores dos materiais estabilizados com cimento . $7^{\text {a }}$ Reunião de Pavimentação Urbana, São José dos Campos, SP, 1996.

BALBO, J.T. Pavimentação asfáltica: materiais, projeto e restauração. $1^{\text {a }}$. ed. São Paulo: Oficina de Textos, 2007. 558 p.

BERNUCCI, L. B. Expansão e contração de solos tropicais compactados e suas aplicações às obras viárias. Classificação de solos tropicais com base na contração e expansão. Dissertação de Mestrado - Departamento de Engenharia de Estruturas e Fundações da EPUSP, São Paulo, SP, 1987.

BERNUCCI, L. B.; MOTTA, L. M. G.; CERATTI J.A. P.; SOARES, J. B. Pavimentação asfáltica, formação básica para engenheiros. $1^{\mathrm{a}}$. ed. Rio de Janeiro.PETROBRAS; ABEDA. 2006. 504 p.

BECHARA, M.F.; FURLAN, A.P.; GIGANTE, A.C.; FABBRI, G.T.P. Propriedades mecânicas de misturas de solo-cimento com solo laterítico e solo não laterítico. $\mathbf{2 4}^{\circ}$ Congresso de Pesquisa e Ensino em Transportes - $24^{\circ}$ ANPET, Salvador, BA, 2010.

CERATTI, J.A.P.; MEDINA, J. Estudo de solos melhorados com cimento sob a ação de cargas repetidas. 18 ${ }^{a}$ Reunião Anual de Pavimentação, Vol. 2. Porto Alegre, RS, 1983.

CERATTI, J.A.P. Estudo do comportamento a fadiga de solos estabilizados com cimento para utilização em pavimentos. Tese de Doutorado - Programa de Pós Graduação em Engenharia da Universidade Federal do Rio de Janeiro, RJ, 1991. 
COSTA, O. P. Avaliação da expansão, contração e resistência à compressão simples de barreiras selantes produzidas com solo laterítico estabilizado quimicamente. Dissertação de Mestrado - Faculdade de Engeharia de Ilha Solteira da Universidade Estadual Paulista, SP, 2005.

COSTA, O. P; LOLLO, J. A. Comportamento contrátil de barreiras selantes de solo estabilizado para base de lagoas de tratamento. Revista brasileira de engenharia agrícola e Ambiental, v. 11, N. 1, p. 115-120, PB, 2006.

GRUBBS, F. E. Sample criteria for testing outlying observations. Annals of Mathematical Statistics, v. 21, p. 27-58, 1950.

- Procedure for detecting outlying observations in samples Technometrics, v. 11, N. 1, p. 01-21, 1969.

LADE, P.V.; LIGGIO, C.D.; YAMAMURO, J.A. Effects of non-plastic fines on minimum and maximum void ratios of sand. Geotechnical Testing Journal, v. 21, No.4, pp. 336-347, 1998.

LYON, T.L; BUCKMAN, H.O. The nature and properties of soils. New York: Macmilla, 1937. 391 p.

LUZ, M.P.; PARREIRA, A.B. Estudo da influência da umidade pós-compactação no índice de suporte CBR de solos do subleito de rodovias do interior de São Paulo. 34a Reunião Anual de Pavimentação, Campinas, SP, 2003.

MASSAD, F. Obras de terra: curso básico de geotecnia. $1^{\text {a }}$. ed. São Paulo: Oficina de textos, 2003. $170 \mathrm{p}$.

MEDINA, J; MOTTA, L. M. G. Mecânica dos pavimentos. 2a . ed. Rio de Janeiro: UFRJ, 2005. 570 p. 
MITCHELL, J.K.; SHEN, C. Behavior of soil-cement in repeated compression on flexure. TRR: Journal of the Transportation Research Board, N 128. p. 68-100 Washington, D.C, 1966.

MITCHELL, J.K. Fundamentals of soil behavior. $2^{\text {nd }}$ ed. Wiley - New York, 1992.

NOGAMI, J. S.; VILLIBOR, D. F. Pavimentação de baixo custo com solos lateríticos. $1^{\text {a }}$. ed. São Paulo: Vilibor, 1995. 240 p.

PARENTE, E. B.; PARREIRA, A. B.; SOARES, J.B. Avaliação do comportamento mecânico de um solo laterítico e de outro não laterítico estabilizados com cimento. XVI ANPET - Congresso de Pesquisa e Ensino em Transportes, Panorama Nacional de Pesquisa em Transportes, v. 1. p. 95-107, 2002.

PINILLA, J.D. et al. Influence of curing time on the resilient modulus of chemichally stabilized soils. Geotechnical Testing Journal, v. 34, N. 4, 2011.

PITTA, M.R. Retração de solo-cimento. $17^{\text {a }}$ Reunião Anual de Pavimentação, Vol. 1 - Brasília, DF, 1982.

PINTO, C.S. Curso básico de mecânica dos solos em 16 aulas. $3^{\mathrm{a}}$ ed. São Paulo: Oficina de Textos, 2006. $367 \mathrm{p}$.

REZENDE, L. R. Técnicas alternativas para a construção de bases de pavimentos rodoviários. Dissertação de mestrado - Faculdade de Tecnologia, Universidade de Brasília. DF, 1991.

SAARENKETO, T. Electrical properties of water in clay and silty soils. Journal of Applied Geophysics, N 40. Pp. 73-88- 1998.

SEBESTA, S. Use of microcracking to reduce shrinkage crack in cement-treated bases. TRR: Journal of the Transportation Research Board, N 1936. Pp. 3-11 Washington, D.C, 2005. 
TEIXEIRA, F.J.; PITTA, M.R. Recuperação de pavimentos de Solo-cimento. 17a Reunião Anual de Pavimentação, Vol. 1 - Brasília, DF, 1982.

TERZAGHI, K. Soil mechanics in engineering pratice. $3^{\text {th }}$. ed. New York: John Willey \& Sons, Inc, 1948. 566p.

TRINDADE, T. P.; CARVALHO, C.A.B.; SILVA, C.H.C.; LIMA, D.C.; BARBOSA, P.S.A. Resilient módulus of soils and soils-cement mixtures. ASTM STP 1437, Resilient modulus testing for pavement componentes, G, N, Durham, W, A, Marr and W.L. DeGroff, Edss., ASTM International, West Conshohoken, PA, 2003.

TOMEI. JR.; R. B. BALBO, J. T. Estudo de propriedades mecânicas de misturas solo brita cimento para pavimentação. $1^{\circ}$ Simpósio Internacional de Iniciação Científica da Universidade de São Paulo, São Paulo, SP, 2005.

VARGAS, M. Introdução à mecânica dos solos. $1^{\text {a }}$ ed. São Paulo: McGraw Hill do Brasil Ltda, São Paulo, 1978. 509 p.

VILLIBOR, D. F.; FORTES, R. M.; FORTES, F. Q.; NOGUEIRA JR, C. Deterioração estrutural de base de solo-cimento e granulares. $36^{\mathbf{a}}$ Reunião Anual de Pacimentação, Curitiba, PR, 2005.

VILLIBOR, D.F. Pavimentos econômicos: novas considerações Tese de Doutorado - Escola de Engenharia de São Carlos, Universidade de São Paulo, São Carlos, SP, 1981.

YOON, S.; FARSAKH, M. A. Laboratory investigation on the strength characteristics of cement-sand as base material. Journal of Civil Engeneering, L.A, 2009. 
ANEXO A - CONTROLE DOS TEMPOS DE CURA 
Tabela A.1 - Dados da compactação Proctor das amostras de solo-cimento nas duas condições de moldagem (UH e UC)

\begin{tabular}{|c|c|c|c|c|c|c|c|c|c|c|c|c|c|c|c|c|c|c|}
\hline \multirow{2}{*}{$\begin{array}{l}\text { Condição } \\
\text { Moldagem }\end{array}$} & \multicolumn{4}{|c|}{ Moldagem } & \multirow{2}{*}{$\begin{array}{c}\text { ASTM C39 } \\
\begin{array}{c}\text { Tolerância } \\
\text { (h) }\end{array}\end{array}$} & \multicolumn{3}{|c|}{ Ensaio } & \multicolumn{3}{|c|}{ RCS } & \multicolumn{4}{|c|}{ Dados Moldagem } & \multicolumn{3}{|c|}{ F. $a / c$} \\
\hline & $\begin{array}{c}\text { Ident. } \\
\mathbf{N}^{\circ}\end{array}$ & Data & Hora & $\begin{array}{c}\text { Cura } \\
\text { (dias) }\end{array}$ & & $\begin{array}{c}\text { Data } \\
\text { Prevista }\end{array}$ & Realizado & Hora & $\begin{array}{l}\text { Força } \\
\text { (KN) }\end{array}$ & $\underset{(\mathrm{mm})}{\Phi}$ & $\begin{array}{l}\text { RCS } \\
\text { (Mpa) }\end{array}$ & $\begin{array}{l}\mathrm{Mu} \\
\text { (g) }\end{array}$ & \begin{tabular}{c|}
$y s$ \\
$\left(\mathrm{~g} / \mathrm{cm}^{3}\right)$
\end{tabular} & $\begin{array}{l}\mathrm{KN} / \mathrm{m}^{3} \\
\left(\mathrm{~g} / \mathrm{cm}^{3}\right)\end{array}$ & $\begin{array}{c}\mathrm{h} \\
(\%)\end{array}$ & $\begin{array}{l}\text { ma } \\
\text { (g) }\end{array}$ & $\begin{array}{c}\text { m cim. } \\
\text { (g) }\end{array}$ & $a / c$ \\
\hline \multirow{6}{*}{ SC-UH } & 1 & 10/jul & $21: 30$ & 7 & \multirow{6}{*}{ \pm 6} & 17/jul & 17/jul & $20: 15$ & 24,40 & 100,00 & 3,11 & 1981,7 & 1,84 & 18,09 & 7,55 & 139,12 & 92,13 & 1,51 \\
\hline & 2 & 10/jul & $22: 00$ & 7 & & $17 / \mathrm{jul}$ & $17 / \mathrm{jul}$ & $20: 30$ & 24,70 & 100,00 & 3,14 & 2042,9 & 1,88 & 18,49 & 8,49 & 159,87 & 94,15 & 1,70 \\
\hline & 3 & 10/jul & $20: 00$ & 7 & & $17 / \mathrm{jul}$ & $17 / \mathrm{jul}$ & $20: 45$ & 27,57 & 100,04 & 3,51 & 2120,4 & 1,94 & 19,01 & 9,51 & 184,14 & 96,81 & 1,90 \\
\hline & 4 & 10/jul & $20: 30$ & 7 & & $17 / j u l$ & $17 / j u l$ & $21: 00$ & 21,80 & 100,02 & 2,77 & 2152,8 & 1,95 & 19,13 & 10,46 & 203,86 & 97,45 & 2,09 \\
\hline & 5 & 10/jul & 21:00 & 7 & & $17 / \mathrm{jul}$ & $17 / \mathrm{jul}$ & $21: 15$ & 14,55 & 100,02 & 1,85 & 2132,5 & 1,91 & 18,76 & 11,61 & 221,83 & 95,53 & 2,32 \\
\hline & 6 & 10/jul & $21: 30$ & 7 & & $17 / \mathrm{jul}$ & $17 / \mathrm{jul}$ & $21: 30$ & 11,93 & 99,87 & 1,52 & 2099,9 & 1,87 & 18,33 & 12,49 & 233,16 & 93,34 & 2,50 \\
\hline \multirow{6}{*}{ SC-UC } & 10 & 09/jul & $20: 00$ & 7 & \multirow{6}{*}{ \pm 6} & 16/jul & 16/jul & 19:30 & 27,10 & 100,01 & 3,45 & $2.033,6$ & 1,89 & 18,54 & 7,65 & 144,52 & 94,45 & 1,53 \\
\hline & 11 & 09/jul & $20: 30$ & 7 & & 16/jul & $16 /$ jul & 19:45 & 32,20 & 100,02 & 4,10 & $2.090,7$ & 1,93 & 18,94 & 8,38 & 161,65 & 96,45 & 1,68 \\
\hline & 12 & 09/jul & 21:00 & 7 & & 16/jul & 16/jul & $20: 00$ & 31,27 & 100,00 & 3,98 & $2.153,6$ & 1,97 & 19,35 & 9,28 & 182,88 & 98,54 & 1,86 \\
\hline & 13 & 09/jul & $21: 30$ & 7 & & 16/jul & $16 / j u l$ & $21: 45$ & 28,00 & 100,03 & 3,56 & $2.194,4$ & 1,99 & 19,56 & 10,13 & 201,85 & 99,63 & 2,03 \\
\hline & 14 & 09/jul & 22:00 & 7 & & $16 / j u l$ & 16/jul & $22: 00$ & 15,59 & 100,06 & 1,98 & $2.171,8$ & 1,95 & 19,15 & 11,33 & 221,02 & 97,54 & 2,27 \\
\hline & 15 & 09/jul & $22: 30$ & 7 & & 16/jul & 16/jul & $22: 15$ & 12,54 & 100,06 & 1,59 & $2.133,0$ & 1,90 & 18,66 & 12,20 & 231,93 & 95,05 & 2,44 \\
\hline
\end{tabular}


Tabela A.2 - Dados da compactação para ensaios mecânicos (MR, RCS, RTCD) na umidade higroscópica (UH)

\begin{tabular}{|c|c|c|c|c|c|c|c|c|c|c|c|c|c|c|c|c|c|c|c|c|c|}
\hline \multirow[b]{2}{*}{$\begin{array}{c}\text { Condição } \\
\text { Mistura }\end{array}$} & \multicolumn{4}{|c|}{ Moldagem } & \multirow{2}{*}{\begin{tabular}{|c|} 
ASTM C39 \\
$\begin{array}{c}\text { Tolerância } \\
\text { (h) }\end{array}$
\end{tabular}} & \multirow{2}{*}{\begin{tabular}{|c|} 
Ensaio \\
Previsto
\end{tabular}} & \multicolumn{2}{|l|}{ RT } & \multicolumn{2}{|l|}{ MR } & \multicolumn{2}{|l|}{ RCS } & \multicolumn{6}{|c|}{ Dados Compactação } & \multicolumn{3}{|c|}{ F. $a / c$} \\
\hline & Ident. $N^{\circ}$ & Data & Hora & $\begin{array}{l}\text { Cura } \\
\text { (dias) }\end{array}$ & & & Realizado & Hora & Realizado & Hora & Realizado & Hora & $\begin{array}{l}\text { ys max } \\
\left(\mathbf{g} / \mathrm{cm}^{3}\right)\end{array}$ & $\begin{array}{l}\text { hot } \\
\text { (\%) }\end{array}$ & $\begin{array}{c}\text { Mu CP } \\
\text { (g) }\end{array}$ & $\begin{array}{c}\text { Ys } \\
\left(\mathbf{g} / \mathrm{cm}^{3}\right)\end{array}$ & h (\%) & GC & ma (g) & $\underset{\text { cim. }}{m}$ & $a / c$ \\
\hline U.H & 1 & $07 /$ jun & 19:00 & 28 & \multirow{6}{*}{ \pm 20} & $05 /$ jul & 05/jul & $20: 15$ & - & - & - & - & 1,952 & 10,8 & $3.360,0$ & 1,93 & 10,84 & 98,9 & 328,60 & 151,57 & 2,17 \\
\hline $\mathrm{U} . \mathrm{H}$ & 2 & 07/jun & $20: 00$ & 28 & & 05/jul & 05/jul & $20: 30$ & $=$ & - & ") & - & 1,952 & 10,8 & $3.402,0$ & 1,96 & 10,80 & 100,2 & 331,60 & 153,52 & 2,16 \\
\hline U.H & 3 & 07/jun & $20: 40$ & 28 & & 05/jul & 05/jul & $20: 45$ & - & - & - & - & 1,952 & 10,8 & $3.416,4$ & 1,96 & 10,89 & 100,5 & 335,51 & 154,04 & 2,18 \\
\hline U.H & 4 & $07 /$ jun & $21: 30$ & 28 & & 05/jul & - & ; & 05/jul & $21: 40$ & "05/jul & $22: 10$ & 1,952 & 10,8 & $3.418,5$ & 1,96 & 10,87 & 100,6 & 335,16 & 154,17 & 2,17 \\
\hline U.H & 5 & $07 /$ jun & $22: 00$ & 28 & & 05/jul & - & "-" & 06/jul & $23: 40$ & $05 / j u l$ & 00:00 & 1,952 & 10,8 & $3.417,3$ & 1,96 & 10,95 & 100,5 & 337,26 & 154,00 & 2,19 \\
\hline U.H & 6 & $07 /$ jun & $22: 40$ & 28 & & $05 / j u l \mid$ & 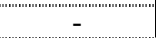 & -" & 06/jul & 01:10 & "' & $01: 20$ & 1,952 & 10,8 & $3.412,6$ & 1,96 & 10,89 & 100,4 & 335,14 & 153,87 & 2,18 \\
\hline \multicolumn{15}{|c|}{ Média } & $3.404,5$ & 1,96 & 10,9 & 100,2 & 333,9 & 153,5 & 2,17 \\
\hline \multicolumn{15}{|c|}{ Desvio Padrão } & 22,6 & 0,01 & 0,1 & 0,6 & 3,2 & 1,0 & 0,01 \\
\hline \multicolumn{15}{|c|}{ Coeficiente de Variação (\%) } & 0,66 & 0,64 & 0,47 & 0,64 & 0,95 & 0,64 & 0,47 \\
\hline U.H & 10 & 09/jun & $10: 40$ & 14 & \multirow{7}{*}{ \pm 10} & 23/jun & 23/jun & $00: 40$ & - & - & - & - & 1,952 & 10,8 & $3.408,8$ & 1,96 & 10,96 & 100,2 & 336,70 & 153,60 & 2,19 \\
\hline U.H & 11 & 09/jun & $11: 20$ & 14 & & $23 /$ jun & $23 /$ jun & $01: 20$ & - & -" & "'-"'-" & - & 1,952 & 10,8 & $3.411,0$ & 1,96 & 10,92 & 100,3 & 335,81 & 153,76 & 2,18 \\
\hline $\mathrm{U} . \mathrm{H}$ & 12 & "09/jun & $12: 00$ & "14"' & & 23/jun & 23/jun & $02: 00$ & $=$ & $=$ & - & - & 1,952 & 10,8 & $3.422,3$ & 1,97 & 10,70 & 100,9 & 330,79 & 154,58 & 2,14 \\
\hline U.H & 13 & 09/jun & $12: 50$ & 14 & & 23/jun & - & $-"$ & $23 /$ jun & 03:00 & 23/jun & $04: 00$ & 1,952 & 10,8 & $3.416,3$ & 1,96 & 10,87 & 100,5 & 334,94 & 154,07 & 2,17 \\
\hline $\mathrm{U} . \mathrm{H}$ & 14 & 09/jun & $13: 30$ & 14 & & 23/jun & $=$ & - & $23 /$ jun & "04:00 & "23/jun" & 05:20 & 1,952 & 10,8 & $3.407,3$ & 1,96 & 10,81 & 100,3 & 332,40 & 153,75 & 2,16 \\
\hline U.H & 15 & 09/jun & $14: 10$ & 14 & & $23 / j u n$ & - & - & 23/jun & $06: 00$ & 23/jun & $06: 40$ & 1,952 & 10,8 & $3.414,6$ & 1,96 & 10,85 & 100,5 & 334,22 & 154,02 & 2,17 \\
\hline $\mathrm{U} . \mathrm{H}$ & 16 & 05/jul & 07:10 & 14 & & 19/jul & - & - & 18/jul & $20: 00$ & 18/jul & $21: 00$ & 1,952 & 10,8 & $3.406,2$ & 1,96 & 10,79 & 100,3 & 331,73 & 153,72 & 2,16 \\
\hline \multicolumn{15}{|c|}{ Média } & $3.412,4$ & 1,96 & 10,8 & 100,5 & 333,8 & 153,9 & 2,17 \\
\hline \multicolumn{15}{|c|}{ Desvio Padrão } & 5,7 & 0,00 & 0,1 & 0,2 & 2,2 & 0,3 & 0,02 \\
\hline \multicolumn{15}{|c|}{ Coeficiente de Variação (\%) } & 0,17 & 0,21 & 0,80 & 0,21 & 0,66 & 0,21 & 0,80 \\
\hline U.H & 30 & 20/jun & 19:40 & 7 & & 27/jun & $27 /$ jun & $19: 40$ & - & - & - & - & 1,952 & 10,8 & $3.398,0$ & 1,96 & 10,37 & 100,5 & 319,26 & \begin{tabular}{|l|}
153,94 \\
\end{tabular} & 2,07 \\
\hline U.H & 31 & 20/jun & $20: 30$ & 7 & & $27 /$ jun & $27 /$ jun & $20: 00$ & - & $=$ & - & - & 1,952 & 10,8 & $3.414,9$ & 1,97 & 10,40 & 100,9 & 321,69 & 154,66 & 2,08 \\
\hline U.H & 32 & 20/jun & 21:10 & 7 & +6 & $27 /$ jun & 27/jun & $20: 15$ & - & - & - & - & 1,952 & 10,8 & $3.423,3$ & 1,98 & 10,37 & 101,2 & 321,64 & 155,08 & 2,07 \\
\hline U.H & 33 & 20/jun & $21: 50$ & "'7"' & \pm 6 & $27 /$ jun & - & - & $27 /$ jun & $21: 20$ & "27/jun "' & $21: 50$ & 1,952 & 10,8 & $3.415,4$ & 1,97 & 10,43 & 100,9 & 322,58 & 154,64 & 2,09 \\
\hline U.H & 34 & 20/jun & $22: 30$ & 7 & & 27/jun & - & - & 27/jun & $23: 00$ & 27/jun & $23: 10$ & 1,952 & 10,8 & $3.406,6$ & 1,96 & 10,44 & 100,7 & 322,03 & 154,23 & 2,09 \\
\hline U.H & 35 & 20/jun & $23: 20$ & 7 & & 27/jun & - & - & $27 /$ jun & $00: 00$ & 28/jun & $00: 30$ & 1,952 & 10,8 & $3.413,0$ & 1,97 & 10,45 & 100,8 & 322,91 & 154,50 & 2,09 \\
\hline & & & & & & & Média & & & & & & & & $3.411,9$ & 1,97 & 10,4 & 100,8 & 321,7 & 154,5 & 2,08 \\
\hline & & & & & & Des & vio Padrão & & & & & & & & 8,6 & 0,01 & 0,0 & 0,3 & 1,3 & 0,4 & 0,01 \\
\hline & & & & & & Coeficient & de Variaçã & o (\%) & & & & & & & 0,25 & 0,25 & 0,34 & 0,25 & 0,40 & 0,25 & 0,34 \\
\hline U.H & 20 & 11/jun & 19:10 & 3 & & 14/jun & 14/jun & $20: 45$ & - & - & - & - & 1,952 & 10,8 & $3.422,8$ & 1,97 & 10,91 & 100,7 & 336,69 & \begin{tabular}{|l|}
154,31 \\
\end{tabular} & 2,18 \\
\hline U.H & 21 & $11 /$ jun & 19:50 & 3 & & $14 /$ jun & 14/jun & $22: 40$ & - & -" & "'-"'"' & - & 1,952 & 10,8 & $3.430,1$ & 1,97 & 10,86 & 101,0 & 336,02 & 154,70 & 2,17 \\
\hline $\mathrm{U} . \mathrm{H}$ & 22 & $11 /$ jun & $20: 30$ & 3 & & 14/jun & 14/jun & $23: 50$ & - & - & - & - & 1,952 & 10,8 & $3.428,9$ & 1,97 & 10,74 & 101,0 & 332,55 & 154,82 & 2,15 \\
\hline U.H & 23 & $11 /$ jun & $21: 10$ & 3 & & $14 / j u n$ & - & - & $14 / j u n$ & $21: 20$ & $14 /$ jun & $22: 10$ & 1,952 & 10,8 & $3.434,9$ & 1,98 & 10,75 & 101,2 & 333,41 & 155,07 & 2,15 \\
\hline U.H & 24 & $11 /$ jun & $21: 50$ & 3 & \pm 2 & 14/jun & $=$ & $=$ & 14/jun & $21: 30$ & 14/jun" & $23: 25$ & 1,952 & 10,8 & $3.439,2$ & 1,98 & 10,82 & 101,3 & 335,79 & 155,17 & 2,16 \\
\hline U.H & 25 & $11 /$ jun & $22: 30$ & 3 & & 14/jun & - & - & 14/jun & 21:40 & 15/jun & $00: 40$ & 1,952 & 10,8 & $3.443,8$ & 1,98 & 10,80 & 101,4 & 335,68 & 155,41 & 2,16 \\
\hline U.H & 26 & 29/jun & $20: 30$ & 3 & & 02/jul & 02/jul & 21:00 & 02/jul & $20: 30$ & - & - & 1,952 & 10,8 & $3.434,0$ & 1,97 & 10,77 & 101,2 & 333,88 & 155,01 & 2,15 \\
\hline $\mathrm{U} . \mathrm{H}$ & 27 & 29/jun & $21: 20$ & 3 & & 02/jul & - & - & 02/jul & $22: 20$ & 02/jul & 23:00 & 1,952 & 10,8 & $3.421,0$ & 1,97 & 10,58 & 100,9 & 327,31 & 154,68 & 2,12 \\
\hline U.H & 28 & 29/jun & $22: 00$ & 3 & & 02/jul & - & - & 02/jul & $23: 50$ & $02 / j u l$ & $00: 00$ & 1,952 & 10,8 & $3.400,2$ & 1,96 & 10,60 & 100,3 & 325,88 & 153,72 & 2,12 \\
\hline & & & & & & & Média & & & & & & & & $3.428,3$ & 1,97 & 10,8 & 101,0 & 333,0 & 154,8 & 2,15 \\
\hline & & & & & & Des & vio Padrão & & & & & & & & 12,8 & 0,01 & 0,1 & 0,3 & 3,9 & 0,5 & 0,02 \\
\hline & & & & & & Coeficiente & de Variaçã & o (\%)' & & & & & & & 0,37 & 0,33 & 1,02 & 0,33 & 1,17 & 0,33 & 1,02 \\
\hline
\end{tabular}


Tabela A.3 - Dados da compactação para ensaios mecânicos (MR, RCS, RTCD) na umidade de campo (UH)

\begin{tabular}{|c|c|c|c|c|c|c|c|c|c|c|c|c|c|c|c|c|c|c|c|c|c|}
\hline \multirow[b]{2}{*}{$\begin{array}{l}\text { Condição } \\
\text { Mistura }\end{array}$} & \multicolumn{4}{|c|}{ Moldagem } & \multirow{2}{*}{$\begin{array}{c}\text { ASTM C39 } \\
\begin{array}{c}\text { Tolerância } \\
\text { (h) }\end{array}\end{array}$} & \multirow{2}{*}{$\begin{array}{l}\text { Ensaio } \\
\text { Previsto }\end{array}$} & \multicolumn{2}{|l|}{ RT } & \multicolumn{2}{|l|}{ MR } & \multicolumn{2}{|l|}{ RCS } & \multicolumn{6}{|c|}{ Dados Compactação } & \multicolumn{3}{|c|}{ F. $a / c$} \\
\hline & $\begin{array}{c}\text { Ident. } \\
\mathbf{N}^{\circ}\end{array}$ & Data & Hora & $\begin{array}{c}\text { Cura } \\
\text { (dias) }\end{array}$ & & & Realizado & Hora & Realizado & Hora & Realizado & Hora & $\begin{array}{l}\text { ys max } \\
\left(\mathrm{g} / \mathrm{cm}^{3}\right)\end{array}$ & $\begin{array}{l}\text { hot } \\
(\%)\end{array}$ & $\begin{array}{c}\text { Mu CP } \\
\text { (g) }\end{array}$ & $\begin{array}{c}\text { Ys } \\
\left(\mathrm{g} / \mathrm{cm}^{3}\right)\end{array}$ & h (\%) & GC & ma (g) & $\underset{\text { cim. }}{m}$ & $a / c$ \\
\hline U.C & 50 & 08/jun & $18: 30$ & 28 & \multirow{6}{*}{ \pm 20} & 06/jul & 06/jul & $20: 00$ & - & - & - & - & 1,995 & 10,75 & $3.451,4$ & 1,98 & 11,04 & 99,2 & 343,15 & 155,41 & 2,21 \\
\hline U.C & 51 & 08/jun & 19:30 & 28 & & 06/jul & 06/jul & $20: 15$ & $=$ & $=$ & - & $=$ & 1,995 & 10,75 & $3.463,2$ & 1,99 & 10,84 & 99,8 & 338,70 & 156,23 & 2,17 \\
\hline U.C & 52 & $08 / j$ un & $20: 40$ & 28 & & $06 / j u l$ & $06 / j u l$ & $20: 30$ & - & - & - & - & 1,995 & 10,75 & $3.464,2$ & 1,99 & 11,00 & 99,6 & 343,30 & 156,05 & 2,20 \\
\hline U.C & 53 & $08 /$ jun & $21: 40$ & 28 & & $06 /$ jul & 年 & se.sur & 06/jul & $21: 20$ & 06/jul & $21: 50$ & 1,995 & 10,75 & $3.469,8$ & 1,99 & 10,88 & 99,9 & 340,47 & 156,47 & 2,18 \\
\hline U.C & 54 & $08 /$ jun & $22: 30$ & 28 & & 06/jul & $=$ & - & 06/jul & $23: 20$ & 06/jul & $23: 40$ & 1,995 & 10,75 & $3.476,0$ & 2,00 & 10,78 & 100,2 & 338,25 & 156,89 & 2,16 \\
\hline U.C & 55 & $08 /$ jun & $23: 15$ & 28 & & $06 / j u l$ & - & - & $07 / j u l \mid$ & $00: 40$ & $07 / j u l$ & $01: 00$ & 1,995 & 10,75 & $3.472,5$ & 2,00 & 10,83 & 100,0 & 339,32 & 156,66 & 2,17 \\
\hline \multicolumn{15}{|c|}{ Média } & $3.466,2$ & 1,99 & 10,9 & 99,8 & 340,5 & 156,3 & 2,18 \\
\hline \multicolumn{15}{|c|}{ Desvio Padrão } & 8,7 & 0,01 & 0,1 & 0,3 & 2,2 & 0,5 & 0,02 \\
\hline \multicolumn{15}{|c|}{ Coeficiente de Variação (\%) } & 0,25 & 0,33 & 0,94 & 0,33 & 0,65 & 0,33 & 0,94 \\
\hline U.C & 60 & 10/jun & $10: 50$ & 14 & \multirow{7}{*}{ \pm 10} & 24/jun & $24 /$ jun & $00: 50$ & - & - & - & - & 1,995 & 10,75 & $3.474,9$ & 2,00 & 10,80 & 100,1 & 338,71 & 156,81 & 2,16 \\
\hline U.C & 61 & $10 /$ jun & $11: 40$ & 14 & & $24 /$ jun & 24/jun & $01: 20$ & - & - & - & - & 1,995 & 10,75 & $3.472,7$ & 2,00 & 10,84 & 100,0 & 339,63 & 156,65 & 2,17 \\
\hline U.C & 62 & $10 /$ jun & $12: 20$ & 14 & & $24 /$ jun & $24 / j u n$ & $02: 20$ & $=$ & - & - & $=$ & 1,995 & 10,75 & $3.467,8$ & 1,99 & 10,83 & 99,9 & 338,86 & 156,45 & 2,17 \\
\hline U.C & 63 & 10/jun & $13: 20$ & 14 & & 24/jun & - & $-=$ & $24 /$ jun & 03:20 & $24 /$ jun & $04: 10$ & 1,995 & 10,75 & $3.477,8$ & 2,00 & 10,76 & 100,2 & 337,86 & 157,00 & 2,15 \\
\hline U.C & 64 & $10 /$ jun & $14: 00$ & 14 & & $24 /$ jun & $=$ & - & $24 /$ jun & $04: 30$ & $24 /$ jun & $05: 50$ & 1,995 & 10,75 & $3.468,6$ & 1,99 & 10,84 & 99,9 & 339,22 & 156,47 & 2,17 \\
\hline U.C & 65 & 10/jun & $14: 40$ & 14 & & $24 / j u n$ & - & - & $24 /$ jun & $06: 30$ & $24 / j u n$ & 07:00 & 1,995 & 10,75 & $3.470,0$ & 1,99 & 10,81 & 100,0 & 338,51 & 156,57 & 2,16 \\
\hline U.C & 66 & 05/jul & $08: 00$ & 14 & & 19/jul & 18/jul & $22: 40$ & 18/jul & $22: 00$ & - & - & 1,995 & 10,75 & $3.505,2$ & 2,02 & 10,79 & 101,0 & 341,38 & 158,19 & 2,16 \\
\hline \multicolumn{15}{|c|}{ Média } & $3.476,7$ & 2,00 & 10,8 & 100,2 & 339,2 & 156,9 & 2,16 \\
\hline \multirow{2}{*}{\multicolumn{15}{|c|}{$\begin{array}{l}\text { Desvio Padrão } \\
\text { Coeficiente de Variacão (\%) }\end{array}$}} & 13,1 & 0,01 & 0,0 & 0,4 & 1,1 & 0,6 & 0,01 \\
\hline & & & & & & & & & & & & & & & 0,38 & 0,39 & 0,27 & 0,39 & 0,33 & 0,39 & 0,27 \\
\hline U.C & 80 & 21/jun & $20: 20$ & 7 & \multirow{8}{*}{ \pm 6} & 28/jun & $28 /$ jun & 19:30 & - & - & - & - & 1,995 & 10,75 & $3.482,5$ & 2,00 & 10,90 & 100,3 & 342,28 & 157,01 & 2,18 \\
\hline U.C & 81 & $21 /$ jun & $21: 00$ & 7 & & 28/jun & $28 /$ jun & 19:45 & - & $=$ & - & - & 1,995 & 10,75 & $3.474,6$ & 1,99 & 11,02 & 99,9 & 344,89 & 156,49 & 2,20 \\
\hline U.C & 82 & $21 /$ jun & $21: 40$ & 7 & & $28 /$ jun & $28 /$ jun & $20: 00$ & - & - & - & - & 1,995 & 10,75 & $3.497,1$ & 2,01 & 10,79 & 100,8 & 340,59 & 157,83 & 2,16 \\
\hline U.C & 83 & $21 /$ jun & $22: 20$ & 7 & & 28/jun & -- & - & $28 /$ jun & $20: 50$ & $28 /$ jun & $21: 20$ & 1,995 & 10,75 & $3.491,5$ & 2,01 & 10,85 & 100,6 & 341,75 & 157,49 & 2,17 \\
\hline U.C & 84 & $21 /$ jun & $23: 00$ & 7 & & $28 /$ jun & - & - & $28 /$ jun & $22: 40$ & 28/jun & $23: 00$ & 1,995 & 10,75 & $3.481,0$ & 2,00 & 11,02 & 100,1 & 345,53 & 156,77 & 2,20 \\
\hline U.C & 85 & $21 /$ jun & $23: 40$ & 7 & & 28/jun & - & - & $28 /$ jun & $00: 00$ & $29 /$ jun & $00: 20$ & 1,995 & 10,75 & $3.489,5$ & 2,01 & 10,84 & 100,5 & 341,27 & 157,41 & 2,17 \\
\hline U.C & 86 & $12 / \mathrm{jul}$ & $20: 40$ & 7 & & 19/jul & - & - & 19/jul & $20: 00$ & 19/jul & $21: 10$ & 1,995 & 10,75 & $3.493,8$ & 2,01 & 10,73 & 100,7 & 338,56 & 157,76 & 2,15 \\
\hline U.C & 87 & $12 / \mathrm{jul}$ & $21: 20$ & 7 & & 19/jul & - & - & 19/jul & $22: 00$ & 19/jul & $22: 40$ & 1,995 & 10,75 & $3.501,8$ & 2,02 & 10,58 & 101,1 & 335,04 & 158,34 & 2,12 \\
\hline & & & & & & & Média & & & & & & & & $3.489,0$ & 2,00 & 10,8 & 100,5 & 341,2 & 157,4 & 2,17 \\
\hline & & & & & & Des & vio Padrão & & & & & & & & 9,0 & 0,01 & 0,1 & 0,4 & 3,4 & 0,6 & 0,03 \\
\hline & & & & & & Coeficient & de Variaçã & 1० (\%) & & & & & & & 0,26 & 0,39 & 1,35 & 0,39 & 0,99 & 0,39 & 1,35 \\
\hline U.C & 70 & 12/jun & $19: 30$ & 3 & & 15/jun & $15 /$ jun & $22: 10$ & - & - & - & - & 1,995 & 10,75 & $3.474,9$ & 2,00 & 10,84 & 100,1 & 339,84 & 156,75 & 2,17 \\
\hline U.C & 71 & $12 /$ jun & $20: 00$ & 3 & & 15/jun & 15/jun & $22: 30$ & - & $=$ & - & $=$ & 1,995 & 10,75 & $3.472,7$ & 2,00 & 10,58 & 100,3 & 332,26 & 157,02 & 2,12 \\
\hline U.C & 72 & $12 /$ jun & $20: 30$ & 3 & & 15/jun & 15/jun & $22: 40$ & - & - & - & - & 1,995 & 10,75 & $3.467,8$ & 1,99 & 10,80 & 99,9 & 338,02 & 156,49 & 2,16 \\
\hline U.C & 73 & $12 /$ jun & $22: 10$ & 3 & \pm 2 & 15/jun & - & - & 15/jun & $21: 30$ & 15/jun & $23: 10$ & 1,995 & 10,75 & $3.477,8$ & 2,00 & 10,94 & 100,1 & 342,95 & 156,74 & 2,19 \\
\hline U.C & 74 & 12/jun & $22: 50$ & 3 & & 15/jun & - & - & 15/jun & $23: 30$ & $16 /$ jun & $00: 30$ & 1,995 & 10,75 & $3.468,6$ & 2,00 & 10,71 & 100,0 & 335,55 & 156,65 & 2,14 \\
\hline U.C & 75 & $12 /$ jun & $23: 20$ & 3 & & 15/jun & - & - & 16/jun & $00: 00$ & $16 /$ jun & $01: 00$ & 1,995 & 10,75 & $3.470,0$ & 1,99 & 10,90 & 99,9 & 341,06 & 156,45 & 2,18 \\
\hline U.C & 76 & $30 /$ jun & $20: 10$ & 3 & & 03/jul & 03/jul & $21: 20$ & 03/jul & 21:00 & - & - & 1,995 & 10,75 & $3.503,1$ & 2,01 & 10,88 & 100,9 & 343,74 & 157,97 & 2,18 \\
\hline & & & & & & & Média & & & & & & & & $3.476,4$ & 2,00 & 10,8 & 100,2 & 339,1 & 156,9 & 2,16 \\
\hline & & & & & & Des & vio Padrão & & & & & & & & 12,3 & 0,01 & 0,1 & 0,3 & 4,1 & 0,5 & 0,02 \\
\hline & & & & & & Coeficient & e Ve Variaçã & o $(\%)$ & & & & & & & 0,35 & 0,33 & 1,16 & 0,33 & 1,21 & 0,33 & 1,16 \\
\hline
\end{tabular}




\section{ANEXO B - DIMENSIONAMENTO DA ESTRUTURA DO PAVIMENTO PELO MÉTODO DO CBR}

\section{Tráfego}

O pavimento foi implantado em uma estrada de terra existente, sujeita a diferentes tipos de tráfego. Devido a estas características, a estrada foi dividida em três segmentos $(A, B$ e $C$ ). Nos segmentos $A$ e $C$, onde em visita ao local da obra verificouse uma crescente expansão do cultivo de cana-de-açúcar, além da proximidade de

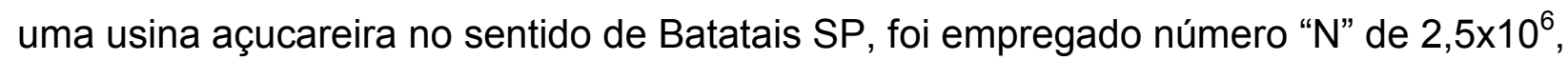
tomando como base projetos estudados anteriormente para estradas do mesmo porte. No Segmento B, que se trata de um acesso à cidade de Itirapuã (com 5.377 habitantes

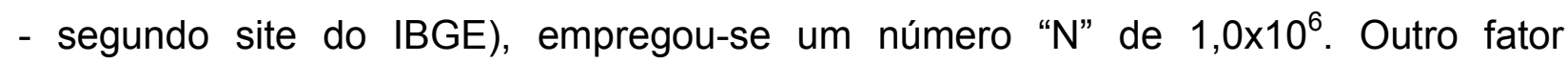
considerado para a adoção dos números "N", é que após a pavimentação da estrada, a mesma atrairá o tráfego de veículos que atualmente utilizam outras estradas da malha municipal, além de atrair o tráfego de municípios vizinhos como Capetinga e São Tomaz de Aquino (MG), que fazem interligação com os municípios de Batatais e Altinópolis (SP). Para o cálculo do número "N" dos pavimentos dos acostamentos empregou-se $5 \%$ do tráfego na pista de rolamento, conforme recomenda a Instrução de Projeto IP-DE-P00/001 do DER/SP. A Tabela B.1 apresenta os valores adotados de número "N" dos segmentos estudados e seus acostamentos.

Tabela B.1 - Número "N" para pista e acostamento em cada segmento

\begin{tabular}{c|c|c}
\hline Local & "N" AASHTO Pista & "N" AASHTO Acostamento \\
\hline Segmento A & $2,5 \times 10^{6}$ & $1,25 \times 10^{5}$ \\
\hline Segmento B & $1,0 \times 10^{6}$ & $5,0 \times 10^{4}$ \\
\hline Segmento C & $2,5 \times 10^{6}$ & $1,25 \times 10^{5}$ \\
\hline
\end{tabular}




\section{Projeto estrutural}

O dimensionamento foi realizado segundo o Método de Dimensionamento de Pavimentos Flexíveis - DER/SP. Desenvolvido pelo professor Murillo Lopes de Souza do Instituto Militar de Engenharia, este método é baseado no método do CBR da USACE e na pista experimental da AASHO, com algumas adaptações e consiste no dimensionamento de uma estrutura capaz de proteger o subleito de rupturas plásticas. São apresentadas espessuras mínimas de revestimento de acordo com número "N" de projeto de acordo com o tráfego esperado, com o intuito de proteger o revestimento contra danos por fadiga. A espessura total do pavimento é dada em função do valor de suporte do subleito, representado pelo ensaio de CBR e com o tráfego previsto de projeto. O ábaco de dimensionamento é apresentado na Figura B.1.

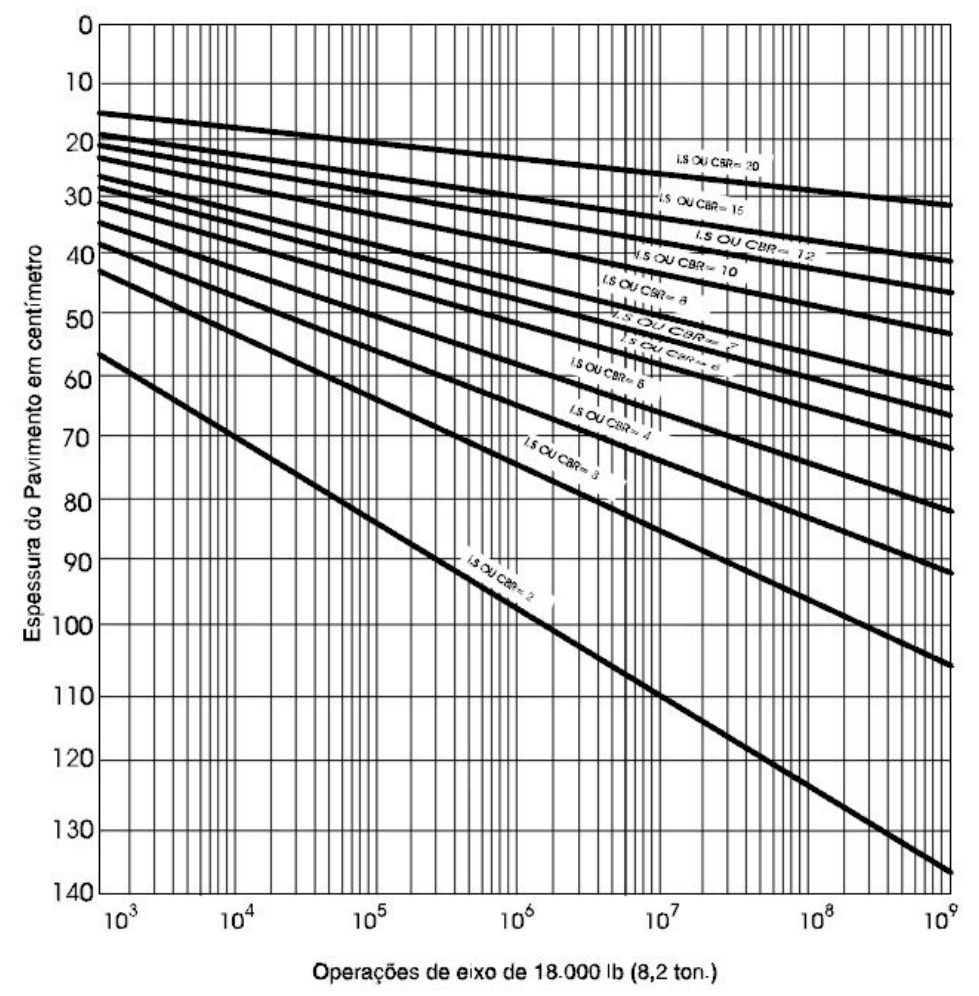

Figura B.1- Ábaco de dimensionamento (Fonte: DNER, 1996) 


\section{Suporte do subleito}

O valor utilizado no dimensionamento é uma média dos valores de CBR apurados em sondagens prévias com a aplicação de estudos de confiabilidade, de acordo com eq.(B.1).

$$
\mathrm{CBR}_{\text {Proj }}=\overline{\mathrm{CBR}}-\frac{s \times t_{0,90}}{\sqrt{\mathrm{n}-1}}
$$

Onde: $\quad \mathrm{CBR}_{\text {proj }}=$ valor de $\mathrm{CBR}$ adotado para o projeto

$\mathrm{CBR}=$ valor médio das amostras

$S=$ desvio padrão dos valores

$\mathrm{t}_{0,90}=$ valores do percentual da distribuição $\mathrm{t}$-Student, confiabilidade de $90 \%$.

$\mathrm{n}=$ número de ensaios realizados

O valor de CBR de projeto calculado foi de $24,5 \%$ para o solo de subleito compactado na energia Normal. Para o dimensionamento foi adotado o valor de $20 \%$, visto que não há curvas de dimensionamento para valores acima de $20 \%$ de CBR.

\section{Reforço do subleito e base}

Para a camada de reforço, a instrução prevê que o material possua valor de suporte superior ao solo empregado como subleito. Foi empregado o solo de jazida compactado na energia intermediária que apresentou valor de 53,2\% de CBR. Para a camada de base, a mesma instrução prevê que esta camada utilize material valor de CBR de no mínimo $80 \%$ e expansão inferior a $1 \%$. O material empregado para esta 
camada foi um Solo-Brita nas proporções de $40 \%$ de solo de jazida e $60 \%$ de brita, compactado na energia Intermediária. Ensaios prévios neste material mostraram valores de CBR de $115 \%$ e expansão nula, atendendo as prerrogativas do método.

\section{Revestimento}

A IP-DE-P00-001 recomenda o uso de espessuras de revestimento de acordo com o tráfego de projeto. Os valores de espessuras de acordo com o tráfego são apresentados na Tabela B.2. O valor adotado para o projeto foi de $4 \mathrm{~cm}$ de espessura, com a ressalva de ser realizada uma análise mecanicista das solicitações atuantes nesta camada.

Tabela B.2 - Tipo e espessura de revestimento de acordo com o tráfego de projeto

\begin{tabular}{c|c}
\hline Parâmetros de Tráfego & Tipo e Espessura \\
\hline $\mathrm{N} \leq 10^{6}$ & Tratamentos Superficiais Asfálticos duplos e triplos \\
$10^{6} \leq \mathrm{N} \leq 5 \times 10^{6}$ & Concreto Asfálticos com $5,0 \mathrm{~cm}$ de espessura \\
$5 \times 10^{\circ} \leq \mathrm{N} \leq 10^{\prime}$ & Concreto Asfálticos com $7,5 \mathrm{~cm}$ de espessura \\
$10^{\prime} \leq \mathrm{N} \leq 2,5 \times 10^{\prime}$ & Concreto Asfálticos com $10,0 \mathrm{~cm}$ de espessura \\
$2,5 \times 10^{\prime} \leq \mathrm{N} \leq 5 \times 10^{\prime}$ & Concreto Asfálticos com $12,5 \mathrm{~cm}$ de espessura \\
$\mathrm{N}>5 \times 10^{\prime}$ & Concreto Asfálticos com $15,0 \mathrm{~cm}$ de espessura \\
\hline
\end{tabular}

\section{Espessuras das camadas}

As espessuras das camadas foram determinadas com o uso das eq.(B.2), (B.3) e (B.4).

$\mathrm{R} \times \mathrm{K}_{\mathrm{R}}+\mathrm{B} \times \mathrm{K}_{\mathrm{B}} \geq \mathrm{H}_{20}$

$\mathrm{R} \times \mathrm{K}_{\mathrm{R}}+\mathrm{B} \times \mathrm{K}_{\mathrm{B}}+\mathrm{h}_{20} \times \mathrm{K}_{\mathrm{s}} \geq \mathrm{Hn}$

$R \times K_{R}+B \times K_{B}+h_{20} \times K_{s}+h_{n} \times K_{R E F} \geq H_{m}$ 
Onde: $\mathrm{R}$ = espessura do revestimento;

$\mathrm{B}=$ espessura da camada de base;

$\mathrm{H}_{20}=$ espessura sobre a sub-base;

$\mathrm{h}_{20}=$ espessura da sub-base;

$\mathrm{H}_{\mathrm{n}}=$ espessura sobre o reforço do subleito;

$\mathrm{h}_{\mathrm{n}}=$ espessura do reforço do subleito;

$\mathrm{H}_{\mathrm{m}}$ = espessura do pavimento;

$K_{R}, K_{B}, K_{S}, K_{R E F}=$ coeficientes de equivalência estrutural das camadas de revestimento, base, sub-base e reforço, respectivamente.

\section{Coeficientes estruturais}

O coeficiente de equivalência estrutural $(K)$ de um material é definido como a relação entre as espessuras de uma base granular e de uma camada com outro material que apresenta o mesmo comportamento em termos de redução das tensões impostas pela carga aplicada. A Instrução de Projeto do DER/SP (IP-DE-P00-001) apresenta os valores dos coeficientes estruturais dos materiais usualmente utilizados nas diversas camadas do pavimento. Para a determinação do $\mathrm{K}$ do reforço é utilizada a eq.(B.5).

$$
\mathrm{K}_{\mathrm{ref}}=\sqrt[3]{\frac{\mathrm{CBR}_{1}}{3 \times \mathrm{CBR}_{2}}}
$$

Onde: $\quad \mathrm{CBR}_{1}=$ suporte da sub-base ou reforço;

$$
\mathrm{CBR}_{2}=\text { suporte do material da camada subjacente. }
$$

De acordo com a IP-DE-P00/001, deve ser empregado no máximo $20 \%$ na relação de CBR1/CBR2, mesmo quando o material apresentar valor superior. A Tabela B.3 apresenta os valores dos coeficientes estruturais dos materiais adotados no dimensionamento. 
Tabela B.3 - Coeficientes estruturais adotados no projeto

\begin{tabular}{c|c}
\hline Camada & Coeficiente Estrutural (K) \\
\hline Revestimento de CBUQ - CAP 30/45 & 2,0 \\
Base de Solo-Brita (40 Solox60 Brita) com SAFL & 1,0 \\
\hline Reforço do Subleito - Calculado & 0,69 \\
\hline
\end{tabular}




\section{ANEXO C - RETROANÁLISE}

\section{Valores de RMSE obtidos para as bacias médias}

Os valores de RMSE foram obtidos com variação simultânea dos valores de MR de todas as camadas, até ser encontrado o menor erro (RMSE), conforme indicado nas Tabelas C1 a C4.

Tabela C. 1 - Valor de RMSE obtido no sentido Batatais $-\mathrm{T}=21 \mathrm{M}$

\begin{tabular}{c|c|c|c|c|c|c|c|c}
\hline \multirow{2}{*}{ Bacia } & \multicolumn{7}{|c|}{ Deflexões $\left(\mathbf{x 1 0} \mathbf{m}^{-2} \mathbf{m m}\right)$} & \multirow{2}{*}{ RMSE } \\
\cline { 2 - 8 } & $\mathrm{d}_{0}$ & $\mathrm{~d}_{20}$ & $\mathrm{~d}_{30}$ & $\mathrm{~d}_{45}$ & $\mathrm{~d}_{60}$ & $\mathrm{~d}_{90}$ & $\mathrm{~d}_{120}$ & \\
\hline Média & 33,0 & 23,1 & 18,1 & 12,8 & 9,5 & 6,0 & 4,4 & \multirow{2}{*}{-} \\
\hline$\sigma$ & 3,9 & 2,2 & 1,2 & 0,5 & 0,4 & 0,2 & 0,2 & \\
\hline Bakfaa & 33,0 & 23,0 & 18,0 & 12,8 & 9,5 & 6,0 & 4,4 & \multirow{2}{*}{0,8} \\
\hline Erro (\%) & 0,1 & 0,4 & 0,5 & 0,4 & 0,1 & 0,2 & 0,5 & \\
\hline Elsym 5 & 33,0 & 23,1 & 18,1 & 12,8 & 9,5 & 6,0 & 4,4 & \multirow{2}{*}{0,2} \\
\hline Erro (\%) & 0,1 & 0,2 & 0,2 & 0,0 & 0,0 & 0,2 & 0,0 & \\
\hline
\end{tabular}

Tabela C. 2 - Valor de RMSE obtido no sentido Patrocínio Paulista $-\mathrm{T}=21 \mathrm{M}$

\begin{tabular}{c|c|c|c|c|c|c|c|c}
\hline \multirow{2}{*}{ Bacia } & \multicolumn{7}{|c|}{ Deflexões $\left(\mathbf{x} \mathbf{1 0}^{-2} \mathbf{m m}\right)$} & \multirow{2}{*}{ RMSE } \\
\cline { 2 - 9 } & $\mathbf{d}_{\mathbf{0}}$ & $\mathbf{d}_{\mathbf{2 0}}$ & $\mathbf{d}_{\mathbf{3 0}}$ & $\mathbf{d}_{\mathbf{4 5}}$ & $\mathbf{d}_{\mathbf{6 0}}$ & $\mathbf{d}_{\mathbf{9 0}}$ & $\mathbf{d}_{\mathbf{1 2 0}}$ & \\
\hline Média & 32,7 & 23,3 & 17,6 & 12,0 & 8,9 & 5,6 & 4,2 & \multirow{2}{*}{-} \\
\hline$\sigma$ & 3,9 & 1,6 & 0,9 & 0,7 & 0,5 & 0,3 & 0,2 & \\
\hline Bakfaa & 32,8 & 22,7 & 17,5 & 12,3 & 9,0 & 5,7 & 4,2 & \multirow{2}{*}{4,1} \\
\hline Erro (\%) & 0,5 & 2,9 & 0,4 & 2,3 & 2,0 & 1,3 & 1,7 & \\
\hline Elsym 5 & 32,8 & 22,7 & 17,5 & 12,3 & 9,0 & 5,7 & 4,2 & \multirow{2}{*}{4,1} \\
\hline Erro (\%) & 0,5 & 2,7 & 0,4 & 2,5 & 1,9 & 1,3 & 1,7 & \\
\hline
\end{tabular}


Tabela C. 3 - Valor de RMSE obtido no sentido Batatais $-\mathrm{T}=33 \mathrm{M}$

\begin{tabular}{c|c|c|c|c|c|c|c|c}
\hline \multirow{2}{*}{ Bacia } & \multicolumn{7}{|c|}{ Deflexões $\left(\mathbf{x} \mathbf{1 0}^{-\mathbf{2}} \mathbf{m m}\right)$} & \multirow{2}{*}{ RMSE } \\
\cline { 2 - 9 } & $\mathbf{d}_{\mathbf{0}}$ & $\mathbf{d}_{\mathbf{2 0}}$ & $\mathbf{d}_{\mathbf{3 0}}$ & $\mathbf{d}_{\mathbf{4 5}}$ & $\mathbf{d}_{\mathbf{6 0}}$ & $\mathbf{d}_{\mathbf{9 0}}$ & $\mathbf{d}_{\mathbf{1 2 0}}$ & \\
\hline Média & 32,9 & 23,0 & 16,3 & 10,8 & 8,0 & 5,4 & 4,2 & \multirow{2}{*}{-} \\
\hline$\sigma$ & 3,4 & 1,6 & 1,0 & 0,5 & 0,4 & 0,3 & 0,2 & \\
\hline Bakfaa & 33,5 & 22,1 & 16,8 & 11,7 & 8,6 & 5,4 & 4,0 & \multirow{2}{*}{11,7} \\
\hline Erro (\%) & 1,8 & 3,7 & 3,2 & 7,6 & 7,8 & 1,3 & 5,5 & \\
\hline Elsym 5 & 33,5 & 22,1 & 16,8 & 11,6 & 8,6 & 5,4 & 4,0 & \multirow{2}{*}{11,6} \\
\hline Erro (\%) & 1,8 & 3,8 & 3,3 & 7,1 & 7,8 & 1,3 & 5,5 & \\
\hline
\end{tabular}

Tabela C.4 - Valor de RMSE obtido no sentido Patrocínio Paulista - T=33M

\begin{tabular}{c|c|c|c|c|c|c|c|c}
\hline \multirow{2}{*}{ Bacia } & \multicolumn{7}{|c|}{ Deflexões $\left(\mathbf{x} \mathbf{1 0}^{-2} \mathbf{m m}\right)$} & \multirow{2}{*}{ RMSE } \\
\cline { 2 - 8 } & $\mathbf{d}_{\mathbf{0}}$ & $\mathbf{d}_{\mathbf{2 0}}$ & $\mathbf{d}_{\mathbf{3 0}}$ & $\mathbf{d}_{\mathbf{4 5}}$ & $\mathbf{d}_{\mathbf{6 0}}$ & $\mathbf{d}_{\mathbf{9 0}}$ & $\mathbf{d}_{\mathbf{1 2 0}}$ & \\
\hline Média & 34,0 & 23,5 & 17,0 & 11,0 & 8,0 & 5,2 & 4,0 & \multirow{2}{*}{-} \\
\hline$\sigma$ & 3,6 & 1,8 & 1,1 & 0,8 & 0,5 & 0,3 & 0,3 & \\
\hline Bakfaa & 33,5 & 22,3 & 16,9 & 11,8 & 8,7 & 5,6 & 4,1 & \multirow{2}{*}{11,5} \\
\hline Erro (\%) & 1,5 & 5,3 & 0,6 & 7,2 & 8,7 & 6,7 & 0,6 & \\
\hline Elsym 5 & 33,5 & 22,3 & 16,9 & 11,8 & 8,7 & 5,6 & 4,1 & \multirow{2}{*}{11,5} \\
\hline Erro (\%) & 1,5 & 5,1 & 0,8 & 7,2 & 8,7 & 6,7 & 0,6 & \\
\hline
\end{tabular}

\section{Valores de RMSE obtidos para as bacias médias $+1 \sigma$}

Os valores de RMSE foram obtidos com variação simultânea dos valores de MR de todas as camadas, até ser encontrado o menor erro (RMSE), conforme indicado nas Tabelas B5 a B8. O formato das bacias retroanalizadas são mostradas nas Figuras C1 a C4.

Tabela C. 5 - Valor de RMSE obtido no sentido Batatais $-\mathrm{T}=21 \mathrm{M}$

\begin{tabular}{c|c|c|c|c|c|c|c|c}
\hline \multirow{2}{*}{ Bacia } & \multicolumn{7}{|c|}{ Deflexões (x10-2 $\mathbf{m m})$} & \multirow{2}{*}{ RMSE } \\
\cline { 2 - 8 } & $\mathbf{d}_{\mathbf{0}}$ & $\mathbf{d}_{\mathbf{2 0}}$ & $\mathbf{d}_{\mathbf{3 0}}$ & $\mathbf{d}_{\mathbf{4 5}}$ & $\mathbf{d}_{\mathbf{6 0}}$ & $\mathbf{d}_{\mathbf{9 0}}$ & $\mathbf{d}_{\mathbf{1 2 0}}$ & \\
\hline Média + $\boldsymbol{\sigma}$ & 36,9 & 25,4 & 19,3 & 13,3 & 9,9 & 6,2 & 4,5 & - \\
\hline Bakfaa & 37,1 & 25,4 & 19,5 & 13,6 & 10,0 & 6,3 & 4,6 & \multirow{2}{*}{$\mathbf{2 , 7}$} \\
\hline Erro (\%) & 0,5 & 0,1 & 1,2 & 2,1 & 0,9 & 1,7 & 0,6 & \\
\hline Elsym 5 & 37,1 & 25,4 & 19,5 & 13,6 & 10,0 & 6,3 & 4,6 & \multirow{2}{*}{$\mathbf{2 , 7}$} \\
\hline Erro (\%) & 0,5 & 0,1 & 1,1 & 2,2 & 0,9 & 1,7 & 0,6 & \\
\hline
\end{tabular}


Tabela C.6 - Valor de RMSE obtido no sentido Patrocínio Paulista - T=21M

\begin{tabular}{c|c|c|c|c|c|c|c|c}
\hline \multirow{2}{*}{ Bacia } & \multicolumn{7}{|c|}{ Deflexões $\left(\mathbf{x} \mathbf{0}^{-\mathbf{2}} \mathbf{m m}\right)$} & \multirow{2}{*}{ RMSE } \\
\cline { 2 - 7 } & $\mathbf{d}_{\mathbf{0}}$ & $\mathbf{d}_{\mathbf{2 0}}$ & $\mathbf{d}_{\mathbf{3 0}}$ & $\mathbf{d}_{\mathbf{4 5}}$ & $\mathbf{d}_{\mathbf{6 0}}$ & $\mathbf{d}_{\mathbf{9 0}}$ & $\mathbf{d}_{\mathbf{1 2 0}}$ & \\
\hline Média $+\boldsymbol{\sigma}$ & 36,5 & 24,9 & 18,5 & 12,7 & 9,4 & 6,0 & 4,4 & - \\
\hline Bakfaa & 36,2 & 24,3 & 18,5 & 12,8 & 9,4 & 6,0 & 4,4 & \multirow{2}{*}{$\mathbf{2 , 5}$} \\
\hline Erro (\%) & 1,0 & 2,6 & 0,1 & 0,9 & 0,2 & 0,0 & 1,7 & \\
\hline Elsym 5 & 36,2 & 24,3 & 18,5 & 12,8 & 9,4 & 6,0 & 4,4 & \multirow{2}{*}{$\mathbf{2 , 2}$} \\
\hline Erro (\%) & 0,9 & 2,4 & 0,1 & 0,6 & 0,2 & 0,0 & 1,4 & \\
\hline
\end{tabular}

Tabela C.7 - Valor de RMSE obtido no sentido Batatais $-\mathrm{T}=33 \mathrm{M}$

\begin{tabular}{c|c|c|c|c|c|c|c|c}
\hline \multirow{2}{*}{ Bacia } & \multicolumn{7}{|c|}{ Deflexões $\left(\mathbf{x} \mathbf{1 0}^{-\mathbf{2}} \mathbf{m m}\right)$} & \multirow{2}{*}{ RMSE } \\
\cline { 2 - 8 } & $\mathbf{d}_{\mathbf{0}}$ & $\mathbf{d}_{\mathbf{2 0}}$ & $\mathbf{d}_{\mathbf{3 0}}$ & $\mathbf{d}_{\mathbf{4 5}}$ & $\mathbf{d}_{\mathbf{6 0}}$ & $\mathbf{d}_{\mathbf{9 0}}$ & $\mathbf{d}_{\mathbf{1 2 0}}$ & \\
\hline Média + $\boldsymbol{\sigma}$ & 36,3 & 24,6 & 17,2 & 11,4 & 8,3 & 5,6 & 4,4 & - \\
\hline Bakfaa & 36,7 & 23,5 & 17,5 & 12,0 & 8,9 & 5,7 & 4,2 & \multirow{2}{*}{$\mathbf{9 , 9}$} \\
\hline Erro (\%) & 1,0 & 4,6 & 1,9 & 5,9 & 6,3 & 0,4 & 6,1 & \\
\hline Elsym 5 & 36,7 & 23,5 & 17,5 & 12,0 & 8,9 & 5,7 & 4,2 & \multirow{2}{*}{$\mathbf{9 , 7}$} \\
\hline Erro (\%) & 1,1 & 4,4 & 1,7 & 5,6 & 6,3 & 0,4 & 6,1 & \\
\hline
\end{tabular}

Tabela C. 8 - Valor de RMSE obtido no sentido Patrocínio Paulista $-\mathrm{T}=33 \mathrm{M}$

\begin{tabular}{c|c|c|c|c|c|c|c|c}
\hline \multirow{2}{*}{ Bacia } & \multicolumn{7}{|c|}{ Deflexões (x10-2 $\mathbf{m m})$} & \multirow{2}{*}{ RMSE } \\
\cline { 2 - 8 } & $\mathbf{d}_{\mathbf{0}}$ & $\mathbf{d}_{\mathbf{2 0}}$ & $\mathbf{d}_{\mathbf{3 0}}$ & $\mathbf{d}_{\mathbf{4 5}}$ & $\mathbf{d}_{\mathbf{6 0}}$ & $\mathbf{d}_{\mathbf{9 0}}$ & $\mathbf{d}_{\mathbf{1 2 0}}$ & \\
\hline Média $+\boldsymbol{\sigma}$ & 37,6 & 25,3 & 18,1 & 11,8 & 8,5 & 5,5 & 4,3 & - \\
\hline Bakfaa & 36,6 & 23,7 & 17,7 & 12,2 & 8,9 & 5,7 & 4,2 & \multirow{2}{*}{$\mathbf{9 , 6}$} \\
\hline Erro (\%) & 2,6 & 6,5 & 2,0 & 3,4 & 4,7 & 2,4 & 3,6 & \\
\hline Elsym 5 & 36,6 & 23,7 & 17,7 & 12,2 & 8,9 & 5,7 & 4,2 & \multirow{2}{*}{$\mathbf{9 , 6}$} \\
\hline Erro (\%) & 2,6 & 6,3 & 2,3 & 3,6 & 4,7 & 2,3 & 3,6 & \\
\hline
\end{tabular}

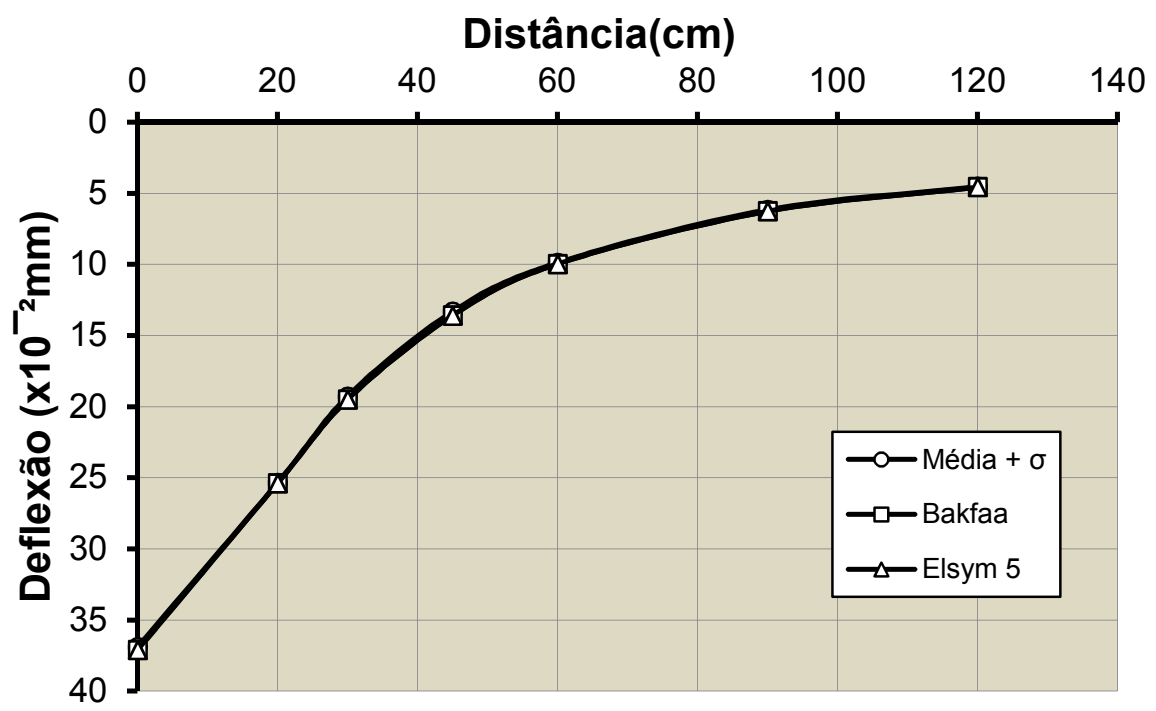

Figura C.1 - Bacias previstas e retroanalizadas no sentido Batatais $-\mathrm{T}=21 \mathrm{M}$ 


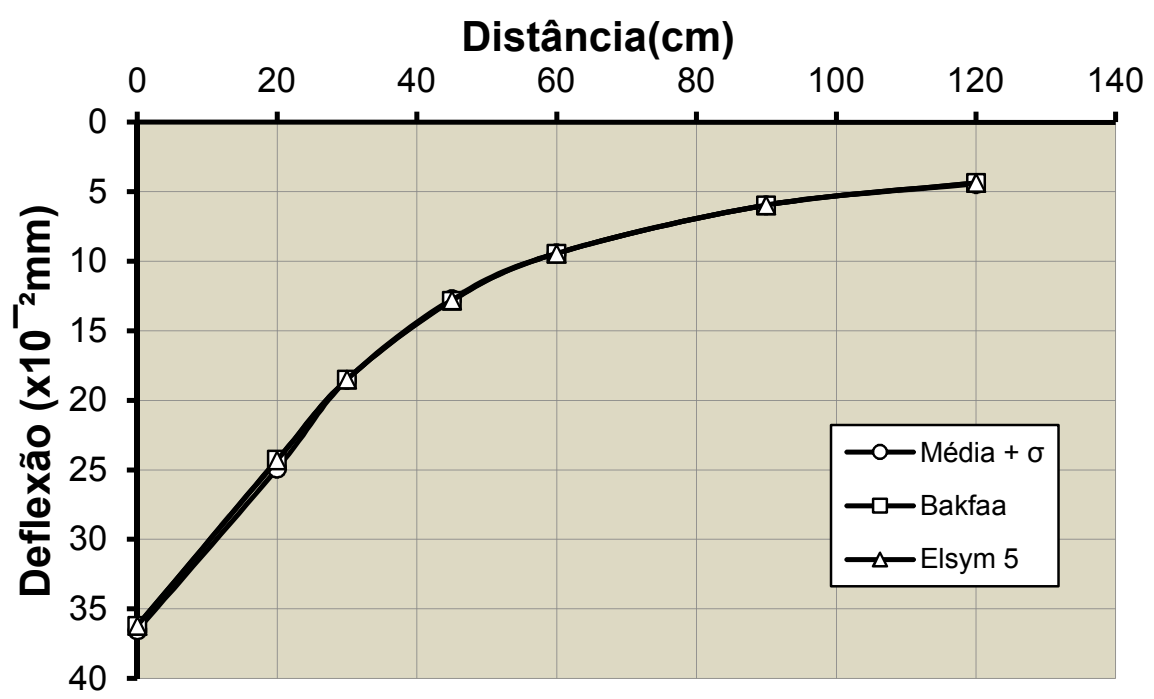

Figura C.2 - Bacias previstas e retroanalizadas no sentido Patrocínio Paulista - T=21M

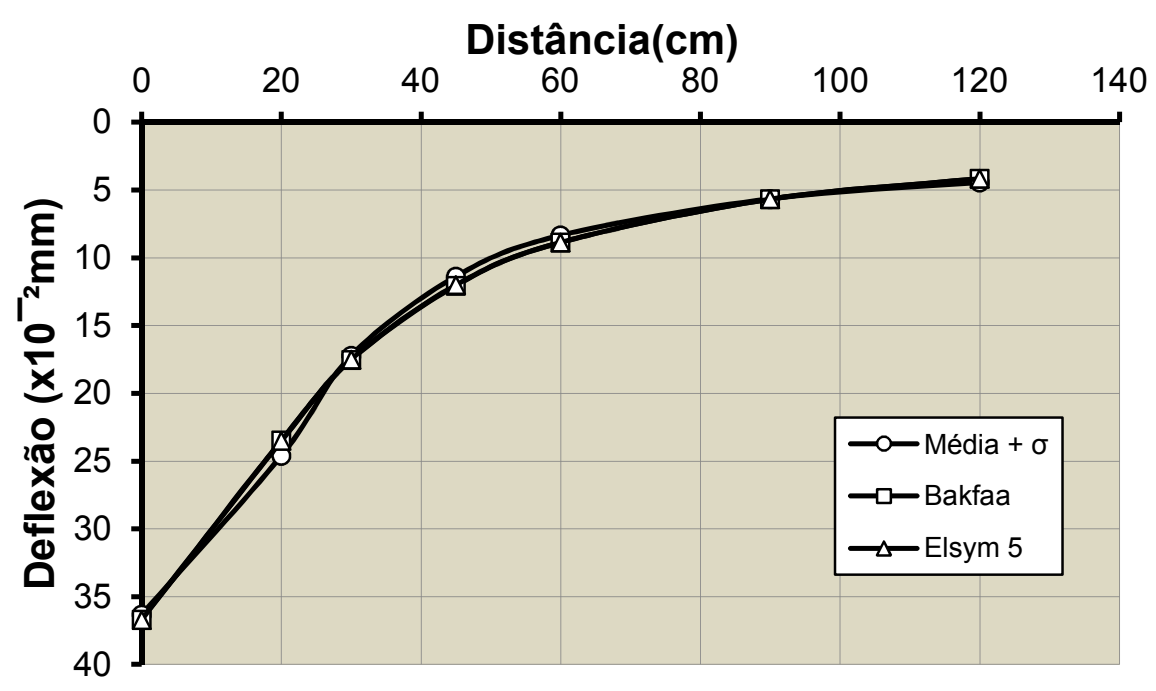

Figura C.3 - Bacias previstas e retroanalizadas no sentido Batatais $-\mathrm{T}=33 \mathrm{M}$ 


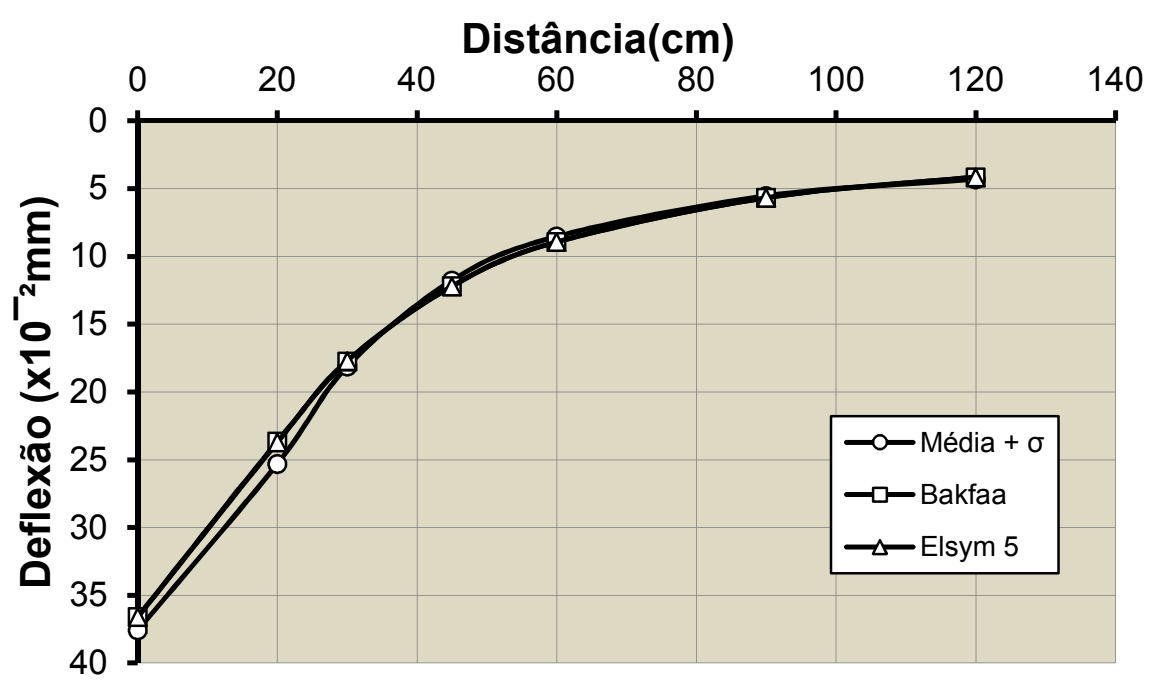

Figura C.4 - Bacias previstas e retroanalizadas no sentido Patrocínio Paulista - T=33M

\section{Valores de RMSE obtidos para as bacias médias - 10}

Os valores de RMSE foram obtidos com variação simultânea dos valores de MR de todas as camadas, até ser encontrado o menor erro (RMSE), conforme indicado nas Tabelas C9 a C12 O formato das bacias retroanalizadas são mostradas nas Figuras C1 a C4.

Tabela C.9 - Valor de RMSE obtido no sentido Batatais $-\mathrm{T}=21 \mathrm{M}$

\begin{tabular}{c|c|c|c|c|c|c|c|c}
\hline \multirow{2}{*}{ Bacia } & \multicolumn{7}{|c|}{ Deflexões $\left(\mathbf{x} 1 \mathbf{0}^{-\mathbf{2}} \mathbf{m m}\right)$} & \multirow{2}{*}{ RMSE } \\
\cline { 2 - 8 } & $\mathbf{d}_{\mathbf{0}}$ & $\mathbf{d}_{\mathbf{2 0}}$ & $\mathbf{d}_{\mathbf{3 0}}$ & $\mathbf{d}_{\mathbf{4 5}}$ & $\mathbf{d}_{\mathbf{6 0}}$ & $\mathbf{d}_{\mathbf{9 0}}$ & $\mathbf{d}_{\mathbf{1 2 0}}$ & \\
\hline Média - $\boldsymbol{\sigma}$ & 29,1 & 20,9 & 16,8 & 12,3 & 9,1 & 5,9 & 4,2 & - \\
\hline Bakfaa & 29,1 & 21,4 & 17,1 & 12,3 & 9,2 & 5,8 & 4,2 & \multirow{2}{*}{$\mathbf{2 , 6}$} \\
\hline Erro (\%) & 0,2 & 2,1 & 1,3 & 0,3 & 1,0 & 1,2 & 0,6 & \\
\hline Elsym 5 & 29,1 & 21,4 & 17,1 & 12,3 & 9,2 & 5,8 & 4,2 & \multirow{2}{*}{$\mathbf{2 , 7}$} \\
\hline Erro (\%) & 0,2 & 2,3 & 1,6 & 0,1 & 1,0 & 1,2 & 0,6 & \\
\hline
\end{tabular}

Tabela C.10 - Valor de RMSE obtido no sentido Patrocínio Paulista - T=21M

\begin{tabular}{c|c|c|c|c|c|c|c|c}
\hline \multirow{2}{*}{ Bacia } & \multicolumn{7}{|c|}{ Deflexões $\left(\mathbf{x} \mathbf{1 0}^{-\mathbf{2}} \mathbf{m m}\right)$} & \multirow{2}{*}{ RMSE } \\
\cline { 2 - 9 } & $\mathbf{d}_{\mathbf{0}}$ & $\mathbf{d}_{\mathbf{2 0}}$ & $\mathbf{d}_{\mathbf{3 0}}$ & $\mathbf{d}_{\mathbf{4 5}}$ & $\mathbf{d}_{\mathbf{6 0}}$ & $\mathbf{d}_{\mathbf{9 0}}$ & $\mathbf{d}_{\mathbf{1 2 0}}$ & \\
\hline Média - $\boldsymbol{\sigma}$ & 28,8 & 21,8 & 16,6 & 11,3 & 8,3 & 5,3 & 4,0 & - \\
\hline Bakfaa & 29,2 & 20,9 & 16,5 & 11,7 & 8,6 & 5,4 & 3,9 & \multirow{2}{*}{$\mathbf{6 , 9}$} \\
\hline Erro (\%) & 1,4 & 3,9 & 1,0 & 3,5 & 3,4 & 1,1 & 3,9 & \\
\hline Elsym 5 & 29,1 & 20,9 & 16,5 & 11,7 & 8,6 & 5,4 & 3,9 & \multirow{2}{*}{$\mathbf{6 , 9}$} \\
\hline Erro (\%) & 1,2 & 3,9 & 0,8 & 3,8 & 3,4 & 1,1 & 3,9 & \\
\hline
\end{tabular}


Tabela C.11 - Valor de RMSE obtido no sentido Batatais $-\mathrm{T}=33 \mathrm{M}$

\begin{tabular}{c|c|c|c|c|c|c|c|c}
\hline \multirow{2}{*}{ Bacia } & \multicolumn{7}{|c|}{ Deflexões $\left(\mathbf{x} \mathbf{0}^{-\mathbf{2}} \mathbf{m m}\right)$} & \multirow{2}{*}{ RMSE } \\
\cline { 2 - 8 } & $\mathbf{d}_{\mathbf{0}}$ & $\mathbf{d}_{\mathbf{2 0}}$ & $\mathbf{d}_{\mathbf{3 0}}$ & $\mathbf{d}_{\mathbf{4 5}}$ & $\mathbf{d}_{\mathbf{6 0}}$ & $\mathbf{d}_{\mathbf{9 0}}$ & $\mathbf{d}_{\mathbf{1 2 0}}$ & \\
\hline Média - $\boldsymbol{\sigma}$ & 29,5 & 21,3 & 15,3 & 10,3 & 7,6 & 5,1 & 4,0 & - \\
\hline Bakfaa & 30,6 & 20,8 & 16,0 & 11,2 & 8,2 & 5,2 & 3,8 & \multirow{2}{*}{$\mathbf{1 3 , 0}$} \\
\hline Erro (\%) & 3,7 & 2,6 & 4,3 & 8,5 & 8,7 & 2,6 & 4,1 & \\
\hline Elsym 5 & 30,6 & 20,8 & 16,0 & 11,2 & 8,2 & 5,2 & 3,8 & \multirow{2}{*}{$\mathbf{1 3 , 2}$} \\
\hline Erro (\%) & 3,6 & 2,5 & 4,5 & 8,8 & 8,7 & 2,6 & 4,1 & \\
\hline
\end{tabular}

Tabela C.12 - Valor de RMSE obtido no sentido Patrocínio Paulista - T=33M

\begin{tabular}{c|c|c|c|c|c|c|c|c}
\hline \multirow{2}{*}{ Bacia } & \multicolumn{7}{|c|}{ Deflexões $\left(\mathbf{x} \mathbf{1 0}^{-\mathbf{2}} \mathbf{m m}\right)$} & \multirow{2}{*}{ RMSE } \\
\cline { 2 - 8 } & $\mathbf{d}_{\mathbf{0}}$ & $\mathbf{d}_{\mathbf{2 0}}$ & $\mathbf{d}_{\mathbf{3 0}}$ & $\mathbf{d}_{\mathbf{4 5}}$ & $\mathbf{d}_{\mathbf{6 0}}$ & $\mathbf{d}_{\mathbf{9 0}}$ & $\mathbf{d}_{\mathbf{1 2 0}}$ & \\
\hline Média - $\boldsymbol{\sigma}$ & 30,5 & 21,7 & 16,0 & 10,2 & 7,5 & 4,9 & 3,8 & - \\
\hline Bakfaa & 30,9 & 20,8 & 15,9 & 11,1 & 8,2 & 5,2 & 3,8 & \multirow{2}{*}{$\mathbf{1 1 , 2}$} \\
\hline Erro (\%) & 1,3 & 4,1 & 0,2 & 8,4 & 9,0 & 6,1 & 0,5 & \\
\hline Elsym 5 & 31,5 & 21,1 & 16,1 & 11,1 & 8,2 & 5,2 & 3,8 & \multirow{2}{*}{$\mathbf{1 1 , 6}$} \\
\hline Erro (\%) & 3,4 & 2,9 & 0,9 & 8,3 & 9,0 & 5,9 & 0,3 & \\
\hline
\end{tabular}

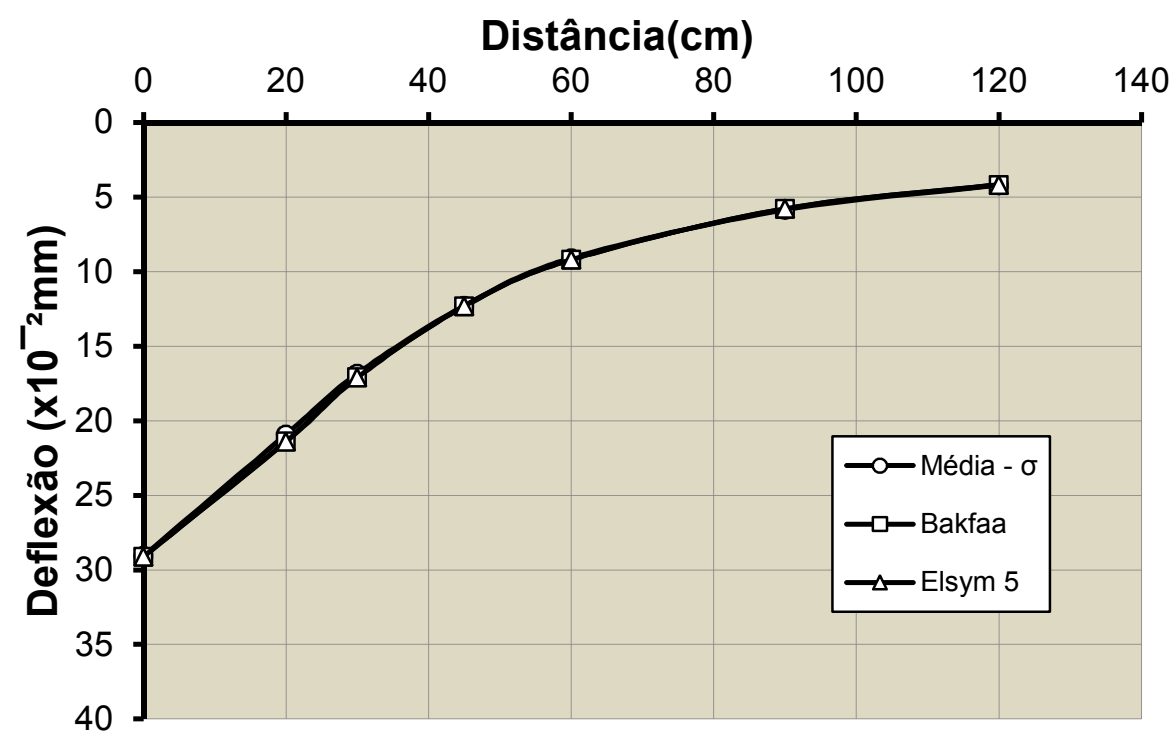

Figura C.5 - Bacias previstas e retroanalizadas no sentido Batatais $-\mathrm{T}=21 \mathrm{M}$ 


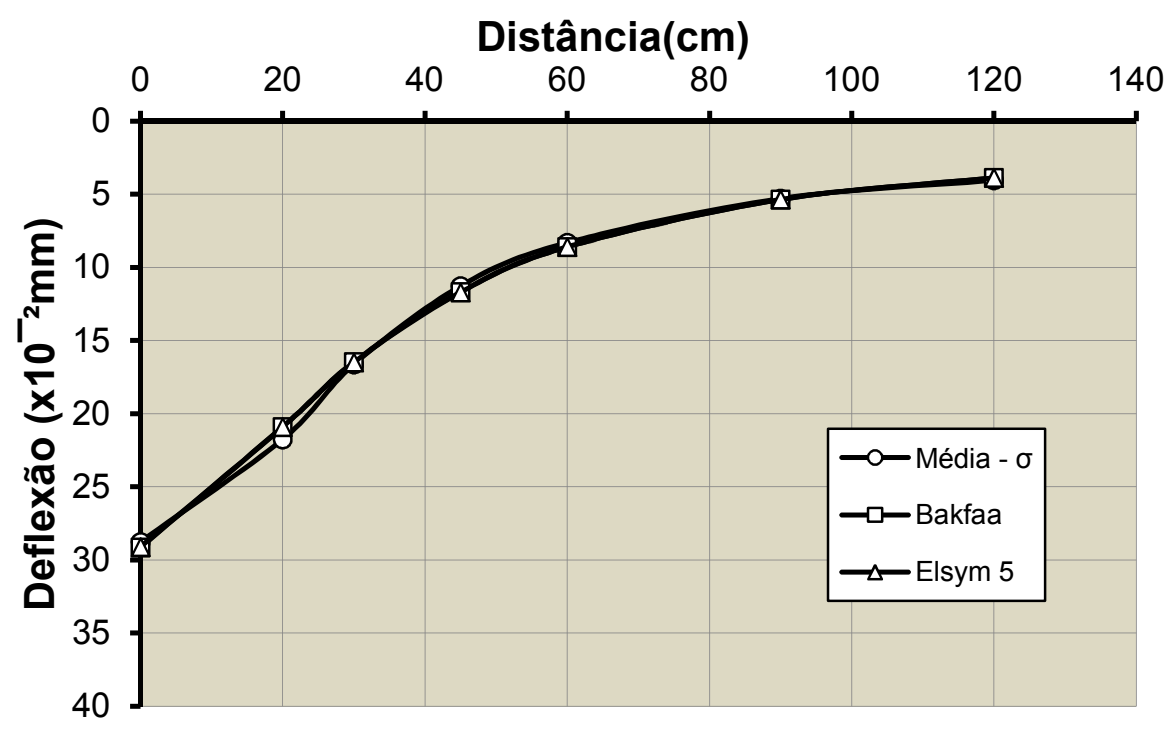

Figura C.6 - Bacias previstas e retroanalizadas no sentido Patrocínio Paulista - T=21M

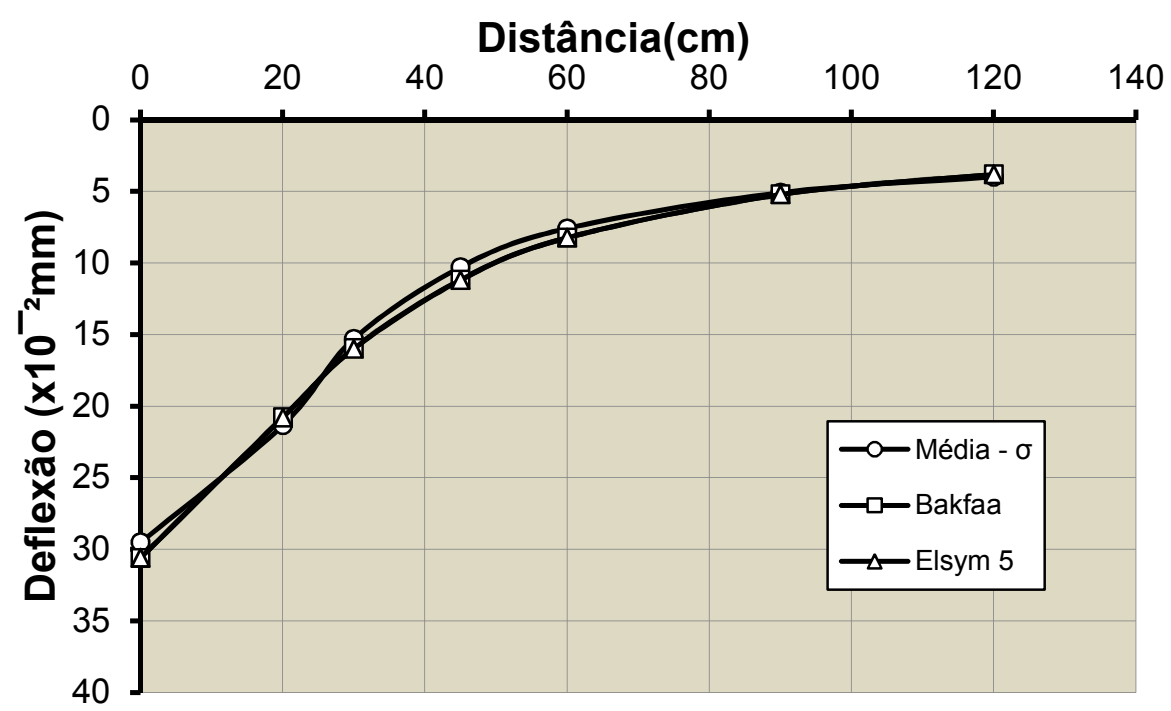

Figura C.7 - Bacias previstas e retroanalizadas no sentido Batatais $-\mathrm{T}=33 \mathrm{M}$ 


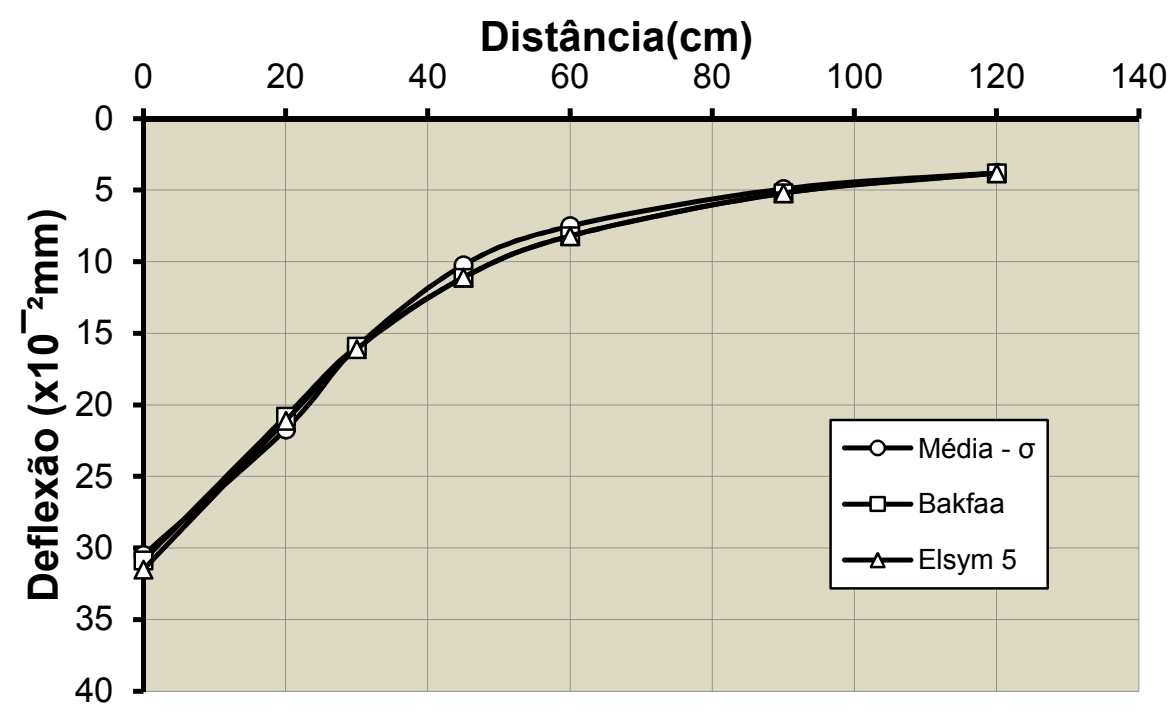

Figura C.8 - Bacias previstas e retroanalizadas no sentido Patrocínio Paulista - T=33M

Valores de RMSE obtidos para a análise paramétrica da espessura da base de solo-cimento

Os valores de RMSE foram obtidos com variação da espessura da camada de solocimento, sendo fixadas as demais camadas abaixo desta e baseados nos valores médios de deflexão. A retroanálise foi realizada até ser encontrado o menor erro (RMSE), conforme indicado nas Tabelas C13 a C16. 
Tabela C.13 - Variação do RMSE com a espessura da base no sentido Batatais - T=21M

\begin{tabular}{|c|c|c|c|c|c|c|c|c|c|c|}
\hline \multirow{2}{*}{$\begin{array}{c}\text { Bacia } \\
\text { Referência }\end{array}$} & \multicolumn{7}{|c|}{ Deflexões $\left(\times 10^{-2} \mathrm{~mm}\right)$} & \multicolumn{3}{|c|}{ Retroanálise } \\
\hline & $d_{0}$ & $d_{20}$ & $d_{30}$ & $d_{45}$ & $d_{60}$ & $d_{90}$ & $d_{120}$ & RMSE & $\mathrm{h}(\mathrm{cm})$ & $\begin{array}{c}\text { MR } \\
(\mathrm{MPa})\end{array}$ \\
\hline Média & 33,0 & 23,9 & 18,3 & 12,7 & 9,3 & 5,9 & 4,5 & \multirow{2}{*}{0} & \multirow{2}{*}{ - } & \multirow{2}{*}{ - } \\
\hline$\sigma$ & 3,9 & 2,2 & 1,2 & 0,5 & 0,4 & 0,2 & 0,2 & & & \\
\hline Bakfaa & 33,6 & 24,0 & 18,5 & 12,9 & 9,4 & 5,9 & 4,3 & \multirow{2}{*}{3,9} & \multirow{2}{*}{12} & \multirow{2}{*}{3059} \\
\hline Erro (\%) & 1,9 & 0,4 & 1,2 & 1,7 & 1,3 & 0,7 & 3,3 & & & \\
\hline Bakfaa & 33,2 & 23,4 & 18,2 & 12,8 & 9,5 & 6,0 & 4,4 & \multirow{2}{*}{4,0} & \multirow{2}{*}{14} & \multirow{2}{*}{2243} \\
\hline Erro (\%) & 0,5 & 2,1 & 0,6 & 1,3 & 1,9 & 1,3 & 2,9 & & & \\
\hline Bakfaa & 33,0 & 23,1 & 18,1 & 12,8 & 9,5 & 6,0 & 4,4 & \multirow{2}{*}{4,7} & \multirow{2}{*}{15} & \multirow{2}{*}{1978} \\
\hline Erro (\%) & 0,0 & 3,3 & 1,4 & 1,1 & 2,1 & 1,8 & 2,6 & & & \\
\hline Bakfaa & 33,4 & 23,0 & 18,0 & 12,8 & 9,5 & 6,0 & 4,4 & \multirow{2}{*}{5,3} & \multirow{2}{*}{16} & \multirow{2}{*}{1683} \\
\hline Erro (\%) & 1,1 & 3,8 & 2,0 & 0,7 & 2,0 & 2,0 & 2,4 & & & \\
\hline Bakfaa & 33,5 & 22,6 & 17,7 & 12,7 & 9,5 & 6,1 & 4,4 & \multirow{2}{*}{6,7} & \multirow{2}{*}{18} & \multirow{2}{*}{1356} \\
\hline Erro (\%) & 1,6 & 5,5 & 3,6 & 0,1 & 2,2 & 2,7 & 2,0 & & & \\
\hline
\end{tabular}

Tabela C.14 - Variação do RMSE com a espessura da base no sentido Patrocínio Paulista - T=21M

\begin{tabular}{|c|c|c|c|c|c|c|c|c|c|c|}
\hline \multirow{2}{*}{$\begin{array}{c}\text { Bacia } \\
\text { Referência }\end{array}$} & \multicolumn{7}{|c|}{ Deflexões $\left(\times 10^{-2} \mathrm{~mm}\right)$} & \multicolumn{3}{|c|}{ Retroanálise } \\
\hline & $d_{0}$ & $d_{20}$ & $d_{30}$ & $d_{45}$ & $d_{60}$ & $d_{90}$ & $d_{120}$ & RMSE & $\mathrm{h}(\mathrm{cm})$ & $\begin{array}{c}\mathrm{MR} \\
(\mathrm{MPa})\end{array}$ \\
\hline Média & 32,7 & 23,3 & 17,6 & 12,0 & 8,9 & 5,6 & 4,2 & & \multirow{2}{*}{ - } & \multirow{2}{*}{ - } \\
\hline$\sigma$ & 3,9 & 1,6 & 0,9 & 0,7 & 0,5 & 0,3 & 0,2 & & & \\
\hline Bakfaa & 32,9 & 23,3 & 17,9 & 12,4 & 9,0 & 5,6 & 4,1 & \multirow{2}{*}{3,7} & \multirow{2}{*}{12} & \multirow{2}{*}{3059} \\
\hline Erro (\%) & 0,7 & 0,1 & 2,0 & 3,0 & 1,4 & 0,2 & 2,4 & & & \\
\hline Bakfaa & 32,9 & 22,9 & 17,7 & 12,3 & 9,0 & 5,7 & 4,2 & \multirow{2}{*}{3,8} & \multirow{2}{*}{14} & \multirow{2}{*}{2152} \\
\hline Erro (\%) & 0,6 & 1,8 & 0,4 & 2,5 & 1,8 & 0,9 & 1,9 & & & \\
\hline Bakfaa & 32,8 & 22,7 & 17,5 & 12,3 & 9,0 & 5,7 & 4,2 & \multirow{2}{*}{4,1} & \multirow{2}{*}{15} & \multirow{2}{*}{1876} \\
\hline Erro (\%) & 0,5 & 2,9 & 0,4 & 2,3 & 2,0 & 1,3 & 1,7 & & & \\
\hline Bakfaa & 33,0 & 22,5 & 17,4 & 12,2 & 9,0 & 5,7 & 4,2 & \multirow{2}{*}{4,9} & \multirow{2}{*}{16} & \multirow{2}{*}{1632} \\
\hline Erro (\%) & 1,1 & 3,6 & 1,1 & 2,0 & 2,0 & 1,6 & 1,4 & & & \\
\hline Bakfaa & 33,1 & 22,1 & 17,1 & 12,2 & 9,1 & 5,8 & 4,2 & \multirow{2}{*}{6,3} & \multirow{2}{*}{18} & \multirow{2}{*}{1326} \\
\hline Erro (\%) & 1,5 & 5,4 & 2,7 & 1,5 & 2,3 & 2,3 & 1,0 & & & \\
\hline
\end{tabular}


Tabela C.15 - Variação do RMSE com a espessura da base no sentido Batatais - T=33M

\begin{tabular}{|c|c|c|c|c|c|c|c|c|c|c|}
\hline \multirow{2}{*}{$\begin{array}{c}\text { Bacia } \\
\text { Referência }\end{array}$} & \multicolumn{7}{|c|}{ Deflexões $\left(\times 10^{-2} \mathrm{~mm}\right)$} & \multicolumn{3}{|c|}{ Retroanálise } \\
\hline & $\mathrm{d}_{0}$ & $d_{20}$ & $d_{30}$ & $d_{45}$ & $d_{60}$ & $d_{90}$ & $d_{120}$ & RMSE & $\mathrm{h}(\mathrm{cm})$ & $\begin{array}{c}\text { MR } \\
\text { (MPa) }\end{array}$ \\
\hline Média & 32,9 & 23,0 & 16,3 & 10,8 & 8,0 & 5,4 & 4,2 & & & \multirow{2}{*}{ - } \\
\hline$\sigma$ & 3,4 & 1,6 & 1,0 & 0,5 & 0,4 & 0,3 & 0,2 & & & \\
\hline Bakfaa & 33,0 & 22,7 & 17,1 & 11,7 & 8,5 & 5,4 & 4,0 & \multirow{2}{*}{10,8} & \multirow{2}{*}{12} & \multirow{2}{*}{2458} \\
\hline Erro (\%) & 0,3 & 1,4 & 5,3 & 8,1 & 7,2 & 0,4 & 6,0 & & & \\
\hline Bakfaa & 33,1 & 22,2 & 16,9 & 11,7 & 8,6 & 5,4 & 4,0 & \multirow{2}{*}{11,3} & \multirow{2}{*}{14} & \multirow{2}{*}{1744} \\
\hline Erro (\%) & 0,7 & 3,2 & 3,8 & 7,8 & 7,7 & 1,0 & 5,8 & & & \\
\hline Bakfaa & 32,5 & 22,1 & 16,8 & 11,7 & 8,6 & 5,4 & 4,0 & \multirow{2}{*}{11,5} & \multirow{2}{*}{15} & \multirow{2}{*}{1479} \\
\hline Erro (\%) & 1,2 & 3,7 & 3,2 & 7,6 & 7,8 & 1,3 & 5,5 & & & \\
\hline Bakfaa & 33,2 & 21,8 & 16,6 & 11,6 & 8,6 & 5,5 & 4,0 & \multirow{2}{*}{11,6} & \multirow{2}{*}{16} & \multirow{2}{*}{1372} \\
\hline Erro (\%) & 0,9 & 5,1 & 2,3 & 7,4 & 8,1 & 1,7 & 5,3 & & & \\
\hline Bakfaa & 33,7 & 21,5 & 16,4 & 11,6 & 8,6 & 5,5 & 4,0 & \multirow{2}{*}{12,1} & \multirow{2}{*}{18} & \multirow{2}{*}{1142} \\
\hline Erro (\%) & 2,5 & 6,4 & 0,8 & 6,9 & 8,3 & 2,3 & 4,8 & & & \\
\hline
\end{tabular}

Tabela C.16- Variação do RMSE com a espessura da base no sentido Patrocínio Paulista - T=33M

\begin{tabular}{|c|c|c|c|c|c|c|c|c|c|c|}
\hline \multirow{2}{*}{$\begin{array}{c}\text { Bacia } \\
\text { Referência }\end{array}$} & \multicolumn{7}{|c|}{ Deflexões $\left(\times 10^{-2} \mathrm{~mm}\right)$} & \multicolumn{3}{|c|}{ Retroanálise } \\
\hline & $d_{0}$ & $d_{20}$ & $d_{30}$ & $d_{45}$ & $d_{60}$ & $d_{90}$ & $d_{120}$ & RMSE & $\mathrm{h}(\mathrm{cm})$ & $\begin{array}{c}\text { MR } \\
\text { (MPa) }\end{array}$ \\
\hline Média & 34,0 & 23,5 & 17,0 & 11,0 & 8,0 & 5,2 & 4,0 & & & \multirow{2}{*}{-} \\
\hline$\sigma$ & 3,6 & 1,8 & 1,1 & 0,8 & 0,5 & 0,3 & 0,3 & & & \\
\hline Bakfaa & 34,1 & 23,1 & 17,3 & 11,8 & 8,6 & 5,5 & 4,1 & \multirow{2}{*}{9,2} & \multirow{2}{*}{12} & \multirow{2}{*}{2233} \\
\hline Erro (\%) & 0,3 & 1,7 & 1,8 & 7,3 & 7,7 & 5,5 & 0,1 & & & \\
\hline Bakfaa & 33,8 & 22,6 & 17,1 & 11,8 & 8,7 & 5,6 & 4,1 & \multirow{2}{*}{10,3} & \multirow{2}{*}{14} & \multirow{2}{*}{1683} \\
\hline Erro (\%) & 0,7 & 4,0 & 0,3 & 7,2 & 8,3 & 6,3 & 0,6 & & & \\
\hline Bakfaa & 33,5 & 22,3 & 16,9 & 11,8 & 8,7 & 5,6 & 4,1 & \multirow{2}{*}{11,5} & \multirow{2}{*}{15} & \multirow{2}{*}{1530} \\
\hline Erro (\%) & 1,5 & 5,3 & 0,6 & 7,2 & 8,7 & 6,7 & 0,6 & & & \\
\hline Bakfaa & 34,3 & 22,2 & 16,9 & 11,8 & 8,7 & 5,6 & 4,1 & \multirow{2}{*}{11,5} & \multirow{2}{*}{16} & \multirow{2}{*}{1275} \\
\hline Erro (\%) & 0,8 & 5,4 & 1,1 & 6,8 & 8,7 & 6,8 & 0,8 & & & \\
\hline Bakfaa & 34,5 & 21,8 & 16,6 & 11,7 & 8,8 & 5,6 & 4,1 & \multirow{2}{*}{13,3} & \multirow{2}{*}{18} & \multirow{2}{*}{1066} \\
\hline Erro (\%) & 1,4 & 7,1 & 2,5 & 6,4 & 9,0 & 7,4 & 1,3 & & & \\
\hline
\end{tabular}

